\begin{tabular}{|l|l|}
\hline 2. To: (Receiving organization) & 3. From: (originet ing organization) \\
C. J. Alderman, Facility & Authorization Basis \\
Cleanup Projects & Management And Implementation \\
\hline 5. Proj./Prog./Dept./Div.: & 6. Design Authoriry/ Design Agent/Cog. \\
Tank Farms.: & T. S. Vail \\
\hline
\end{tabular}

8. originator Remarks:

Feasibility Study, $K$ Basin, criticality safety

11. Receiver Remarks:

11A. Design Basel ine Document?

[] Yes

$[X]$ No
4. Related EDT No.:
N/A

7. Purchase Order No.:

$N / A$

9. Equip./Component No.: $\mathrm{N} / \mathrm{A}$.

10. System/Bldg./Facility: Tank Farms

12. Major Assm. Dwg. No.: N/A

13. Permit/Permit Application No.: $N / A$

14. Required Response Date: $\mathrm{N} / \mathrm{A}$

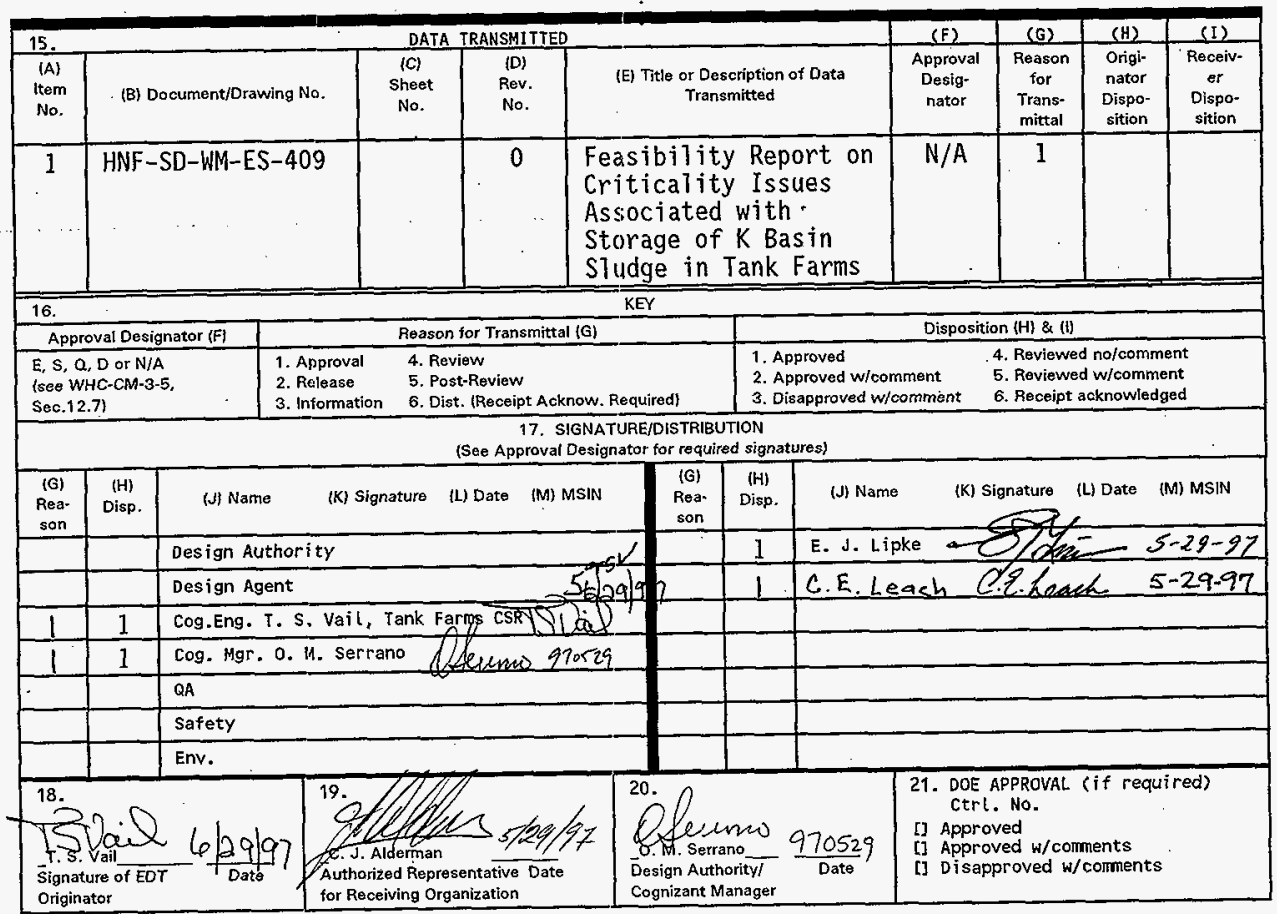

BD-7400-172-2 (05/96) GEF097 


\section{Feasibility Report on Criticality Issues Associated with Storage of K Basin Sludge in Tank Farms}

\section{Terry S. Vail}

Duke Engineering \& Services Hanford, Richland, WA 99352

U.S. Department of Energy Contract DE-AC06-96RL13200
EDT/ECN: 621200
UC: 2030
Org Code: 2 NI50
Charge Code: LD133
B\&R Code: 1LDH010205
Total Pages: $27 \%$

Key Words: Feasibility Study, K Basin, criticality safety, AW-105, sludge

Abstract: This feasibility study provides the technical justification for conclusions about $K$ Basin sludge storage options. The conclusions, solely based on criticality safety considerations, depend on the treatment of the sludge. The two primary conclusions are, 1) untreated sludge must be stored in a critically safe storage tank, and 2) treated sludge (dissolution, precipitation and added neutron absorbers) can be stored in a standard Double contained Receiver Tank (DCRT) or 241-AW-105 without future restrictions on tank operations from a criticality safety perspective.

\footnotetext{
TRADEMARK DISCLAIMER. Reference herein to any specific commercial product, process, or service by trade name, trademark, manufacturer, or otherwise, does not necessarily constitute or imply its endorsement, recommendation, or favoring by the United States Government or any agency thereof or its contractors or subcontractors.
}

Printed in the United States of America. To obtain copies of this document, contact: Document Control Services, P.O. Box 950, Mailstop H6-08, Richland WA 99352, Phone (509) 372-2420; Fax (509) 376-4989.
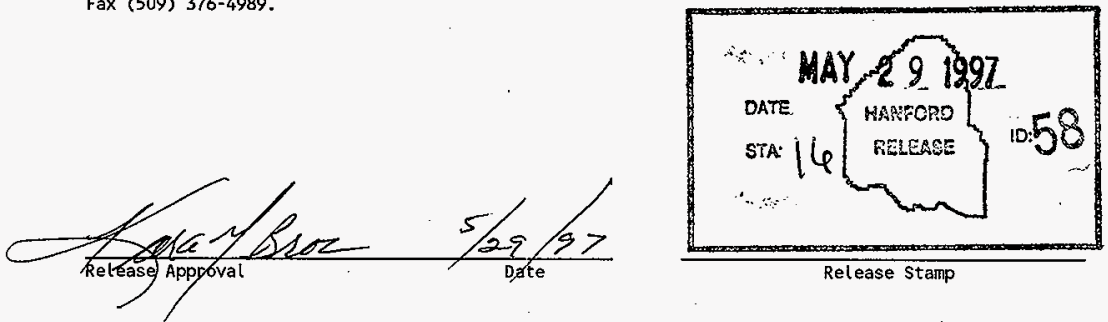

Release stamp 


\section{Feasibility Report on Criticality Issues Associated with Storage of $K$ Basin Sludge in Tank Farms}

Main Report Authors:

P. M. Daling (1)

T. S. Vail (2)

Appendix A Authors:

G. A. Whyatt (1)

D. I. Kaplan (1)

K. M. Krupka (1)

S. V. Mattigod (1)

J. R. Serne (1)

Appendix B Author:

C. A. Rogers ${ }^{(3)}$

Appendix C. Authors:

D. G. Erickson ${ }^{(4)}$

K. N. Schwinkendorf ${ }^{(4)}$

Contributing Author:

E. J. Lipke ${ }^{(2)}$

Date Published

May 1997

Prepared for the U.S. Department of Energy

Assistant Secretary for Environmental Management

Project Hanford Management Contractor for the

U.S. Department of Energy under Contract DE-AC06-96RL13200

(1) Pacific Northwest National Laboratories

(2) DE\&S Hanford, Inc.

(3) Lockheed Martin Hanford Corporation

(4) Fluor Daniel Northwest

Approved for public release; distribution is unlimited 
HNF-SD-WM-ES-409, Rev. 0

This page intentionally left blank. 


\section{CONTENTS}

1.0 INTRODUCTION ......................... . . . . . . . . . .

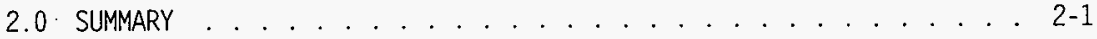

3.0 DESCRIPTION OF ALTERNATIVES - 3-1

3.1 ALTERNATIVE 1 - BASELINE STORAGE CONFIGURATION IN EXISTING DST $3-1$

3.2 ALTERNATIVE 2 - STORAGE IN EXISTING DST WITH FURTHER USE RESTRICTIONS . . . . 3-1

3.3 ALTERNATIVE 3 - STORAGE IN NEW TANK

3.4 ALTERNATIVE 4 - STORAGE IN NEW CRITICALLY $\dot{Y}$ SAFE TANK $\ldots \ldots . .3-2$

3.5 SLUDGE PRETREATMENT OPTIONS . . . . . . . . . . . . . . . 3-3

4.0 TECHNICAL FINDINGS AND CONCLUSIONS ........... . . . . . . .

4.1 CRITICALITY SAFETY APPROACH FOR K BASIN SLULGE $\cdots$

4.1.1 Depleted Uranium Addition . . . . . . . . . . . . . 4-2

4.1.2 Iron Addition . . . . . . . . . . 4-3

4.1.3 Quantity of Added Absorbers . . . . . . . . . . . . 4-4

4.2 CHEMISTRY SUMMARY . . . . . . . . . . . . . . . . . .

4.3 CRITICALITY SAFETY ANALYSIS SUMMARY

4.4 EVALUATION OF CRITICALITY SAFETY ALTERNATIVES . . . . . . $4-7$ 4.4.1 Alternative 1 - Baseline Storage Configuration in Existing

DST Alterative1 - Baseline Storage Configuration in Existing

4.4.2 Alternative 2 - Storage in Existing DST with Further Use

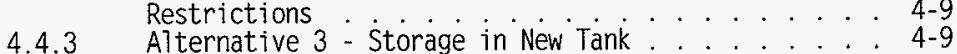

4.4.4 Alternative 4 - Storage in a New Criticaily-safe Tank

4.5 CONCLUSIONS

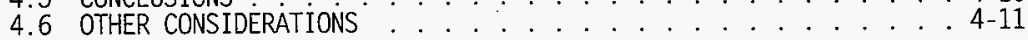

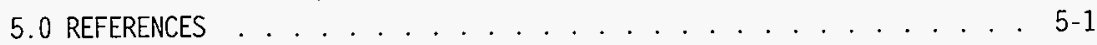

Appendix A Investigation of Chemical and Physical Segregation Mechanisms Relevant to Criticality Feasibility Assessment of the Transfer of K Basin Sludge to Tank AW-105

Appendix B Criticality Safety of Disposing of K Basins Sludge

Appendix $C$ Parametric Calculations of Reactivity Suppression by Addition of Various Poisons 
HNF-SD-WM-ES-409, Rev. 0

\section{LIST OF TABLES}

3.1. Summary Description of Each S7udge Storage Alternative . . . . . . 3-2

4.1. Criticality Safety Approach for K Basin Sludges........ 4-3

4.2. Summary of Technical Findings for Each Sludge Storage Aiternative . 4-8 
HNF-SD-WM-ES-409, Rev. 0

\subsection{INTRODUCTION}

Spent Nuclear Fuel (SNF) is stored in the 105-K East (KE) and 105-K West (KW) Basins in the form of irradiated uranium fuel elements clad in aluminum or zirconium alloy and immersed in water. Some of the spent $N$ Reactor fuel elements stored in the KE and KW Basins are damaged to the extent that the uranium metal fuel is exposed to the water and has undergone deterioration to form $K$ Basin sludge. The sludge also contains sand, dust, ion exchange resins, and corrosion products from storage canisters and equipment in the Basins, and other contaminants. Deterioration of fue 7 elements and disposal of the resulting sludge at tank farms are physical and chemical conditions which are not bounded by existing tank farms Criticality Safety Evaluation Reports (CSERs): The major difference between the K Basin sludge and waste currently stored in tank farms, is the sludge has not been processed to separate plutonium and other radionuclides and so has never been subjected to the chemical treatment of dissolution and precipitation as has most of the existing tank wastes. As a result. $K$ Basin sludge has a relatively high plutonium concentration in addition to containing substantial amounts of enriched uranium. K Basin sludge also has a larger overall particle size distribution than tank wastes and contains particles that are 0.25 -inch in diameter or less. This report considers the differences in sludge and tank waste characteristics in terms of their implications on criticality safety. Alternative approaches to assuring criticality safety are identified and evaluated.

The storage of $K$ Basin sludge in the Tank Farms system, with eventual retrieval, treatment and disposal at an off-site repository, requires comparison of the storage alternatives. The chemical and physical characteristics of the sludge pose a potential criticality safety concern that will impact storage and final disposal decisions. This feasibility study examines storage options from a criticality safety perspective and provides sufficient information to support the $K$ Basin sludge relocation decision process.

The $K$ Basin sludge relocation, treatment and storage alternatives are grouped into three broad categories (Hatch 1997) and a fourth derived from one of the original three, as described below.

(1) Current baseline storage in an existing double she11 tank (DST) AW-105 with unrestricted usage of that tank for other waste storage.

(2) Storage at AW-105 with restriction of further use for waste acceptance and storage until final retrieval of its wastes for vitrification.

(3) Expedited construction of one or more sma11, Resource Conservation and Recovery Act of 1976 (RCRA)-compliant tanks specifically for interim storage of the sludge prior to vitrification. For criticality evaluation purposes, such new tanks may be envisioned similar to existing DCRTs $(50,000 \mathrm{gal})$ or smaller.

(4) Construction of a new critically-safe tank has been recognized as an additional subset of Alternative 3 . 
This feasibility study does not define design criteria for new equipment or modifications to existing equipment for sludge retrieval. transportation or discharge into the tank farm system. Minimum acceptance parameters for the treatment of sludge, if necessary, will be identified, but design specifications are not part of the scope of this feasibility study. In addition. this report does not evaluate the overall costs, safety. programmatic, and schedule aspects of the alternative storage configurations for $K$ Basin sludge, nor does it evaluate the feasibility of designing a pretreatment process to alleviate criticality safety concerns. Additional studies are being conducted to address these other aspects of $K$ Basin sludge management alternatives.

The rest of this report contains descriptions of alternative sludge storage and pretreatment configurations (Chapter 3) and a summary of the technical findings regarding each configuration (Chapter 4). Chapter 4 also contains a comparative evaluation of the sludge storage alternatives and conclusions about the technical viability of each alternative. Detailed evaluations of the chemistry, criticality safety, and neutronics of the $K$ Basin sludge storage alternatives are presented in Appendices A, B, and $C$. respectively. 
HNF-SD-WM-ES-409, Rev. 0

\subsection{SUMMARY}

This feasibility study provides the technical justification for conclusions about $K$ Basin sludge storage options. The conclusions, solety based on criticality safety considerations. depend on the treatment of the sludge. It is concluded that:

1. Untreated sludge must be stored in a critically safe storage tank.

2. Treated sludge (dissolution, precipitation and added absorbers) can be stored in a standard Double Contained Receiver Tank (DCRT) or 241-AW-105 without future restrictions on tank operations from a criticality safety perspective.

It is concluded that the addition of either depleted uranium or iron during dissolution and precipitation treatment can provide the assurance that a criticality is prevented. The use of depleted uranium is particularly attractive since the possibility of absorber separation is minimized. Sufficient information is provided to enable a final choice of alternative. However, specific discharge criteria and the appropriate margin of safety will be developed in the final Criticality Safety Evaluation Report (CSER) after a specific alternative is designated.

Sludge currently in the $K$ Basins contains a quantity of fissile materials (U-235 and Pu-239) that poses a criticality concern for retrieval and storage. The discharge of untreated sludge into a storage tank is expected to form a layer enriched with fissile isotopes. This evaluation allows for the fact that the composition and distribution of fissile materials currently stored in DST 241-AW-105 cannot be predicted with quantified accuracy and assumes that interaction between untreated K Basin sludge and the solids in 241-AW-105 can occur. The discharge of the $K$ Basin sludge into 241-AW-105 must be preceded with a treatment that reduces the particle size sufficiently to allow agglomeration to prevent segregation. The added quantity of absorbers must provide assurance that worst case fissile material segregation will not exceed $a k_{\infty}$ of 0.95 . The treatment of the $K$ Basin sludge which provides the technical defensibility for an adequate margin of safety is the dissolution and rapid precipitation of the fuel sludge with added neutron absorbers. Future waste management activities in 241-AW-105 wi11 not be impacted by the described treatment process.

The construction of standard design Double Contained Receiver Tanks (DCRTs) for the purpose of storing $K$ Basin sludge would eliminate the need to address interaction of untreated $K$ Basin sludge with other fissile material bearing solids. However, concerns with the segregation of fissile materials from untreated sludge must be addressed. The addition of insoluble neutron absorbers will not alleviate the separation concern because the settling velocity of large fuel pieces exceeds the settling velocity of submicron particles of neutron absorbers, thus potentially leading to separation of fissile materials from absorbers. Storage of the K Basin sludge in a new DCRT(s) must be preceded by the dissolution and rapid precipitation treatment with added neutron absorbers. 
The construction of a storage tank that includes engineered features to prevent a criticality makes possible the storage of the $K$ Basin sludge without pretreatment. The sludge from the $K$ Basins could be discharged and stored in a critically safe tank without the dissolution and precipitation treatment and neutron absorbers need not be added. However, stringent requirements for the design, construction and operation of a critically safe tank must be met. The assurance that a criticality is prevented for all design basis accidents must be justified and technically defensible. 
HNF-SD-WM-ES-409, Rev. 0

\subsection{DESCRIPTION OF ALTERNATIVES}

This section describes four main alternatives for storage of $K$ Basin sludge in 241-AW-105 (AW-105) in a critical7y-safe manner. The alternatives involve various storage configurations and include some specific suba)terriatives that accomplish the same purpose using slightly different configurations. Requirements may be different across alternatives and reflect the philosophy that either the storage configuration or the sludge would have to be made critically-safe. Alternative storage and pretreatment strategies are summarized in Table 3.1. The table indicates the decision to construct a new tank(s) or to use existing AW-105, clearly hinges on the particle size and the decision to add neutron absorbers to the sludge. The key elements of each sludge storage strategy are described in the following sections.

\subsection{ALTERNATIVE 1 - BASELINE STORAGE CONFIGURATION IN EXISTING DST}

This alternative is the current project baseline involving storage of $k$ Basin sludge in double-shel1 tank (DST) AW-105. The sludge would be retrieved from the Basins, chemically-adjusted to meet tank farm waste acceptance criteria, transported via a specially-designed shipping container to the tank. and offloaded into the tank via a specially-designed sludge transfer system. The alternative would allow storage of additional tank waste in AW-105; i.e., the tank would not be isolated or restricted from receiving transfers of additional material. The existing DSTs provide no engineered features for prevention of criticality including no geometry control. spacing control, or control of fissile material distribution mechanisms (i.e., no way to redistribute fissile material in a predictable manner).

\section{3:2 ALTERNATIVE 2 - STORAGE IN EXISTING DST WITH FURTHER USE RESTRICTIONS}

This alternative is nearly the same as Alternative 1 except that subsequent use of the AW-1.05 for additional transfers would be restricted. The same activities would be undertaken to retrieve, chemically-adjust, transport, and offload the sludge into the tank. The DST would be isolated until final retrieval of its wastes for disposai. As with Alternative 1, the tank provides no engineered features for prevention of criticality (i.e., no geometry control, spacing control, or control of fissile material distribution mechanisms).

\subsection{ALTERNATIVE 3 - STORAGE IN NEW TANK}

This alternative would involve construction of one or more small. Resource Conservation and Recovery Act (RCRA)-compliant tanks constructed specifically for interim storage of $K$ Basin sludge prior to disposal. The tanks are envisioned to be sma11, similar to existing Double-Contained Receiver Tanks (DCRTS), and would not be inherently critically-safe. Similar to Alternatives 1 and 2, the new tank would provide no engineered features for criticality prevention. Since this is a new tank system, it would be designed to modern standards, including resistance to seismic events and other Design Basis Accidents (DBAs) and natural phenomena hazards. 
Table 3.1. Summary Description of Each Sludge Storage Alternative

\begin{tabular}{|c|c|c|}
\hline \multirow{2}{*}{$\begin{array}{l}\text { Alterna- } \\
\text { tive }\end{array}$} & \multicolumn{2}{|r|}{ Description } \\
\hline & Storage Configuration & Sludge Pretreatment Option Considered \\
\hline \multirow[t]{4}{*}{1} & \multirow{4}{*}{$\begin{array}{l}\text { Existing DST AW-105: no } \\
\text { further use } \\
\text { restrictions }\end{array}$} & 1A. No pretreatment \\
\hline & & 1B. Particle size reduced $<1270 \mu \mathrm{m}$ \\
\hline & & 1C. Add neutron absorbers ${ }^{(a)}$ \\
\hline & & $\begin{array}{l}\text { 10. Chemical pretreatment: particle } \\
\text { size less than } 50 \mathrm{\mu m}\end{array}$ \\
\hline \multirow[t]{4}{*}{2.} & \multirow{4}{*}{$\begin{array}{l}\text { Existing DST AW-105; } \\
\text { further use restricted }\end{array}$} & 2A. No pretreatment \\
\hline & & 2B. Particle size reduced $<1270 \mu \mathrm{m}$ \\
\hline & & 2C. Add neutron absorbers ${ }^{(a)}$ \\
\hline & & $\begin{array}{l}\text { 20. Chemical pretreatment: particle } \\
\text { size less than } 50 \mu \mathrm{m}\end{array}$ \\
\hline \multirow[t]{4}{*}{3.} & \multirow[t]{4}{*}{ New RCRA-compliant tank } & $3 \mathrm{~A}$. No pretreatment \\
\hline & & 3B. Particle size reduced $<1270 \mu \mathrm{m}$ \\
\hline & & 3C. Add neutron absorbers ${ }^{(a)}$ \\
\hline & & $\begin{array}{l}\text { 3D. Chemical pretreatment: particle } \\
\text { size less than } 50 \mu \mathrm{m}\end{array}$ \\
\hline \multirow[t]{4}{*}{4.} & \multirow{4}{*}{$\begin{array}{l}\text { New critically-safe } \\
\text { tank }\end{array}$} & 4A. No pretreatment \\
\hline & & $4 \mathrm{~B}$. Particle size reduced $<1270 \mu \mathrm{m}$ \\
\hline & & 4C. Add neutron absorbers ${ }^{(a)}$ \\
\hline & & $\begin{array}{l}\text { 40. Chemical pretreatment: particle } \\
\text { size less than } 50 \mu \mathrm{m}\end{array}$ \\
\hline
\end{tabular}

(a) The choice of absorbers is either depleted uranium or iron.

\subsection{ALTERNATIVE 4 - STORAGE IN NEW CRITICALLY-SAFE TANK}

Alternative 4 is the construction of a new, critically-safe storage tank constructed specifically for interim storage of $K$ Basin sludge. The sludge would be transferred into the new tank and stored until final disposition. This Alternative would involve design and construction of a tank with some combination of geometry controls, fixed poisons, and/or fissile material distribution controls. The degree to which these controls are utilized depends on the characteristics of the sludge and thus on the degree of pretreatment applied to the sludge. As with Alternative 3, the new 
critically-safe tank would be designed to modern standards, including seismic resistance and resistance to other DBAs and natura? phenomena.

The assurance that a criticality is prevented must be justified by the configuration and operation of the new tank(s). A new tank would have to be designed and installed with critically safe features. The tank geometry, use of neutron absorbers, criticality detection and monitoring systems, and surveillance requirements must render the storage of the sludge critically safe for a 11 normal and credible abnormal conditions.

\subsection{SLUDGE PRETREATMENT OPTIONS}

A number of suboptions involving varying degrees of sludge pretreatment are possible within each major alternative described above. A total of four potential pretreatment options are considered. Under sludge treatment option $A$, the sludge would not be pretreated, except for chemical adjustments made to meet tank farm waste acceptance criteria, such as $\mathrm{pH}$ and nitrate and nitrite concentrations.

Treatment option B involves mechanical pretreatment of the sludge to reduce the particle size to less than $1270 \mathrm{~mm}$. This could also involve mechanically-separating particles from the bulk sludge so that the maximum particle size in the stored sludge material would be smaller than $1270 \mu \mathrm{m}$. enhancing homogeneity. The assurance that a criticality is prevented, would need to be justified by a combination of the increased minimum critical mass, particle segregation, and the engineered features of new tank(s). The minimum critical mass of uranium increases significantly as the particle size is decreased. Criticality is precluded for $0.947 \mathrm{wt} \% \mathrm{U}-235$ enriched fue 7 in the form of particles with a diameter less than $1270 \mu \mathrm{m}$. For 1.25 wt\% U-235 enriched fuel, criticality is possible at any particle size, but requires about $1.500 \mathrm{~kg}$ of uranium (18 $\mathrm{kg} \mathrm{U}-235$ ) for particles less than $1270 \mu \mathrm{m}$. This alternative requires assurance that sludge particles are less than $1270 \mu \mathrm{m}$. but chemical treatment would not be required.

Treatment option $C$ consists of controlling criticality through the addition of neutron absorbers. Iron and depleted uranium are considered here. To assure criticality safety, it must be shown that 1) a sufficient quantity of absorber is available to assure subcriticality. and 2) the absorber materials will not segregate from the fissile material under normal and credible accident conditions. Very small particle sizes would minimize segregation of fissile material and absorbers.

Treatment option $D$ involves chemical dissolution and re-precipitation to ensure particle sizes are very small (less than approximately $50 \mu \mathrm{m}$; to be confirmed in the CSER). The only feasible way to achieve very smail particles is through chemical dissolution and precipitation. This option results in sludge that is critically-safe and the treated sludge can be stored safely without requiring additional engineered features (such as control of geometry. spacing, and distribution mechanisms) on the tank storage configuration. This option may also require the addition of neutron absorbers. 
HNF-SD-WM-ES-409, Rev. 0

This page intentionally left blank. 


\subsection{TECHNICAL FINDINGS AND CONCLUSIONS}

This chapter summarizes the criticality safety approach taken in this study and the technical findings related to the chemistry, criticality safety, and neutronics calculations associated with $K$ Basin sludge. A comparative evaluation of the various sludge storage strategies described in Chapter 3 is presented. The benefits and limitations of each alternative are described in terms of criticality safety. Detailed information on the chemistry, criticality safety, and neutronics calculations are presented in Appendices A, $B$, and $C$, respectively.

\subsection{CRITICALITY SAFETY APPROACH FOR K BASIN SLUDGE}

Assurance of criticality safety can be achieved in any of three ways. including 1) control of the concentrations of fissile materials (including addition of neutron absorbers). 2) control of the total masses of fissile materials, and 3) geometry control. Historically, the approach in tank farms has been to control the concentrations of fissile materials such that the wastes could be stored without limits on total quantities and without geometry control (i.e... the storage tanks provide no geometry control or control over the distribution of fissile material in the tank). After the wastes have been transferred into the tank, all control over the fissile material geometry and other criticality-related parameters is lost. Therefore, the philosophy was to provide assurance that the waste was critically-safe before it was transferred into the tank. The controls on transfers to the tank farm system focused, and still focus, on maintaining low concentrations of plutonium in solids sent to the tank farm. Currently, the Pu concentration limit in tank farms is $0.013 \mathrm{~g} / \mathrm{L} \mathrm{Pu}$ in solid/liquid mixtures (Vail 1995). This is anticipated to be increased to $0.04 \mathrm{~g} / \mathrm{L}$ when a new set of criticality controls resulting from the Tank Waste Remediation System Basis for Interim Operation (TWRS BIO; LMHC 1997) is implemented. These limits were derived from a goal to maintain Pu concentrations in tank farm solids below $1.17 \mathrm{~g} / \mathrm{L}$. The actual control was placed on the concentration of solid/liquid waste slurries transferred to the tank farms because historically the solids content of the slurries could not be measured.

The general approach to assuring criticality safety in $K$ Basin sludges will be similar to that used for wastes generated from chemical separations processes. The detailed criticality safety evaluations and criticality safety controls are likely to be different, but the general approach and bases would be the same. One significant difference is that the concentration of $\mathrm{Pu}$ in certain K Basin sludges (settled solids) are on the order of $7 \mathrm{~g} / \mathrm{L}$. This is substantially more reactive than typical chemical separations waste and exceeds the boundaries of previous tank farm Criticality Safety Evaluation Reports (CSERs). This is the main reason why substantial scrutiny is being placed on assurance of criticality safety for K Basin sludges. On the other hand, it does not mean that $K$ Basin sludge would not be acceptable at tank farms but rather additional analyses are needed to define the appropriate limits and controls to establish a defensible basis for assuring criticality safety under normal and credible abnormal conditions.

As stated above, $K$ Basin sludge is more reactive than typical tank farm wastes. The Pu concentration is above the goal of maintaining the 
concentration of Pu below $1.17 \mathrm{~g} / \mathrm{L}$ in settled solids. Whereas the solids content of wastes transferred in the past to tank farms could not be accurately measured, the opportunity exists to measure the solids content of each batch of $K$ Basin sludge transferred to tank farms. Therefore, it is possible to justify a higher fissile concentration in the $K$ Basin solids than in past transfers to tank farms. This would eliminate the need for a limit on the Pu concentration in solid/liquid slurries, as was done in the past and offers the potentia] to significantly increase the Pu concentration limit on solids. In other words, the margin of subcriticality for storage of K Basin sludge can be smaller than the margin built into storage of chemical separations wastes. This can be justified on the basis that the solids content of $K$ Basin sludge will be accurately measured, leading to much more accurate control of $\mathrm{Pu}$ concentration in $\mathrm{K}$ Basin sludge than typical tank farm wastes. An additional difference is that $K$ Basin sludges contain significant quantities of uranium, some of which has been enriched to $0.95 \mathrm{wt} \% \mathrm{U}-235$ and some enriched to 1.25 wt: U-235. As a result, the controls implemented to assure criticality safety for $K$ Basin sludges are likely to be different than those implemented to assure criticality safety of wastes generated by chemical separations processes.

The general criticality safety analysis approach for $K$ Basin sludges is illustrated in Table 4.1. As shown, two options are being addressed. The first involves addition of depleted uranium as the neutron absorber and the second adds iron. Within each option are two separate analyses, one for 0.95 wt\% U-235 enriched uranium (K East Basin) and the second is for $1.25 \mathrm{wt} \%$ enriched uranium ( $K$ West Basin). The analytical strategies for these four cases are briefly described in the following paragraphs.

\subsubsection{Depleted Uranium Addition}

Addition of depleted uranium to the $K$ Basin sludge as a neutron absorber is an option for the prevention of a criticality. A homogeneous uranium oxide system is subcritical when the U-235 content is less than $1.03 \mathrm{wt} \%$.

Therefore, the lower-enriched sludges ( $0.95 \mathrm{wt} \%$ ) in KE Basin wi 11 be subcritical provided that homogeneity can be assured for all normal and credible abnormal conditions. The added depleted uranium must be mixed uniformly with the enriched uranium to ensure that the enrichment limit is not exceeded in any portion of the sludge. For the higher-enriched $K$ west Basin sludge, a sufficient quantity of depleted uranium would have to be added to reduce the enrichment to $1.03 \mathrm{wt} \%$ or less and criticality is prevented provided homogeneity can be assured.

The addition of depleted uranium is a particularly attractive option, since it will be easy to demonstrate that the neutron absorber (U-238) wi11 not chemically or physically segregate from the fissile material (U-235) under normal and credible abnormal conditions. Also, for the same mass ratio of absorber to fissile material, the volume of depleted uranium solids will be less than the volume of iron to be added to the sludge. However, the addition of depleted uranium assures that a criticality is prevented when only uranium is considered, all particles are less than $1270 \mathrm{\mu m}$, and the enrichment is less than 1.03 wt\% U-235. The K Basin sludge also contains Pu-239. For K Basin sludge particles of this size. segregation of Pu-239 from U-238 can be expected. However, addition of depleted uranium followed by acid dissolution 
Table 4.1. Criticality Safety Approach for K Basin Sludges

\begin{tabular}{|c|c|c|c|}
\hline \multicolumn{2}{|c|}{ Depleted Uranium } & \multicolumn{2}{|c|}{ Neutron Absorber Addition } \\
\hline $\begin{array}{l}0.95 w t \% \text { U-235 } \\
\text { (KE Basin) }\end{array}$ & $\begin{array}{c}1.25 w t \% \text { U- } 235 \\
\text { (KW Basin) }\end{array}$ & $\begin{array}{l}0.95 w t \% \text { U-235 } \\
\text { (KE Basin) }\end{array}$ & $\begin{array}{l}1.25 w t \% \text { U-235 } \\
(\text { KW Basin) }\end{array}$ \\
\hline $\begin{array}{l}\text { Prove uranium } \\
\text { metal is enriched } \\
\text { to } 0.95 \mathrm{wt} \% \mathrm{U}-235 \\
\text { or less }\end{array}$ & $\begin{array}{l}\text { Prove enough } \\
\text { depleted } U \text { is } \\
\text { added to reduce } \\
U-235 \text { enrichment } \\
\text { to below } 1.03 \text { wt\% }\end{array}$ & \multicolumn{2}{|c|}{$\begin{array}{l}\text { 1. Select } K_{\text {eff }} \\
\text { 2. Select absorber material } \\
\text { 3. Determine absorber quantity }\end{array}$} \\
\hline \multicolumn{2}{|c|}{$\begin{array}{l}\text { Need homogeni-zation to prevent } \\
\text { fissile particle segregation from } \\
\text { larger particles }\end{array}$} & \multicolumn{2}{|c|}{$\begin{array}{l}\text { Need homogenization to prevent } \\
\text { particle separation from larger } \\
\text { particles }\end{array}$} \\
\hline \multicolumn{2}{|c|}{$\begin{array}{l}\text { Sma11 particle size needed to prevent } \\
\text { segregation of } \mathrm{Pu} \text { from } \mathrm{U}\end{array}$} & \multicolumn{2}{|c|}{$\begin{array}{l}\text { Sma11 particle size needed to prevent } \\
\text { segregation from neutron absorbers }\end{array}$} \\
\hline \multicolumn{2}{|c|}{$\begin{array}{l}\mathrm{pH}>8 \text { needed to prevent } \\
\text { solubilization of fissile materials }\end{array}$} & \multicolumn{2}{|c|}{$\begin{array}{l}\mathrm{pH}>8 \text { needed to prevent } \\
\text { solubilization of fissile materials }\end{array}$} \\
\hline \multicolumn{2}{|c|}{$\begin{array}{l}\text { Demonstrate subcritical and that } \\
\text { there is no credible } \mathrm{U} \text {. Pu enrichment } \\
\text { mechanism. }\end{array}$} & \multicolumn{2}{|c|}{$\begin{array}{l}\text { Calculate } U \text { concentration that would } \\
\text { give } k_{\infty}=0.95 \text {. Divide result by } \\
\text { maximum calculated separation factor } \\
\text { to calculate new } U \text { concentration. } \\
\text { Then calculate new } k_{\infty} \text { using new } U \\
\text { concentration. }\end{array}$} \\
\hline
\end{tabular}

and rapid precipitation would result in much smaller particles and would make it relatively easy to demonstrate that segregation of $\mathrm{Pu}-239$ from $\mathrm{U}-238$ will be minimized.

\subsubsection{Iron Addition}

Iron is another effective neutron absorber. As was done for depleted uranium additions, separate cases were analyzed for iron additions: the first one is for $0.95 \mathrm{wt} \%$ enriched material and the second is for 1.25 wt\% enriched materia?. The criticality analyses for both cases begin by selecting an appropriate $k_{\text {eff }}$, selecting the absorber material (ferric nitrate was selected), and then determining the absorber quantity needed to achieve the selected $k_{\text {eff }}$. Other conditions are similar to the depleted uranium case. including a requirement for a well-mixed system in terms of particle size to prevent fissile material segregation from larger particles. A further requirement is to prevent segregation of fissile material from neutron absorbers. It is also required that the $\mathrm{pH}$ is greater than 8 to prevent $U$ and Pu solubilization. 
The criticality analysis performed for iron additions will be conducted as follows. First, the uranium concentration required to result in a $k_{\infty}=0.95$ will be calculated. This uranium concentration will then be divided by the maximum separation factor determined in Appendix $A$ to determine a new uranium concentration. A new value of $k_{\infty}$ will be calculated using this new uranium concentration. Finally, the quantity of iron needed to ensure this new $k_{\infty}$ is not exceeded is determined. This quantity of iron must be wellmixed with uranium.

An alternative methodology calculates the iron addition recuired to maintain $k_{\infty}=0.95$. The calculated amount of metal is tripled to allow for maximum calculated segregation, and a new $k_{\text {eff }}$ for the system is calculated. This quantity of iron must be well-mixed with uranium.

\subsubsection{Quantity of Added Absorbers}

The operational criteria for discharging $K$ Basin sludge into DST 241-AW105 depends on the storage alternative. After an alternative is selected. operational criteria will be established in the final CSER. The capability to ensure or verify waste homogeneity does not currently exist on the Hanford site, so the limits must be based on worst case assumptions about interaction between the $K$ Basin sludge and the plutonium currently stored in 241-AW-105. The quantity of neutron absorbers added to the $K$ Basin sludge depends on the quantity of $K$ Basin sludge and the accepted margin of safety.

The estimated $k_{\infty}$ of the tank waste currently stored in 241-AW-105 is extremely low, about 0.05 . It is expected that the required margin of safety for the $K$ Basin sludge would not be this low. After consideration of al1 concentrating mechanisms, the added neutron absorbers are not expected to bring the $k_{\infty}$ of the mixture below 0.6. Basically, the quantity of neutron absorbing solids we11 mixed with the uranium must be at least enough to ensure that $k_{\infty}$ will not exceed 0.95 with optimal moderation and full reflection. after taking into account uranium segregation through gravity settling and chemical processes and neutronic interactions with other sludge for a11 normal and credible abnormal conditions.

The iron to be added as described above is a minimum. A larger quantity may be needed to ensure that the mass ratio meets the requirement throughout the sludge after taking into account difficulties in providing uniform mixing. In addition, neutronic interaction with DST AW-105 sludge has not been factored in. Although all available characterization data indicates that DST AW-105 sludge should not contribute significantly to neutronic interaction. uncertainties are sufficiently great that a larger fraction of iron may be required.

\subsection{CHEMISTRY SUMMARY}

A discussion of the chemistry concerns associated with the relocation and storage of $\mathrm{K}$ Basin sludge is contained in Appendix $\mathrm{A}$. Conclusions pertinent to decisions concerning the storage aiternatives are summarized in this section.

Segregation of fuel particles during settling was examined. The waste receiving tank has no impact on the degree of particle segregation since the 
parameters which impact segregation are independent of the containment vesse]. The untreated sludge in the $K$ Basins, both $K$ East and $K$ West, contain an unquantified mass and volume of large particles $>100 \mu \mathrm{m}$. Although many of the samples indicate that flocculation and agglomeration of small particles exists, the data does not exclude the presence of large primary particles. The observed particle segregation after exposing the solids to sonication. which promotes the breakup of agglomerates, indicates that segregation is the result of large primary particles not different agglomerate sizes.

Segregation tests with samples of K Basin floor, weasel pit and canister sludge all indicate that some segregation is expected to occur between the fissile material and neutron absorbers, if the sludge were to be stored without pretreatment.

The segregation of large primary particles is not a criticality safety concern if assurance is provided that these particles are a subcritical mixture of fissile isotopes and neutron absorbing materials. Also, confidence that disturbing the solids will not significantly change the mass ratio of fissile to absorber materials must be provided. Results of segregation tests on the KE floor, weasel pit and canister sludge do not provide confidence that fissile materials will not separate from neutron absorbers. In fact. segregation of untreated sludge is clearly expected to occur. Layers of high concentration fissile material due to settling is unacceptable from a criticality safety perspective.

The margin of criticality safety is increased by the addition of neutron absorbers which remain intimately associated with the fissile isotopes regardless of the future waste management activities. Iron in the form of ferric nitrate $\left(\mathrm{Fe}\left(\mathrm{NO}_{3}\right)_{3}\right)$ has been added to waste batches transferred to the tank farms from the Plutonium Finishing Plant (PFP). The compatibility of added $\mathrm{Fe}\left(\mathrm{NO}_{3}\right)_{3}$ with tank waste is less of an issue than some other neutron absorbers which could be effective but whose impacts on operations have not been evaluated. The addition of ferric nitrate to untreated sludge has a minor impact on the nitrate concentration required for corrosion control. However, the formation of solid phase iron in an oxidized system will produce submicron particles of iron which have not been shown to remain intimately associated with the larger fissile material particles. The precipitation of iron hydroxides within untreated $K$ Basin sludge would not assure agglomeration between the fissile material and added iron or uranium.

The intimate mixing of the slurry components and the formation of very small primary particles to facilitate agglomeration and prevent particle segregation would be accomplished with the dissolution of $K$ Basin sludge and added ferric nitrate followed by rapid precipitation. This process wi 17 require the close monitoring of the nitrate concentration to ensure the slurry does not exceed a nitrate concentration of $5.5 \mathrm{M}$, for compliance with the corrosion, specifications. The sludges currently stored in the double shell tanks were formed by the same acid dissolution and precipitation process.

Waste transfer records indicate that double shell tank 241-AW-105 currently stores about $13 \mathrm{~kg}$ of plutonium in $1.08 \mathrm{E} 3 \mathrm{~kL}(286,000 \mathrm{gal})$ of solids. The tank plutonium inventory based on extrapolating sample data over the entire tank contents indicate an inventory of $22 \mathrm{~kg}$. An estimated $60 \%$ of the plutonium inventory was transferred into the tank between June 1994 and April 1995 which means this material is located at the top of the existing 
solids layer. Sample data does not conclusively corroborate the expected location of the enriched plutonium layer but to assume this material is near the top of the solids is conservative relative to an addition of $\mathrm{K}$ Basin sludge. The predicted segregation of fissile material from absorbers due to settling of the untreated $K$ Basin sludge could result in a thick layer with an unacceptably high concentration of fissile material at the top of the solids in AW-105.

The chemical composition of the $K$ Basin sludges after acid dissolution, added iron and rapid precipitation will be quite similar to the sludges in AW-105. The mixing of treated K Basin sludge and solids in AW-105 is not expected to result in significant chemical reactions, chemical incompatibility or solubility concerns with fissile material or neutron absorbers. The dissolution and reprecipitation treatment of the K Basin sludge will provide assurance that particle agglomeration will prevent any significant segregation. The interaction between treated sludge and the solids currently stored in 241-AW-105 would be minimized since agglomerated solids provides an inherent margin of criticality safety.

\subsection{CRITICALITY SAFETY ANALYSIS SUMMARY}

A discussion of the criticality safety concerns associated with the relocation and storage of the $K$ Basin sludge is contained in Appendix $B$. The conclusions pertinent to decisions concerning the storage alternatives are summarized in this section.

The U-235 enrichment of analyzed sludge samples from KE Basin ranges from 0.695 to $0.734 \%$. Although, these values are low enough to ensure subcriticality, the sludge covered by these samples represents only a small fraction of the total sludge in the $K$ Basins. An evaluation would bound the composition of the sludge not represented by sample analysis with the assumption that this material is the same composition as the green (unirradiated) fuel.

For pieces of uranium enriched to $0.95 w t \% \mathrm{U}-235$ the $\mathrm{k}_{\text {eff }}$ equal to 0.98 results in a uranium mass of $2886 \mathrm{~kg}$ or $27 \mathrm{~kg}$ of U-235. As the pieces of uranium are reduced in size the minimum critical mass increases to infinity and a criticality is precluded. At a particle size of $1270 \mu \mathrm{m}$ the system is effectively considered homogeneous and a criticality is precluded. For uranium enriched to $1.25 \mathrm{wt} \% \mathrm{U}-235$, criticality is possible for any particle size. Assurance that a criticality is prevented can be provided for small uranium particles mixed with neutron absorbers.

The quantity of added absorbers must satisfy specific technical requirements. Added absorbers much smaller in size than the primary fissile material particles may not prevent the separation of waste components. However, particle size reduction by dissolution and precipitation can provide the justification that all particles will be less than $50 \mu \mathrm{m}$. According to Serne et a1. (1996), fissile material concentration increases due to settiing would not be expected to exceed a factor of 2.5. The addition of iron or depleted uranium to treated sludge must provide the assurance that after consideration of concentrating mechanisms, the $k_{\infty}$ of the mixture will never exceed 0.95 . 
Assurance that untreated K Basin sludge discharged into 241-AW-105 wil1 not settle into a thick layer of enriched uranium fuel pieces can not be provided. Actually, the transfer of untreated sludge into any containment vessel will result in the segregation of fuel pieces, creating a heterogeneous mixture and a smaller critical mass. The preferential segregation of fissile materials from absorbers creating a heterogeneous mixture and smaller critical mass is most easily mitigated by particle size reduction. Reducing the particle size of uranium fuel to a size approximately equivalent to the surrounding absorbers provides some assurance that the sludge is a homogeneous mixture.

A heterogeneous mixture of fuel sludge can be safely managed provided either geometry or mass is controlled. For 0.95 wt\% enriched uranium pieces a criticality is prevented if the storage containment limits slab thickness to less than $43.2 \mathrm{~cm}$ (17.0 in.). The fuel pieces enriched to $1.25 \mathrm{wt} \%$ could be stored in a slab with a thickness no greater than $30 \mathrm{~cm}(11.8 \mathrm{in}$.). The identified dimensions of these "critically safe" containment vessels are boundary conditions, so the actual design would provide an additional margin of safety. Dimensions of other critically safe tanks are found in Appendix $B$, Table 3.2.

\subsection{EVALUATION OF CRITICALITY SAFETY ALTERNATIVES}

This section examines each $K$ Basin sludge storage configuration alternative and treatment option in terms of their potential to assure criticality safety. The technical findings about each storage configuration alternative and four sludge treatment options are summarized in Table 4.2.

\subsubsection{Alternative 1 - Baseline Storage Configuration in Existing DST}

In this aiternative. $K$ Basin sludge would be retrieved from $K$ Basins, transported to tank farms, and offloaded and stored in AW-105. Under alternative $1 \mathrm{~A}$ (no pretreatment), the sludge would be stored without any pretreatment except for necessary chemical adjustments such as $\mathrm{pH}$ and nitrate/nitrite additions. This alternative would provide no criticality control. The tank would not be geometrically safe and the sludge could not be guaranteed subcritical under all normal and credible abnormal conditions. Consequent1y, Alternative 1A's criticality potential was judged to be unsafe. Alternative 1B (particle size reduced to $1270 \mu \mathrm{m}$ ) was judged to be unsafe because it cannot be definitively shown that segregation of fissile materials from primary particles can be prevented. leading to formation of a layer of sludge with high fissile material concentration. As a result, neither the sludge nor the storage tank would be inherently critically safe. Similarly. Alternative $1 C$ (addition of neutron absorbers) was also judged to be unsafe. If iron is added, segregation of iron from the fissile materials cannot be precluded at this particle size. If depleted uranium is added, segregation of plutonium from uranium can not be precluded under alt normal and credible abnormal conditions.

Alternative 10 (chemical pretreatment) was judged to be a safe storage configuration for $\mathrm{K}$ Basin sludge in $\mathrm{AW}-105$ as long as neutron absorbers are also added. The chemical dissolution and reprecipitation process envisioned would result in a very small particle size $(<50 \mu \mathrm{m})$ creating a fairly 
HNF-SD-WM-ES-409, Rev. 0

Table 4.2. Summary of Technical Findings for Each Sludge Storage Alternative

\begin{tabular}{|c|c|c|c|c|}
\hline \multirow{2}{*}{$\begin{array}{l}\text { Al- } \\
\text { ter- } \\
\text { na- } \\
\text { tive }\end{array}$} & \multicolumn{2}{|c|}{ Description } & \multirow{2}{*}{$\begin{array}{l}\text { Critica- } \\
\text { Iity } \\
\text { Potential }\end{array}$} & \multirow{2}{*}{ Comments } \\
\hline & Storage Configuration & $\begin{array}{c}\text { Sludge Pretreatment } \\
\text { Option }\end{array}$ & & \\
\hline \multirow[t]{4}{*}{1.} & \multirow{4}{*}{$\begin{array}{l}\text { Existing DST AW-105: } \\
\text { no further use } \\
\text { restrictions }\end{array}$} & 1A. No pretreatment & Unsafe & $\begin{array}{l}\text { Tank and siudge provide no } \\
\text { criticaity control. }\end{array}$ \\
\hline & & $\begin{array}{l}\text { 1B. Particle size } \\
\text { reduced }<1270 \mu\end{array}$ & Unsafe & $\begin{array}{l}\text { Segregation of fissile materials } \\
\text { from primary particles would require } \\
\text { criticaity controls. }\end{array}$ \\
\hline & & $\begin{array}{l}\text { 1C. Add neutron } \\
\text { absorbers }\end{array}$ & Unsafe & $\begin{array}{l}\text { Segregation of fissile materials } \\
\text { from added absorbers would require } \\
\text { criticality control. }\end{array}$ \\
\hline & & $\begin{array}{l}\text { 10. Chemical } \\
\text { pretreatment: particle } \\
\text { size }<50 \mu\end{array}$ & $\begin{array}{l}\text { Safe if IC } \\
\text { is also } \\
\text { performed }\end{array}$ & $\begin{array}{l}\text { Sludge made inherently critically } \\
\text { safe: tank configuration not } \\
\text { relevant to criticality safety. }\end{array}$ \\
\hline \multirow[t]{4}{*}{2.} & \multirow[t]{4}{*}{$\begin{array}{l}\text { Existing DST AW-105; } \\
\text { further use restricted }\end{array}$} & 2A. No pretreatment & Unsafe & $\begin{array}{l}\text { Tank and sludge provide no } \\
\text { criticality control. }\end{array}$ \\
\hline & & $\begin{array}{l}\text { 2B. Particle size } \\
\text { reduced }<1270 \mu\end{array}$ & Unsafe & $\begin{array}{l}\text { Segregation of fissile materials } \\
\text { from primary particles would require } \\
\text { criticality controls. }\end{array}$ \\
\hline & & $\begin{array}{l}\text { 2C. Add neutron } \\
\text { absorbers. }\end{array}$ & Unsafe & $\begin{array}{l}\text { Segregation of fissile materials } \\
\text { from added absorbers would require } \\
\text { criticality control. }\end{array}$ \\
\hline & & $\begin{array}{l}\text { 20. Chemical } \\
\text { pretreatment: particle } \\
\text { size <50p }\end{array}$ & $\begin{array}{l}\text { Safe if } 2 \mathrm{C} \\
\text { is also } \\
\text { performed }\end{array}$ & $\begin{array}{l}\text { Sludge made inherently critically } \\
\text { safe; tank configuration not } \\
\text { relevant to criticality safety }\end{array}$ \\
\hline \multirow[t]{4}{*}{3.} & \multirow[t]{4}{*}{$\begin{array}{l}\text { New RCRA-compliant } \\
\text { tank }\end{array}$} & 3A. No pretreatment & Unsafe & $\begin{array}{l}\text { Tank and sludge provide no } \\
\text { criticality control }\end{array}$ \\
\hline & & $\begin{array}{l}\text { 3B. Particle size } \\
\text { reduced }<1270 \mu\end{array}$ & Unsafe & $\begin{array}{l}\text { Segregation of fissile materials } \\
\text { from primary particles would require } \\
\text { criticality controls. }\end{array}$ \\
\hline & & $\begin{array}{l}\text { 3C. Add neutron } \\
\text { absorbers }\end{array}$ & Unsafe & $\begin{array}{l}\text { Segregation of fissile materials } \\
\text { from added absorbers would require } \\
\text { criticality control. }\end{array}$ \\
\hline & & $\begin{array}{l}\text { 30. Chemical } \\
\text { pretreatment: particie } \\
\text { size }<50 \mu\end{array}$ & $\begin{array}{l}\text { Safe if } 3 C \\
\text { is also } \\
\text { performed }\end{array}$ & $\begin{array}{l}\text { Sludge made inherently critically } \\
\text { safe: tank configuration not } \\
\text { relevant to criticality safety }\end{array}$ \\
\hline \multirow[t]{4}{*}{4.} & \multirow[t]{4}{*}{$\begin{array}{l}\text { New critically-safe } \\
\text { tank }\end{array}$} & 4A. No pretreatment & Safe & $\begin{array}{l}\text { Tank configuration provides } \\
\text { criticality control. }\end{array}$ \\
\hline & & $\begin{array}{l}\text { 4B. Particle size } \\
\text { reduced <1270 }\end{array}$ & Safe & $\begin{array}{l}\text { Tank configuration provides } \\
\text { criticality control: particle size } \\
\text { reduction enhances subcriticality. }\end{array}$ \\
\hline & & $\begin{array}{l}\text { 4C. Add neutron } \\
\text { absorbers }\end{array}$ & Safe & $\begin{array}{l}\text { Tank configuration provides } \\
\text { criticality control: neutron } \\
\text { absorber additions enhance } \\
\text { subcriticality. }\end{array}$ \\
\hline & & $\begin{array}{l}\text { 40. Chemical } \\
\text { pretreatment: particle } \\
\text { size <50 }\end{array}$ & Sofe & $\begin{array}{l}\text { Tank and sludge both inherently } \\
\text { criticality safe. }\end{array}$ \\
\hline
\end{tabular}


homogeneous system that would preclude significant primary particle and neutron absorber segregation. Consequently, the sludge would be critically safe; i.e., subcritical under all normal and credible abnormal tank conditions.

\subsubsection{Alternative 2 - Storage in Existing DST with Further Use Restrictions}

This alternative is very similar to Alternative 1 except that no further waste transfers would be allowed into AW-105 following the sludge transfers. From a criticality perspective, although further additions could reduce the subcritical margin, restricting further transfers into AW-105 would provide little benefit. In Appendix B, it was shown that sludge as it currently exists (i.e., without pretreatment), cannot be guaranteed to be subcritical. Therefore, restricting further use of the tank would have no effect on criticality safety and the conclusions derived from the evaluation of Alternatives $1 \mathrm{~A}$ to 10 would also be reached for Alternatives $2 \mathrm{~A}$ to $2 \mathrm{D}$, respectively. It was concluded that the only viable sludge storage configuration in this alternative would be 20 in which the sludge is made critically-safe via added neutron absorbers, chemical dissolution and reprecipitation.

\subsubsection{Alternative 3 - Storage in New Tank}

This alternative involves storage of $K$ Basin sludge in a new, standarddesign storage system, possibly similar to an existing DCRT. As with Alternatives 1 and 2, the storage system would provide no criticality controls, such as fixed absorbers or geometry control. As a result, since the sludge cannot be guaranteed critically-safe and particle and absorber segregation mechanisms are credible (unless sludge is pretreated), storage in a new standard-design storage system would achieve little in terms of criticality safety. There may be other justification for a new storage tank (e.g., driven by safety, regulatory, or programmatic concerns), but from a criticality safety perspective, a new standard design tank without criticality controls would not reduce criticality concerns. As a result. Alternatives 3A, $3 B$, and $3 C$ were judged to be unsafe from a criticality safety perspective and Alternative 3D (pretreatment and added absorbers), would be a safe configuration.

\subsubsection{Alternative 4 - Storage in a New Critically-safe Tank}

In this Alternative, a new storage system would be constructed that provides criticality controls via geometry control, fixed poisons, etc. In this Alternative, the storage system would be inherently safe regardless of the material stored within it. As a result, the fissile material concentration, particle size, and particle/absorber segregation mechanisms associated with $K$ Basin sludge would be irrelevant: i.e.. the storage tank would assure subcriticality. The conclusion derived here is that all four of the potential storage configurations included in this Alternative would be critically safe. Particle size reduction, addition of absorbers, and chemical pretreatment would not be necessary as long as the storage tank provides all the criticality controls. These sludge treatment options would increase the margin of criticality safety but would not be required to demonstrate subcriticality under a 11 normal and credible abnormal conditions. Other 
technical or programmatic issues may drive the decision to implement some form of pretreatment in this alternative but would not be necessary to ensure criticality safety. For example, chemical pretreatment would resolve the criticality safety issue and would also reduce the Environment, Safety, and Health (ES\&H) risks associated with flammable gas. generation and retention and potential uranium metal reactions in the sludge in it's present form. It should be noted that in this option. the presence of uranium hydride and unoxidized uranium metal constituents are an additional source of hydrogen generation beyond that from radiolysis alone. Thus, this option would require provisions for controlling hydrogen generation and retention by the sludge.

\subsection{CONCLUSIONS}

The first conclusion is related to the fissile material concentrations in $K$ Basin sludge. Preliminary characterization data on some of the $K$ Basin sludge materials, namely the $K$ East and $K$ West Basin canister and fuel wash sludges, indicate fissile material concentrations may be in excess of $7 \mathrm{~g} / \mathrm{L}$ Pu-239. This concentration is well above the current criticality prevention limit of $1 \mathrm{~g} / \mathrm{L}$. Consequent7y, a new criticality prevention limit for the tank farms would have to established to allow the transfer and storage of $K$ Basin sludge.

Overall, it was concluded that there are only 7 viable $K$ Basin sludge storage configurations from the 16 alternatives examined in this report. The current baseline configuration of storing K Basin sludge in AW-105 without pretreatment was not among the 7 viable alternatives These are:

1. Baseline storage in AW-105 with chemical pretreatment of sludge to reduce particle size below $50 \mathrm{~mm}$ and added neutron absorbers.

2. Storage in AW-105 with further use restrictions and chemical pretreatment

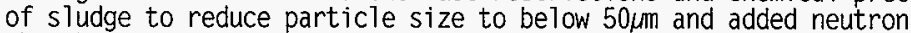
absorbers.

3. Storage in a new standard-design tank system with chemical pretreatment of sludge to reduce particle size to below $50 \mu \mathrm{m}$ and added neutron absorbers.

4. Storage in a critically-safe tank with or without pretreatment (sludge as-is, with particle size control. with neutron absorbers, with chemical pretreatment).

In the first three alternatives, the storage system would provide no criticality controls so the sludge would be made inherently critically safe. In the fourth alternative, the storage system would be made inherently critically-safe so the sludge would not need to be pretreated to provide criticality control. The treatment options evaluated would increase the margin of subcriticality but would not be required from a criticality safety perspective. Therefore, there are really two different criticality prevention alternatives for $K$ Basin sludge:

- Process the sludge to make it criticality safe via added neutron absorbers and chemical pretreatment such as chemical dissolution and reprecipitation. so that it could be stored in any configuration. 
- Construct a criticaliy-safe storage system, negating the need to pretreat the sludge to provide criticality controls; i.e., design and construct the storage system critically safe.

\subsection{OTHER CONSIDERATIONS}

This study examined $K$ Basin sludge storage issues entirely from a criticality safety perspective. There are other issues and possibly more optimum sludge treatment and storage configurations that merit some consideration. These other considerations are summarized below:

- $\quad K$ Basin sludge contains polychiorinated biphenyls (PCBs) leading to the possibility that management and disposal of the sludge could be regulated under the Toxic Substances Control Act (TSCA). Currently, tank farm wastes are managed under the Resource Conservation and Recovery Act (RCRA). The appropriate regulatory pathway for $K$ Basin sludge is currentiy being investigated and may have an effect on the future management and disposition of the sludge.

- There are ES\&H-related safety issues associated with sludge, including some that are unique to tank farms (presence of potentially pyrophoric uranium metal and hydrides in the sludge) and some that are not unique but may be exacerbated by the presence of $K$ Basin sludge in a DST

(flammable gas generation and retention). A preliminary safety assessment has been conducted and concluded that these other safetyrelated issues can be adequately controlled, based on current knowiedge of the chemical and physical properties of the sludge. The chemical pretreatment process envisioned here (dissolution followed by reprecipitation) for criticality control may also alleviate some of these ES\&H-related safety issues.

- This criticality feasibility study did not address the cost. schedule. and other programmatic impacts of the criticality prevention alternatives. These other impacts may be significant as the current baseline storage configuration (storage in AW-105 without pretreatment) was determined not be viable from a criticality perspective.

- The sludge treatment and storage configurations examined here were not optimized with respect to the material to be stored. It may be possible to separate the sludges in the Basins into two or more categories then handle and treat each category of sludge differently in accordance with it's own criticality safety requirements. For example, it may be possible to treat the largest volume of sludge (KE floor and pit sludge) in a much less comprehensive manner than chemical dissolution and reprecipitation. This could lead to lower costs and still result in assurance of subcriticality even though only a relatively small amount of material would be subjected to more rigorous criticality controls.

- Public and stakeholder acceptance of the selected sludge storage configuration has not yet been evaluated. 
HNF-SD-WM-ES-409, Rev. 0

This page intentionally left blank. 


\subsection{REFERENCES}

Hatch, H. J. 1997. "K Basin S7udge Storage and Disposal Recommendation." Letter 9751592 to J. D. Wagoner, U. S. Department of Energy. Richland Operations Office. Fluor-Daniel Hanford, Co. . Richland. Washington.

LMHC. 1997. Tank Waste Remediation System Basis for Interim Operation. HNFSD-WM-BI0-001, Revision F. Lockheed-Martin Hanford Company, Richland, Washington.

Serne, R. J.. G. A. Whyatt, S. V. Mattigod, Y. Onishi, P. G. Doctor, B. N. Bjornstad, M. R. Powe11, L. M. Li]jegren, J. H. Westik, Jr. N. J. Aimo, R. P. Recknagle, G. R. Golcar, T. B. Miley, G. R. Holdren, D. W. Jeppson, R. K. Biyani, and G. S. Barney. 1996. Fluid Dynamic Particulate Segregation, Chemical Processes, and Natural Ore Analog Discussions that Relate to the Potential for Criticality in Hanford Tanks. WHC-SD-WM-TI-757, Rev. 0. Westinghouse Hanford Co., Richland, Washington.

Vail, T. S. 1995. Criticality Prevention Specifications, Waste Storage Tanks and Associated Equipment. CPS-T-149-00010. Westinghouse Hanford Co., Richland. Washington. 
HNF-SD-WM-ES-409, Rev. 0

This page intentionally left blank. 
HNF-SD-WM-ES-409, Rev. 0

\section{APPENDIX A}

INVESTIGATION OF CHEMICAL AND PHYSICAL SEGREGATION MECHANISMS RELEVANT TO CRITICALITY FEASIBILITY ASSESSMENT OF THE TRANSFER OF

$K$ BASIN SLUDGES TO TANK AW-105

Greg A. Whyatt

Dan I. Kaplan

Ken M. Krupka

Shas V. Mattigod

Jeff R. Serne 


\section{S.1 EXECUTIVE SUMMARY}

This appendix examines the transfer of $K$ basin sludges to Tank AW-105 to determine the potential for chemical and physical mechanisms which could result in segregation and concentration of fissile material. The basin sludges have particle sizes too large to prevent particle segregations. The degree of size reduction required to control particle segregation cannot reliably be obtained through mechanical means. Therefore, complete dissolution and reprecipitation of the sludge is recommended to control particle size. Due to the high fissile content of $K$ basin sludges (especially $K$ West canisters), a neutron absorber will need to be added to the sludge. Iron and depleted uranium are being considered as neutron absorbers. If the added neutron absorbers are precipitated with the sludge, agglomeration wi11 greatly reduce the potential for particle segregation, thus assuring neutron absorbers remain associated with fissile materials. No chemical reactions which could result in the segregation of precipitated iron or depleted uranium from fissile components $\left({ }^{235} \mathrm{U},{ }^{239} \mathrm{Pu}\right)$ are anticipated.

\section{S.2 DETAILED SUMMARY}

Sludges from the $K$ basins wi 71 be transferred to tank storage prior to final treatment and disposa1. Three potential candidates for the destination of the $K$ basin sludge include Tank AW-1.05, a newly constructed tank of conventional design, and a newiy constructed tank of critically safe design. This appendix examines the transfer of $\mathrm{K}$ basin sludges to Tank AW-105 to determine the potential for chemical arıd physical mechanisms which could result in segregation and concentration of fissile materia?. Because segregation would not be an issue for tanks of critically safe design, this option is not considered in this appendix. Many of the conclusions reached for AW-105 also would apply to a separate tank of conventional design assuming the same sludge treatment and adjustment for corrosion specifications is applied.

Analyses based on XRD data showed the KE basin floor and pit sludges contained U-bearing crystal7ine phases such as uraninite $\left(\mathrm{UO}_{2}\right)$, studtite $\left[\mathrm{UO}_{3}\left(\mathrm{H}_{2} \mathrm{O}_{2}\right) \cdot 3 \mathrm{H}_{2} \mathrm{O}\right]$. becquere 7 ite $\left[\mathrm{Ca}\left(\mathrm{UO}_{2}\right)_{6} \mathrm{O}_{4}(\mathrm{OH})_{6} \cdot 8 \mathrm{H}_{2} \mathrm{O}\right]$. and compreignecite $\left[\mathrm{K}_{2}\left(\mathrm{UO}_{2}\right)_{6} \mathrm{O}_{4}(\mathrm{OH})_{6} \cdot 8 \mathrm{H}_{2} \mathrm{O}\right]$. In contrast, the $\mathrm{KE}$ canister sludges contained mainly uraninite $\left(\mathrm{UO}_{2}\right)$, and schoepite $\left(\mathrm{UO}_{3} \cdot 2 \mathrm{H}_{2} \mathrm{O}\right)$. The main Fe-bearing crystalline minerals identified in the floor and pit sludges were goethite $(\alpha-$ $\mathrm{FeOOH})$ and lepidocrocite $(\gamma-\mathrm{FeOOH})$.

A review of 1iterature indicates the following general sequence of products for the oxidation of uranium metal nuclear fuel in aqueous solutions 
HNF-SD-WM-ES-409, Rev. 0

$$
\begin{gathered}
\text { Reducing } \rightarrow \rightarrow \rightarrow \rightarrow \rightarrow \rightarrow \rightarrow \rightarrow \rightarrow \rightarrow \rightarrow \rightarrow \rightarrow \rightarrow \rightarrow \rightarrow \rightarrow \rightarrow \rightarrow \rightarrow \text { Oxidizing } \\
\mathrm{U} \rightarrow \mathrm{UO}_{2} \rightarrow \mathrm{UO}_{2+\mathrm{x}} \rightarrow \mathrm{U}_{3} \mathrm{O}_{7} \rightarrow \mathrm{U}_{3} \mathrm{O}_{8} \rightarrow \mathrm{UO}_{3} \cdot \mathrm{xH}_{2} \mathrm{O} \text { (the mineral schoepite) }
\end{gathered}
$$

This sequence is consistent with the uranium-bearing phases identified in $K$ Basin sludges.

The oxidation of nuclear fuel is enhanced by products formed by radiolysis of water. This process forms radiolytic species (e.g., $\mathrm{H}_{2} \mathrm{O}_{2}, \mathrm{O}_{2}$, $e_{a q}$, etc.) which produces an oxidizing environment near the fuel surface. Radiolysis of aqueous solutions in contact with air also produces nitric acid with concomitant increase in acidity (decreasing $\mathrm{pH}$ ) and nitrate concentrations. Leaching studies of $\mathrm{UO}_{2}$ under various $\mathrm{H}_{2} \mathrm{O}_{2}$ concentrations indicate the precipitation of studtite $\left\{\mathrm{UO}_{4} \cdot 4 \mathrm{H}_{2} \mathrm{O}\left[\equiv \mathrm{UO}_{3}\left(\mathrm{H}_{2} \mathrm{O}_{2}\right) \cdot 3 \mathrm{H}_{2} \mathrm{O}\right]\right\}$ on the surface of $\mathrm{UO}_{2}$. . The chemistry of the final oxidation products are typically more complex for waters containing dissolved constituents, such as dissolved calcium, potassium, and silica. Schoepite $\left(\mathrm{UO}_{3} \cdot 2 \mathrm{H}_{2} \mathrm{O}\right)$, for example, can transform into more complex minerals, such as becquerelite $\left(\mathrm{CaU}_{6} \mathrm{O}_{19} \cdot 10 \mathrm{H}_{2} \mathrm{O}\right)$. compreignacite $\left(\mathrm{K}_{2} \mathrm{U}_{6} \mathrm{O}_{19} \cdot 11 \mathrm{H}_{2} \mathrm{O}\right)$, uranophane $\left[\mathrm{Ca}\left(\mathrm{UO}_{2}\right)_{2}\left(\mathrm{SiO}_{3}\right)_{2}(\mathrm{OH})_{2} \cdot 5 \mathrm{H}_{2} \mathrm{O}\right]$, boltwoodite $\left[\mathrm{K}\left(\mathrm{H}_{3} \mathrm{O}\right) \mathrm{UO}_{2}\left(\mathrm{SiO}_{4}\right) \cdot \mathrm{xH}_{2} \mathrm{O}\right]$, sklodowskite $\left[\mathrm{Mg}\left(\mathrm{UO}_{2}\right)_{2}\left(\mathrm{SiO}_{3}\right)_{2}(\mathrm{OH})_{2} \cdot 5 \mathrm{H}_{2} \mathrm{O}\right]$, and others.

The chemica1 reaction model MINTEQA2 was used to calculate the solubilities and associated aqueous speciation of dissolved uranium, plutonium, and other relevant components for selected $K$ East Basin floor, wease 1 pit, and canister water compositions. The basin floor and weasel pit water samples calculate to be at near equilibrium with respect to schoepite $\left(\mathrm{UO}_{3} \cdot 2 \mathrm{H}_{2} \mathrm{O}\right)$. The speciation of dissolved uranium in these two waters is dominated by U(VI) carbonate complexes, such as $\left(\mathrm{UO}_{2}\right)_{2} \mathrm{CO}_{3}(\mathrm{OH})_{3}$ and $\mathrm{UO}_{2}\left(\mathrm{CO}_{3}\right)_{2}^{2-}$. The close agreement between the uranium solubilities predicted for oxidizing conditions versus the uranium concentrations reported for the basin floor. weasel pit, and canister water samples suggests that these waters represent oxidizing conditions.

The two canister waters, however, calculate to be oversaturated with respect to schoepite. The aqueous speciation of dissolved U(VI) at these slightly acidic $\mathrm{pH}$ values are dominated by the uncomplexed $\mathrm{UO}_{2}^{2+}$ species and hydroxyl complexes, such as $\left(\mathrm{UO}_{2}\right)_{3}(\mathrm{OH})_{5}^{+}$and $\left(\mathrm{UO}_{2}\right)_{4}(\mathrm{OH})_{7}^{*}$. Uranium solubilities were also calculated as a function of redox conditions for Eh values from 800 to $-300 \mathrm{mV}$. The calculated concentrations of dissolved uranium under reducing conditions are six orders of magnitude lower than under oxidizing conditions.

The MINTEQA2 results for dissolved plutonium in basin floor and weasel pit water samples indicates that aqueous speciation of dissolved plutonium is 
dominated by the hydroxyl carbonate complex $\mathrm{Pu}(\mathrm{OH})_{2}\left(\mathrm{CO}_{3}\right)_{2}^{2 \cdot}$. The plutonium aqueous speciation for the two canister waters, which are more acidic than the basin floor and weasel pit waters, is dominated by the hydroxyl complexes, such as $\mathrm{Pu}(\mathrm{OH})_{4}^{\circ}(\mathrm{aq})$ and $\mathrm{Pu}(\mathrm{OH})_{3}^{+}$. Solubility limits given in the literature for $\mathrm{PuO}_{2} \cdot \mathrm{xH}_{2} \mathrm{O}(\mathrm{am})$ and $\mathrm{PuO}_{2}(\mathrm{cr})$ bracket the plutonium concentrations measured in these four water samples suggesting that a plutonium dioxide solid may be controlling the plutonium concentrations in these waters.

Iron- and aluminum-containing solids may form as a result of the corrosion of steel racks and aluminum canisters, respectively. The concentrations of dissolved iron predicted using MINTEQA2 are consistent with the below-detection-limit values obtained by chemical analysis. Based on the aluminum analyses reported for two canister water samples, aluminum oxide hydrate solids, such as $\mathrm{Al}(\mathrm{OH})_{3}$ (am), may be controlling the concentrations of dissolved a Tuminum in some canisters.

Although the $K$ basin sludges come from a different source than the sludges currently in Tank AW-105, the two sludges exhibit some common chemical composition (especially after adjustmerit of $\mathrm{K}$ basin sludge to meet corrosion specifications). In general the sludges are predominately metal hydrous oxides such as $\mathrm{U}, \mathrm{Fe}, \mathrm{Zr}, \mathrm{Al}, \mathrm{Si}$; and al kaline earth carbonates/hydroxides $(\mathrm{Ca}, \mathrm{Mg})$. After adjustment of $\mathrm{K}$ basin sludges to. meet tank corrosion specifications, mixing the basin water and sludge with Tank AW-105 sludge and supernatant should have no significant impact on iron. uranium or plutonium solubilities in either the $\mathrm{K}$ basin or tank sludges. No reactions which could result in the segregation of iron from fissile or of plutonium from uranium are anticipated. Addition of the sludge to Tank AW-105 will triple the uranium content of the tank and significantly increase the iron content if iron is added for neutron absorption.

Tank AW-105 received a large portion of the fissile material currently in the tank in the form of transfers of neutralized solutions of relatively pure U(VI) nitrate solutions from PUREX. To enable these transfers, credit was taken for the presence of cadmium. However. the cadmium is not required to maintain subcriticality in the tank. Not all data available on these transfers has not been evaluated, nor has the fate of cadmi um in the tank environment been explored in this apperidix. These transfers are expected to have formed a high fissile concentration layer on the top of the sludge. The presence of a high U/Pu concentration layer is not conclusively detected by the most recent grab samples from the tank.

It was determined that, at one time, a floating layer of TBP/NPH existed on top of the supernate layer in AW-105. This organic layer is the same solvent used to extract uranium and plutonium in PUREX. It is uncertain if 
HNF-SD-WM-ES-409, Rev. 0

this layer still exists in AW-105. However, a review of the chemistry determined that under high $\mathrm{pH}$ conditions, the uranium and plutonium will not concentrate in such an organic layer. This is consistent with data obtained for fissile concentrations in an organic layer in single shell tank C-103, a tank which contains PUREX wastes similar to those sent to AW-105.

The various indications of particle size tend to confirm that on a number basis, the majority of particles are less than a micron in diameter. However, the sludges also contain particles larger than $100 \mu$ m which may represent a substantial fraction of the sludge mass. Evidence of flocculation is seen in the reduction of sizes on sonication, and in the fast settling of most samples. However, sonication has a limited effect on larger sizes suggesting the presence of super-micron primary particles which are not agglomerates. In addition. the observation that most solids settle rapidly in samples where very fine particulate remains unflocculated suggests that large primary particles may represent a substantial fraction of the sludge mass. Evidence of size segregation was observed in subsamples taken from different layers of sludge after settling. While sonication produces a shift in the size distributions to smaller sizes, the lower subsamples maintained a larger size distribution relative to the upper samples. The observation that the difference between upper and lower subsamples was not eliminated by sonication may indicate that the segregation is driven by larger primary particles rather than a segregation of different agglomerate sizes. Recently obtained sieve analysis of KE canister sludge indicating 40wt\% or more of the mass being $>710$ $\mu \mathrm{m}$ supports this hypothesis.

Evaluation of samples which were settled and then sampled at different layers, determined that changes in fissile to absorber ratios occurred indicating some segregation of the uranium and plutonium corrosion products from other sludge materials during settling.

Finally, 1-dimensional calculations of segregation determined that there is significant potential for segregation of precipitated iron from untreated sludge. Elimination of metallic uranium will reduce the extent of segregation but is not sufficient to avoid segregation. Size reduction has been considered as a possible treatment approach. The specific size to which reduction must be achieved will depend on how much dilution with iron is considered acceptable. However, the size is clearly less than $177 \mu \mathrm{m}$ and is estimated to be $50 \mu \mathrm{m}$ or less. Reduction to some size less than $10 \mu \mathrm{m}$ would assure agglomeration which would prevent segregation. Since a previous study (Precechtel and Packer, 1997) determined that commercial vendors could not commit to achieving even the $177 \mu \mathrm{m}$ size criteria, it appears likely that complete dissolution and reprecipitation may be needed to assure that particle sizes are sufficiently smal1 so that agglomeration will prevent any 
significant segregation.

Thus, while evidence of flocculation in the existing sludge is present in many samples, there is also evidence that large primary particles are present. These large particles will drive segregation of the sludge particles and while insignificant on a number basis, are significant on a mass basis. Agglomeration can not be counted on to prevent segregation of the sludge without treatment to reduce the particle size.

However. if the sludge is completely dissolved and rapidly precipitated with neutron poisons; the segregation issue is very similar to that considered previously for tank sludges. A review of mining literature for mineral segregations indicates that even specialized separation devices dramatically lose efficiency for particles that are $<10 \mu \mathrm{m}$. Thus, it is very unlikely that any significant segregation will occur after the sludge particle sizes are reduced to $<10 \mathrm{\mu m}$ as a result of precipitation. The precise degree of segregation that could occur under these conditions has not been determined.

Calculations to quantify the expected flocculation behavior (DLVO calculations) have been performed. Assuming the salt content is at least 0.1 $\mathrm{M}$, and the $\mathrm{pH}$ is high, flocculation or coagulation of the precipitated sludge particles which are greater than $400 \mathrm{~nm}$ and is expected. Higher salt concentrations increase the tendency to flocculate. For very fine particulate in the $10 \mathrm{~nm}$ range, dispersion is predicted unless the supernatant is relatively concentrated. This may be an artifact of the assumptions (especially Hamaker constant) needed to make the calculation. However, particles in this size range have non-negligible diffusivities relative to settling velocities which makes particle segregation due to settling unlikely. Also, interaction between larger flocs and smaller particles may result in flocculation of particles which would not flocculate with particles of similar size. 
HNF-SD-WM-ES-409, Rev. 0

\section{Table of Contents}

Executive Summary . . . . . . . . . . . . . . . . ii

Detailed Summary ....................... i

Foreword . . . . . . . . . . . . . . . x

A.1 Introduction . . . . . . . . . . . . . . . A1.1

A.2 Background Chemistry for K Basin Sludge . . . . . . . . . . A2.1

A.2.1 105-K East Basin Water and Sludge Interstitial

Environment . . . . . . . . . . . A2.1

A.2.2 Uranium and Plutonium Corrosion Products Expected . . . A2.3

A.2.2.1 Minerology of Uranium Corrosion Products . . . . A2.4

A.2.2.2 Plutonium Precipitate Products . . . . . . . . A2.8

A.2.2.3 Solubilities of Corrosion Products . . . . . . . A2.9

A.2.2.3.1 MINTEQA2 Chemical Reaction Model . . . A2.9

A.2.2.3.2 Thermodynanic Database . . . . . . . A2.12

A.2.2.3.3 Uranium . . . . . . . . . . . . . . A2.13

A.2.2.3.4 Plutonium . . . . . . . . . . . . A2.19

A.2.2.3.5 Other Components . . . . . . . . A2.20

A. 2.3 Segregation of ${ }^{235} \mathrm{U}$ from ${ }^{238} \mathrm{U}$. . . . . . . . . . . A2.21

A.2.4 K West vs. K East Basin Corrosion Environment . . . . . A2.22

A.2.5 Expected Changes in Environments Isolated from General Basin Water. . . . . . . . . . . . A2.23

A.3 Characterization Data and Sludge Observations . . . . . . . . . A3.1

A.3.1 Chemical Composition of KE Basin Floor and weasel

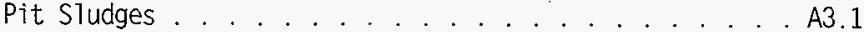

A.3.2 Composition of KE Canister Sludge . . . . . . . . A3.3

A.3.3 Sludge Interstitial Solution Analysis . . . . . . . . . A3.4

A.3.4 Uranium and Iron Bearing Minerals Identified in

KE Basin Sludges . . . . . . . . . . . . . . . . A3.6

A.3.4.1 Basin Froor and Weasel Pit Sludges . . . . . . A3.6

A.3.4.2 Canister Sludges . . . . . . . . . . . . . A3.10

A.3.5 Sludge and Particle Densities . . . . . . . . . . . A3.12

A.3.6 Corrosion Reactions and Products . . . . . . . . . . . A3.14

A.3.7 Semiquantitative Analysis and Estimation of

Crystallite Size . . . . . . . . . . . . . . A3.17

A.3.8 Particle Size Methods and Data . . . . . . . . . A3.20

A.3.8.1 Microtrac . . . . . . . . . . . . . . A3.20

A.3.8.1.1 KE Floor and Pit Sludge Samples... . A3.20

A.3.8.1.2 KE Canister Sludge Samples . . . . . . . A3.21

A.3.8.2 Brinkman 2010 . . . . . . . . . . . . . A3.23 
A.3.8.3 Optical Microscopy Data . . . . . . . . . . . . . A3.24

A.3.8.4 Minera1 Particle Sizes and Morphology from TEM Data . . . . . . . . . . . . . . . A3.25

A.3.8.5 Sedimentation Rate Tests . . . . . . . . . A3.26

A.3.8.5.1 KE Canister Sludge Samples . . . . . . . A3.26

A.3.8.5.2 KE Floor and Weasel Pit Sludge Data . . A3.27

A.3.8.6 Sieve Analyses . . . . . . . . . . . . . . . A3.27

A.3.8.7 Particle Size Conciusions . . . . . . . . . . A3.28

A.3.9 Segregation Tests of K Basin Sludges . . . . . . . . . . A3.29

A.3.9.1 Segregation Tests on KE Floor and Weasel Pit

Sludge Samples. . . . . . . . . . . . A3.29

A.3.9.2 Segregation Observed in Settling of KE Canister

Sludge Samples ............. . A3.30

A.3.10 Gas Generation and Expectation of Metal1ic Uranium. . . A3.35

A.4 Adjustment of S1udge Prior to Introduction into Tank AW-105 . . . A4.1

A.4.1 Iron Addition . . . . . . . . . . . . . . . . . . A4.1

A.4.2 State of Iron . . . . . . . . . . . . A4.4

A.4.3 Potential Coprecipitation . . . . . . . . . . . . . . A4.6

A.4.4 Mineralogica]/Solubility Changes Compared to

K Basins Conditions . . . . . . . . . . . . . . A4.8

A.5 Implications of STudge Addition to Tank AW-105 . . . . . . . . A5.1

A.5.1 Transfer of K Basin Sludges to AW-105 . . . . . . . . . . A5.1

A.5.1.1 K Basin S7udge Pretreatment and Transport . . . . A5.1

A.5.2 Tank AW-105 . . . . . . . . . . . . A5.4

A.5.2.1 History of Tank 105-AW . . . . . . . . . A5.4

A.5.2.2 Pu Content in Transfers to AW-105 . . . . . A5.5

A.5.2.3 Current Tank Status . . . . . . . . . . . A5.7

A.5.2.4 Sampling History of Tank . . . . . . . . . . . . A5.8

A.5.2.5 Current Composition of Supernatant Liquid

in Tank AW-105 . . . . . . . A5.8

A.5.2.6 Composition of the Sludge in Tank AW-105 . . . A5.16

A.5.2.7 Organics in AW-105 . . . . . . . . . . . . . . . A5.19

A.5.2.8 Summary . . . . . . . . . . . . . . . A5.26

A.5.3 Mixing the Basin and Tank Sludges . . . . . . . . . . A5.28

A.5.4 Prediction of Particle Segregation Using 1-Dimensional

Sett]ing Calculation . . . . . . . . . . . . A5.30

A.5.4.1 Theory . . . . . . . . . . . . . . . . A5.30

A.5.4.2 Model Description . . . . . . . . . . . A5.31

A.5.4.3 Caseft1, Scoping Calculation. . . . . . . . . A5.32

A.5.4.4 Case\#2, Less Conservative Calculation . . . . . A5.39

A.5.5 Gravity Segregation . . . . . . . . . . . . A5.42

A.5.6 Dissolution -and Reprecipitation of K Basin Sludges . . A5.45 
A.5.7 Radiolysis . . . . . . . . . . . . . . . . . A5.47

A.5.7.1 Radiolysis Effects on KE Basin S7udges . . . A5.48

A.5.7.2 Radiolysis Effects on Dissolved and

Reprecipitated KE Basin Sludges ..... A . A5.48

A.5.8 Analysis of Flocculation and Dispersion of

K Basin Sludge Particulate . . . . . . . . . . . . A4.49

A.5.8.1 Overview of DLV0 Theory . . . . . . . . . . . A5.49

A.5.8.2 Justification of Input Parameters Used in

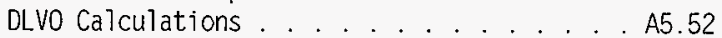

A.5.8.3 DLVo Results . . . . . . . . . . . . . A5.57

A.5.8.3.1 Particle Size . . . . . . . . . . . . A5.57

A.5.8.3.2 Solution Salt Concentration . . . . . A5.58

A.5.8.3.3 Temperature . . . . . . . . . . . . A5.58

A.5.8.3.4 Hamaker Constant . . . . . . . . . . . . A5.58

A.5.8.3.5 Best Estimate vs Conservative

Baseline-Estimates . . . . . . . . A5.59

A.5.8.3.6 Suspension of Colloids with Different Sizes . . . . . . . . . A5.59

A.5.8.4 Kinetic Considersations of Aggregation: Theory and

Initial Results . . . . . . . . . . . A5.59

A.5.8.5 DLVO Conclusions . . . . . . . . . . . A5.60

A.6 References . . . . . . . . . . . . . . . . . A6.1 
HNF-SD-WM-ES-409, Rev. 0

\section{FOREWORD}

This document uses 7aboratory characterization data on KE canister sludge. In some cases, the data has not been peer reviewed, and is reported here prior to being reported and discussed in a formal laboratory report. Some information has been obtained through, and footnoted as. "personal communication". It is possible that some changes in data could occur in the process of peer review and final reporting. This approach was made necessary by the timing of this report. 


\section{A.1 INTRODUCTION}

It is planned to remove sludges from the KE and KW basins. The destination for the sludge has not been decided. Three potential candidates for the destination include Tank AW-105, a newly constructed tank of conventional design, and a newly constructed tank of critically safe design. If an option other than the critically safe tank is selected, a neutron absorber may need to be added to the sludge to prevent criticality. The fuel stored in KE basin was initial1y $0.95 \%$ enriched in ${ }^{235} \mathrm{U}$ and the sludge cannot achieve criticality as long as the sludge can be considered as homogeneous. However, some spent fuel stored in closed canisters at the KW basin were initially enriched to $1.25 \% 235 \mathrm{U}$. This sludge can achieve criticality if sufficient material is gathered into a favorable geometry regardless of the homogeneity of the sludge. Thus, neutron absorbers must be added to prevent criticality. Depleted uranium and iron have been considered for this purpose.

This appendix reviews the characterization data available on $K$ basin sludge chemical and physical properties and utilizes this information to assess the potential mechanisms for segregation of the $K$ basin sludges from neutron absorbers. In the case of a critically safe tank, neutron poisons are not required, so this appendix does not address this option.

Chapter 2 provides background information on the corrosion products that would be expected to result from corrosion of the metallic uranium fuel. Data on the basin water environment is used in the MINTEQA2 code to predict the solubility controlling phases for uranium and plutonium in the basin environment. Discussion of the potential differences that might be seen in areas in the KE basin isolated from the basin water, and of differences that may be seen in the $\mathrm{KW}$ fuel canister environment is provided.

Chapter 3 summarizes and evaluates the characterization data that is available for the KE and KW sludges. Data from a wide range of sources is evaluated to determine chemical composition of the sludges and the waters in equilibrium with the sludge and the mineralogy and morphology of the sludge. Particle size and density of the sludge is evaluated. In addition, the results of settling segregation tests are evaluated to determine the degree of segregation that may occur within the sludge samples themselves.

Chapter 4 describes the addition of a neutron absorber and adjustment to tank corrosion specification that would be required prior to transfer to Tank AW-105. Options including and not including $K$ basin sludge dissolution are considered. The potential benefits from coprecipitation are evaluated and the changes in mineralogy and solubility compared to the conditions in the $K$ basins are discussed. 
Chapter 5 provides a detailed examination of the data relevant to the characterization of the content of Tank AW-105. The chemical implications of adding $\mathrm{K}$ basin sludge to $\mathrm{AW}-105$ are then considered. The potential for segregation of fissile particles from added iron is assessed using a simplified 1-dimensional model. In addition, previous findings on particle segregations from the mineral processing industry are reviewed, and calculations are provided to assess the tendency of particles to flocculate. 
HNF-SD-WM-ES-409, Rev 0

\section{A.2 BACKGROUND CHEMISTRY. FOR K BASIN SLUDGE}

This chapter discusses background information related to the chemistry of $K$ basin sludges. Discussion is provided on the corrosion environment and the mineralogy of precipitated uranium and plutonium phases. A description of the MINTEQA2 model is provided and results of calculations are provided for uranium and plutonium speciation. Discussion is provided on the possible impacts of environments in KE that are isolated from basin water, and for the KW canisters which are sealed.

\section{A.2.1 105-K East Basin Water and STudge Interstitial Environment}

Chemical characterization of twenty sludge samples (sixteen basin floor and four weasel pit) and associated water samples from the 105-K East Basin were reported by Miller (1995). Analyses of pH, dissolved metals, radionuclides, and anionic constituents were reported for water samples from two of the sludge samples. These waters were decanted supernatants from basin floor sludge sample KES-M-13 and weasel pit sludge sample KES-T-20. These analyses are listed below in Table A.2.1. The majority of the water analyses reported by Miller (1995. Table 1) were for "clear water from centrifuged sludge" from the twenty basin floor and weasel pit sludge samples. The analyses for the "clear water from centrifuged sludge" samples included pH and ion chromatography (IC) analysis of anionic constituents, but did not include analyses of radionuciides or dissolved metals.

Analyses of twenty sludge samples and associated water samples from nine fuel canisters in 105-K East Basin are listed in Miller (1997). Analyses (see Table A.2.1) of pH, dissolved metals, radionuclides, and anionic constituents were completed for only two water samples identified as "Cyl water". These samples were taken from Canisters 96-05 and 96-01. "Cy1 water" samples are samples of water used in sludge settling studies conducted in graduated cylinders. The water in these samples is a portion of the water shipped with the sludge samples taken from the basinl. Other water samples were analyzed for $\mathrm{pH}$ and anionic constituents, but not dissolved metals and radionuclides (Mi11er 1997).

It should be noted that the analyses of water samples listed in Miller (1995, 1997) did not include analyses of dissolved silica and Eh (redox

1 B.J. Makenas to K.L. Pearce, Email, May 19, 1997. (Duke Engineering and Services, Hanford. Inc. Richland Washington) 
state). ${ }^{1}$ Concentrations of dissolved silica, as will be discussed later. would be useful in evaluating the potential formation of alkali/alkaline earth uranyl silicate corrosion products. Silica analyses would also assist in the determination of potential solubility controls for dissolved silica in these waters when compared to characterization results for silica-containing solids identified in the basin sludges. Although difficult to measure, especially given the environmental factors associated with the $K$ Basin. determination of the redox state, via Eh, of water samples in contact with the basin, weasel pit, and canister sludges would help the evaluation of corrosion products of the metallic uranium fuel. The solubilities of many metals, such as uranium (Langmuir 1978) and plutonium (Serne et a7. 1996), are extremely sensitive to $\mathrm{pH}$ and redox conditions. Moreover, as will be noted later, the radiolysis of these waters by the spent fuels may generate oxidizing conditions that are higher than one would assume from equilibrium with atmospheric oxygen.

The concentrations of dissolved metals and the anionic constituents listed for floor and pit sludge samples in Table A.2.1 indicate that the dominant dissolved cationic constituents are calcium and uranium with minor concentrations of sodium, and trace quantities of zinc. In these water samples, the principal anionic constituents are total inorganic carbon (TIC) and sulfate. The minor anionic constituents are nitrate and chloride. The measured $\mathrm{pH}$ values show that these solutions are very slightly alkaline.

In comparison, the water samples from the 105-K East Basin canisters 96-05 and 96-01 contained high concentrations of dissolved uranium ( $\sim 00$ to $300 \mathrm{mg} / 1$ ) which constitute the principal cationic constituent. Nitrate is the major anionic constituent in these water samples. Minor amounts of sulfate and trace concentrations of chloride were also measured in these samples. The $\mathrm{pH}$ measurements indicate about 1.5 to 3 orders of magnitude more acidity in these samples as compared to the water samples from $105-K$ East basin and pit sludges. These significantly higher acidities and nitrate concentrations are indicative of alpha radiolytic effects. Experimental data indicate that alpha

1 The parameter Eh is defined as the potential of a half-cel1. measured against the standard hydrogen half-cell. It is sometimes referred to as the oxidation potential or redox potential. A measurement of Eh indicates the intensity of the oxidizing or reducing conditions of a system with the hydrogen-electrode potential serving as a reference point of zero volts. Positive Eh values indicate oxidizing conditions, where as negative Eh values indicate reducing conditions. Values of Eh are usually stated in units of volts or millivolts. The concept of redox potential of aqueous systems, the governing equations, and its measurement and limitations in ground-water systems are discussed in Hem (1986). 
Table A.2.1. Analysis of Water Samples from 105-K East Basin Floor, Weasel Pit, and Canister Sludges from Miller $(1995,1997)$.

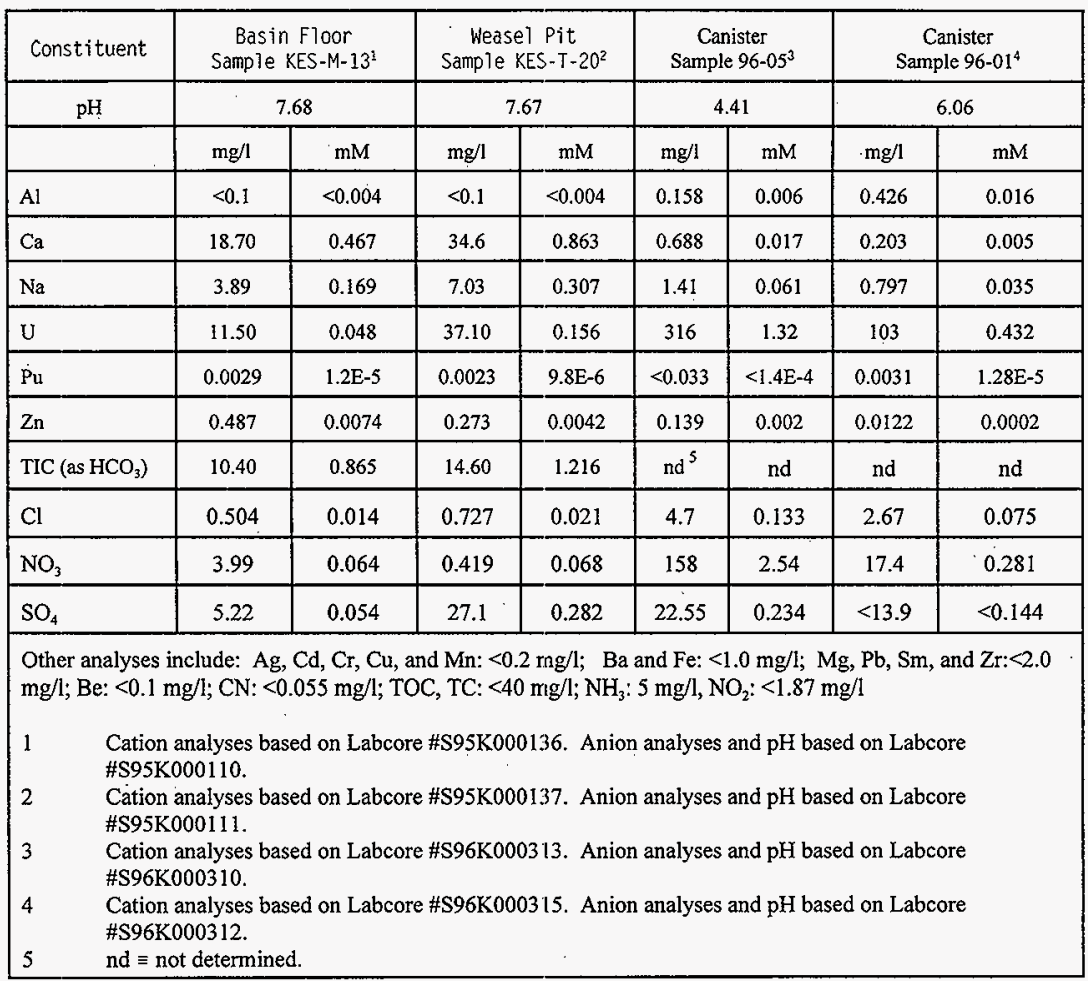

radiolysis in aqueous solutions result in the production of nitric acid with concomitant increase in acidity (decreasing $\mathrm{pH}$ ) and nitrate concentrations (Rai et a7. 1980b). Analyses of total inorganic carbon and total organic carbon were not determined for these samples.

\section{A.2.2 Uranium and Plutonium Corrosion Products Expected}

Irradiated $N$ reactor fuel stored at the $K$ basins experiences corrosion of metallic uranium exposed to the basin water as a result of defects in the Zircaloy-2 (Zry-2) cladding. Johnson and Burke (1995) provide a historical 
overview of the $K$ Basins fuel storage operations and summarize the results of corrosion studies of materials storage in the K. Basins. Corrosion of the Zry-2 clad metallic uranium fuel results in the precipitation of solid phases that are typically hydrated and oxidized relative to original fuel phases. This section will attempt to identify these corrosion products using data from published studies of uranium ore deposits and leaching studies of uraninite $\left[\mathrm{UO}_{2}(\mathrm{cr})\right]$ as well as calculations of the equilibrium thermodynamic solubilities of dissolved uranium and other corrosion-related components for chemical conditions applicable to the $\mathrm{K}$ Basin waters. ${ }^{1}$ Because the chemistry of plutonium dissolved in the $K$ Basins waters and sludges is important to issues of criticality associated with the disposal of $\mathrm{K}$ Basins wastes, the aqueous speciation and solubility of plutonium were also calculated relative to the chemical conditions in the $\mathrm{K}$ Basins waters. These predicted corrosion products and associated solution chemistries will be compared in Section A.3 to data reported from characterization studies of the $K$ Basin sludges and fuels.

\section{A.2.2.1 Mineralogy of Uranium Corrosion Products}

Uranium metal is readily oxidized by water at room temperature (Cordfunke 1969, Tyfield 1988). The oxidation of uranium metal results in a formation of $\mathrm{UO}_{2}$ and $\mathrm{UH}_{3}$ (uranium hydride), which in turn oxidizes to $\mathrm{UO}_{2}$, according to the following reactions:

$$
\begin{gathered}
\mathrm{U}+2 \mathrm{H}_{2} \mathrm{O} \rightarrow \mathrm{UO}_{2}+2 \mathrm{H}_{2}(\mathrm{~g}) \\
\mathrm{UH}_{3}+2 \mathrm{H}_{2} \mathrm{O} \rightarrow \mathrm{UO}_{2}+3.5 \mathrm{H}_{2}(\mathrm{~g})
\end{gathered}
$$

The corrosion of uranium metal fuel relative to the chemical environments in the Hanford waste tanks AW-103 and AW-105 is described in detai 7 by Danielson et al. (1995).2

The corrosion and dissolution of $\mathrm{UO}_{2}$ in oxidizing aqueous solutions has

1 The general aqueous chemistry, solubility considerations, and thermodynamic properties of uranium aqueous species and solids are reviewed by Langmuir (1978) and Wanner and. Forest (1992). The general mineralogy of primary and secondary uranium solids is described by. Frondel (1958) .

2 Danielson, M. J., A. L. Lund, and S. G. Pitman, August 30, 1995. The Corrosion of Uranium in a Double-Shell Tank Environment. Unpublished Letter Report Transmitted from S. M. Short to C. J. Alderman of Westinghouse Hanford Company, Richland Washington. 
been studied extensively. The solid $\mathrm{UO}_{2}$ is important as a component in nuclear fuels as well as a primary mineral in important uranium ore deposits. Grambow (1989) completed an extensive evaluation of the literature describing the results of dissolution and oxidation studies of spent fuel, $\mathrm{UO}_{2}$, and uraninite (crystalline $\mathrm{UO}_{2}$ ). In general, the sequence of $\mathrm{UO}_{2}$ oxidation products identified in spent fuel and $\mathrm{UO}_{2}$ dissolution studies is

$$
\begin{aligned}
& \text { Reducing } \rightarrow \rightarrow \rightarrow \rightarrow \rightarrow \rightarrow \rightarrow \text { Oxidizing } \\
& \mathrm{UO}_{2} \rightarrow \mathrm{UO}_{2+\mathrm{x}} \rightarrow \mathrm{U}_{3} \mathrm{O}_{7} \rightarrow \mathrm{U}_{3} \mathrm{O}_{8} \rightarrow \mathrm{UO}_{3} \cdot \mathrm{xH}_{2} \mathrm{O} .
\end{aligned}
$$

The presence of the intermediate oxidation products and the degree of hydration of the uranyl oxide/hydrate depends on the temperature and other associated conditions. The review by Grambow (1989) contains an extensive bibliography. The reader is referred to those references regarding the types and conditions of the experiments that were evaluated by Grambow.

Corrosion of spent nuclear fuel is unique in one important aspect relative to dissolution studies of depleted uranium solids and natural uraninite samples. The oxidation of spent nuclear fuel is enhanced by products formed by radiolysis of water. This process forms radiolytic species (e.g., $\mathrm{H}_{2} \mathrm{O}_{2}, \mathrm{O}_{2}, \mathrm{e}_{\mathrm{aq}}^{-}$, etc.) which produces an oxidizing environment near the fuel surface. This oxidizing environment in turn affects the solubility of $\mathrm{UO}_{2}$ in the fuel matrix. Several studies have been conducted on the effects of radiolysis. specifically the effects of hydrogen peroxide $\left(\mathrm{H}_{2} \mathrm{O}_{2}\right)$, on the oxidation of $\mathrm{UO}_{2}$ fuel (Diaz-Arocas et a1. 1995; Shoesmith et a1. 1985; Sunder et a1. 1987, 1989, 1990, 1992). The effects of the individual radiolysis products on the corrosion process is not clearly understood. Experiments conducted with $\mathrm{O}_{2}$ and $\mathrm{H}_{2} \mathrm{O}_{2}$ present indicate that the oxidation of $\mathrm{UO}_{2}$ is accelerated by approximately 200 times relative to the rate measured with only dissolved $\mathrm{O}_{2}$ present (Shoesmith et a1. 1985). Studies by Sunder et al (1992) indicate that the oxidation process produced by radiolysis products occurs in two stages. The initial stage consists of the formation of a thin layer of $\mathrm{UO}_{2+x}$, with a stoichiometry close to $\mathrm{UO}_{2.33}\left(\equiv 1 / 3 \mathrm{U}_{3} \mathrm{O}_{7}\right)$ and a thickness similar to that obtained in unirradiated oxygenated solutions conducted over longer time frames. The second stage involves the subsequent oxidative corrosion of this $\mathrm{UO}_{2+x}$ surface layer to form soluble U(VI) species and secondary phases, probably hydrate schoepite $\left(\mathrm{UO}_{3} \cdot \mathrm{XH}_{2} \mathrm{O}\right)$ on the $\mathrm{UO}_{2}$ surface. Diaz-Arocas et a1. (1995) conducted leaching studies of $\mathrm{UO}_{2}$ under various $\mathrm{H}_{2} \mathrm{O}_{2}$ concentrations. They identified the mineral studtite $\left(\mathrm{UO}_{4} \cdot 4 \mathrm{H}_{2} \mathrm{O}\right.$, uranyl peroxide dihydrate $)^{1}$ by $X$-ray diffraction as a secondary precipitate on the

1 The formula for studtite, $\mathrm{UO}_{4} \cdot 4 \mathrm{H}_{2} \mathrm{O}$, is sometimes written as $\mathrm{UO}_{3} \cdot \mathrm{H}_{2} \mathrm{O}_{2} \cdot 3 \mathrm{H}_{2} \mathrm{O}$ to reflect the hydrogen peroxide component in the composition of this solid. 
$\mathrm{UO}_{2}$ surface.

Erikson et a1. (1993) conducted characterization and corrosion studies of depleted uranium armor-piercing projectiles. Although the geochemical environment associated with these materials is different than those for the storage and expected disposal of $\mathrm{N}$ Reactor metallic uranium fuel, there are similarities in the identified corrosion products of the metaliic uranium. $x$-ray diffraction analysis of a depleted uranium fragment taken from contaminated soil at a target range inclicated the presence of a mixture of dehydrated schoepite $\left(\mathrm{UO}_{3} \cdot \mathrm{H}_{2} \mathrm{O}\right)$ and metastudtite $\left(\mathrm{UO}_{4} \cdot 2 \mathrm{H}_{2} \mathrm{O}\right.$. a dehydrated form of studtite). Oxidation products identified in three corrosion experiments of depleted uranium penetrators included a mixture of black and yellow alteration products that contained hyperstoichiometric U(IV) oxides $\left(\mathrm{UO}_{2+x}\right)$ (e.g. ,

$\left.\mathrm{UO}_{2.6667}-1 / 3 \mathrm{U}_{3} \mathrm{O}_{8}\right)$ and schoepite $\left(\mathrm{UO}_{3} \cdot 2 \mathrm{H}_{2} \mathrm{O}\right)$. The formation of metastudtite under these conditions is not understood given that hydrogen peroxide or radiolysis products should not be factors in the oxidative corrosion of these uranium penetrators.

The chemistry of the final oxidation products are typically more complex when considering aqueous solutions containing dissolved constituents common to soil and ground waters, such as dissolved calcium and silica. For example, Wronkiewicz et a1. (1991, 1992) and Bates et al. (1990) studied the leaching behavior of unirradiated $\mathrm{UO}_{2}$ with a dilute ground water under unsaturated conditions at $90^{\circ} \mathrm{C}$. Phases identified by $X$-ray diffraction on the reacted $\mathrm{UO}_{2}$ surface included schoepite $\left(\mathrm{UO}_{3} \cdot 2 \mathrm{H}_{2} \mathrm{O}\right)$, dehydrated schoepite $\left(\mathrm{UO}_{3} \cdot 0.8 \mathrm{H}_{2} \mathrm{O}\right)$, compreignacite $\left(\mathrm{K}_{2} \mathrm{U}_{6} \mathrm{O}_{19} \cdot 11 \mathrm{H}_{2} \mathrm{O}\right)$, uranophane $\left[\mathrm{Ca}\left(\mathrm{UO}_{2}\right)_{2}\left(\mathrm{SiO}_{3}\right)_{2}(\mathrm{OH})_{2} \cdot 5 \mathrm{H}_{2} \mathrm{O}\right]$,

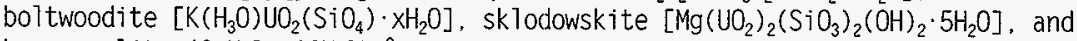
becquerelite $\left(\mathrm{CaU}_{6} \mathrm{O}_{19} \cdot 1 \mathrm{H}_{2} \mathrm{O}\right)$. $^{2}$

Finch and Ewing (1990, 1992b) and Janeczek and Ewing (1992a,b) have reviewed the oxidation and dissolution products of the mineral uraninite (crystalline $\mathrm{UO}_{2}$ ). Their conclusions are based on results from their own mineralogical studies of natural uraninite and uranium ore deposit samples as wel] as information gleaned from the literature. The schematic pathway for the dissolution of $\mathrm{UO}_{2}$ in oxidizing aqueous solutions is as follows:

I Unless otherwise stated, the use of a mineral name implies a crystalline compound by definition.

2 The formula for becquerelite is often listed different ways by various investigators. The differences are typically in the degree and nature of hydration, such as becquerelite $\mathrm{CaU}_{5} \mathrm{O}_{19} \cdot 10 \mathrm{H}_{2} \mathrm{O}, \mathrm{CaU}_{6} \mathrm{O}_{19} \cdot 11 \mathrm{H}_{2} \mathrm{O}$, or $\mathrm{Ca}\left(\mathrm{UO}_{2}\right)_{6} \mathrm{O}_{4}(\mathrm{OH})_{6} \cdot 8 \mathrm{H}_{2} \mathrm{O}$. 
HNF-SD-WM-ES-409, Rev 0

Initial stage consists of radiolytic surface oxidation of $\mathrm{UO}_{2}$ :

$$
\mathrm{UO}_{2}+\frac{\mathrm{x}}{2} \mathrm{O}_{2} \rightarrow \mathrm{UO}_{2+\mathrm{x}}
$$

Full oxidation follows resulting in the formation of U(VI)-oxide hydrates, which may contain other cations (e.g., calcium and potassium) that are present in the contacting aqueous solution:

$$
\begin{aligned}
\mathrm{UO}_{2+\mathrm{x}}+\left(\frac{1-\mathrm{x}}{2}\right) \mathrm{O}_{2}+2 \mathrm{H}_{2} \mathrm{O} \rightarrow \mathrm{UO}_{3} \cdot 2 \mathrm{H}_{2} \mathrm{O} \text { (Schoepite) } \\
6 \mathrm{UO}_{2+\mathrm{x}}+\mathrm{O}_{2}+\mathrm{Ca}^{2+}+(16-6 \mathrm{x}) \mathrm{H}_{2} \mathrm{O} \rightarrow \\
\rightarrow \mathrm{Ca}\left(\mathrm{UO}_{2}\right)_{6} \mathrm{O}_{4}(\mathrm{OH})_{6} \cdot 8 \mathrm{H}_{2} \mathrm{O} \text { (Becquerelite) }+(1 \mathrm{O}-12 \mathrm{x}) \mathrm{H}^{+}
\end{aligned}
$$

Final alteration may include formation of uranyl silicates or phosphates depending on the presence of these dissolved constituents and their relative proportions:

$$
\begin{aligned}
\mathrm{Ca}\left(\mathrm{UO}_{2}\right)_{6} \mathrm{O}_{4}(\mathrm{OH}) \cdot 8 \mathrm{H}_{2} \mathrm{O}+6 \mathrm{SiO}_{2}+2 \mathrm{Ca}^{2+}+7 \mathrm{H}_{2} \mathrm{O}- & + \\
+ & 3 \mathrm{Ca}\left[\left(\mathrm{UO}_{2}\right)\left(\mathrm{SiO}_{3} \mathrm{OH}\right)\right]_{2} \cdot 5 \mathrm{H}_{2} \mathrm{O}+\mathrm{H}^{+}
\end{aligned}
$$

Natural uraninite is not a pure mineral and is always partially oxidized. Although its composition is nominally given as $\mathrm{UO}_{2}$, uraninite is actually nonstoichiometric and has a highly defective structure (Janeczek and Ewing 1992a). The nonstoichiometry and defects are caused by oxidation of uranium from +4 to +6 , cationic substitution, and damage from $\alpha$-decay. To reflect this nonstoichiometry and these potential cation substitutions, Janeczek and Ewing (1992a) have formulated the revised formula $\left(U_{1-x-y-}^{4 *}\right.$ $\left.\mathrm{v}_{x} \mathrm{U}_{\mathrm{f}}^{+} \mathrm{REE}_{y}^{3+} \mathrm{M}_{z}^{2+}\right) \mathrm{O}_{2+\mathrm{x}-(0.5 y)-z}$ for uraninite. The formula shows that the concentrations of excess oxygen required to counteract the increase in positive charge from $\mathrm{U}^{6+}$ is less than that indicated from the amount of $\mathrm{U}^{6+}$ alone. Janeczek and Ewing suggest that the combination of nonstoichiometry and cation substitution may increase the stability field of uraninite under oxidizing conditions relative to synthetic $\mathrm{UO}_{2+x}$.

Uraninite remains relatively insoluble as it oxidizes to $\mathrm{UO}_{2.25}$. Oxidation of $\mathrm{UO}_{2}$ beyond $\mathrm{UO}_{2.33}\left(\equiv 1 / 3 \mathrm{U}_{3} \mathrm{O}_{7}\right)$ in an aqueous environment is rapid and is accompanied by hydration to produce the urany] [U(VI)] oxide hydrates. Although $\mathrm{U}_{3} \mathrm{O}_{8}$ has not been identified in nature, the sheet structures in uranyl oxide hydrates are similar to the $\mathrm{U}_{3} \mathrm{O}_{8}$ structure (Finch and Ewing 1991b). Schoepite is the first uranyl oxide hydrate to form.

In nature, schoepite always coexists with alkali and alkaline earth uranyl oxide hydrates (Finch and Ewing 1991b). For example, solubility studies by Amaia Sandino and Grambow (1994) indicate that uranyl hydroxide 
transforms essentially spontaneous $7 y$ to becquerelite $\left(\mathrm{CaU}_{6} \mathrm{O}_{19} \cdot 11 \mathrm{H}_{2} \mathrm{O}\right)$ and compreignacite $\left(\mathrm{K}_{2} \mathrm{U}_{6} \mathrm{O}_{19} \cdot 11 \mathrm{H}_{2} \mathrm{O}\right)$ at room temperature after short contact times in solutions containing dissolved calcium and potassium, respectively. Uraniumseries disequilibrium data and microscopic analysis by Finch et a1. (1995) of natural mineral specimens indicate that becquerelite can remain stable for hundreds of thousands of years or longer in geologic environments. Sodium uranyl hydrates are rare in nature. The mineral clarkeite $\left[\left(\mathrm{Na}_{2}, \mathrm{Ca}, \mathrm{Pb}\right)_{2} \mathrm{U}_{2}\right.$ $\left.(0 . \mathrm{OH})_{7}\right]$ has only been found at two localities (Finch and Ewing 1992b). The specimen that they studied was formed by the alteration of uraninite by hydrothermal (i.e., high temperature) alkali solutions. Sodium uranates (e:g, $\mathrm{Na}_{2} \cup_{2} \mathrm{O}_{7}$ ), however, have been identified as precipitates in laboratory experiments involving high $\mathrm{pH}$ and high alkali solutions containing dissolved uranium.

Phases such as schoepite and becquerelite can in turn transform to more chemically complex minerals such as uranophane $\left(\mathrm{CaU}_{2} \mathrm{Si}_{2} \mathrm{O}_{11} \cdot 6 \mathrm{H}_{2} \mathrm{O}\right)$ and soddyite $\left(\mathrm{U}_{2} \mathrm{SiO}_{8} \cdot 2 \mathrm{H}_{2} \mathrm{O}\right)$ in the presence of dissolved silica, or the autunite series of uranyl phosphate minerals [e.g., $\mathrm{Ca}\left(\mathrm{UO}_{2}\right)_{2}\left(\mathrm{PO}_{4}\right)_{2} \cdot 10 \mathrm{H}_{2} \mathrm{O}$ ] in the presence of dissolved phosphate (Finch and Ewing 1992a. Sowder et at. 1996). The sequence of alteration reactions depend on the ratio of dissolved silica to phosphate. The results of Soweder et al. (1996) indicate that the presence of dissolved silica $\left(10^{-3} \mathrm{M}\right)$ may even impede the trarsformation of schoepite to becquerelite.

\section{A.2.2.2 Plutonium Precipitate Products}

Because plutonium is present in the spent fuels stored in $\mathrm{K}$ Basin, the potential precipitation of separate plutonium phases is a consideration in the evaluation of the chemistry of the K Basin and canister sludges and their treatment and disposal. Unlike the conceptual model described above for the oxidation and corrosion of metallic uranium fuel which is based on studies of spent fuel corrosion, $\mathrm{UO}_{2}$ dissolution, and uraninite alteration. the composition of plutonium solids in oxidizing aqueous solutions is based on direct solubility studies (e.g., Rai and Ryan 1982) and identification of possible solids controlling the plutonium concentrations in contaminated soils (e.g. . Rai et al. 1980a). These studies indicate that $\mathrm{PuO}_{2} \cdot \mathrm{XH}_{2} \mathrm{O}$ (am) is the likely precipitate formed in such aqueous environments.

Serne et al. (1996) review the important chemical processes that control chemistry of plutonium in aqueous systems, especially from the perspective of storage in Hanford Site tank environments. Based on an evaluation of the literature, they conclude that a partially crystalline Pu(IV) oxide. described as $\mathrm{PuO}_{2} \cdot \mathrm{xH}_{2} \mathrm{O}(\mathrm{am})$, would be the "solubility-controlling" solid in the chemical environments inside Hanford Site tank. Key references that they cite 
HNF-SD-WM-ES-409, Rev 0

regarding the nature of the plutonium solid include Rai et al. (1980a), Delegard (1987), and Yamaguchi et a1. (1994). They also cite a personal communication from Hobbs and Karraker who identified $\mathrm{PuO}_{2} \cdot \mathrm{xH}_{2} \mathrm{O}$ (am) in the precipitated phase from waste supernatants. Serne et al. also used solubility calculations to show that the solubility data from Yamaguchi et a7. (1994), Delegard (1995), Hobbs et a1. (1993), and Hobbs (1995) was consistent with $\mathrm{PuO}_{2} \cdot \mathrm{XH}_{2} \mathrm{O}$ (am) being the most likely solubility-controlling phase. The reader is referred to the detailed discussion and evaluation described in Serne et a1. (1996).

\section{A.2.2.3 Solubilities of Corrosion Products}

A computerized chemical reaction model (or geochemical mode1). MINTEQA2. was used to calculate the solubilities and associated aqueous speciation of dissolved uranium, plutonium, and other relevant components in waters having the chemical compositions listed in Table A.2.1. Chemical reaction models use the principles of equilibrium thermodynamics to calculate chemical equilibria in mineral-water-gas systems. The thermodynamic principles and equations that govern these calculations are discussed in detail elsewhere, such as Bolt and Bruggenwert (1978), Garrels and Christ (1965). Lindsay (1979), Morel (1983), Nordstrom and Munoz (1985), Sposito (1989, 1994), Stumm and Morgan (1981), and others. The status, development, and application of chemical reaction models are reviewed in Erdal (1985), Jackson and Bourcier (1986); Jacobs and What ley (1985), Jenne (1979, 1981), Kincaid et a1. (1984). Loeppert et a1. (1995), Melchior and Bassett (1990) Mercer et a1. (1981). Nordstrom et a1. (1979). Nordstrom and Bal1 (1984), Nordstrom and Munoz (1985), and others.

\section{A.2.2.3.1 MINTEQA2 Chemical Reaction Model.}

The MINTEQA2 computer code and its predecessor versions are described by Allison et al. (1991, MINTEQA2), Brown and Allison (1987, MINTEQA1), Peterson et a1. (1987, MINTEQ), and Felmy et a1. (1984, MINTEQ). The MINTEQ code was originally constructed for the U.S. Environmental Protection Agency (EPA) by combining the mathematical structure of the MINEQL code (Westall et al. 1976) with the thermodynamic database and geochemical attributes of the WATEQ3 code (Ba11 et a1. 1981). MINTEQA2 (Version 3.11), the most current version of MINTEQ available from EPA ${ }^{1}$. The MINTEQA2 code is used in conjunction with a thermodynamic database to calculate cornplex chemical equilibria among aqueous

1 Copies of MINTEQA2 and its documentation are available from the Center for Exposure Assessment Modeling (CEAM). U.S. Environmenta1 Protection Agency. Office of Research and Development, Environmental Research Laboratory, 960 College Station Road, Athens, Georgia. 
species, gases, and solids, and between dissolved and adsorbed states. The code has four submodels to calculate aqueous speciation/complexation. oxidation-reduction, gas-phase equilibria, solubility and saturation state (i.e., saturation index), precipitation/dissolution of solid phases, and adsorption.

The MINTEQA2 speciation submodel uses a thermodynamic database to calculate the activities of the uncomplexed (e.g., $U^{4+}, \mathrm{UO}_{2}^{2+}$ ) and complexed ${ }^{1}$ [e.g. . UOH $H^{3+}, \mathrm{UO}_{2} \mathrm{OH}^{+}, \mathrm{UO}_{2}\left(\mathrm{CO}_{3}\right)_{2}^{2-}, \mathrm{UO}_{2} \mathrm{SO}_{4}^{\circ}(\mathrm{aq})$, or $\left.\mathrm{UO}_{2} \mathrm{PO}_{4}^{-}\right]$aqueous species for an initial water composition. The activities of individual aqueous species are corrected for ionic strength using the Davies or extended Debye-Hückel equations. Aqueous speciation is only reliable if the quality of the chemical analysis of the water is adequate. The water composition is usually obtained by direct measurement of major cations and anions. pH. Eh. and trace constituents. As a quality check of the water chemical analysis, the MINTEQA2 model calculates the anion/cation imbalance for each speciated water composition. The anion/cation imbalance is calculated using the equation

$$
\underset{\text { Imbalance }}{\text { Anion/Cation }}(\%)=\frac{[\text { Anions (equiv. } / 1)-\text { Cations (equiv. } / 1)]}{[\text { Anions (equiv. } / 1)+\text { Cations (equiv. } / 1)]} \times 100 .
$$

For aqueous solutions having simple compositions and accurate analytical work, the anion/cation imbalance should not exceed a few percent (Hem 1985).

After calculating the aqueous speciation for a given water composition, solubility-equilibria hypotheses are tested. Ion activity products (IAPs) are calculated from the activities of the species using the stoichiometries of the solubility reactions for minerals and other solids in the MINTEQA2 thermodynamic database. For example, the solubility reaction for uraninite $\left[\mathrm{UO}_{2}(\mathrm{cr})\right]$ is

$$
\mathrm{U}^{4+}+2 \mathrm{H}_{2} \mathrm{O}=\mathrm{UO}_{2}(\mathrm{cr})+4 \mathrm{H}^{+}
$$

Because the activities of $\mathrm{UO}_{2}$ and $\mathrm{H}_{2} \mathrm{O}$ are essentially equal to unity, the IAP for the above reaction is

$$
\text { IAP }=\frac{\left\{\mathrm{UO}_{2}\right\}\left\{\mathrm{H}^{+}\right\}^{4}}{\left\{\mathrm{U}^{4+}\right\}\left\{\mathrm{H}_{2} \mathrm{O}\right\}}=\frac{\left\{\mathrm{H}^{+}\right\}^{4}}{\left\{\mathrm{U}^{4+}\right\}}
$$

1 The importance of aqueous complexation is discussed in Lindsay (1979), Morel (1983), and Stumm and Morgan (1981). Complexation with ligands, such as carbonate, sulfate, and phosphate, can significantly increase the total concentrations of a dissolved metals and affect their mobility in solid-aqueous systems. 
where the quantities within " \{\} " denote activities. " The log equilibrium constant $\left(\log \mathrm{K}_{r, 298}^{\circ}\right)$ for this reaction at $25.0^{\circ} \mathrm{C}(298 \mathrm{~K})$ in the MINTEQA2 thermodynamic database is 13.90. Ratios of the $\log$ IAPS to the $\log K_{r . T}$ values in the MINTEQA2 database for the same solids are calculated to test the assumption that certain of the dissolved constituents in the aqueous solution are in equilibrium with particular solid phases. This ratio, [log $\left.\left(I A P / K_{r, T}\right)\right]$, is referred to as the saturation index. The calculated saturation indices indicate if the aqueous solution is at

\author{
Equilibrium: $\quad \log \left(\operatorname{IAP} / \mathrm{K}_{\mathrm{r}, \mathrm{T}}\right) \approx 0$, \\ Oversaturated: $\quad \log \left(\mathrm{IAP} / \mathrm{K}_{\mathrm{r}, \mathrm{T}}\right)>0$, \\ or \\ Undersaturated: $\quad \log \left(\operatorname{IAP} / \mathrm{K}_{\mathrm{r}, \mathrm{T}}\right)<0$,
}

with respect to a specified solid phase. This information allows one to ascertain permissible equilibrium solubility controls for dissolved constituents in that aqueous solution.

The results from the solubility model [i.e., , $\log \left(I A P / K_{r, T}\right)$ values], are in turn used by MINTEQA2 as input for the optional mass transfer submodel. The user may select this submodel to predict the mass of a solid phase(s) that precipitates or dissolves in a specified solid-aqueous system. If a given water composition calculates to be initially oversaturated.

$\left[\log \left(\mathrm{IAP} / \mathrm{K}_{\mathrm{r}, \mathrm{T}}\right)>0\right]$, with respect to a solid phase(s), the mass transfer model will decrease [i.e., precipitate the solid phase(s)] the masses of the appropriate dissolved constituents until the water composition is at equilibrium. [log $\left.\left(A P / K_{r, T}\right)=0\right]$, with respect to that solid phase(s). If a given water calculates to be undersaturated. $\left[\log \left(A P / K_{r, T}\right)=0\right]$, with respect to a solid phase(s), the mass transfer model will increase [i.e., dissolve the solid phase(s)] the masses of the appropriate dissolved constituents unti] the water composition is at equilibrium with respect to that solid phase(s).

1 In general terms, the activity of an ion is its effective concentration that determines its behavior to other ions with which it might react. An activity of an ion is equal to its concentration only in infinitely dilute solutions. The activity of an ion is related to its analytical concentration by an activity coefficient, $\gamma$. Activities, activity coefficients, and associated thermodynamic relationships are discussed in detail in Lewis and Randa 11 (1961). Morel (1983). Sposito (1984), and Stumm and Morgan (1981). 
HNF-SD-WM-ES-409, Rev 0

\section{A.2.2.3.2 Thermodynamic Database.}

The MINTEQA2 thermodynamic database includes the log equilibrium constants ( $\left.\log \mathrm{K}_{\mathrm{r}, 228}^{\circ}\right)$ and enthalpies (heats) of reaction $\left(\Delta \mathrm{H}_{\mathrm{r} .298}^{\circ}\right)$ for aqueous speciation, oxidation/reduction, mineral solubility, and gas solubility reactions. The reference temperature for the MINTEQA2 database, as with most chemical reaction models, is $298 \mathrm{~K}\left(25.0^{\circ} \mathrm{C}\right)$. The 1 og equilibrium constants ( 1 og $K_{r, T}^{\circ}$ ) may be based on values that have been experimentally-determined or calculated from Gibbs free energies of reaction $\left(\Delta G_{r, T}^{\circ}\right)$ according to the equation:

$$
\log \mathrm{K}_{\mathrm{r}, \mathrm{T}}^{\circ}=\frac{-\Delta \mathrm{G}_{\mathrm{r}, \mathrm{T}}^{\circ}}{2.303 \mathrm{RT}}
$$

where $T$ is temperature in degrees Kelvin. $R$ is the gas constant $(1.9872$ $\mathrm{cal} / \mathrm{mo} \cdot \mathrm{K}$ ), and $\Delta G_{r, T}^{\circ}$ is in units of $\mathrm{cal} / \mathrm{mol}$. Values for $\Delta G_{r, T}^{\circ}$ are calculated from published values for the Gibbs free energy of formation $\left(\Delta G_{f, 298}^{\circ}\right)$ for each product and reactant in the aqueous speciation or solubility reaction by the equation:

$$
\Delta \mathrm{G}_{\mathrm{r}, 298}^{\circ}=\sum \Delta \mathrm{G}_{\mathrm{f}, 298}^{\circ} \text { (products) }-\sum \Delta \mathrm{G}_{\mathrm{f}, 298}^{\circ} \text { (reactants). }
$$

To calculate aqueous speciation and solubilities at temperatures other than $25^{\circ} \mathrm{C}$, the equilibrium constants are recalculated by the MINTEQA2 code to the temperature $T$ of interest using the van't Hoff relation:

$$
\log \mathrm{K}_{\mathrm{r}, \mathrm{T}}^{\circ}=\log \mathrm{K}_{\mathrm{r}, 298}^{\circ}-\frac{\Delta \mathrm{H}_{\mathrm{r}, 298}^{\circ}}{2.303 \mathrm{R}}\left(\frac{1}{\mathrm{~T}}-\frac{1}{298}\right) \text {. }
$$

Values for enthalpies of reaction are calculated from published enthalpy of formation values $\left(\Delta \mathrm{H}_{f, 298}^{\circ}\right)$ using the equation:

$$
\Delta \mathrm{H}_{\mathrm{r}, 298}^{\circ}=\sum \Delta \mathrm{H}_{\mathrm{f}, 298}^{\circ} \text { (products) }-\sum \Delta \mathrm{H}_{\mathrm{f}, 298}^{\circ} \text { (reactants). }
$$

Values for $\Delta H_{r .298}^{\circ}$ cannot be calculated for some reactions, because $\Delta H_{f, 298}^{\circ}$ values have not been determined for one or more reaction products and/or reactants. In these cases, the MINTEQA2 code assumes that

$$
\log \mathrm{K}_{\mathrm{r}, \mathrm{T}}^{\circ} \approx \log \mathrm{K}_{\mathrm{r}, 298}^{\circ}
$$

Because of the limitations in using the van't Hoff relation for extrapolations over a wide range of temperature, applications of the MINTEQA2 code are limited to temperatures less than $100^{\circ} \mathrm{C}$. 
Except for the thermodynamic constants for the aqueous species and solids containing uranium and plutonium, the thermodynamic database used for the MINTEQA2 calculations described below is that supplied by EPA with MINTEQA2 (Version 3.11). The original MINTEQA2 database for the uranium aqueous species and solids was replaced to include the more recent compilation of uranium thermodynamic data in Wanner and Forest (1992). The thermodynamic data used for the plutonium aqueous species and solids are principally from Lemire and Tremaine (1980), Falck (1992), and Yamaguchi et a1. (1994).

\section{A.2.2.3.3 Uranium.}

As noted in Section A.2.1, the redox conditions, as indicated by Eh values, are not known for the K Basin floor, weasel pit, and canister water compositions listed in Table A.2.1. To calculate the aqueous speciation and possible solubility controls for these waters, it was initially assumed that these waters were in equilibrium with atmospheric oxygen and therefore oxidizing. At these $\mathrm{pH}$ and redox conditions, essentially all of the dissolved uranium will be present in the +6 valence state. Because total dissolved carbonate or inorganic carbon analyses were not reported for the two canister waters in Table A.2.1, it was assumed that the canister waters were in equilibrium with atmospheric $\mathrm{CO}_{2}$ at a partial pressure of $10^{-3.5} \mathrm{~atm}$.

The calculated anion/cation imbalances and equilibrium ionic strength based on the speciated compositions for the 105-K East Basin floor. weasel pit, and canister waters are listed in Table A.2.2. The calculated speciated anion/cation imbalances suggest that the chemical analyses of the 105-K East Basin floor and weasel pit water samples are satisfactory. However, the charge imbalances for the speciated compositions of the Canister 96-05 and 96-01 waters are 28 and 38\%, respectively, with an excess of anionic species. These imbalances are unreasonably high and may indicate that some of the analyses for these water samples are in error and/or that one or more important constituents is missing in the analyses. Identifying the source of this problem is beyond the scope of this effort. However, it should be noted that the concentrations of nitrate in the canister waters are 1-3 orders of magnitude higher than those reported for the 105-K East Basin floor and wease 1 pit waters listed in Table A.2.1. If one assumes that the nitrate measurements in the canister samples are too high, decreasing the total nitrate concentration by one order of magnitude from $2.8 \times 10^{-4}$ to $2.8 \times 10^{-5}$ results in a decrease in the anion/cation imbalance from 38 to $15 \%$. 
Table A.2.2. Calculated Anion/Cation Imbalances and Equilibrium Ionic

Strength Based on the Speciated Compositions for the 105-K East Basin Floor. Weasel Pit, and Canister Waters.

\begin{tabular}{|c|c|c|c|}
\hline Sample & $\mathrm{pH}$ & $\begin{array}{c}\text { Anion/Cation } \\
\text { Imbalance (\%) } \\
\text { After } \\
\text { Speciation }\end{array}$ & $\begin{array}{c}\text { Equilibrium } \\
\text { Ionic Strength } \\
\text { (m) }\end{array}$ \\
\hline K Basin Floor & 7.68 & $5 \%$ & 0.0016 \\
\hline Weasel Pit & 7.67 & $7 \%$ & 0.0030 \\
\hline $\begin{array}{c}\text { Canister 96-05 } \\
\text { Cylinder Water }\end{array}$ & 4.41 & $28 \%$ & 0.0032 \\
\hline $\begin{array}{l}\text { Canister 96-01 } \\
\text { Cylinder Water }\end{array}$ & 6.06 & $38 \%$ & 0.00028 \\
\hline
\end{tabular}

The resu7ts of MINTEQA2 aqueous speciation and saturation index calculations for uranium dissolved in these four waters assuming oxidizing conditions are 1isted in Table A.2.3. The 105-K East Basin floor and weasel pit water samples calculate to be at near equilibrium with respect to schoepite $\left(\mathrm{UO}_{3} \cdot 2 \mathrm{H}_{2} \mathrm{O}\right)$. The dissolved uranium in the two waters is dominated by $\mathrm{U}(\mathrm{VI})$ carbonate complexes, such as $\left(\mathrm{UO}_{2}\right)_{2} \mathrm{CO}_{3}(\mathrm{OH})_{3}^{-}$and $\mathrm{UO}_{2}\left(\mathrm{CO}_{3}\right)_{2}^{2-}$.

The two canister waters calculate to be oversaturated with respect to schoepite as indicated by the saturation indices. The MINTEQA2 calculations are based on the uranium analyses determined by phosphorescence. The aqueous speciation of dissolved U(VI) at these slightly acidic pH values are dominated by the uncomplexed $\mathrm{UO}_{2}^{2+}$ species and hydroxyl complexes, such as $\left(\mathrm{UO}_{2}\right)_{3}(\mathrm{OH})_{5}^{+}$and $\left(\mathrm{UO}_{2}\right)_{4}(\mathrm{OH})_{7}^{+}$. The uranium concentrations in the canister 96-05 and 96-01 waters were determined by two methods. The concentrations determined by phosphorescence (Table A.2.1) are significantly greater than the $6.13 \times 10^{-6}$ and $<2.10 \times 10^{-6} \mathrm{~mol} / 1$ dissolved uranium determined by ICP for the canister 96-05 and 96-01 waters, respectively. If the ICP analyses for uranium are used for the MINTEQA2 calculations, the schoepite saturation indices and anion/cation imbalances are -1.415 and $82 \%$ for the canister 96-05 water, and 0.289 and $74 \%$ for the canister $96-01$ water. The modeling results based on the ICP analysis of dissolved uranium appear less reliable than the results based on the phosphorescence analyses. 
Table A.2.3 Calculated Uranium Aqueous Speciation and Schoepite Saturation Indices for 105-K East Basin Floor. Weasel Pit and Canister Water Compositions Listed in Table A.2.1.

\begin{tabular}{|c|c|c|c|c|}
\hline Sample & pH & \multicolumn{2}{|c|}{$\begin{array}{l}\text { Dominant Uranium } \\
\text { Aqueous Species (\%) }\end{array}$} & $\begin{array}{c}\text { Schoepite } \\
\text { Saturation } \\
\text { Index }\end{array}$ \\
\hline K Basin Floor & 7.68 & $\begin{array}{l}\left(\mathrm{UO}_{2}\right)_{2} \mathrm{CO}_{3}(\mathrm{OH})_{3}^{-} \\
\mathrm{UO}_{2}\left(\mathrm{CO}_{3}\right)_{2}^{2-} \\
\mathrm{UO}_{2}(\mathrm{OH})_{2}^{\circ}(\mathrm{aq}) \\
\mathrm{UO}_{2}\left(\mathrm{CO}_{3}\right)_{3}^{4-} \\
\mathrm{UO}_{2} \mathrm{CO}_{3}^{\circ}(\mathrm{aq})\end{array}$ & $\begin{array}{r}72 \% \\
19 \% \\
6 \% \\
2 \% \\
1 \%\end{array}$ & -0.049 \\
\hline Weasel Pit & 7.67 & $\begin{array}{l}\left(\mathrm{UO}_{2}\right)_{2} \mathrm{CO}_{3}(\mathrm{OH})_{3}^{-} \\
\mathrm{UO}_{2}\left(\mathrm{CO}_{3}\right)_{2}^{2-} \\
\mathrm{UO}_{2}(\mathrm{OH})_{2}^{\circ}(\mathrm{aq}) \\
\mathrm{UO}_{2}\left(\mathrm{CO}_{3}\right)_{3}^{4-}\end{array}$ & $\begin{array}{r}77 \% \\
17 \% \\
3 \% \\
3 \% \\
\end{array}$ & +0.162 \\
\hline $\begin{array}{l}\text { Canister 96-05 } \\
\text { Cylinder Water }\end{array}$ & 4.41 & $\begin{array}{l}\mathrm{UO}_{2}^{2+} \\
\left(\mathrm{UO}_{2}\right)_{2}(\mathrm{OH})_{2}^{2+} \\
\left(\mathrm{UO}_{2}\right)_{3}(\mathrm{OH})_{5}^{+} \\
\left(\mathrm{UO}_{2}\right)_{3}(\mathrm{OH})_{4}^{2+} \\
\mathrm{UO}_{2} \mathrm{OH}^{+} \\
\left(\mathrm{UO}_{2}\right)_{4}(\mathrm{OH})_{7}^{+} \\
\mathrm{UO}_{2} \mathrm{SO}_{4}^{\circ}(\mathrm{aq}) \\
\left(\mathrm{UO}_{2}\right)_{2} \mathrm{OH}^{3+}\end{array}$ & $\begin{array}{r}31 \% \\
30 \% \\
23 \% \\
5 \% \\
4 \% \\
3 \% \\
2 \% \\
1 \% \\
\end{array}$ & +0.491 \\
\hline $\begin{array}{l}\text { Canister } 96-01 \\
\text { Cylinder Water }\end{array}$ & 6.06 & $\begin{array}{l}\left(\mathrm{UO}_{2}\right)_{3}(\mathrm{OH})_{5}^{+} \\
\left(\mathrm{UO}_{2}\right)_{4}(\mathrm{OH})_{7}^{+} \\
\mathrm{UO}_{2}(\mathrm{OH})_{2}^{\circ}(\mathrm{aq}) \\
\left(\mathrm{UO}_{2}\right)_{2} \mathrm{CO}_{3}(\mathrm{OH})_{3}^{-}\end{array}$ & $\begin{array}{r}58 \% \\
24 \% \\
8 \% \\
8 \% \\
\end{array}$ & +1.022 \\
\hline
\end{tabular}

Concentrations of dissolved uranium were calculated using MINTEQA2 and assuming oxidizing conditions and equilibrium with respect to the solubility of schoepite (Figure A.2.1). The predicted uranium solubilities are in excellent agreement with the uranium concentrations measured for the $105-K$ East Basin floor and weasel pit water samples, but significantly less than those measured for the two canister water samples. These results are consistent with the saturation indices listed in Table A.2.3. 
HNF-SD-WM-ES-409, Rev 0

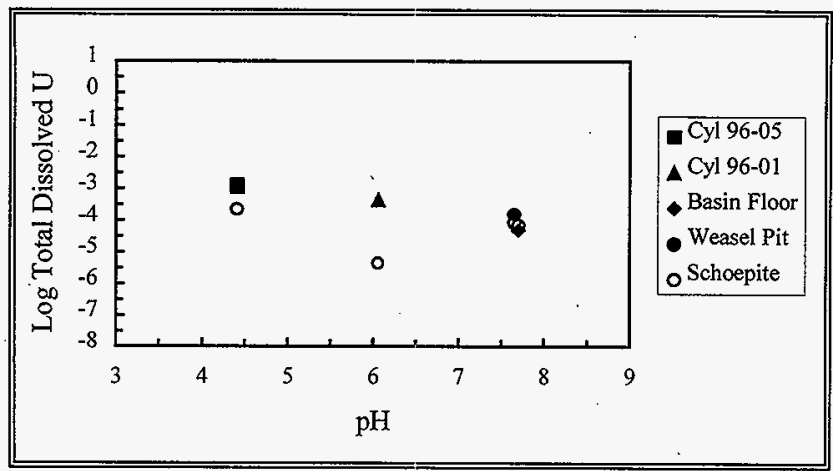

Figure A.2.1. Measured Concentrations of Dissolved Uranium versus Those Predicted from the Equilibrium Solubility of Schoepite as a Function of $\mathrm{pH}$ at $25^{\circ} \mathrm{C}$ and $0 x i d i z i n g$ Conditions.

The reason for the oversaturation observed with respect to schoepite in the two canister samples is not known. Because schoepite readily precipitates in ambient-temperature studies conducted at laboratory time frames (Krupka et a1. 1985, Bruno and Sandino 1989), one should expect better agreement between the Taboratory analyses and modeling results if schoepite is present in such waters, the chemical analyses are accurate and complete, and the thermodynamic data are adequate. The dissolved uranium concentrations predicted to be in equilibrium with schoepite might be underestimated if an important complexing ligand for uranium is missing in the reported analyses and/or chemical reaction model. The surplus of anionic charge, as indicated by anion/cation imbalances for these two waters, however, suggests that this is probably not the case. Because the water and sludges in the canisters are not in complete circulation with the woters in the K Basin. the physicochemical conditions in the canisters are different and probably more isolated than those for the $K$ Basin floor and weasel pit. The lower pH values and higher nitrate values for the two canister waters compared to the $105-K$ East Basin floor and weasel pit samples support this conclusion. If the sludge/water mixtures inside the canister are exposed to a higher. more sustained radiation field, precipitates inside the canisters might be less crystalline than precipitates on the basin floor due to radiation damage. Solubility measurements by Bruno and Sandino (1989) indicate that the solubility of amorphous $\mathrm{UO}_{3} \cdot 2 \mathrm{H}_{2} \mathrm{O}$ is approximately one order of magnitude greater than the solubility of schoepite [crystalline $\mathrm{UO}_{3} \cdot 2 \mathrm{H}_{2} \mathrm{O}$ ] at the same pH 
value. If the crystallinity argument is valid, this might explain the oversaturation calculated for the two canister waters with respect to schoepite.

As noted previously, all of the MINTEQA2 calculations described above assumed oxidizing conditions. The solubility of uranium however is a function of redox conditions (Langmuir 1978). The concentrations of dissolved uranium are typically several orders of magnitude lower at reducing (low Eh values values) versus oxidizing conditions, and will be controlled by U(IV)-containing solids, such as $\mathrm{U}_{3} \mathrm{O}_{8}$ and uraninite $\left(\mathrm{UO}_{2}\right)$, instead of schoepite. Moreover, these U(IV) phases are possible corrosion products of the uranium metal fuel stored in the canisters. A series of MINTEQA2 calculations were completed to predict the concentrations of dissolved uranium as a function of Eh. The water analyses listed in Table A.2.1 were used as the initial water compositions, and the solids uraninite, $\mathrm{U}_{3} \mathrm{O}_{8}$, and schoepite were selected as possible equilibrium solubility controls for dissolved uranium. MINTEQA2 was then used to calculate the concentrations of dissolved uranium as function of Eh from very oxidizing conditions $(800 \mathrm{mV})$ to very reducing conditions $(-300 \mathrm{mV})$ for each of the four water compositions in Table A.2.1 assuming everything but dissolved uranium and Eh remain constant. The maximum and minimum Eh values are within the Eh.pH-conditions for the decomposition of water to oxygen and hydrogen, respectively. MINTEQA2 automatically determined from the available thermodynamic database which of the three uranium solids was the most stable solubility control for each set of Eh and $\mathrm{pH}$ conditions and water composition.

The results of these calculations for the 105-K East Basin floor and Canister 96-05 water samples are shown in Parts $A(t o p)$ and $B$ (bottom) of Figure A.2.2. respectively. The results for the weasel pit and canister sludge sample 96-01 water samples do not differ significantly from the results shown in Figure A.2.2. The thick horizontal bars at the far right edge of the two figures indicate the initial uranium concentrations reported for these two water samples. The vertical thin dashed lines in Figure A.2.2 separate the Eh regions where the solubility of dissolved uranium is controlled by uraninite, $\mathrm{U}_{3} \mathrm{O}_{8}$, or schoepite. At reducing conditions (left side of Figure A.2.2), the uranium concentrations are controlled by uraninite. At intermediate redox conditions (area between the two vertical dashed 7ines), the MINTEQA2 calculations indicate $\mathrm{U}_{3} \mathrm{O}_{8}$ as the uranium solubility control. At oxidizing conditions (right side of Figure A.2.2), uranium concentrations are controlled by schoepite. The thick, curved dashed lines in Figure A.2.2 indicate the relative concentrations of total dissolved U(IV), U(V), and U(VI). 
HNF-SD-WM-ES-409, Rev 0
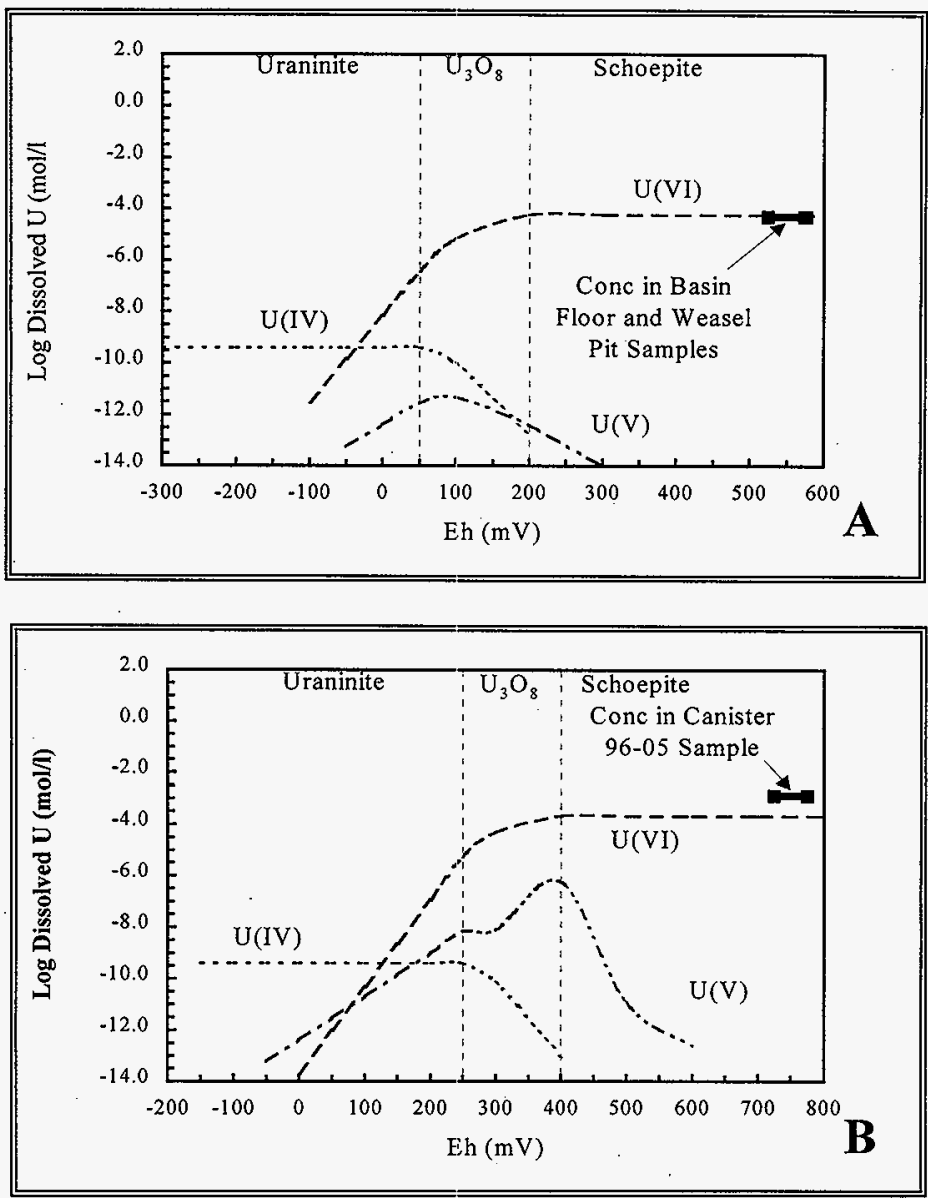

Figure A.2.2. Concentrations of Total Dissolved Uranium Predicted to be in Equilibrium with Schoepite. $\mathrm{U}_{3} \mathrm{O}_{8}$, and Uraninite as a Function of Eh for the 105-K East Basin Floor and Weasel Pit Waters (Top Figure A) and Canister 96-05 Water (Bottom Figure B). 
HNF-SD-WM-ES-409, Rev 0

The trends in the concentrations of dissolved uranium as a function of Eh are the same for these four water compositions. At oxidizing conditions. dissolved uranium is present as U(VI) and controlled to high concentrations (approximately $10^{-4}$ to $10^{-5} \mathrm{~mol} / 7$ ) by schoepite. As Eh decreases, the concentrations of the more reduced valence state of uranium increase. At Eh values from approximately 400 to $150 \mathrm{mV}, \mathrm{U}_{3} \mathrm{O}_{8}$ controls the solubility of dissolved uranium, and concentrations of dissolved uranium decreases, primarity as a decrease in U(VI), by several orders magnitude. Below redox conditions of 150-250 mV, uraninite is predicted to be the solubility control for dissolved uranium. At these reducing conditions, uranium is present primarily in the U(IV) redox state, and is controlled to very low concentrations of approximately $10^{-10} \mathrm{~mol} / 1$. Solubility studies by Rai et a]. (1990) indicate that the initial solubility control (i.e., initial precipitate) for U(IV) under reducing conditions and ambient temperature is amorphous $\mathrm{UO}_{2} \cdot \mathrm{XH}_{2} \mathrm{O}$ instead of uraninite (crystal7ine $\mathrm{UO}_{2}$ ). If $\mathrm{UO}_{2} \cdot \mathrm{xH}_{2} \mathrm{O}$ (am) is selected as the solubility control at these conditions, the total concentration of dissolved uranium would be approximately $\left.10^{-8} \mathrm{mo}\right] / 1$, two orders of magnitude greater than the solubilities predicted by the solubility of uraninite. Regardless of which $\mathrm{UO}_{2}$ phase is selected as the solubility control, the low concentrations of dissolved uranium predicted for reducing conditions are approximately six orders of magnitude lower than the uranium concentrations reported for these water samples.

Although enthalpy of formation $\left(\Delta \mathrm{H}_{\mathrm{f}, 298}^{\circ}\right)$ values are available for studtite $\left(\mathrm{UO}_{4} \cdot 4 \mathrm{H}_{2} \mathrm{O}\right.$, uranyl peroxide dihydrate), there are no entropy or Gibbs free energy of formation $\left(\Delta G_{f}^{\circ}, 298\right)$ values for this solid phase (Wanner and Forrest 1992). The lack of these values precludes the calculation of saturation indices or solubilities for this phase.

\section{A.2.2.3.4. Plutonium.}

As noted previous7y, it was assumed that these waters were in equilibrium with atmospheric oxygen and therefore oxidizing. At these $\mathrm{pH}$ and redox conditions, it was assumed that a 11 of the dissolved plutonium wi11 be present in the +4 valence state (Serne et a1. 1996). Because total dissolved carbonate or inorganic carbon analyses were not reported for the two canister waters in Table A.2.1, it was assumed that the canister waters were in equilibrium with atmospheric $\mathrm{CO}_{2}$ at a partial pressure of $10^{-3.5} \mathrm{~atm}$.

The results of MINTEQA2 aqueous speciation and saturation index calculations for plutonium dissolved in these four waters are listed in Table A.2.4. The dissolved plutonium in 105-K East Basin floor and weasel pit water samples is dominated by the hydroxyl carbonate complex $\mathrm{Pu}(\mathrm{OH})_{2}\left(\mathrm{CO}_{3}\right)_{2}^{2}$ - The plutonium aqueous speciation for the two canister waters, which are 
more acidic than the 105-K East Basin floor and weasel pit water. is dominated by the hydroxy? complexes, such as $\mathrm{Pu}(\mathrm{OH})_{4}^{\circ}(\mathrm{aq})$ and $\mathrm{Pu}(\mathrm{OH})_{3}^{+}$.

Table A.2.4 Calculated Plutonium Aqueous Speciation and $\mathrm{PuO}_{2} \cdot \mathrm{XH}_{2} \mathrm{O}$ (am) Saturation Indices for 105-K East Basin Floor, Weasel Pit, and Canister Water Compositions Listed in Table A.2.1.

\begin{tabular}{|l|c|lr|}
\hline \multicolumn{1}{|c|}{ Sample } & pH & \multicolumn{2}{c|}{$\begin{array}{c}\text { Dominant Plutonium } \\
\text { Aqueous Species (\%) }\end{array}$} \\
\hline K Basin Floor & 7.68 & $\mathrm{Pu}(\mathrm{OH})_{2}\left(\mathrm{CO}_{3}\right)_{2}^{2-}$ & $95 \%$ \\
& & $\mathrm{Pu}(\mathrm{OH})_{4}^{\circ}(\mathrm{aq})$ & $5 \%$ \\
\hline Weasel Pit & 7.67 & $\mathrm{Pu}(\mathrm{OH})_{2}\left(\mathrm{CO}_{3}\right)_{2}^{2-}$ & $97 \%$ \\
& & $\mathrm{Pu}(\mathrm{OH})_{4}^{\circ}(\mathrm{aq})$ & $3 \%$ \\
\hline Canister 96-05 & 4.41 & $\mathrm{Pu}(\mathrm{OH})_{4}^{\circ}(\mathrm{aq})$ & $57 \%$ \\
Cylinder Water & & $\mathrm{Pu}(\mathrm{OH})_{3}^{+}$ & $41 \%$ \\
& & $\mathrm{Pu}(\mathrm{OH})_{2}^{2+}$ & $2 \%$ \\
\hline Canister 96-01 & 6.06 & $\mathrm{Pu}(\mathrm{OH})_{4}^{\circ}(\mathrm{aq})$ & $98 \%$ \\
Cylinder Water & & $\mathrm{Pu}(\mathrm{OH})_{3}^{+}$ & $2 \%$ \\
\hline
\end{tabular}

The concentrations of dissolved plutonium measured for 105-K East Basin floor, weasel pit, and two canister water samples are compared in Figure A.2.3 to the solubility limits given by Rai et al. (1980a) for $\mathrm{PuO}_{2} \cdot \mathrm{XH}_{2} \mathrm{O}$ (am) (upper dotted line in Figure A.2.3) and $\mathrm{PuO}_{2}$ ( $\mathrm{cr}$ ) (lower dotted line in Figure A.2.3). These solubility limits bracket the plutonium concentrations measured in these four water samples suggesting that a plutonium dioxide solid may be controlling the plutonium concentrations in these waters.

\section{A.2.2.3.5 Other Components.}

Iron-containing solids may form as a result of the corrosion of steel racks. Aqueous speciation and saturation indices could not be calculated for iron-containing solids because the concentrations of dissolved iron in the 105-K East Basin floor, weasel pit, and Canister 96-05 and 96-01 waters (Table A.2.1) were below detection limits. MINTEQA2 was however used to predict the concentrations of dissolved iron based on solubilities of Tepidocrocite $[\gamma-\mathrm{FeO}(\mathrm{OH})]$ and goethite $[\alpha-\mathrm{FeO}(\mathrm{OH})]$ for the compositions of these four waters. The calculated equilibrium solubilities of dissolved iron were in the subpart per trillion range and thus consistent with the nondetect values listed for these waters. 


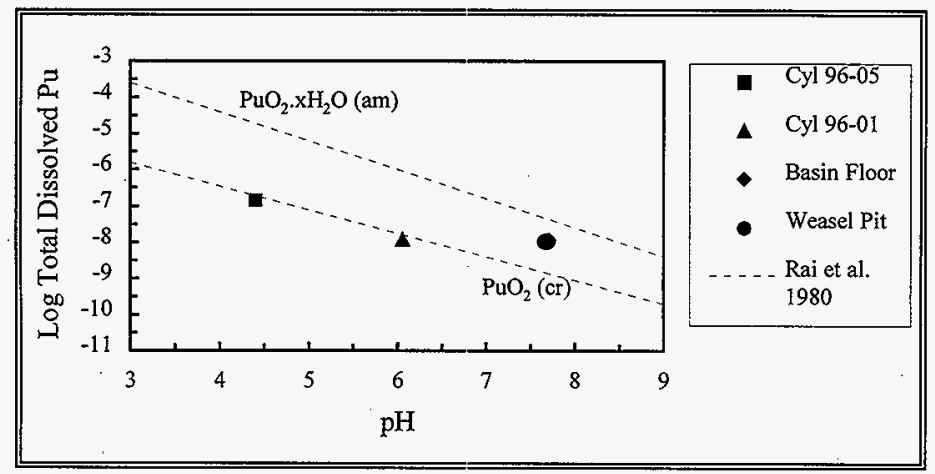

Figure A.2.3. Measured Concentrations of Dissolved Plutonium Versus Solubility Limits for $\mathrm{PuO}_{2} \cdot \mathrm{XH}_{2} \mathrm{O}$ (am) (Upper Dotted Line) and $\mathrm{PuO}_{2}(\mathrm{cr}$ ) (Lower Dotted Line) from Rai et a1. (1980a).

Aluminum precipitates may form from the corrosion of aluminum canisters. Aluminum analyses were only available for the Canister 96-05 and 96-01 water samples. Given the limited data, the MINTEQA2 calculations were inconclusive regarding possible solubility controls for dissolved aluminum. Based on the saturation indices, the water from Canister 96-05 ( $\mathrm{pH}=4.41)$ calculated to be undersaturated with al1 aluminum oxide hydrates in the MINTEQA2 thermodynamic database. On the other hand, the Canister 96-01 water $(\mathrm{pH}=6.06$ ) calculated to be oversaturated with several aluminum oxide hydrate solids including $\mathrm{Al}(\mathrm{OH})_{3}(\mathrm{am})$.

It should be noted that analyses of dissolved silica were not determined for these waters. The lack of these data precluded saturation index/solubility calculations for any silica-containing solids, including $\mathrm{SiO}_{2}$ and alkali/alkaline earth uranyl silicate corrosion products.

\section{A.2.3 Segregation of ${ }^{235} \mathrm{~W} /{ }^{238} \mathrm{U}$}

No preferential segregation of ${ }^{235} U$ from ${ }^{238} \mathrm{U}$ is expected in the uranium precipitates that form in the storage or disposal treatment of $K$ Basin sludges. The chemical and physical properties of different isotopes of the same element are only slightly different. Chemical properties depend 
primarily on ionic charge and the arrangement of outermost electrons. Atoms of isotopes differ only in nuclear mass, but have the same electron distribution. Therefore, except for the isotopes of a few of the lighter elements (e.g., hydrogen, carbon, oxygen, and sulfur), ordinary chemical reactions, such as oxidation, dissolution, and precipitation processes, in the laboratory or nature, lead to essentially no separation of isotopes (Krauskopf 1979).

Moreover, the assumption of no preferential segregation of ${ }^{235} \mathrm{U}$ from ${ }^{238} \mathrm{U}$ in uranium precipitates is further supported by the extensive range of nonstoichiometry and cation substitutions (discussed briefly in Section A.2.2.1) observed in natural samples of uraninite and many of its oxidation/alteration products [for example, see Finch and Ewing (1991a, 1992b) and Janeczek and Ewing (1992b)].

\section{A.2.4 K West Versus K East Basin Corrosion Environments}

Because the canisters stored in $K$ west are sealed in a way that does not allow their waters to mix with basin water, the corrosion environment associated with these canisters may be different than that for the K East canisters which are open to the basin water. Experimental data indicate that a) pha radiolysis in aqueous solutions in equilibrium with air results in the production of nitric acid with concomitant increase in acidity (decreasing $\mathrm{pH}$ ) and nitrate concentrations (e.g., see Rai et al. 1980). Studies by DíazArocas et a1. (1995), Shoesmith et al. (1985). Sunder et al. (1992), and others indicate that radiolysis of water also forms species, such as hydrogen peroxide, which results in an oxidizing environment near the surface of nuclear fuel. Therefore, one might expect the $K$ West canister waters to be more acidic, have higher nitrate concentrations, and be as or more oxidizing than the $K$ East waters, because dissolved radiolytic species cannot escape from the sealed $K$ West canisters. On the other hand, irradiation experiments of air/water mixtures by Gray and McVay (1985) indicate that nitric acid formation requires the presence of a gass phase containing both $\mathrm{N}_{2}$ and $\mathrm{O}_{2}$. They found no measurable change in $\mathrm{pH}$ and dissolved nitrate concentrations for a single-phase air-saturated water (no gas phase present) irradiated for twelve days at an average gamma dose rate for $\sim 5 \mathrm{Mrad} / \mathrm{h}$. Based on the results of Gray and McVay (1985), one might assume that the buildup of nitric acid in the $K$ West canisters wi 17 be restricted or prevented, compared to the open $K$ East canisters, by the limited gas space $(5.6$ to $6.4 \mathrm{~cm}$ ) of nitrogen established on the top of the $20.51-\mathrm{cm}$ wide sealed canisters [dimensions from Trimble (1997b)].

Assessment of the corrosion environment inside the sealed $k$ West Basin canisters is complicated by the fact that the compositions reported for $\mathrm{K}$ west 
canister waters represent a mixture of canister and basin waters. Analyses of 1 iquid and gas samples from $K$ West Basin fuel canisters are reported by Trimble (1995a,b:1996a,b:1997a,b) and (Trimble and Welsh 1997). Liquid samples were taken with the canister barrels flooded which was necessitated by the sampling methods. After flooding, the canister was set aside for eight or more hours to allow the barrel liquid reach equilibrium with the flood water via thermal mixing (Trimble 1996a). During the second sampling and characterization campaign for the $K$ West basin canisters, the liquid sampling was completed 24 or more hours after flooding (Trimble 1997b). Trimble estimated that this increased the water in the canister by 10 to $16 \%$.

The $\mathrm{pH}$ values measured in the second sampling campaign for the waters from the flooded $K$ West Basin canisters range from 6.34 to 11.85 with a mean of 8.58 (Trimble 1997b). The nitrate concentrations for the waters from the flooded $K$ West Basin canisters range from $<0.2$ to $488 \mu \mathrm{g} / \mathrm{ml}$ (mean 45.8 ). ${ }^{1}$ The uranium concentrations range from 0.011 to $5,044 \mu \mathrm{g} / \mathrm{ml}$ (mean $350 \mu \mathrm{g} / \mathrm{ml}$ ). The $\mathrm{pH}$ values for cylinder waters and supernatants from the $K$ East canisters range from 4.41 to 8.39 (mean 7.05) (Mi 17er 1997). Except for the nitrate concentrations of 158 and $17.4 \mu \mathrm{g} / \mathrm{m}]$ in the Canister 96-05 and 96-01 water samples, all of the nitrate concentrations in the other supernatant samples were below detection 1 imits of $1.53 \mu \mathrm{g} / \mathrm{ml}$. The uranium are 316 and $103 \mu \mathrm{g} / \mathrm{ml}$, respectively.

Because of the limited $\mathrm{K}$ West Basin canister water characterization, and the complex aqueous complexation and solubility reactions for dissolved uranium at basic $\mathrm{pH}$ conditions, it is not possible to predict the response in the equilibrium solubility of dissolved uranium for the higher $\mathrm{pH}$ values measured for the $K$ West Basin canister waters.

\section{A.2.5 Expected Changes in Environments Isolated from General Basin Water}

The water compositions reported in Table A.2.1 represent water samples separated from sludge-containing samples. These waters therefore have been in intimate contact with sludges and probably represent the chemistry of sludge "pore waters." Their compositions may thus represent the maximum concentrations of dissolved constituents compared to the composition of the general circulating basin water.

For those areas where the sludge has remained relatively undisturbed

1 When the canisters were sealed, $10 \mathrm{~g}$ of potassium nitrite was added as a corrosion inhibitor resulting in a concentrations of $500 \mathrm{mg} / 1$ dissolved nitrite (Trimble 1996a). This nitrite oxidizes over time to form nitrate. 
from basin operations or sampling campaigns, one might speculate that some of the oldest corrosion products, those nearest the basin floor. may have altered with time. These materials may have experienced crystal growth and/or alteration to more complex uranyl hydrated oxide phases, such as becquerelite $\left(\mathrm{Ca}_{6} \mathrm{O}_{19} \cdot 11 \mathrm{H}_{2} \mathrm{O}\right)$ and compreignacite $\left(\mathrm{K}_{2} \mathrm{U}_{6} \mathrm{O}_{19} \cdot 11 \mathrm{H}_{2} \mathrm{O}\right)$ as discussed in Section A.1.2.1. 
HNF-SD-WM-ES-409, Rev. 0

\section{A.3 CHARACTERIZATION DATA AND SLUDGE OBSERVATIONS}

This chapter summarizes the characterization data available for $K$ basin sludges including composition. mineralogy, density and particle size as well as conclusions derived from experimental testing intended to assess the potential for segregation.

\section{A.3.1 Chemical Composition of KE Basin Floor and Wease] Pit Sludges}

Samples of sludges from the KE basin floor and weasel pit were dried at $110^{\circ} \mathrm{C}$ and analyzed for various chemical constituents (Makenas, 1996). The chemical analyses indicated that a number of constituents in these sludges such as $\mathrm{Ag}, \mathrm{Sm}, \mathrm{Se}, \mathrm{Tl}, \mathrm{PO}_{4}, \mathrm{NO}_{3}, \mathrm{NO}_{2}, \mathrm{Cl}$, and $\mathrm{F}$ were at or below detection limits. The chemical constituents in these sludges are provided on an oxide basis in Table A.3.1. For the multiple redox state elements $\mathrm{Fe}$ and $\mathrm{U}$ the oxide basis was computed on the highest oxidation states (trivalent and hexavalent respectively). For $\mathrm{Cr}$, the trivalent state was used to compute the oxide basis as this is the most common valence state found in minerals. The data show that $\mathrm{A} 1, \mathrm{Fe}, \mathrm{U}$, total carbon, and acid insoluble residues (silicate minerals) dominate the chemical composition of the sludges. Calcium. Mg and $\mathrm{Na}$ are minor components of the sludge mass, whereas all the remaining constituents namely $\mathrm{B}, \mathrm{Be}, \mathrm{Cd}, \mathrm{Cr}, \mathrm{Cu}, \mathrm{K}, \mathrm{Mn}, \mathrm{Pb}, \mathrm{Pu}, \mathrm{Zn}$, and $\mathrm{Zr}$ exist in trace quantities. The KE basin floor and weasel pit sludges are chemically similar.

The closure of the mass balance for the analyses based on oxide sum indicated a range from a low of $82.01 \%$ (Sample XES-S-19) to a high of $171.14 \%($ Sample KES-H-18). Sample KES-H-18 contained $97.3 \%$ by weight of insoluble residue, and lost $55.9 \%$ of its weight between $110^{\circ} \mathrm{C}$ and $500^{\circ} \mathrm{C}$. On average, a chemical mass balance of about $93.5 \%$ was calculated for these sludge samples (excluding values for samples KES-H-9, KES-H-18, and sample KES-T-20B for which TGA data was not available). Therefore, on average, the mass balance closed to within about $6.5 \%$ for these samples. Discrepancies in chemical mass balance may arise from several sources.

One contributor to a poor mass balance closure may be the sample inhomogeneity (Makenas. Personal Communication). The analytical scheme used for these samples utilized separate sample splits for analysis of TC, TGA, and ICP analyses (Makenas, 1996). Because the samples were difficult to homogenize, variability may exist between sample splits. Thus, measurements conducted on various splits of the same sample may contribute to the lack of mass balance closure. A second possible contributor is any water in the. form of hydroxyis or hydrates that was not released during TGA measurements. The mass of hydration water and hydroxyls associated with minerals in soils and 
Table A.3.1. Chemical Composition of KE Basin Floor and Weasel Pit Sludge Samples (wt\% of dry sludge)

\begin{tabular}{|c|c|c|c|c|c|c|c|c|c|c|c|c|c|c|c|}
\hline \multirow[b]{2}{*}{$\begin{array}{l}\text { Oxide } \\
\text { Basis }\end{array}$} & \multicolumn{10}{|c|}{ Basin Floor } & \multicolumn{5}{|c|}{ Weasel Pit } \\
\hline & KES-L-1 & KES-A-2 & KES-B-3 & KES-C-4 & KES-N-5 & KES-J-6 & KES-H-8 & KES-F-10 & KES-E-11 & KES-I-15 & KES-P-16 K & KES-Q-17 & KES-R- 18 & KES-S-19 & KES-T-20B \\
\hline $\mathrm{Al}_{2} \mathrm{O}_{3}$ & 12.21 & 14.38 & 25.13 & 15.59 & 19.84 & 6.41 & 3.53 & 8.29 & 15.46 & 11.03 & 6.07 & 5.74 & 4.99 & 9.39 & 10.01 \\
\hline $\mathrm{B}_{2} \mathrm{O}_{3}$ & 0.06 & 0.09 & 0.18 & 0.09 & 0.20 & 0.08 & 0.04 & 0.06 & 0.09 & 0.05 & 0.05 & 0.03 & 0.06 & 0.00 & 0.00 \\
\hline $\mathrm{BaO}$ & 0.03 & 0.00 & 0.03 & 0.03 & 0.03 & 0.02 & 0.06 & 0.00 & 0.03 & 0.00 & 0.02 & 0.01 & 0.00 & 0.07 & 0.07 \\
\hline $\mathrm{BeO}$ & 0.02 & 0.02 & 0.04 & 0.02 & 0.02 & 0.01 & 0.00 & 0.01 & 0.03 & 0.00 & 0.01 & 0.00 & 0.00 & 0.00 & 0.01 \\
\hline $\mathrm{CaO}$ & 0.36 & 0.35 & 0.62 & 1.00 & 4.04 & 1.01 & 1.71 & 0.17 & 1.05 & 0.23 & 0.71 & 0.72 & 2.11 & 2.03 & 3.62 \\
\hline CdO & 0.02 & 0.02 & 0.04 & 0.03 & 0.03 & 0.02 & 0.01 & 0.01 & 0.03 & 0.01 & 0.01 & 0.01 & 0.00 & 0.01 & 0.01 \\
\hline $\mathrm{Cr}_{2} \mathrm{O}_{3}$ & 0.04 & 0.13 & 0.08 & 0.09 & 0.07 & 0.21 & 0.01 & 0.12 & 0.11 & 0.07 & 0.18 & 0.08 & 0.22 & 0.12 & 0.16 \\
\hline $\mathrm{CuO}$ & 0.06 & 0.15 & 0.17 & 0.11 & 0.11 & 0.10 & 0.01 & 0.06 & 0.13 & 0.07 & 0.05 & 0.07 & 0.06 & 0.03 & 0.05 \\
\hline $\mathrm{Fe}_{2} \mathrm{O}_{3}$ & 11.65 & 44.18 & 23.16 & 32.45 & 24.16 & 58.19 & 2.16 & 56.90 & 39.60 & 53.47 & 49.47 & 23.88 & 63.76 & 37.03 & 35.03 \\
\hline $\mathrm{K}_{2} \mathrm{O}$ & 0.00 & 0.00 & 0.00 & 0.00 & 0.00 & 0.00 & 0.32 & 0.00 & 0.00 & 0.00 & 0.00 & 0.07 & 0.00 & 0.24 & 0.23 \\
\hline $\mathrm{MgO}$ & 0.11 & 0.28 & 0.27 & 0.43 & 0.83 & 0.43 & 0.37 & 0.24 & 0.32 & 0.12 & 0.21 & 0.24 & 0.35 & 0.40 & 0.45 \\
\hline $\mathrm{MnO}$ & 0.04 & 0.07 & 0.10 & 0.09 & 0.10 & 0.10 & 0.03 & 0.06 & 0.11 & 0.08 & 0.06 & 0.04 & 0.07 & 0.06 & 0.10 \\
\hline $\mathrm{Na}_{2} \mathrm{O}$ & 0.09 & 0.11 & 0.16 & 0.08 & 0.15 & 0.08 & 4.39 & 0.05 & 0.10 & 0.04 & 0.05 & 0.04 & 0.08 & 0.19 & 0.19 \\
\hline $\mathrm{PbO}$ & 0.03 & 0.06 & 0.06 & 0.06 & 0.06 & 0.12 & 0.02 & 0.05 & 0.08 & 0.05 & 0.06 & 0.04 & 0.07 & 0.05 & 0.05 \\
\hline $\mathrm{PuO}_{2}$ & 0.06 & 0.03 & 0.11 & 0.10 & 0.06 & 0.03 & 0.00 & 0.01 & 0.07 & 0.01 & 0.04 & 0.02 & 0.01 & 0.02 & 0.01 \\
\hline $\mathrm{UO}_{3}$ & 52.51 & 7.28 & 17.30 & 15.38 & 14.18 & 7.68 & 0.30 & 2.76 & 12.26 & 3.93 & 13.46 & 8.81 & 2.39 & 6.44 & 7.02 \\
\hline $\mathrm{ZnO}$ & 0.08 & 0.16 & 0.15 & 0.17 & 0.16 & 0.24 & 0.01 & 0.11 & 0.19 & 0.10 & 0.16 & 0.08 & 0.21 & 0.12 & 0.10 \\
\hline $\mathrm{Z}_{2}$ & 0.08 & 0.11 & 0.11 & 0.11 & 0.07 & 0.10 & 0.01 & 0.03 & 0.11 & 0.02 & 0.12 & 0.05 & 0.09 & 0.04 & 0.09 \\
\hline $\mathrm{CO}_{2}$ & 1.78 & 1.48 & 9.27 & 1.96 & 2.97 & 1.95 & 4.04 & 1.15 & 2.24 & 1.52 & 1.84 & 1.48 & 2.41 & 1.58 & 2.01 \\
\hline $\mathrm{H}_{2} \mathrm{O}$ & 2.1 & 5.9 & 3.3 & 1.8 & 14.5 & 6.6 & 55.9 & 13.4 & 3.5 & 12.3 & 8.4 & 3.5 & 10.6 & 6.4 & NM \\
\hline Residue & 5.73 & 14.80 & 7.35 & 15.00 & 14.30 & 13.10 & 97.30 & 15.80 & 15.20 & 8.36 & 19.10 & 51.80 & 14.10 & 17.80 & 32.60 \\
\hline $\begin{array}{l}\text { Oxide } \\
\text { Sum }\end{array}$ & 87.05 & 89.58 & 87.64 & 84.58 & 95.88 & 96.45 & 170.22 & 99.28 & 90.71 & 91.46 & 100.05 & 96.73 & 101.59 & 82.01 & 91.80 \\
\hline
\end{tabular}

Source: Makenas et a1. (1996)
NM
not measured

$\mathrm{H} 20$ values estimated from TGA data (Silvers 1995) as weight loss observed from $110^{\circ} \mathrm{C}$ to $500^{\circ} \mathrm{C}$ 
sediments are generalily determined by loss in weight when the samples are heated from $110^{\circ} \mathrm{C}$ to $1000^{\circ} \mathrm{C}$ (Van 0lphen and Fripiat, 1979; Bain and Smith. 1987). For these sludge samples the TGA data extended on $7 y$ to $500^{\circ} \mathrm{C}$. Therefore, the computed weight loss between $110^{\circ} \mathrm{C}$ and $500^{\circ} \mathrm{C}$ may not represent the entire mass of hydration water and hydroxyls present in these samples. Omission of one or more important chemical constituents can contribute to a mass balance discrepancy. However, basin and pit sludges were analyzed for a 11 the significant chemical constituents. Therefore, omission of an important chemical constituent is unlikely to contribute to poor mass balance closure.

\section{A.3.2 Composition of KE Canister Sludge}

Samples of centrifuged sludges from the KE basin canisters were analyzed for various chemical constituents (Miller 1997). The data on an oxide basis are presented as wt\% of dry sludge in Table A.3.2. The sludge mass was converted to dry mass using gravimetric water content values for centrifuged sludge (Mi17er 1997). The data showed that a number of constituents in these sludge samples such as $\mathrm{Ag}$. Sm, Se, $\mathrm{Tl}, \mathrm{NO}_{3}, \mathrm{NO}_{2}, \mathrm{Cl}$, and $\mathrm{F}$ were at or below detection limits. The chemical constituents (on oxide basis) in these samples were computed on the dry sludge basis (Table A.3.2). The oxide basis of multiple redox state elements $\mathrm{Fe}$ and $U$ was computed for the highest oxidation state (trivalent and hexavalent respectively). For $\mathrm{Cr}$, the trivalent state was used to compute the oxide basis as this is the most common valence state found in minerals. The data show that in eight of the samples, U content represents between $47 \%$ and $97 \%$ of the sludge on an oxide basis. Aluminum (as $\mathrm{Al}_{2} \mathrm{O}_{3}$ ) in canister sludge samples ranged about 2 to $39 \%$ by mass, whereas. Fe (as $\mathrm{Fe}_{2} \mathrm{O}_{3}$ ) ranged from almost none $(0.09 \%$ ) to about $48.5 \%$ by mass. Sludge sample 96-01 contained anomaloușly high $\mathrm{Na}$ content ( $51 \%$ by wt). Total carbon content (oxide basis) of these sludge samples varied from about 0.3 to $15 \%$ by mass. Al1 the remaining constituents ramely $\mathrm{B}, \mathrm{Be}, \mathrm{Cd}, \mathrm{Cr}, \mathrm{Cu}, \mathrm{K}, \mathrm{Mn}, \mathrm{Pb}, \mathrm{Pu}$, $\mathrm{Zn}$, and $\mathrm{Zr}$ exist in trace quantities.

In these sludge samples, there were no measurable quantities of acid insoluble residues. ${ }^{1}$ Although preliminary TGA data now exists for canister sludge samples to estimate water weight loss above $110^{\circ} \mathrm{C}$, this data has not been incorporated into the mass balance shown in Table A.3.2.

${ }^{1}$ Personal communication. R. B. Baker to G. A. Whyatt, 5/21/97 
Table A.3.2 Chemical Composition of KE Basin Canister Sludge Samples (wt \% of dry sludge)

\begin{tabular}{|l|rrrrrrrrrrrrr|}
\hline Oxide Basis & $96-01$ & $96-05$ & $96-08$ & $96-09$ & $96-13$ & $96-15$ & $96-04 \mathrm{U}$ & $96-041$ & $96-06 \mathrm{M}$ & $96-06 \mathrm{~L}$ & $96-11 \mathrm{U}$ & $96-11 \mathrm{~L}$ \\
\hline $\mathrm{Al}_{2} \mathrm{O}_{3}$ & 8.11 & 2.60 & 18.93 & 31.71 & 2.74 & 3.30 & 29.88 & 22.00 & 2.80 & 2.03 & 38.58 & 18.21 \\
$\mathrm{~B}_{2} \mathrm{O}_{3}$ & 0.10 & 0.05 & 0.15 & 0.18 & 0.05 & 0.06 & 0.20 & 0.08 & 0.05 & 0.05 & 0.48 & 0.11 \\
$\mathrm{BaO}$ & 0.00 & 0.01 & 0.02 & 0.02 & 0.01 & 0.02 & 0.05 & 0.02 & 0.00 & 0.01 & 0.10 & 0.00 \\
$\mathrm{BeO}$ & 0.00 & 0.01 & 0.02 & 0.03 & 0.01 & 0.00 & 0.02 & 0.01 & 0.00 & 0.00 & 0.08 & 0.04 \\
$\mathrm{CaO}$ & 0.08 & 0.11 & 0.24 & 0.26 & 0.10 & 0.00 & 0.36 & 0.23 & 0.00 & 0.00 & 0.21 & 0.51 \\
$\mathrm{CdO}$ & 0.00 & 0.00 & 0.01 & 0.02 & 0.00 & 0.00 & 0.01 & 0.01 & 0.00 & 0.00 & 0.04 & 0.03 \\
$\mathrm{Cr}_{2} \mathrm{O}_{3}$ & 0.49 & 0.00 & 0.05 & 0.09 & 0.00 & 0.00 & 0.00 & 0.02 & 0.00 & 0.00 & 0.14 & 0.17 \\
$\mathrm{CuO}$ & 0.00 & 0.01 & 0.04 & 0.19 & 0.01 & 0.01 & 0.07 & 0.03 & 0.01 & 0.01 & 0.19 & 0.14 \\
$\mathrm{Fe}_{2} \mathrm{O}_{3}$ & 0.09 & 1.02 & 13.24 & 36.31 & 0.40 & 1.02 & 14.07 & 8.86 & 0.26 & 0.11 & 25.38 & 53.90 \\
$\mathrm{~K}_{2} \mathrm{O}$ & 0.62 & 0.00 & 0.00 & 0.00 & 0.00 & 0.00 & 0.00 & 0.00 & 0.00 & 0.00 & 0.00 & 0.00 \\
$\mathrm{MgO}$ & 0.00 & 0.38 & 0.34 & 0.40 & 0.32 & 0.35 & 0.29 & 0.27 & 0.00 & 0.00 & 0.00 & 0.00 \\
$\mathrm{MnO}$ & 0.03 & 0.00 & 0.02 & 0.11 & 0.00 & 0.00 & 0.03 & 0.02 & 0.00 & 0.00 & 0.15 & 0.10 \\
$\mathrm{Na}_{2} \mathrm{O}$ & 48.49 & 0.06 & 0.12 & 0.13 & 0.06 & 0.07 & 0.16 & 0.09 & 0.06 & 0.06 & 0.34 & 0.11 \\
$\mathrm{P}_{2} \mathrm{O}_{5}$ & 0.73 & 0.00 & 0.00 & 0.26 & 0.00 & 0.00 & 0.00 & 0.00 & 0.00 & 0.00 & 0.34 & 0.19 \\
$\mathrm{PbO}$ & 0.01 & 0.00 & 0.02 & 0.10 & 0.00 & 0.00 & 0.06 & 0.00 & 0.00 & 0.00 & 0.10 & 0.08 \\
$\mathrm{PuO}_{2}$ & 1.33 & 0.29 & 0.22 & 0.07 & 0.20 & 0.20 & 0.46 & 0.24 & 2.39 & 2.24 & 0.17 & 0.05 \\
$\mathrm{UO}_{3}$ & 0.00 & 93.55 & 58.96 & 18.96 & 89.71 & 87.61 & 46.97 & 50.12 & 92.01 & 91.43 & 23.47 & 13.76 \\
$\mathrm{ZnO}$ & 0.00 & 0.01 & 0.07 & 0.21 & 0.00 & 0.01 & 0.11 & 0.04 & 0.00 & 0.00 & 0.22 & 0.26 \\
$\mathrm{ZrO}_{2}$ & 0.00 & 0.00 & 0.03 & 0.06 & 0.00 & 0.01 & 0.14 & 0.04 & 0.00 & 0.00 & 0.00 & 0.04 \\
$\mathrm{CO}_{2}$ & 14.76 & 0.37 & 1.65 & 5.53 & 0.35 & 0.46 & 3.19 & 2.18 & 0.46 & 0.28 & 6.66 & 3.72 \\
\hline $\mathrm{Oxide}_{2} \mathrm{Sum}$ & 74.84 & 98.48 & 94.14 & 94.66 & 93.96 & 93.12 & 96.05 & 84.25 & 98.06 & 96.21 & 96.63 & 91.43 \\
\hline
\end{tabular}

Source: Miller 1997.

\section{A.3.3 Sludge Interstitial Solution Analysis}

The characterization data available for interstitial solutions was presented and discussed previously in section A.2.1. The charge balance (anion/cation balance), the ionic strength, and $U$ speciation calculations for these interstitial solutions were presented previously (Tables A.2.2, and A.2.3). The data show that in floor and pit sludge decantates, the dominant dissolved cationic constituents are $\mathrm{Ca}$ and $\mathrm{U}$ with minor concentrations $\mathrm{Na}$, and trace amounts of $\mathrm{Zn}$. In these decantates. TIC and $\mathrm{SO}_{4}$ are the principal and $\mathrm{NO}_{3}$ and $\mathrm{Cl}$ are the minor anionic constituents. The measured $\mathrm{pH}$ values show that these solutions are very slightly alkaline. Calculations to determine charge balance indicate that in both cases there is an excess of cationic charge which indicates that one or more anionic constituents are unaccounted. Soluble TOC may account for these charge imbalances but, the relatively high detection limits $(40 \mathrm{mg} / 1)$ precludes any definite conclusions. The calculated stoichiometric ionic strengths indicated that the decantates from the basin and pit sludges are relatively dilute solutions. A summary of the data along with the charge balance information is provided in Table A.3.3

In comparison, the water samples from the canisters contained high 
Table A.3.3. Analysis of Decantates from KE-Basin Floor, Weasel Pit, and Canister Sludges

\begin{tabular}{|c|c|c|c|c|c|c|c|c|}
\hline \multirow{2}{*}{ Constituent } & \multicolumn{2}{|c|}{ Basin Floor } & \multicolumn{2}{|c|}{ Weasel Pit } & \multicolumn{2}{|c|}{ Canister 96-05 } & \multicolumn{2}{|c|}{ Canister 96-01 } \\
\hline & $\mathrm{mg} / 1$ & $\mathrm{mM}$ & $\mathrm{mg} / 1$ & $\mathrm{mM}$ & $\mathrm{mg} / \mathrm{\imath}$ & $\mathrm{mM}$ & $\mathrm{mg} / 1$ & $\mathrm{mM}$ \\
\hline $\mathrm{AI}$ & $<0.1$ & $<0.004$ & $<0.1$ & $<0.004$ & 0.158 & 0.006 & 0.426 & 0.016 \\
\hline $\mathrm{Ca}$ & 18.70 & 0.467 & 34.6 & 0.863 & 0.688 & 0.017 & 0.203 & 0.005 \\
\hline $\mathrm{Na}$ & 3.89 & 0.169 & 7.03 & 0.307 & 1.41 & 0.061 & 0.797 & 0.035 \\
\hline u & 11.50 & 0.048 & 37.10 & 0.156 & 316 & 1.32 & 103 & 0.432 \\
\hline$P_{u}$ & 0.0029 & $1.2 E-5$ & 0.0023 & $9.8 \mathrm{E}-6$ & $<0.033$ & $<1.4 E-4$ & 0.0031 & $1.28 \mathrm{E}-5$ \\
\hline $\mathrm{Zn}$ & 0.487 & 0.0074 & 0.273 & 0.0042 & 0.139 & 0.002 & 0.0122 & 0.0002 \\
\hline $\mathrm{TIC}(\mathrm{HCO})$ & 10.40 & 0.865 & 14.60 & 1.216 & - & - & - & - \\
\hline $\mathrm{Cl}$ & 0.504 & 0.014 & 0.727 & 0.021 & 4.7 & 0.133 & 2.67 & 0.075 \\
\hline NO3 & 3.99 & 0.064 & 0.419 & 0.068 & 158 & 2.54 & 17.4 & 0.281 \\
\hline S04 & 5.22 & 0.054 & 27.1 & 0.282 & 22.55 & 0.234 & $<13.9$ & $<0.144$ \\
\hline $\mathrm{pH}$ & $7.68 \mathrm{SU}$ & & $7.67 \mathrm{SU}$ & & $4.41 \mathrm{SU}$ & & $6.06 \mathrm{SU}$ & \\
\hline Cations & $\begin{array}{l}1.212 \\
\mathrm{meq} / 1\end{array}$ & & $\begin{array}{l}2.353 \\
\mathrm{meq} / 1\end{array}$ & & $\begin{array}{l}2.797 \\
\mathrm{meq} / 1\end{array}$ & & $\begin{array}{l}0.957 \\
\text { meq/1 }\end{array}$ & \\
\hline Anions & $\begin{array}{l}1.052 \\
\text { meq/1 }\end{array}$ & & $\begin{array}{l}1.869 \\
\mathrm{meq} / 1\end{array}$ & & $\begin{array}{l}3.242 \\
\mathrm{meq} / 1\end{array}$ & & $\begin{array}{l}0.356 \\
\text { meq } / 1\end{array}$ & \\
\hline Charge Balance & $\begin{array}{l}+0.160 \\
\text { meg } / 1\end{array}$ & & $\begin{array}{l}+0.484 \\
\mathrm{meq} / 1\end{array}$ & & $\begin{array}{l}-0.345 \\
\mathrm{meq} / 1\end{array}$ & & $\begin{array}{l}+0.601 \\
\mathrm{meq} / 1\end{array}$ & \\
\hline $\begin{array}{l}\text { Stoichiometric } \\
\text { Ionic Strength }\end{array}$ & 0.0017 & & 0.0034 & & 0.0045 & & 0.0011 & \\
\hline
\end{tabular}

Basin floor Sample: KES-M-13, Weasel pit sample: KES-T-20

$\mathrm{Ag}, \mathrm{Cd}, \mathrm{Cr}$, $\mathrm{Cu}$, and $\mathrm{Mn}:<0.2 \mathrm{mg} / 1$; $\mathrm{Ba}$ and $\mathrm{Fe}:<1.0 \mathrm{mg} / 1 ; \mathrm{Mg}, \mathrm{Pb}, \mathrm{Sm}$, and $\mathrm{Zr}:<2.0$ $\mathrm{mg} / 1$; Be: $<0.1 \mathrm{mg} / 1$; $\mathrm{CN}:<0.055 \mathrm{mg} / 1$; TOC. TC: $<40 \mathrm{mg} / 1: \mathrm{NH}_{3}: 5 \mathrm{mg} / 1, \mathrm{NO}_{2}:<1.87 \mathrm{mg} / 1$ Source: Interim Chemical and Radiochemical Analytical Report of KE Basin Sludge WHCSD-SNF-DP-004, Rev 1. 1995.

Interim Chemical and Radiochemical Characterization of $105 \mathrm{KE}$ Basin Canister Sludge WHIC-SD-WM-DP-228, Rev 0. 1997.

concentrations of dissolved $U(\sim 100$ to $300 \mathrm{mg} / 1)$ which constitute the principal cationic constituent. Nitrate is the anionic constituent in these water samples. Minor amounts of $\mathrm{SO}_{4}$ and trace concentrations of $\mathrm{Cl}$ were also measured in these samples. The $\mathrm{pH}$ measurements indicate about one and a half to three orders of magnitude more acidity in canister water samples as compared to the decantates from basin and pit sludges. These significantly higher acidities and $\mathrm{NO}_{3}$ concentrations may reflect the effects of alpha 
HNF-SD-WM-ES-409, Rev. 0

radiolysis. Experimental data indicate that alpha radiolysis in aqueous solutions result in the production of $\mathrm{HNO}_{3}$ with concomitant increase in acidity (decreasing $\mathrm{pH}$ ) and $\mathrm{NO}_{3}$ concentrations (Rai et al. 1980). The charge balance calculations showed an excess anionic charge for sample 96-05 and an excess cationic charge for the sample 96-01. The TIC or TOC for these samples were not determined therefore it is difficult to resolve the source of these unbalanced charges.

Uranium and $\mathrm{pH}$ data from these analyses were used to indirectly determine the solubility-controlling $U$ solid phases in the sludge material (section A.2.2.3.4). Equilibrium solubilities of schoepite/metaschoepite and uraninite phases as a function of $\mathrm{pH}$ have been determined by a number of investigators (Gayer and Leider. 1955, 1957; Bruno et a1., 1987; Ryan and Rai, 1983; Rai et a1., 1990). These solubility data (see Figure A.2.2) indicate that at $\mathrm{pH}$ values of the samples (4.4 to 7.7 , see Table A.2.1), schoepite/metaschoepite $\left(\mathrm{UO}_{3} \cdot 2 \mathrm{H}_{2} \mathrm{O}\right)$ has about four orders of magnitude greater solubility than uraninite $\left(\mathrm{UO}_{2}\right)$. It is seen from the figure that the compositions of interstitial waters from basin and pit sludges, and the two samples of water from the KE canisters appear to represent the equilibrium solubility of the schoepite/metaschoepite $\left(\mathrm{UO}_{3} \cdot 2 \mathrm{H}_{2} \mathrm{O}\right)$ mineral. Such a

solubility constraint suggests that the dissolved $U$ in these water samples may exist in hexavalent state. Additionally, it appears that $U$ solubility in these sludges are being controlled by the solubility of schoepite/ metaschoepite $\left(\mathrm{UO}_{3} \cdot \mathrm{2H}_{2} \mathrm{O}\right)$ like mineral phase rather than by other $U$ bearing phases that are also present in these sludges.

\section{A.3.4 Uranium and Iron Bearing Minerals Identified in KE Basin Siudges}

\section{A.3.4.1 Basin Floor and Weasel Pit Sludges}

Sixteen samples of sludge from the $K$ East basin floor and weasel pit. and twe lve samples of sludge from spent fuel storage canisters were analyzed by X-ray diffraction (XRD) analysis to identify the crystalline phases (Silvers et a1., 1995, 1997). Two of the floor and pit sludges were also examined by transmission electron microscopy (TEM) coupled with electron diffraction and energy dispersive X-ray analysis. The data obtained from both $X R D$ and TEM analyses show that both $U$ and $F e$ in these sludges exist as one or more crystalline phases (see Table A.3.4 for detaj7s). However, a comparison of the types of U-bearing minerals identified by XRD and TEM (see Table A.3.5) shows no agreement between the data generated by the two techniques. Among $\mathrm{Fe}$ - bearing minerals only goethite was identified by both these techniques. 


\section{HNF-SD-WM-ES-409, Rev. 0}

Identification of other Fe bearing minerals by these two techniques are also mutually exclusive.

Uraninite $\left(\mathrm{UO}_{2}\right)$ appears to be a ubiquitous phase being identified in thirteen of the sludge samples. Studtite, a U(VI) peroxide phase was found in several samples of floor and pit sludges and also as a corrosion product on the surfaces of spent fuel elements. X'RD analysis indicated that a. schoepite/metaschoepite type phase $\left(\mathrm{UO}_{3} \cdot \mathrm{2H}_{2} \mathrm{O}\right)$ occurred in four canister sludge samples (see Table A.3.4 for details). It is important to note that the original XRD data identified an $U$ oxide phase $\left(U_{4} \mathrm{O}_{9}\right)$ with the International Center for Diffraction Data (ICDD) card number 20-1344 (Silvers et a1., 1997) as the best match for the observed diffraction pattern. Our recent check of ICDD data base showed that the data for $\mathrm{U}_{4} \mathrm{O}_{9}$ has been superseded by the diffraction data for a uraninite phase with the ICDD card number 41-1422.

Transmission electron microscopic examination of one each of basin (KESM-13), and pit (KES-T-20) samples showed tabular (two dimensions that are much larger or longer than the third) particles ranging in size from $0.01 \times 1 \mu \mathrm{m}$ to $0.4 \times 4 \mu \mathrm{m}$ (Figures 1.5, 2.5, and 3.7 in Silvers et al. 1995). These Ubearing particles were reported as amorphous material. However, these particles with tabular morphology and indicated size distinctly resemble the scanning electron micrograph of synthetic uranium peroxide studied by Cordfunke and Van Der Giessen (1963, refer to Figure 1 of reference). 
Table A.3.4. Solid Phases of U and Fe Identified in KE Basin Floor and Weasel Pit STudge Samples Using XRD and TEM.

\begin{tabular}{|c|c|c|c|c|}
\hline Sample & Solid Phase U & $\begin{array}{l}\text { Conc. of } U \text { in dried } \\
\text { sludge }(\% \mathrm{wt})^{*}\end{array}$ & Solid Phase Fe & $\begin{array}{l}\text { Conc. of } \mathrm{Fe} \text { in dried } \\
\text { sludge (\% wt) }\end{array}$ \\
\hline KES-L-1 & $\mathrm{UO}_{3}\left(\mathrm{H}_{2} \mathrm{O}_{2}\right) \cdot 3 \mathrm{H}_{2} \mathrm{O}$ & $32.7 . \quad 43.7$ & $\begin{array}{l}\alpha \text {-FeOOH } \\
\gamma \text {-FeOOH }\end{array}$ & 8.15 \\
\hline KES-A-2 & $\begin{array}{l}\mathrm{UO}_{3}\left(\mathrm{H}_{2} \mathrm{O}_{2}\right) \cdot 3 \mathrm{H}_{2} \mathrm{O} \\
\mathrm{UO}_{2}\end{array}$ & 5.08 .6 .06 & & 30.9 \\
\hline KES-B-3 & $\begin{array}{l}\mathrm{CaU}_{6} \mathrm{O}_{19}, 12 \mathrm{H}_{2} \mathrm{O} \\
\mathrm{K}_{2} \mathrm{UO}_{4}\end{array}$ & $16.8,14.4$ & $\begin{array}{l}\alpha-\mathrm{FeOOH} \\
\gamma-\mathrm{FeOOH}\end{array}$ & 16.2 \\
\hline KES-C-4 & $\mathrm{vO}_{2}$ & $7.1, \quad 12.8$ & & 22.7 \\
\hline KES-N-5 & $\mathrm{UO}_{3}\left(\mathrm{H}_{2} \mathrm{O}_{2}\right) \cdot 3 \mathrm{H}_{2} \mathrm{O}$ & 10.1 .11 .8 & & 16.9 \\
\hline KES-J-6 & & $5.78,6.39$ & $\begin{array}{l}\alpha-\mathrm{FeOOH} \\
\gamma-\mathrm{FeOOH}\end{array}$ & 40.7 \\
\hline KES-H-8 & & $0.31 \cdot 0.25$ & & 1.51 \\
\hline KES-0-9 & $\mathrm{UO}_{2}$ & 32.1 & & \\
\hline KES-F-10 & & $2.51 . \quad 2.30$ & $\begin{array}{l}\alpha-\mathrm{FeOOH} \\
\mathrm{Y}-\mathrm{FeOOH} \\
\mathrm{Li}_{2} \mathrm{NiFe}_{2} \mathrm{O}_{4}\end{array}$ & 39.8 \\
\hline KES-E-11 & & $10.1,10.2$ & $\begin{array}{l}\alpha-F e 00 H \\
\gamma-F e O O H\end{array}$ & 27.7 \\
\hline KES-K-12 & & $3.18,3.28$ & $\begin{array}{l}\alpha-\mathrm{FeOOH} \\
Y-\mathrm{FeOOH} \\
\mathrm{Li}_{2} \mathrm{NiFe}_{2} \mathrm{O}_{4}\end{array}$ & 37.8 \\
\hline KES-M-13 & $\begin{array}{l}\text { Am. } U \\
\text { material } \\
\beta-\mathrm{U}_{3} \mathrm{O}_{8} \\
\mathrm{UF}_{4}-1.5 \mathrm{H}_{2} \mathrm{O}\end{array}$ & & $\begin{array}{l}\text { An. Fe } \\
\text { material } \\
\beta-F e 00 H \\
\delta \text {-FeOOH }\end{array}$ & \\
\hline KES-I-15 & & $3.04, \quad 3.27$ & $\begin{array}{l}\alpha-\mathrm{FeOOH}_{2} \\
\mathrm{LiCuFe}_{2} \mathrm{O}_{4}\end{array}$ & 37.4 \\
\hline KES-P-16 & & 9.64. 11.2 & $\gamma-\mathrm{Fe} O \mathrm{OH}$ & 34.6 \\
\hline KES-Q-17 & & 7.27 .7 .33 & $\alpha-\mathrm{FeOOH}$ & 16.7 \\
\hline KES-R-18 & & 2.35. 1.99 & $\begin{array}{l}\alpha-\mathrm{FeOOH} \\
\gamma-\mathrm{FeOOH}\end{array}$ & 44.6 \\
\hline KES-S-19 & & 5.36 & $\begin{array}{l}\alpha-\mathrm{FeOOH} \\
\gamma-\mathrm{FeOOH}\end{array}$ & 25.9 \\
\hline KES-T-20 & $\begin{array}{l}\text { Am. } U \\
\text { material } \\
\mathrm{B}_{-}-\mathrm{U}_{3} \mathrm{O}_{8} \\
\mathrm{UF}_{4}-1.5 \mathrm{H}_{2} \mathrm{O}\end{array}$ & & $\begin{array}{l}\text { Am. Fe } \\
\text { material } \\
\alpha-\mathrm{FeOOH} \\
\mathrm{B}-\mathrm{FeOOH} \\
\mathrm{Y}^{-} \mathrm{Fe}_{2} \mathrm{O}_{3} \\
\mathrm{Fe}_{3} \mathrm{O}_{4}\end{array}$ & 24.5 \\
\hline
\end{tabular}




\section{Table A.3.4 (cont.)}

Source: Silvers (1996). A11 samples were analyzed by XRO except samples KES- M-13, and KES-T-20 which were analyzed by TEM.

ND: Crystalline phases not detected.

*U concentration in these sludges were measured by both $X$-ray fluorescence and by ICP following dissolution.

Fe concentrations were measured by ICP (Makenas, 1996).

Table A.3.5 Comparison of XRD and TEM Identification of $U$ and Fe Solid Phases in KE-Basin Floor and Pit Sludges

XRD

$\mathrm{UO}_{2}$ (Uraninite)

$\mathrm{UO}_{3}\left(\mathrm{H}_{2} \mathrm{O}_{2}\right) \quad 3 \mathrm{H}_{2} \mathrm{O}$ (Studtite)

$\mathrm{CaU}_{6} \mathrm{O}_{19} 12 \mathrm{H}_{2} \mathrm{O}$

$\mathrm{K}_{2} \mathrm{UO}_{4}$

$\alpha-\mathrm{FeOOH}$ (Goethite)

$\mathrm{Y}$-FeOOH (Lepidocrocite)

$\mathrm{Li}_{2} \mathrm{NiFe}_{2} \mathrm{O}_{4}$
TEM-ED

Amorphous $U$ material

$\mathrm{B}^{-} \mathrm{U}_{3} \mathrm{O}_{8}$

$\mathrm{UF}_{4} 1.5 \mathrm{H}_{2} \mathrm{O}$

Amorphous Fe material
$\quad \alpha-\mathrm{FeOOH}$ (Goethite)
$\beta-\mathrm{Fe} 0 \mathrm{OH}$ (Akaganeite)
$\delta-\mathrm{FeOOH}$ (Feroxyhyte)
$\mathrm{Y}^{-} \mathrm{Fe}_{2} \mathrm{O}_{3}$ (Maghemite)
$\mathrm{Fe}_{3} \mathrm{O}_{4}$ (Magnetite)

Moreover. U-peroxide phase was identified in three basin sludge samples using XRD (see Table A.3.4). Therefore, it appears that the tabular material observed by TEM in samples KES-M-13, and KES-T-20 are probably the U-peroxide particles.

Presence of a mixed valent $\mathrm{U}$-oxide phase namely $\beta-\mathrm{U}_{3} \mathrm{O}_{8}$ with a platy (shaped like plates) morphology was observed by TEM (Figure 1.12 in Silvers et a1.. 1995). Because this crystalline phase was not identified by XRD, in any of the other 16 sludge samples it is most likely that the $\beta-U_{3} \mathrm{O}_{8}$ mineral may be present as a minor phase in these sludges. Similarly, a hydrated Ufluoride phase $\left(\mathrm{UF}_{4} \cdot 1.5 \mathrm{H}_{2} \mathrm{O}\right)$ with acicular (needle-shaped) morphology was observed by TEM analyses (Fig 2.11 in Silvers et a1.: 1995). The average $F$ content of dried sludge is $1.08 \mu \mathrm{g} / \mathrm{g}(0.0001 \%)$. If we assume that all of the $\mathrm{F}$ in the sludge is associated with $\mathrm{U}$ in the form of $U \mathrm{~F}_{4} \cdot 1.5 \mathrm{H}_{2} \mathrm{O}$, the total content of this crystalline phase in the dried sludge would be an 
HNF -SD-WM-ES-409, Rev, 0

insignificant $0.00049 \%$. Therefore, even if it is present in these sludge samples, the $\mathrm{UF}_{4} \cdot 1 \cdot 5 \mathrm{H}_{2} \mathrm{O}$ phase is inconsequential as far as influencing any physical and chemical properties of these sludges.

Goethite and lepidocrocite were two of the most common Fe-oxyhydroxide minerals that were identified in basin and pit sludge samples (Table A.3.4). Among the eighteen samples of basin and pit sludges, goethite occurred in 11 samples and lepidocrocite was reported in 9 samples.

Presence of goethite and lepidocrocite were also detected in some of the canister sludge samples. Transmission electron microscopy data indicated that the basin (KES-M-13) and pit (KES-T-20) sludge samples contained amorphous Fe material. The electron micrographs of this material indicate that this Febearing phase is somewhat similar to microcrystalline (nm size) 2-line ferrihydrite characterized by Schwertmann and Corne11 (see Figure 8-2, 1991).

TEM data also indicate that other Fe-bearing phases such as akaganeite. feroxyhte, maghemite, and magnetite are present in the basin (KES-M-13) and pit (KES-T-20) sludge samples. Because these phases were not detected by XRD in any of the other 16 basin and pit sludge samples, we can conclude that these crystalline phases probably constitute only a minor or a trace fraction of the basin and pit sludge mass.

\section{A.3.4.2 Canister STudges}

Identification of $U$ and $F e$ bearing solid phases in $K$ East basin canister sludges conducted by XRD (Silvers 1997) are listed in Table A.3.6. Five of these sludge samples apparently contain three different U-bearing phases namely $\cup_{2}, U_{4} \mathrm{O}_{9}$, and $\mathrm{U}_{3} \mathrm{O}_{7}$, . Four other sludge samples apparently consist of four $\mathrm{U}$-bearing solid phases $\left(\mathrm{UO}_{2}, \mathrm{U}_{4} \mathrm{O}_{9}, \mathrm{U}_{3} \mathrm{O}_{7}\right.$, and $\left.\mathrm{UO}_{3} \cdot 2 \mathrm{H}_{2} \mathrm{O}\right)$. According to Silvers (1997), $\mathrm{UO}_{2}, \mathrm{U}_{4} \mathrm{O}_{9}$, and $\mathrm{U}_{3} \mathrm{O}_{7}$ phases have very simi $7 \mathrm{ar}$ XRD patterns and cannot be distinguished from each other. However, $\mathrm{U}_{4} \mathrm{O}_{9}$ is indicated to provide the best fit for the measured XRD data. Four Fe-containing minerals $\alpha$ - (FeOOH, $\mathrm{Y}-\mathrm{FeOOH}, \mathrm{Y}-\mathrm{Fe}_{2} \mathrm{O}_{3}$, and $\mathrm{Fe}_{3} \mathrm{O}_{4}$ were identified in one (96-09) of the canister sludge samples. Lepidocrocite $(\gamma-\mathrm{FeOOH})$, and $\gamma-\mathrm{Fe}_{2} \mathrm{O}_{3}$ were identified in 9611-L sludge sample (sample 96-11 was taken from an empty canister). These data indicate solid phase composition of canister sludges are dominated mainly by the $U$ metal corrosion products. 
HNF-SD-WM-ES-409, Rev. 0

Table A.3.6. Solid Phases of $U$ and Fe Identified in $K$ East Basin Canister Sludge Samples Using $X$-ray Diffraction

\begin{tabular}{|c|c|c|c|}
\hline Sample & Solid Phase U & U Conc. ( $\%$ wt) & Solid Phase Fe \\
\hline $96-01$ & $\begin{array}{l}\mathrm{UO}_{2} \\
\mathrm{U}_{4} \mathrm{O}_{9} \\
\mathrm{U}_{3} O_{9}\end{array}$ & 82.3 & \\
\hline 96-01-MAG & & & $\begin{array}{l}\alpha-\mathrm{FeOOH} \\
\gamma-\mathrm{Fe}_{2} \mathrm{O}_{3} \\
\mathrm{Fe}_{3} \mathrm{O}_{4} \\
\mathrm{FeCr}_{2} \mathrm{O}_{4}\end{array}$ \\
\hline $96-04-\mathrm{L}$ & $\begin{array}{l}\mathrm{UO}_{2} \\
\mathrm{U}_{4} \mathrm{O}_{9} \\
\mathrm{U}_{3} \mathrm{O}_{9} \\
\mathrm{OO}_{3} \cdot 2 \mathrm{H}_{2} \mathrm{O} .\end{array}$ & 54.6 & \\
\hline 96-04-Flakes* & $\mathrm{UO}_{3} \cdot 2 \mathrm{H}_{2} \mathrm{O}$ & & \\
\hline $96-04-U$ & $\begin{array}{l}\mathrm{UO}_{2} \\
\mathrm{U}_{4} \mathrm{O}_{9} \\
\mathrm{U}_{3} \mathrm{O}_{7} \\
\mathrm{UO}_{3} \cdot 2 \mathrm{H}_{2} \mathrm{O}\end{array}$ & & \\
\hline $96-05$ & $\begin{array}{l}\mathrm{UO}_{2} \\
\mathrm{U}_{4} \mathrm{O}_{9} \\
\mathrm{U}_{3} \mathrm{O}_{7} \\
\mathrm{UO}_{3} \cdot 2 \mathrm{H}_{2} \mathrm{O}\end{array}$ & 88.1 & \\
\hline $96-06-L$ & $\begin{array}{l}\mathrm{UO}_{2} \\
\mathrm{U}_{4} \mathrm{O}_{9} \\
\mathrm{U}_{3} 0_{7}\end{array}$ & 84.3 & \\
\hline $96-06-M$ & $\begin{array}{l}\mathrm{UO}_{2} \\
\mathrm{U}_{4} \mathrm{O}_{9} \\
\mathrm{U}_{3} \mathrm{O}_{7} \\
\mathrm{UO}_{3} \cdot 2 \mathrm{H}_{2} \mathrm{O}\end{array}$ & 82.6 & \\
\hline $96-08$ & $\begin{array}{l}\mathrm{UO}_{2} \\
\mathrm{U}_{4} \mathrm{O}_{9} \\
\mathrm{U}_{3} \mathrm{O}_{7}\end{array}$ & 40.4 & \\
\hline $96-09$ & & 8.8 & $\begin{array}{l}\alpha-\mathrm{FeOOH} \\
\gamma-\mathrm{FeOOH} \\
\gamma-\mathrm{FeOH}_{2} \\
\mathrm{Fe}_{3} \mathrm{O}_{4}\end{array}$ \\
\hline 96-09-Flakes & & & $\mathrm{Fe}_{3} \mathrm{O}_{4}$ \\
\hline $96-11-\mathrm{L}$ & & 9.3 & 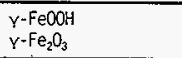 \\
\hline $96-13-1$ & $\begin{array}{l}\mathrm{UO}_{2} \\
\mathrm{U}_{4} \mathrm{O}_{9} \\
\mathrm{U}_{3} \mathrm{O}_{7}\end{array}$ & 73.2 & \\
\hline $96-13-2$ & $\begin{array}{l}\mathrm{UO}_{2} \\
\mathrm{U}_{4} \mathrm{O}_{9} \\
\mathrm{U}_{3} \mathrm{O}_{7}\end{array}$ & 90.8 & \\
\hline $96-15$ & $\begin{array}{l}\mathrm{UO}_{2} \\
\mathrm{U}_{4} \mathrm{O}_{9} \\
\mathrm{U}_{3} \mathrm{O}_{7} \\
\end{array}$ & 81.3 & \\
\hline
\end{tabular}


Table A.3.6. (cont).

Data Source for XRD and U analyses: Silvers (1997).

ND: Crystalline phases not detected.

* $\mathrm{Zr}$-hydrides $\left(\mathrm{ZrH}\right.$ and $\left.\mathrm{Z} \mathrm{rH}_{1,66}\right)$ and metallic $\mathrm{Zr}$ were also identified in this sample.

$\mathrm{UO}_{3}\left(\mathrm{H}_{2} \mathrm{O}_{2}\right) \cdot 3 \mathrm{H}_{2} \mathrm{O}$ and $\mathrm{UO}_{3}\left(\mathrm{H}_{2} \mathrm{O}_{2}\right) \cdot \mathrm{H}_{2} \mathrm{O}$ were identified as corrosion products on the surfaces of fuel elements(Marschman and Abrefah. 1997).

\section{A.3.5 Sludge and Particle Densities}

The densities of al1 $\mathrm{U}$ and Fe bearing crystal7ine minerals that were identified in the basin floor, pit. and canister sludges are listed in Table A.3.7. The U-bearing minerals show a wide range of density differences $(3.58$ to 10.98) depending on their structures and composition. Iron bearing minerals exhibit a narrower range in densities that vary from 3.56 to 5.18.

Table A.3.7. Densities of $U$ and Fe Minerals present in KE Basin Floor. Pit and Canister Sludges.

\begin{tabular}{|c|c|c|c|}
\hline U Mineral & $\begin{array}{l}\text { Densit } \\
\text { y } \mathrm{g} / \mathrm{ml}\end{array}$ & Fe Mineral & $\begin{array}{l}\text { Density } \\
\mathrm{g} / \mathrm{ml}\end{array}$ \\
\hline $\begin{array}{l}\mathrm{UO}_{3}\left(\mathrm{H}_{2} \mathrm{O}_{2}\right) \quad 3 \mathrm{H}_{2} \mathrm{O} \\
\text { (Studtite) }\end{array}$ & 3.58 & $\alpha-\mathrm{FeOOH}$ (Goethite) & 4.26 \\
\hline $\mathrm{UO}_{2}$ (Uraninite) & 10.98 & $\beta$-Fe0OH (Akageneite) & 3.56 \\
\hline $\mathrm{UO}_{3} 2 \mathrm{H}_{2} \mathrm{O}$ (Schoepite) & 4.83 & $\begin{array}{l}Y^{-} \\
\text {FeOOH(Lepidocrocite) }\end{array}$ & 4.09 \\
\hline $\begin{array}{l}\mathrm{UO}_{3} 2 \mathrm{H}_{2} \mathrm{O} \\
\text { (Metaschoepite) }\end{array}$ & 5.00 & $\delta$-FeOOH (Feroxyhyte) & 4.20 \\
\hline $\mathrm{B}-\mathrm{U}_{3} \mathrm{O}_{8}$ & 8.33 & $\gamma-\mathrm{Fe}_{2} \mathrm{O}_{3}$ (Maghemite) & 4.87 \\
\hline $\mathrm{K}_{2} \mathrm{UO}_{4}$ & 5.10 & $\mathrm{Fe}_{3} \mathrm{O}_{4}$ (Magnetite) & 5.18 \\
\hline $\mathrm{UF}_{4} 1.5 \mathrm{H}_{2} \mathrm{O}$ & 6.12 & $\mathrm{FeCr}_{2} \mathrm{O}_{4}$ (Chromite) & $4.5-4.8$ \\
\hline
\end{tabular}


The densities of dried canister sludge samples were determined by Silvers et a1. (1997). The sludge densities and the mineral phases identified in these samples are 7 isted in Table A.3.8. Comparing the mineral densities listed in Table A.3.7 with the mineral phases and sludge density of each sample, and assuming that the sludge samples consist mainly of crystalline phases leads to the conclusion that for these data to be consistent, about $70 \%$ by mass of the 96-06. L sludge sample has to be made up of the mineral, uraninite. Similarly, the sludge sample 96-06-M is estimated to contain about $35 \%$ by mass of uraninite with the remaining mass accounted for by the mineral schoepite. Further, schoepite would account for almost 217 of the sludge sample 96-04-L, whereas. lepidicrocite seems to be the main crystalline phase in sludge sample $96-11-\mathrm{L}$.

Table A.3.8. Crystalline Mineral Mass Estimated from Sludge and Mineral Densities

\begin{tabular}{|c|c|c|c|c|}
\hline $\begin{array}{l}\text { Sludge } \\
\text { Sample }\end{array}$ & $\begin{array}{l}\text { Phases } \\
\text { Identified }\end{array}$ & $\begin{array}{l}\text { Dried } \\
\text { Sludge } \\
\text { Density } \\
\mathrm{g} / \mathrm{m} 7\end{array}$ & $\begin{array}{l}\text { Dominant } \\
\text { based on } \\
\text { Densities }\end{array}$ & Phases \\
\hline $96-04-L$ & $\begin{array}{l}\mathrm{UO}_{3} 2 \mathrm{H}_{2} \mathrm{O} \\
\mathrm{UO}_{2}\end{array}$ & 4.76 & $\mathrm{UO}_{3} 2 \mathrm{H}_{2} \mathrm{O}$ & $-100 \%$ \\
\hline $96-06-L$ & $\mathrm{UO}_{2}$ & 7.88 & $\mathrm{UO}_{2}$ & $\sim 70 \%$ \\
\hline $96-06-M$ & $\begin{array}{l}\mathrm{UO}_{3} 2 \mathrm{H}_{2} \mathrm{O} \\
\mathrm{UO}_{2}\end{array}$ & 6.90 & $\begin{array}{l}\mathrm{UO}_{3} 2 \mathrm{H}_{2} \mathrm{O} \\
\mathrm{UO}_{2}\end{array}$ & $\begin{array}{l}\sim 65 \% \\
\sim 35 \%\end{array}$ \\
\hline 96-11-L & $\begin{array}{l}\gamma-\mathrm{FeOOH} \\
\gamma-\mathrm{Fe}_{2} \mathrm{O}_{3}\end{array}$ & 3.49 & $\begin{array}{c}\gamma-\mathrm{Fe} 0 \mathrm{OH} \\
\gamma-\mathrm{Fe}_{2} \mathrm{O}_{3}\end{array}$ & $\begin{array}{r}\sim 70 \% \\
\sim \quad 10 \%\end{array}$ \\
\hline
\end{tabular}


HNF-SD-WM-ES-409, Rev. 0

\section{A.3.6 Corrosion Reactions and Products}

A comparison between the $U$ and $F e$ corrosion products identified in these canister sludge samples with known corrosion mechanisms and pathways will provide some information about dominant corrosion reactions and transformations within the storage basin environment. Corrosion of metal1ic. U can occur by hydride formation and oxidation (Katz and Rabinowitz 1951) as follows.

$$
\mathrm{U}(\text { meta } 1)+2 \mathrm{H}_{2} \mathrm{O} \rightarrow \mathrm{UO}_{2} \text { (uraninite) }+2 \mathrm{H}_{2}
$$

The hydrogen accelerates the corrosion process through hydride formation (Katz and Rabinowitz. 1951; Vdovenko, 1960)

$$
\begin{aligned}
& \mathrm{U}(\text { metal })+2 \mathrm{H}_{2} \rightarrow \mathrm{UH}_{3}+\mathrm{H}^{+-} \\
& \mathrm{UH}_{3}+4 \mathrm{OH}^{-}(\mathrm{aq})-\mathrm{UO}_{2} \text { (uraninite) }+2 \mathrm{H}_{2} \mathrm{O}+1.5 \mathrm{H}_{2}(\mathrm{~g})+6 e-
\end{aligned}
$$

Because $\mathrm{UH}_{3}$ was not detected in any of the sludge samples, its oxidative dissolution under storage basin conditions appears to be kinetically a fast reaction. Hydrolysis of aqueous tetravalent $U$ under near neutral $\mathrm{pH}$ conditions can also occur extremely rapidly and this reaction can be represented by,

$$
\mathrm{U}^{4+}(\mathrm{aq})+4 \mathrm{HH}^{-}(\mathrm{aq}) \rightarrow \mathrm{U}(\mathrm{OH})_{4}{ }^{0}(\mathrm{aq})
$$

Following hydrolysis, a uraninite phase can precipitate as follows.

$$
\mathrm{U}(\mathrm{OH})_{4}{ }^{0}(\mathrm{aq})-\mathrm{UO}_{2} \text { (uraninite) }+2 \mathrm{H}_{2} \mathrm{O}
$$

Uraninite can oxidize to form mixed valence state oxide phases (such as $\mathrm{U}_{3} \mathrm{O}_{8}$ reported to be present in two of the sludge samples) and finally into a schoepite/metaschoepite phase,

$$
\begin{aligned}
& 3 \mathrm{UO}_{2} \text { (uraninite) }+2 \mathrm{H}_{2} \mathrm{O} \rightarrow \mathrm{U}_{3} \mathrm{O}_{8}\left(\text { solid) }+4 \mathrm{H}^{+}(\mathrm{aq})+4 \mathrm{e}^{-}\right. \\
& \mathrm{U}_{3} \mathrm{O}_{8}\left(\text { solid) }+3 \mathrm{H}_{2} \mathrm{O} \rightarrow 3 \mathrm{UO}_{3} \cdot 2 \mathrm{H}_{2} \mathrm{O} \text { (schoepite) }+4 \mathrm{H}^{+}(\mathrm{aq})+2 \mathrm{e}^{-}\right.
\end{aligned}
$$

Additional1y, from radiolysis, a strong oxidant such as $\mathrm{H}_{2} \mathrm{O}_{2}$ is known to form in the aqueous medium. If radiolysis is intense enough to produce sufficient concentrations of this oxidant. or if $\mathrm{H}_{2} \mathrm{O}_{2}$ is added to these corrosion products, a peroxide phase (studtite) has been known to form from these phases.

$$
\mathrm{UO}_{2} \text { (uraninite) }+\mathrm{H}_{2} \mathrm{O}_{2}+4 \mathrm{H}_{2} \mathrm{O} \rightarrow \mathrm{UO}_{3}\left(\mathrm{H}_{2} \mathrm{O}_{2}\right) 3 \mathrm{H}_{2} \mathrm{O} \text { (studtite) }+2 \mathrm{H}^{+}(\mathrm{aq})+2 \mathrm{e}^{-}
$$


HNF-SD-WM-ES-409, Rev. 0

$$
\begin{aligned}
& \mathrm{U}_{3} \mathrm{O}_{8} \text { (solid) }+3 \mathrm{H}_{2} \mathrm{O}_{2}+10 \mathrm{H}_{2} \mathrm{O}-3 \mathrm{UO}_{3}\left(\mathrm{H}_{2} \mathrm{O}_{2}\right) 3 \mathrm{H}_{2} \mathrm{O} \text { (studtite) }+2 \mathrm{H}^{+} \text {(aq) }+2 \mathrm{e}^{-} \\
& \mathrm{UO}_{3} \cdot 2 \mathrm{H}_{2} \mathrm{O} \text { (schoepite) }+\mathrm{H}_{2} \mathrm{O}_{2}+\mathrm{H}_{2} \mathrm{O} \rightarrow \mathrm{UO}_{3}\left(\mathrm{H}_{2} \mathrm{O}_{2}\right) 3 \mathrm{H}_{2} \mathrm{O} \text { (studtite) }
\end{aligned}
$$

Currently, data about the kinetics of these reactions are not available. Therefore, it is difficult to assess the reaction sequence that resulted in the formation of studtite in the basin environment. However, the assemblage of major $U$ minerals that have been identified in the sludge samples is consistent with the set of products that are known to form from corrosion of metallic uranium, thus we feel confident that the thermodynamic calculations presented in chapter A.2 are useful and support our overall conclusions on the chemical aspects of criticality.

The presence of iron bearing solid phases in these sludges as corrosion products can be better understood from published literature on formation and transformation of Fe-compounds and minerals as products of corrosion. The data has been summarized by Schwertmann and Taylor (1989) and Schwertmann and Cornel1 (1991). The formation and transformation pathways for various hydrolytic iron compounds are schematically shown in Figure A.3.1. Available data (Schwertmann and Cornel1 1991) indicate that the formation of iron hydroxide, oxyhydroxide, and oxide phases depend mainly on Eh-pH conditions. presence of ligands and crystallization inhibitors, rate of oxidation, time and temperature during aging of precipitates.

Because the basin and pit sludge samples contain goethite and 1epidocrocite as the two most common Fe-bearing minerals, the major corrosion pathway in this environment appears to be via the initial formation of ferrous ion through oxidation of metallic iron. Upon hydrolysis and dependent upon the oxidation to the ferric state, $\mathrm{pH}$ conditions, and the presence of inhibitors, formation of one or more phases (ferrihydrite, green rust, magnetite, and feroxyhyte) would occur. The formation and transformation pathways shown in Figure A.3.1 indicate that all the major and trace Febearing phases that were reported to occur in the sludge samples such as, ferrihydrite, goethite, lepidocrocite, magnetite, maghemite, and feroxyhyte can originate from initial hydrolysis of ferrous iron. Therefore the only phase which appears to be inconsistent with this mineral assemblage is akageneite (reported to occur in KES-M-13). According to Schwertmann and Cornel1 (1991) the formation akageneite typically occurs from hydrolysis of ferric iron and precipitation below $\mathrm{pH}$ of 5 . Presence of chloride ions exceeding $0.1 \mathrm{M}$ in concentration is also necessary for the formation of this phase. Because the low pH and high chloride conditions have not been known to occur in the storage basin, the formation of akagenite in the basin would not be expected. 
Figure A.3.1 Formation and Transformation Pathways of Iron Corrosion Products (Adapted from Schwerman and Corne11 1991)

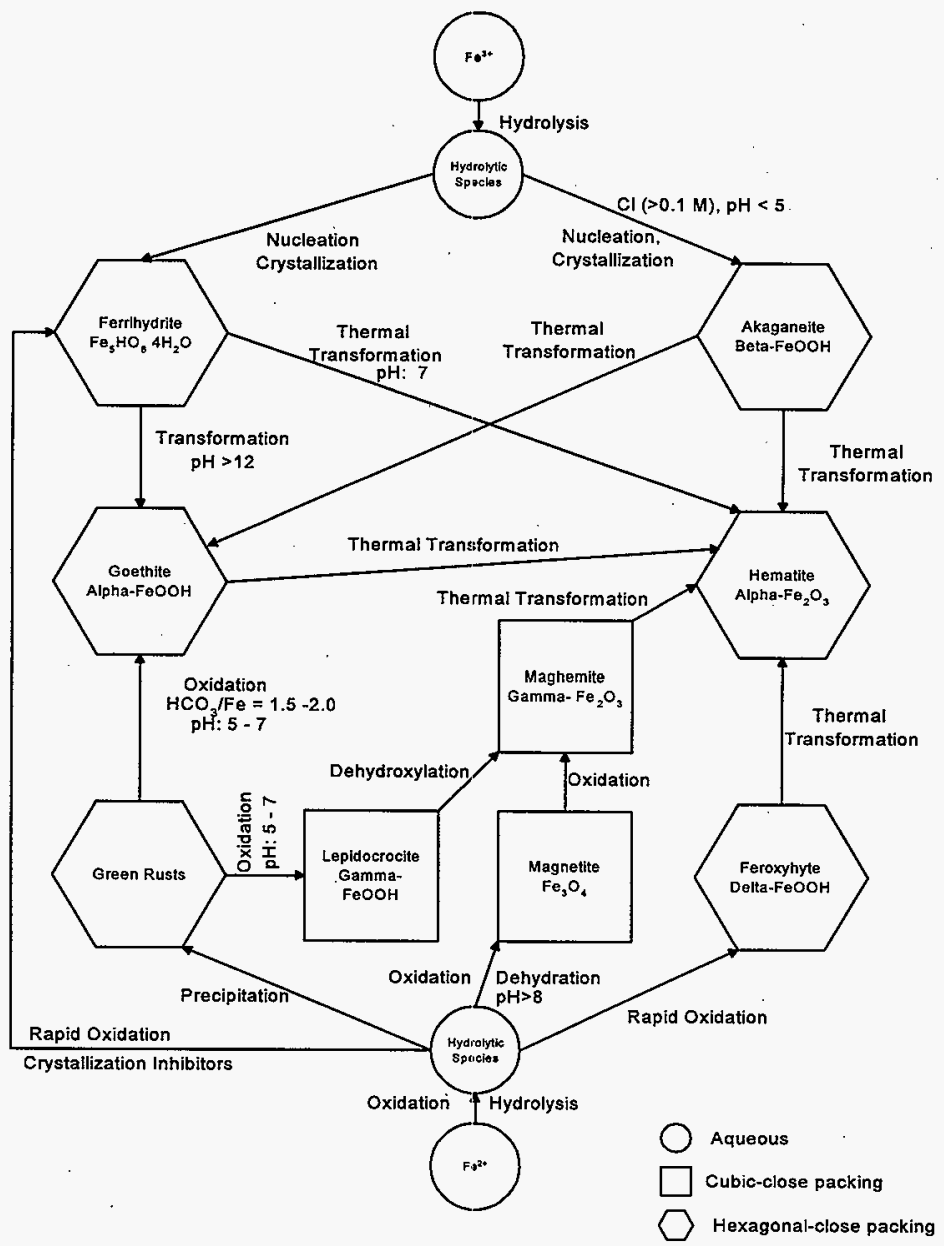




\section{A.3.7 Semiquantitative Analysis and Estimation of Crystallite Size}

$X$-ray diffraction data can be used for quantitative determination of crystalline components with appropriate standards (Bragg 1967). In the absence of standards, semiquantitative estimates of crystalline components can be obtained by the method of intensity scaling. In this method, after background subtraction, the most intense diffraction peaks of each reference crystalline component is scaled to match the most intense peaks of respective component in the experimental diffraction pattern. The scale factor derived for each component is used to calculate the mass of each crystalline phase in the sample.

The X-ray diffraction peak widths reflect the average size of crystallites in the direction normal to the set of diffracting crystallographic planes (Smith, 1989). This relationship between crystallite size and the diffraction peak width is known as the scherrer equation.

$$
D=(K \lambda) /(B \cos \theta)
$$

Where, $D=$ Crystallite size in angstroms

$K=$ Shape Constant $=0.89$

$\lambda=$ the wave length of incident $x$-rays in angstrom

$B=$ Corrected half width of the diffraction profile due to sample $\theta=$ Diffraction angle.

The semiquantitative analysis and the crystallite size determinations were conducted from previously obtained diffraction data (Silvers 1997). The value of $\lambda$ was known and $\theta$, and $B$ were determined from raw diffraction data. Prior to obtaining XRD measurements, most samples were pulverized in a "wiggle-bug" (Silvers 1995, 1997). A few samples were prepared by hand grinding (using manipulators) using a boron carbide mortar and pestle (Silvers 1995). Because of the sample preparation, crystallite sizes may have changed from the original sample prior to grinding. Diffraction data for nine KE basin and pit sludge samples, and three KE canister sludge samples were analyzed using JADE+ software.

The samples were prepared by analysis by air drying and ball milling to provide a homogenized sample with sma11, relatively uniform particle sizes (Silvers 1995). The sample preparation procedure should be considered in interpreting the results for crystallite size. However, the analysis showed (see Table A.3.7) that uraninite is microcrystalline and is a dominant mineral in canister sludges. Also, metaschoepite $(50-70 \mathrm{~nm}$ size) was found in two of the three canister sludges. Thirty five to $45 \%$ by mass of uraninite also occurs in two of the basin floor sludge samples. One of the basin floor samples (KES-N-5) seem to consist entirely of studtite with crystallites 
HNF-SD-WM-ES-409, Rev. 0

ranging from $40-60 \mathrm{~nm}$. This estimated crystallite dimension for studtite appears to match the preferentially oriented dimension (thickness) of the long rectangular shaped studitite particles observed by TEM. Alkali and alkaline earth uranates $(35-40 \%)$ such as becquere $]_{\text {te }}\left[\mathrm{Ca}\left(\mathrm{UO}_{2}\right)_{6} \mathrm{O}_{4}(\mathrm{OH})_{6} \cdot 8 \mathrm{H}_{2} \mathrm{O}\right]$ and compreignecite $\left[\mathrm{K}_{2}\left(\mathrm{UO}_{2}\right)_{6} \mathrm{O}_{4}(\mathrm{OH})_{6} \cdot 8 \mathrm{H}_{2} \mathrm{O}\right]$ were also found in two of the basin floor sludge samples with crystaliite size of about $550 \mathrm{~nm}$ and $950 \mathrm{~nm}$ respectively.

Iron corrosion products such as goethite ( 5 - $40 \%$ of bulk sample) and lepidocrocite $(5-35 \%)$ were found in a number of sludge samples. On average, crystallites of lepidocrocite were estimated to be about three to thirty times larger than goethite crystallites. In three sludge samples, $25: 30 \%$ by mass of microcrystalline (35 to $40 \mathrm{~nm}$ ) magnetite was also found with goethite and lepidocrocite. According to Schwertmann and Corne17 (1991) microcrysta77ine $(<100 \mathrm{~nm})$ magnetite formed under surface environmental conditions are typically of biogenic in origin.

These data indicate that in KE canister sludges, U corrosion products such as uraninite and metaschoepite comprise a major fraction (85 - 100\%) of the sludge mass. A7so, two of the basin floor sludge samples (KES-A-2, KES-N5) contained mainly $U$ corrosion products such as uraninite and studtite. Among the basin floor sludge samples. Fe corrosion products such as goethite and lepidocrocite typically constituted 35 to $75 \%$ of the sludge mass.

These data indicate that $\mathrm{a} 11 \mathrm{U}$ and Fe- containing minerals in basin floor, pit and canister sludges are microcrystalline in nature and that these minerals (except in one case) comprise the dominant fraction of the sludge mass. 
Table A.3.9. Semiquantitative Analysis and Crystallite Size Estimation for Samples of KE Basin Floor. Pit and Canister Sludges

\begin{tabular}{|c|c|c|c|c|c|c|}
\hline $\begin{array}{l}\text { Sample } \\
\text { Location }\end{array}$ & Solid Phase & Composition & ICOD No. & $\begin{array}{l}\text { Estimate } \\
\text { d Mass \% }\end{array}$ & Indices & $\begin{array}{l}\text { Crystallite } \\
\text { Size (nm) }\end{array}$ \\
\hline $\begin{array}{l}\text { KES-L-1 } \\
\text { Bas in Floor }\end{array}$ & $\begin{array}{l}\text { Studt ite } \\
\text { Becquerel ite } \\
\text { Goethite } \\
\text { Lepidocrocite } \\
\text { Humbol dt ine } \\
\text { Chabazite } \\
\text { Imogol ite } \\
\end{array}$ & $\begin{array}{l}\mathrm{UO}_{3}\left(\mathrm{H}_{2} \mathrm{O}_{2}\right) \cdot 3 \mathrm{H}_{2} \mathrm{O} \\
\mathrm{Ca}\left(\mathrm{UO}_{2}\right)_{6} \mathrm{O}_{4}(\mathrm{OH})_{6} \cdot 8 \mathrm{H}_{2} \mathrm{O} \\
\alpha-\mathrm{FeOOH} \\
\mathrm{Y}-\mathrm{FeOOH} \\
\mathrm{FeC}_{2} \mathrm{O}_{4} \cdot 2 \mathrm{H}_{2} \mathrm{O} \\
\mathrm{CaAl}_{2} \mathrm{Si}_{4} \mathrm{O}_{12} \cdot 6 \mathrm{H}_{2} \mathrm{O} \\
\mathrm{Al}_{2} \mathrm{SiO}_{3}(\mathrm{OH})_{4}\end{array}$ & $\begin{array}{c}16-0206 \\
39-0516 \\
29-0713 \\
8-0098 \\
23-0293 \\
34-0137 \\
38-0447\end{array}$ & $\begin{array}{l}20 \\
15 \\
15 \\
15 \\
15 \\
15 \\
5\end{array}$ & $\begin{array}{c}<110> \\
<002> \\
<110> \\
<020> \\
- \\
- \\
-\end{array}$ & $\begin{array}{c}45 \\
500 \\
25 \\
55 \\
- \\
- \\
-\end{array}$ \\
\hline $\begin{array}{l}\text { KES-A-2 } \\
\text { Bas in Floor }\end{array}$ & $\begin{array}{l}\text { Uraninite } \\
\text { Studtite } \\
\text { Compreignecite }\end{array}$ & $\begin{array}{l}\mathrm{UO}_{2} \\
\mathrm{UO}_{3}\left(\mathrm{H}_{2} \mathrm{O}_{2}\right) \cdot 3 \mathrm{H}_{2} \mathrm{O} \\
\mathrm{K}_{2}\left(\mathrm{UO}_{2}\right)_{5} \mathrm{O}_{4}(\mathrm{OH})_{6} \cdot 8 \mathrm{H}_{2} \mathrm{O}\end{array}$ & $\begin{array}{l}41-1422 \\
16-0206 \\
17-0167 \\
\end{array}$ & $\begin{array}{l}45 \\
15 \\
40 \\
\end{array}$ & $\begin{array}{l}<200> \\
<100> \\
<002>\end{array}$ & $\begin{array}{l}<10 \\
57 \\
950 \\
\end{array}$ \\
\hline $\begin{array}{l}\text { KES-B-3 } \\
\text { Bas in Floor }\end{array}$ & $\begin{array}{l}\text { Goethite } \\
\text { Lepidocrocite } \\
\text { Becquerel ite } \\
\text { Unidentified phase }\end{array}$ & $\begin{array}{l}\alpha \text {-FeOOH } \\
\gamma-\mathrm{FeOOH} \\
\mathrm{Ca}\left(\mathrm{UO}_{2}\right)_{6} \mathrm{O}_{4}(\mathrm{OH})_{6} \cdot 8 \mathrm{H}_{2} \mathrm{O} \\
\end{array}$ & $\begin{array}{c}29-0713 \\
8-0098 \\
39-0516 \\
-\end{array}$ & $\begin{array}{l}20 \\
15 \\
35 \\
30 \\
\end{array}$ & $\begin{array}{c}<110\rangle \\
<020\rangle \\
<002\rangle \\
-\end{array}$ & $\begin{array}{c}21 \\
51 \\
550 \\
- \\
\end{array}$ \\
\hline $\begin{array}{l}\text { KES-N-5 } \\
\text { Bas in Floor }\end{array}$ & studtite & $\mathrm{UO}_{3}\left(\mathrm{H}_{2} \mathrm{O}_{2}\right) \cdot 3 \mathrm{H}_{2} \mathrm{O}$ & $16-0206$ & 100 & $\langle 110\rangle$ & 41 \\
\hline $\begin{array}{l}\text { KES-J-6 } \\
\text { Basin Floor }\end{array}$ & $\begin{array}{l}\text { Goethite } \\
\text { Lepidocrocite } \\
\text { Unident ified phase }\end{array}$ & $\begin{array}{l}\alpha-\mathrm{FeOOH} \\
Y-\mathrm{FeOOH} \\
-\end{array}$ & $\begin{array}{c}29-0713 \\
8-0098 \\
- \\
\end{array}$ & $\begin{array}{l}35 \\
35 \\
30\end{array}$ & $\begin{array}{c}<110> \\
<020> \\
-\end{array}$ & $\begin{array}{l}19 \\
71 \\
- \\
\end{array}$ \\
\hline $\begin{array}{l}\text { KES-0-9 } \\
\text { Basin Floor }\end{array}$ & $\begin{array}{l}\text { Uraninite } \\
\text { Lepidocrocite } \\
\text { Quartz } \\
\text { Calcite } \\
\text { Halloysite } \\
\text { Haiweeite } \\
\end{array}$ & $\begin{array}{l}\mathrm{UO}_{2} \\
\mathrm{Y}-\mathrm{FeOOH} \\
\mathrm{SiO}_{2} \\
\mathrm{CaCO}_{3} \\
\mathrm{AL}_{2} \mathrm{Si}_{2} \mathrm{O}_{5}(\mathrm{OH})_{4} \\
\mathrm{Ca}_{3}(\mathrm{UO})_{4} \mathrm{Si}_{30} \mathrm{O}_{27} \cdot 24 \mathrm{H}_{2} \mathrm{O}\end{array}$ & $\begin{array}{c}41-1422 \\
8-0098 \\
46-1045 \\
5-0586 \\
29-1429 \\
13-0118 \\
\end{array}$ & $\begin{array}{l}30 \\
5 \\
30 \\
20 \\
<5 \\
<5\end{array}$ & $\begin{array}{l}<200\rangle \\
<020\rangle \\
<101> \\
<104> \\
<001> \\
<002>\end{array}$ & $\begin{array}{l}<10 \\
590 \\
1150 \\
1990 \\
56 \\
55\end{array}$ \\
\hline $\begin{array}{l}\text { KES-F-10 } \\
\text { Basin Floor }\end{array}$ & $\begin{array}{l}\text { Goethite } \\
\text { Lepidocrocite } \\
\text { Magnetite }\end{array}$ & $\begin{array}{l}\alpha-\mathrm{FeOOH} \\
Y-\mathrm{FeOOH}_{3} \\
\mathrm{Fe}_{3} \mathrm{O}_{4}\end{array}$ & $\begin{array}{c}29-0713 \\
8-0098 \\
19-0629 \\
\end{array}$ & $\begin{array}{l}40 \\
35 \\
25\end{array}$ & $\begin{array}{l}<110> \\
<210> \\
<311>\end{array}$ & $\begin{array}{l}20 \\
72 \\
35 \\
\end{array}$ \\
\hline $\begin{array}{l}\text { KES-K-12 } \\
\text { Bas in Floor }\end{array}$ & $\begin{array}{l}\text { Goethite } \\
\text { Lepidocrocite } \\
\text { Magnetite }\end{array}$ & $\begin{array}{l}\alpha-\mathrm{FeOOH} \\
\mathrm{Y}-\mathrm{FeOOH} \\
\mathrm{Fe}_{3} \mathrm{O}_{4} \\
\end{array}$ & $\begin{array}{c}29-0713 \\
8-0098 \\
19-0629\end{array}$ & $\begin{array}{l}35 \\
35 \\
30 \\
\end{array}$ & $\begin{array}{l}<110\rangle \\
\langle 210\rangle \\
\langle 311\rangle \\
\end{array}$ & $\begin{array}{l}25 \\
89 \\
36 \\
\end{array}$ \\
\hline $\begin{array}{l}\text { KES-I - } 15 \\
\text { Bas in Floor }\end{array}$ & $\begin{array}{l}\text { Goethite } \\
\text { Lepidocrocite } \\
\text { Magnetite } \\
\text { Gibbsite } \\
\text { Humboldtine } \\
\text { Unidentified phase }\end{array}$ & $\begin{array}{l}\alpha-\mathrm{FeOOH} \\
\gamma-\mathrm{FeOOH} \\
\mathrm{Fe}_{3} \mathrm{O}_{4} \\
\mathrm{Al}_{4}(\mathrm{OH})_{3} \\
\mathrm{FeC}_{2} \mathrm{O}_{4} \cdot 2 \mathrm{H}_{2} \mathrm{O} \\
-\end{array}$ & $\begin{array}{c}29-0713 \\
8-0098 \\
19-0629 \\
33-0018 \\
13-0293 \\
- \\
\end{array}$ & $\begin{array}{l}25 \\
10 \\
20 \\
10 \\
10 \\
25\end{array}$ & $\begin{array}{l}<110> \\
\langle 020> \\
\langle 311> \\
- \\
- \\
-\end{array}$ & $\begin{array}{c}26 \\
540 \\
43 \\
- \\
= \\
-\end{array}$ \\
\hline $\begin{array}{l}\text { KES-Q-17 } \\
\text { Weasel Pit }\end{array}$ & $\begin{array}{l}\text { Goethite } \\
\text { Lepidocrocite } \\
\text { Quartz } \\
\text { Feldspar }\end{array}$ & $\begin{array}{l}\alpha-\mathrm{FeOOH} \\
Y-\mathrm{FeOOH} \\
\mathrm{SiO}_{2} \\
(\mathrm{Ca}, \mathrm{Na})(\mathrm{Si}, \mathrm{Al})_{4} \mathrm{O}_{8}\end{array}$ & $\begin{array}{c}29-0713 \\
8-0098 \\
46-1045 \\
41-1481 \\
\end{array}$ & $\begin{array}{r}5 \\
5 \\
30 \\
60 \\
\end{array}$ & $\begin{array}{l}<110> \\
<020\rangle \\
\langle 101\rangle \\
<004>\end{array}$ & $\begin{array}{c}20 \\
620 \\
790 \\
1720 \\
\end{array}$ \\
\hline 96-01 Canister & Uraninite & $\mathrm{UO}_{2}$ & 41-1422 & 100 & $<200>$ & $<10$ \\
\hline $\begin{array}{l}96-04-\mathrm{L} \\
\text { Canister }\end{array}$ & $\begin{array}{l}\text { Uraninite } \\
\text { Metaschoepite } \\
\text { Lepidocrocite } \\
\text { Al hydroxide }\end{array}$ & $\begin{array}{l}\mathrm{UO}_{2} \\
\mathrm{UO}_{3} \cdot 2 \mathrm{H}_{2} \mathrm{O} \\
\mathrm{Y}-\mathrm{FeOOH} \\
\mathrm{AL}(\mathrm{OH})_{3}\end{array}$ & $\begin{array}{c}41-1422 \\
43-0364 \\
8-0098 \\
20-0011 \\
\end{array}$ & $\begin{array}{c}30 \\
55 \\
5 \\
10 \\
\end{array}$ & $\begin{array}{c}<200> \\
<002> \\
- \\
- \\
\end{array}$ & $\begin{array}{c}<10 \\
68 \\
- \\
- \\
\end{array}$ \\
\hline $\begin{array}{l}96-05 \\
\text { Canister }\end{array}$ & $\begin{array}{l}\text { Uraninite } \\
\text { Metaschoepi te }\end{array}$ & $\begin{array}{l}\mathrm{UO}_{2} \\
\mathrm{UO}_{3} \cdot 2 \mathrm{H}_{2} \mathrm{O}\end{array}$ & $\begin{array}{l}41-1422 \\
43-0364\end{array}$ & $\begin{array}{c}95 \\
5\end{array}$ & $\begin{array}{l}<200\rangle \\
\langle 002\rangle\end{array}$ & $\begin{array}{l}<10 \\
50\end{array}$ \\
\hline
\end{tabular}


HNF-SD-WM-ES-409, Rev. 0

\section{A.3.8 Particle Size Methods and Data}

Particle size information is available from several sources. The various methods used for determination of particle sizes are discussed briefly in order to understand the measurements that are produced. Results of measurements are discussed in the subsequent section.

\section{A.3.8.1 Microtrac}

The Microtrac instrument uses forward, back and 90 degree laser light scattering to cover a particle size range of 0.12 to $700 \mathrm{~mm}$. Due to the dependence on light scattering, the instrument registers flocs of particles as large particles. To determine if the instrument is actually detecting flocs rather than individual particles, the sample is sonicated at increasing power levels and the size distribution remeasured. Reductions in the measured size distribution due to sonication is taken as evidence of floc destruction which indicates the initially measured distribution included flocs.

\section{A.3.8.1.1 KE Floor and Pit STudge Sample Measurements}

Measurement of the particle size distribution of KE samples using the Microtrac instrument is reported by Silvers (1995). For measurements on KE floor and pit sludge samples, the circulator system was operated at $60 \mathrm{ml} / \mathrm{s}$. According to vendor literature this flow rate should keep the following particles suspended: $40 \mu \mathrm{m}$ diameter, $\rho \leq 10 \mathrm{~g} / \mathrm{ml} ; 150 \mu \mathrm{m}$ diameter, $\rho \leq 5 \mathrm{~g} / \mathrm{ml}$; and $400 \mu \mathrm{m}$ diameter, $\rho \leq 2.5 \mathrm{~g} / \mathrm{ml}$. Thus, the ability to detect metallic uranium particles $(\rho=19 \mathrm{~g} / \mathrm{ml})$ is 7 imited to some diameter $<40 \mu \mathrm{m}$. Uranium oxide and hydrate phases range in density from 3.6 to $11 \mathrm{~g} / \mathrm{ml}$ (see Table A.3.6) such that these particles may not be accurately represented at sizes beginning around $40 \mu \mathrm{m}$ for the most dense phases and 200 to $300 \mu \mathrm{m}$ for the less dense phases. Particle flocs may have lower densities and may be better represented than pure phases at larger particle sizes. Samples were prepared by adding $<0.5 \mathrm{~g}$ of sludge to $5 \mathrm{ml}$ of water with $\mathrm{pH}$ adjusted to 8 . A subsample was then taken by pipetting $2-3 \mathrm{~m} 7$ of this slurry to the instrument. The sample was taken near the bottom to ensure large particles that settled at the bottom of the container were represented in the sample. The sample was then entrained (the instrument uses a total volume of $100 \mathrm{ml}$ ) in a $0.001 \mathrm{M} \mathrm{KCl}$ solution adjusted to $\mathrm{pH} 8$. At this $\mathrm{pH}$, the particles are negatively charged with a zeta potential of about. $-20 \mathrm{mV}$. To evaluate the data, particles were assumed to be non-spherical and to absorb laser light.

The pipetting procedure may result in some over or under representation at the larger particle sizes. Also, under reporting due to settling of 
larger particles in the instrument is possible. However, while the range of the instrument goes as high as $700 \mu \mathrm{m}$. the data above about $100 \mu \mathrm{m}$ from this instrument cannot be considered quantitative without additional review.

The results of the particle size analyses of floor and pit sludge samples using the Microtrac instrument are summarized by Makenas et al. (1996). Particle size distributions are provided for the upper and lower sections of the two "research" samples. The samples are designated M13T. M13B. M20T, and M20B, where "13" refers to a sample from the main basin floor. "20" refers to a sample from the weasel pit, and " $T$ " and "B" refer to top and bottom sections of the sample after settling. The particle size distributions on a number basis (i.e., each particle being equally weighted regardless of size) are clearly dominated by submicron particles. Most samples show a clear shift to smaller sizes in the presence of sonication which suggests that the submicron particles exist as agglomerates prior to sonication. The only exception to this trend was sample M20T which was initially finer than for the other samples and showed little shift on sonication. This would indicate little agglomeration of the finer particles in the sample. However, the duplicate analysis of this sample indicated some agglomeration although still less than for the other samples.

The volume-based size distributions (i.e., each particle is weighted by its volume) for the same samples are centered at much larger sizes due to the much larger volume of the larger particles compared to small particles. For M13T, the particle size distribution is centered at about $15 \mu \mathrm{m}$, while M13B is centered at about $30 \mathrm{~mm}$. Results of duplicate analyses were very consistent. This is evidence of segregation by size during settling of the sample from the basin floor. The volume distributions. for M20T and M20B are much more similar with distributions centered at about $20 \mu \mathrm{m}$. All the distributions show some shift to smaller sizes on sonication indicating some agglomeration. The data for M20T and M20B at sizes above $200 \mu \mathrm{m}$ is not consistent between duplicate analyses, and these particles appear to disappear on sonication. It is speculated by Silvers (1995) that these larger particles may be particles of an ion exchange resin used in the basins. the size of which is sharply peaked at $700 \mu \mathrm{m}$. If so, the particles are either destroyed or settle out during the sonication period. Based on the discussion of the technique (above), the data at the upper size range cannot be considered quantitative. However, it can be concluded that some material up to $700 \mu \mathrm{m}$ is present.

\section{A.3.8.1.2 KE Canister Sludge Samples}

The measurement of particle sizes using the Microtrac instrument of KE canister sludges is discussed only briefly in an informal. memo by P.A. 
Smith. ${ }^{2}$ The test instruction for these measurements (P.A. Smith, 1997) indicates these measurements were made in deionized. water. No attempt to control or monitor the pH was reported. Similar to the procedure used for analysis of the floor and pit sludges, the KE.canister sludge was subjected to a sample transfer procedure involving a disposable pipette prior to analysis. However, specific details are not provided. The particles were assumed to be transparent with a refractive index of 1.51. While this assumption is different than used to evaluate floor and pit sludge. the errors due to variation in this parameter are believed to be small.

As of this writing. collection of particle size data for the KE' canister sludge is not complete and the preliminary information that is available has not been peer reviewed. However, preliminary particle size data has been obtained using the Microtrac instrument for the following sludge samples:

96-04-L and $-U / L$ (taken from a stain 7 ess steel canister)

96-06-L and $-M$ (taken from an aluminum canister)

$96-11-\mathrm{L}$

(taken form an empty canister)

In the sample number format 96-AA-BB, the "AA" refers the initial sample obtained from a KE canister and the "BB" refers to the vertical layer from which a subsample was taken after allowing the sludge to settle in a graduated cylinder (i.e., lower $(L)$, middle $(M)$ or the interface between the upper and lower layers $(\mathrm{U} / \mathrm{L}))$. Sample 96-11 settled into two visually distinct layers (Silvers 1997). The material in the bottom of 96-04 may not have been fully suspended by the air sparge prior to settling. During the settling test, gas was generated near the bottom of sample 96-06 causing the sample to rise like a piston within the graduated cylinder. ${ }^{3}$

There is significant evidence of size segregation in the 96-04 samples. The particle size distribution on a number basis of the lower sample indicates nearly al1 particles are larger than 3 um with 90\% less than $10 \mu \mathrm{m}$. The "U/L" sample indicates a size distribution with nearly a 17 particles $>0.8 \mu \mathrm{m}$ with $90 \%$ less than $2.5 \mu \mathrm{m}$. The particle size distribution on a volume basis a7so shows evidence of segregation. indicating nearly $10 \%$ at $700 \mu \mathrm{m}$, and $50 \%>100 \mu \mathrm{m}$ in the lower sample, while the U/L sample did not contain material larger than $100 \mathrm{~mm}$. While the results in the upper size range are qualitative in nature. there is a clear difference between the samples. Sonication reduced the sizes of both the "L" and "U/L" samples although the lower sample remained much

2 P.A. Smith, 1997., personal communication, "Radiocolloid Data

3 Personal communication. Paul Bredt, 1997. 
HNF-SD-WM-ES-409, Rev. 0

larger than " $\mathrm{U} / \mathrm{L}$ " sample in both the number and volume distributions.

The size distributions on a number basis for sample 96-06 lower and middle samples indicate some size segregation. The distribution of the middle sample begins at about $0.5 \mu \mathrm{m}$ with $90 \%<1.4 \mu \mathrm{m}$ while the lower sample distribution begins at about 0.8 with $90 \%<1.8 \mu \mathrm{m}$. The size distribution on a volume basis gives a stronger indication of segregation with the lower sample having $50 \%$ of the volume in sizes $>300 \mu \mathrm{m}$ and $65 \%>100 \mu \mathrm{m}$. The upper sample has $50 \%<10 \mu \mathrm{m}$ and only about $3 \%>100 \mu \mathrm{m}$. Sonication results in some size reduction in the number distributions, indicating some agglomeration of the finer particles. The results of sonication are difficult to interpret for the volume distributions. In the lower sample, the sonication appears to eliminate the peaks above $300 \mu \mathrm{m}$. However, in the middle sample, sonication produces peaks above $300 \mu \mathrm{m}$ that accourt for $50 \%$ of the volume. Duplicate analyses have not been performed for these samples. Based on the qualitative nature of the volume distribution data at the large particle sizes, probably a 11 that should be concluded is that these samples may contain particles in the 300 to $700 \mu \mathrm{m}$ size range that may occount for a substantial fraction of the particle volume.

The size distribution on a number basis for sample $96-11$ is nearly all larger than $0.6 \mu \mathrm{m}$ but smaller than $6 \mu \mathrm{m}$. The volume distribution is a bell shaped curve centered at about $17 \mu \mathrm{m}$ with $90 \%<52 \mu \mathrm{m}$ and a tail out to $300 \mu \mathrm{m}$. Sonication produces reductions in both the number and volume distributions indicating some agglomeration of the particles.

\section{A.3.8.2 Brinkman 2010}

The Brinkman 2010 Particle Size Analyzer determines particles sizes in the 0.1 to $60 \mu \mathrm{m}$ size range by measuring the time required for a rapidly moving laser beam to traverse selected particles maintained in a stirred suspension of glycerol/water solution. No data were obtained on floor or pit sludge samples using this instrument, but data was collected for the canister sludge samples 96-04 L. 96-06 L, 96-06M and 96-11-L (Silvers 1997). The samples were prepared by ultrasonically dispersing the sludge into a glycerol/water solution. sampling the oispersion and then mixing into a larger volume of glycerol/water solution. All of these samples were also measured using the Microtrac so qualitative comparisons between the data can be made.

Except for sample 96-04L, the size distributions on a number basis measured by the Brinkman 2010 were similar to the unsonicated results obtained with the Microtrac. In the case of sample 96-04L, the Brinkman sample results matched the $40 \mathrm{~W}$ sonicated sample more closely while being somewhat finer than the unsonicated sample. In a 17 cases, the Brinkman measurements indicated a 
more "normal" tail for the small end of the distribution while the Microtrac indicated a peak with no "tail" on the distribution to the smaller sizes. It is not clear if this is a result of the sample conditions during measurement or differences in the operation of the instrument itself.

The size distributions on a volume basis measured using the Brinkman 2010 show less material at the larger particles sizes. Sample 96-04L shows no material greater than $20 \mu \mathrm{m}$ while the Microtrac indicates only $15 \%$ finer than $22 \mu \mathrm{m}$ without sonication and $53 \%<22 \mu \mathrm{m}$ at $40 \mathrm{~W}$ sonication. Similarly, Brinkman analysis of sample 96-06L shows particles up to $3 \mu \mathrm{m}, 96-06 \mathrm{M}$ up to $10 \mathrm{~m}$, and 96-11 up to $30 \mathrm{~mm}$, while the Microtrac volume distribution indicates substantial material above $30 \mathrm{\mu m}$. The reason for the discrepancy has not been determined.

\section{A.3.8.3 , Optical Microscopy Data}

The Brinkman 2010 analyzer also has the capability of obtaining still pictures of particles in suspension. The pictures can then be analyzed to collect size and shape information. The size of particles that can be discriminated using optical microscopy is limited depending on the wavelength of light used for illumination. Reasonable lower size limits are in the 0.5 to $1.0 \mu \mathrm{m}$ size range (Hesketh 1986. Dennis 1976). A number of images from each sample are analyzed for numerous characteristics including (but not limited to) Ferret's diameter (determined by measuring the distance between tangents to the particle edges which are drawn perpendicular to the bottom of the microscope field) and aspect ratio (a measure of particle shape calculated as the minimum/maximum Ferret's diameter). In addition, an average Feret's diameter is determined by calculating the Ferret's diameter after rotation of the image by $0,45,90$ and 135 degrees. The particle size and shape data are only semi-quantitative and cannot be directly compared since each parameter selects acceptable particles based on different criteria. Data for average Feret's diameter is reported for sizes down to $0.75 \mu \mathrm{m}$. Measurement of a sufficient number of particles to obtain good statistics is labor intensive. However, the particle shapes may be observed directly with this technique, information which is not available via the Microtrac instrument.

Data were collected for the same samples as for the Brinkman 2010 (above). For each sample between eight and eleven photos were taken containing a total of 411 to 491 particles and statistics were collected on a variety of geometric factors (Silvers 1.997). However, only the average Feret's diameter distribution on a number basis, the size distribution on a volume basis and the aspect ratio will be summarized here. An aspect ratio near 0 indicates needle-like particles while a value of 1 is obtained from spherical particles. 
HNF-SD-WM-ES-409, Rev. 0

The number distribution data for Sample 96-04L qualitatively confirms the data collected using the Brinkman 2010 laser data. The volume distribution is significantly affected by a single $31.5 \mu \mathrm{m}$ particle. The aspect ratio averages 0.72 with almost a 11 particles having an aspect ratio > 0.4 .

The number distribution for sample 96-06L indicates more particles larger than $3 \mu \mathrm{m}$ than was seen by the Brinkman 2010 laser data. The volume distribution appears to be more consistent with that obtained using the Microtrac than that obtained by the Brinkman 2010 laser data. The particles in this samples have an aspect ratio average of 0.66 with almost al1 >0.4.

Results for 96-06M are similar to 96-06L. The number distribution qualitatively confirms the results obtained using the Brinkman 2010 laser data. The volume distribution is significantly affected by a single particle in the 35 to $40 \mu \mathrm{m}$ range. The shape factor averages 0.71 with almost al1 particles having an aspect ratio $>0.4$.

The number distribution for sample $96-11$ is qualitatively consistent with the Brinkman 2010 laser data. The volume distribution confirms that this sample has more larger particles in it that the other samples. In addition. this sample has the lowest average aspect ratio (0.6) with much more material in the 0.2 to 0.4 aspect ratio range than other samples.

\section{A.3.8.4 Mineral Particle Sizes, and Morohology from TEM Data.}

The transmission electron micrographs of mineral particles from KE basin and canister sludge were obtained as part of mineral identification and morphological determination process (Silvers 1995). The data obtained from these observations are listed in Table A.3.10. The data show that some of the minera 7 s, such as $\mathrm{UF}_{4} \cdot 1.5 \mathrm{H}_{2} 0$ and feroxyhytes, exist mainly as aggregates of individual nanometer-sized crystallites. Other minerals were observed to be present as individual particles with platy or lath-like morphologies with average particle dimensions ranging up to a few microns. The particle sizes noted by TEM refer to mainly length and width of the particles and the thicknesses were not discernable because of the preferred orientation of the platy or lath-like crystals in the microscopic field of view. 
Table A.3.10. Morphology and Approximate Particle Size of Uranium- and IronBearing Minerals Determined from TEM.

\begin{tabular}{|c|c|c|}
\hline Mineral & $\begin{array}{c}\text { Particle } \\
\text { Dimension } \\
(\mu \mathrm{m})\end{array}$ & Morphology \\
\hline$\beta-U_{3} O_{8}$ & $\sim 3 \times 1.5$ & Platy \\
\hline $\mathrm{UF}_{4} \cdot 1.5 \mathrm{H}_{2} \mathrm{O}$ & $-0.4 \times 0.5$ & $\begin{array}{l}\text { Aggregates of } \mathrm{nm} \text {-sized } \\
\text { particles }\end{array}$ \\
\hline $\begin{array}{l}\text { U peroxide } \\
\text { (see A.3.4.1) }\end{array}$ & $\begin{array}{l}\sim 0.01 \times \\
0.1 \text { to } 0.4 \\
\times 4\end{array}$ & Lath-1ike crystals \\
\hline Goethite & $\sim 0.2 \times 0.5$ & Lath- like \\
\hline Maghemite & $-1.5 \times 2$ & Platy \\
\hline Magnetite & $\begin{array}{l}-0.4 x \\
0.4\end{array}$ & Equidimensional \\
\hline Feroxyhyte & $\sim 0.2 \times 0.2$ & $\begin{array}{l}\text { Aggregates of nm-sized } \\
\text { particles }\end{array}$ \\
\hline Akageneite & $\sim 0.2$ long & Needle-7ike \\
\hline
\end{tabular}

\section{A.3.8.5 Sedimentation Rate Tests}

In general, sedimentation tests are performed by mixing the particles into a uniform slurry and then allowing the particles to settle over time. The division between slurry and clear supernatant is then tracked to provide data on the settling rate of the particles. This method is most sensitive to the finer particles which settle last and can be distinguished easily from a layer of clear supernatant.

\section{A.3.8.5.1 KE Canister Sludge Samples}

Sedimentation rate data were generated for nine canister sludge samples. These samples were tested in an $8-\mathrm{cm}$ diameter graduated cylinder with a slurry total volume of 1.77 iters at $35^{\circ} \mathrm{C}$. Tabular data were not immediately available so information was taken from plots in Silvers (1997). To determine the effective particle size, it was assumed for this evaluation that the fluid had a density of $1 \mathrm{~g} / \mathrm{cm}^{3}$; the particle was spherical with a density of 5 
$\mathrm{g} / \mathrm{cm}^{3}$; and that the viscosity of the fluid was $1 \mathrm{cP}$. The linear settling region was then used to determine a settling rate which was converted to particle size using Stokes Law. Because of these assumptions, the particle size provides only a qualitative comparison to particle size data for the smallest particles or flocs in the sample. Two samples which showed the slowest settling particles indicate particle sizes of $0.54 \mu \mathrm{m}$ and $0.86 \mu \mathrm{m}$. These sizes are qualitatively consisterit with some non-sonicated particle size distribution information. Other particle settling velocities demonstrated much more rapid settiing indicating particles in the $5 \mu \mathrm{m}$ range. Based on other data that consistently shows numerous particles near the $1 \mathrm{im}$ size range, it appears likely that flocculation is occurring. However, it could a]so be an indication that fines were lost in previous transfers as indicated by Silvers (1997)

"During dewatering, some samples settled incompletely, leaving excess

murky water. This may have resulted in significant sludge loss." It has not been determined to which samples this caution applies. Without additional detail, it appears possible that the finest fraction may have been washed out of some samples.

\section{A.3.8.5.2 KE Floor and Weasel Pit Sludge Data}

- Settling tests were conducted for a total of twelve samples (Miller 1995). While sufficient data to estimate particles sizes were not reported with the data, the samples were settled in either 1 or 2 liter graduated cylinders so the general approach was the same as used on the canister sludge samples. Most samples settled within a couple hours. However, one sample required about a day and three samples settled incompletely and a murky supernate remained. This information qualitatively indicates that the finest fraction of many of the samples is either missing or is agglomerated, but that some samples contain some quantity of fine submicron particles that do not agglomerate under the conditions of the settling test. If the lack of fine particles in many samples is due to agglomeration, the inconsistent result may be the result in variations in ionic strength or $\mathrm{pH}$ between supernatants.

\section{A.3.8.6 Sieve Analyses}

Data concerning large particles can be obtained using sieves. Sieves al low measurement of the content of particles at sizes larger than the Microtrac instrument can reliably measure and due to the large volume per particle, large particles can represent a significant fraction of the sludge - mass while being minor when considered on a number basis. In addition, these large particles are most likely to segregate due to their very high settling velocities. 
No sieve data was generated for KE floor and pit sludge. However, some data is available for samples of KE canister sludge which were used in the settling studies in graduated cylinders. The data has been tabulated in preliminary form ${ }^{4}$ but has not been peer reviewed or formally reported. Samples of the settled sludge were wet sieved and the dry wt\% of solids retained on each sieve was measured. The data, summarized in Table A.3.11, indicate a substantial fraction of the canister sludge mass exists as particles larger than $710 \mu \mathrm{m}$ which is approximately the upper size limit for detection of particles using the Microtrac instrument. The only exception among the samples analyzed was 96-11 $L$ which was obtained from an empty canister.

Table A.3.11. Sieve Analysis of KE Canister Sludge Samples

\begin{tabular}{|l|l|l|l|l|}
\hline & \multicolumn{4}{|l|}{ Dry wt\% of Sett7ed Solids Sample } \\
\hline Sieve Opening & $96-04 \mathrm{~L}$ & $96-06 \mathrm{M}$ & $96-06 \mathrm{~L}$ & $96-11 \mathrm{~L}$ \\
\hline $3350 \mu \mathrm{m}(0.132 \mathrm{in.})$ & 0 & 5 & 3 & 0 \\
\hline $2360 \mu \mathrm{m}(0.0937$ in. $)$ & 12 & 6 & 3 & 0.05 \\
\hline $1180 \mu \mathrm{m}(0.0469$ in. $)$ & 22 & 20 & 15 & 0.7 \\
\hline $710 \mu \mathrm{m}(0.0278$ in. $)$ & 9 & 11 & 22 & 1 \\
\hline Total dry Wt\% $>710 \mu \mathrm{m}$ & 44 & 42 & 42 & 1.75 \\
\hline Dry wt\% passing $710 \mu \mathrm{m}$ opening & 56 & 58 & 58 & 98 \\
\hline
\end{tabular}

\section{A.3.8.7 Conclusions Regarding Particle Size}

The various analyses of particle size tend to confirm that, on a number basis, the majority of particles are less than $1 \mu \mathrm{m}$ in diameter. However. data obtained by wet sieving indicates a significant mass fraction of $\mathrm{KE}$ canister sludge particles are larger than $710 \mu \mathrm{m}$. In addition, the particle size distribution on a volume basis obtained using the Microtrac instrument indicates most of the volume is in particles larger than $10 \mu \mathrm{m}$ with some particles larger than $100 \mathrm{~mm}$. Evidence of flocculation is seen in the reduction of sizes on sonication measured using the Microtrac, and in the fast settling observed in most samples. However, observations that sonication has

${ }^{4}$ a1 1 data taken from: Personal Communication J. M. Tingey to G. R. Golcar. Wet Sieving, 5/20/97. 
HNF-SD-WM-ES-409, Rev, 0

a limited effect on larger sizes and that most solids settle rapidly in samples where very fine particulate remains unflocculated suggest the presence of super-micron primary particles which are not agglomerates. The presence of large primary particles is clearly apparent in the sieve analysis data. Evidence of size segregation was observed in subsamples taken from different layers of sludge after settling. While sonication produces a shift in the size distributions to smaller sizes, the lower subsamples remained with a larger size distribution than the upper samples. The observation that the difference between upper and lower subsamples was not eliminated by sonication may indicate that the segregation is driven by larger primary particles rather than a segregation of different agglomerate sizes.

Thus, while evidence of flocculation in the existing sludge is present in many samples, there is also evidence that large primary particles are present. When considering segregation of untreated sludge, these large particles will easily segregate from micron-sized precipitates. Agglomeration cannot be relied upon to significantly prevent segregation of the untreated canister sludge.

\section{A.3.9 Segregation Tests of $K$ Basin Sludges}

\section{A.3.9.1 Segregation Tests on KE Floor and Weasel Pit Sludge Samples}

Two samples, one taken from the main basin floor (KES-M13) and one taken from the weasel pit (KES-M20), were evaluated for segregation. The samples were suspended and allowed to settie and material from the top half $(T)$ and bottom half (B) were analyzed to evaluate segregation within the samples.

For the floor sludge samples (KES-M13T, KES-M13B), analysis was performed for ${ }^{239} \mathrm{Pu} /{ }^{240} \mathrm{Pu}$ with results reported on an as-settled, centrifuged. or dry solids basis (Makenas et al, 1996). Uranium analysis was performed and reported on an as-settled basis(Silvers 1995). No chemical analysis was performed on this sample so a comparison of ratios of fissile to neutron absorption cross section is not possible. On a dried sludge basis, the mass fraction $\mathrm{Pu}$ in the upper layer is approximately twice that in the lower layer (or stated differently, 1.33 times the mean of the two samples). If the Pu data is used to estimate the relative difference between as-settled and dried basis (possibly a questionable assumption), the uranium data then indicates similar mass fraction uranium in the solids from the top and bottom layers (about $7 \%$ higher in upper layer compared to the lower, or stated differently, the upper layer is about 3\% higher than the mean).

For the weasel pit sludge samples (KES-M20T, KES-M20B), chemical analysis was obtained allowing changes in the ratio of fissile material to 
neutron absorption cross section to be determined (Silvers 1995, Makenas et a1.. 1996). The contributions to absorption from Al, B, Ba, Be, Ca, Cd, Cr, $\mathrm{Cu}, \mathrm{Fe}, \mathrm{Mg}, \mathrm{Mn}, \mathrm{Na}, \mathrm{Pb}, \mathrm{Zn}$, and $\mathrm{Zr}$ were considered. Surprisingly, the boron in the lower layer makes a significant difference in the absorption crosssection and cadmium is not at negligible levels. The source of boron and cadmium is not known.

If boron and cadmium are eliminated from the calculation of neutron absorption cross section, the difference in the ratio of fissile to neutron absorption indicates that Pu:absorption ratio in the lower layer is $16 \%$ higher than the mean ratio of the upper and lower samples (stated differently, the ratio is $39 \%$ higher in lower layer than the ratio in the upper 1ayer). Uranium is only slightly concentrated in the lower layer indicating a ratio of $U$ to absorber $4.5 \%$ higher than the mean ratio (or stated differently, the $U$ :absorber ratio in the lower layer is $9 \%$ higher than the ratio in the upper layer).

The results indicate substantially more segregation if the boron and cadmium are included in the absorption cross section. This is primarily the result of a boron concentration which is below detection in the bottom layer and about a factor of 10 higher in the top layer. If $\mathrm{B}$ and $\mathrm{Cd}$ are included. the ratios of fissile to absorption relative to the mean ratio for the samples are $\mathrm{Pu}, 1.48$ and $U, 1.38$ (stated differently, the $U$ ratio was a factor of 2.86 higher and the Pu ratio a factor of 2.25 higher in the lower layer compared to the upper layer).

Overall, the results indicate that some segregation should be expected to occur between fissile material and neutron absorbers in the floor and pit sludge samples. The limited number of subsamples limit the degree to which the maximum segregation can be identified for the samples. It should be recognized that the upper and lower values being measured are actualiy the result of the average composition over half of the settled height. Thus, the experiment is not able to detect thin, high concentration layers except through the effect on the average concentration in half of the sample. No clear trend for the segregation was observed between the two samples. The floor sludge sample indicates Pu concentrates at the top of the sample while the wease 7 pit sludge sample indicates $U$ and Pu concentrate at the bottom of the sample. The reasons are not known. Based on these results, some segregation of fissile material from absorbers would be expected for the untreated floor and weasel pit sludge.

\section{A.3.9.2 Segregation Observed in Settling of KE Canister S7udge Samples}

Three samples of KE canister sludge were subjected to special 
HNF-SD-WM-ES-409, Rev, 0

characterization tests. In these tests, the samples were placed in a graduated cylinder. suspended in basin water by bubbling gas into a graduated cylinder and allowing the sludge to settle into layers. The samples were then sub-sampled in horizontal layers (top, middle, bottom) and the sub-samples analyzed for composition, including $U$ (phosphorescence and ICP), ${ }^{239} \mathrm{Pu} /{ }^{240} \mathrm{Pu}$. ${ }^{238} \mathrm{Pu}$ and cations by ICP. Supernatant above the samples was also analyzed by IC for anions although the supernatant analyses were not factored into the evaluation discussed here. The details of the chemical analyses are provided in Miller (1997). Analysis of these sub-samples provides some indication of the degree to which fissile components may segregate from neutron poisons due to settling.

Many of the analyses were performed on the solution resulting from an acid digestion of the sample. It was. assumed that the major fissile elements (U. Pu) and the primary non-fissile neutron absorbers were completely represented in the acid digestion. The data was analyzed by first using the ICP analysis to determine the neutron absorption cross section in barns per gram of sample. Uranium and plutonium were excluded from the absorber cross section because the objective of the calculation was to detect the degree of segregation of uranium and plutonium from non-fissile absorber materials. Inclusion of the fissile absorption cross section would mask the degree of segregation occurring. Similarly, water and anions detected in the supernatant over the samples were not included in the absorption cross section because these may vary with the degree of consolidation of a sludge sample and it is segregation of solids from solids that is of interest. Ratios of the $U$ or $\mathrm{Pu}$ to the absorption cross section were then calculated. The use of a ratio between fissile and absorber contents eliminates errors due to different water contents as well as preventing error due to dilution of a layer by acidinsoluble sand (insoluble sand would not be included in the absorption cross section but its absorption cross section is negligible). An average ratio between fissile content and absorber was determined for each original sample by averaging the results of the subsamples. The degree of deviation of the subsamples from the mean was then calculated and reported as a percentage increase or decrease in fissile material relative to absorber content.

Using this approach, the ratio of fissile to absorber ratios varies over a limited range. For example, if two samples are taken and all the fissile ends up in the lower section with absorbers distributed equally between the sub-samples, the top section will have a value of 0 and the bottom section will have a value of 2 . This is because the concentration of the lower half of the sample is assigned to half of the settled sludge volume with all the fissile material which doubles the calculated fissile concentration. Values in excess of 2 can be obtained only by effectively displacing absorbers by fissile or non-absorbing elements. The detectable degree of segregation 
HNF-SD-WM-ES-409, Rev. 0

increases as more sub-samples are taken. For the case of three sub-samples and a uniform distribution of absorbers with sludge volume, the maximum result is 3 .

A statistical analysis has not been performed to determine what degree of deviation in the fissile:absorber ratios can be considered statistically significant. Fortunately, there are two separate analytical methods (each performed in duplicate) to provide some corroboration of results. Also, it is the largest segregation results that are of interest so that the significance of a low segregation result is not important (e.g. a $3 \%$ difference is effectively a. lack of segregation and its significance is not important). In general, agreement between the results based on different analytical techniques was very good.

Surprisingly, in calculating the neutron absorption cross section, boron accounted for 50 to $98 \%$ of the absorption cross section and cadmium for between 4 and $11 \%$. Because of the large absorption cross section of these elements, the results were calculated both with and without the presence of these two absorbers. Results are presented in detail for the case excluding $B$ and $\mathrm{Cd}$ with only a summary conclusion for the case with the B and $\mathrm{Cd}$. Without boron and cadmium the aluminum and iron account for an average of 93\% of the absorption cross section. The relative importance between iron and aluminum varied with the sample.

Sample 96-04 was subsampled into an upper and lower sample. The results for the degree of segregation of this sample are shown in Table A.3.12. The uranium results for this sample are consistent and indicate an increase in concentration at the bottom of the sample of $21 \%$ (phosphorescence) or $24 \%$ (ICP). The Pu results are also consistent, indicating that the upper layer is enriched in Pu relative to the mean by $7.3 \%$ (Pu239/240) or $6.7 \%$ (Pu-238).

Sample 96-06 was sub-sampled into an upper, middle and lower layer. The results for the degree of segregation of this sample are shown in Table A.3.13. The uranium results for this sample are consistent and indicate an increase in concentration at the bottom of the sample of $23 \%$ (phosphorescence). or $21 \%$ (ICP). The Pu results for this sample are also consistent, indicating that the lower layer is enriched in Pu relative to the mean by $62 \%\left({ }^{239} \mathrm{Pu} /{ }^{240} \mathrm{Pu}\right.$ ) or $64 \%\left({ }^{238} \mathrm{Pu}\right)$ : The Pu results are also consistent in indicating that the upper layer contains only about $12 \%$ as much Pu relative to absorbers compared to the mean sample composition.

Sample 96-06 was sub-sampled into an upper, middle and lower layer. The results for the degree of segregation of this sample are shown in Table A.3.14. The uranium results for this sample are consistent and indicate an 
Table A.3.12. Sample 96-04. Fissile Elements to Absorption Cross Section Ratios: Ratio for Selected Sub-Sample Divided by Mean Ratio of Sample 96-04

\begin{tabular}{|l|l|l|}
\hline \multicolumn{1}{|c|}{ Analysis } & \multicolumn{1}{|c|}{ Sample 96-04-U } & \multicolumn{1}{c|}{ Sample 96-04-L } \\
\hline U by Phosphorescence & 0.795 & \multicolumn{1}{c|}{ Lower Layer/Mean } \\
\hline U by ICP & 0.756 & 1.205 \\
\hline${ }^{239} \mathrm{Pu}{ }^{240} \mathrm{Pu}$ & 1.073 & 1.244 \\
\hline${ }^{238} \mathrm{Pu}$ & 1.067 & 0.927 \\
\hline
\end{tabular}

Table A.3.13. Sample 96-06. Fissile Elements to Absorption Cross Section Ratios: Ratio for Selected Sub-Sample Divided by Mean Ratio of Sample 96-06

\begin{tabular}{|l|l|l|l|}
\hline & Sample 96-06-U & Sample 96-06-M & Sample 96-06-L \\
\hline \multicolumn{1}{|c|}{ Analysis } & Upper Layer/Mean & Middle Layer/Mean & Lower Layer/Mean \\
\hline $\begin{array}{l}\text { U by } \\
\text { Phosphorescence }\end{array}$ & 0.895 & 0.880 & 1.225 \\
\hline U by ICP & 0.918 & 0.873 & 1.209 \\
\hline${ }^{239} \mathrm{Pu} /{ }^{240} \mathrm{Pu}$ & 0.123 & 1.258 & 1.619 \\
\hline${ }^{238} \mathrm{Pu}$ & 0.125 & 1.239 & 1.636 \\
\hline
\end{tabular}

Table A.3.14. Sample 96-11, Fissile Elements to Absorption Cross Section Ratios: Ratio for Selected Sub-Sample Divided by Mean Ratio of Sample 96-11

\begin{tabular}{|l|l|l|}
\hline & \multicolumn{1}{|c|}{ Sample $96-011-U$} & \multicolumn{1}{c|}{ Sample $96-11-\mathrm{L}$} \\
\hline \multicolumn{1}{|c|}{ Analysis } & \multicolumn{1}{|c|}{ Upper Layer/Mean } & \multicolumn{1}{c|}{ Lower Layer/Mean } \\
\hline$U$ by Phosphorescence & 1.509 & 0.491 \\
\hline$U$ by ICP & 1.503 & 0.497 \\
\hline${ }^{239} \mathrm{Pu} /{ }^{240} \mathrm{Pu}$ & 1.648 & 0.352 \\
\hline${ }^{238} \mathrm{Pu}$ & 1.628 & 0.372 \\
\hline
\end{tabular}


increase in concentration at the top of the sample of $51 \%$ (phosphorescence) or $50 \%$ (ICP). The Pu results for this sample are also consistent, indicating that the upper layer is enriched in $\mathrm{Pu}$ relative to the mean by $65 \%\left({ }^{239} \mathrm{Pu} /{ }^{240} \mathrm{Pu}\right)$ or $63 \%\left({ }^{238} \mathrm{Pu}\right)$.

Overa 11, the results indicate that some segregation should be expected to occur between fissile material and neutron absorbers. The limited number of subsamples limit the degree to which the maximum segregation can be identified for the samples. The maximum increase in fissile to absorber ratios was a value of 1.65 for two samples and 1.64 for three sub-samples. The most severe segregation overa 17 was a depletion of $\mathrm{Pu}$ in the upper segment of 96-06 to a value of $12 \%$ of the initial value. Expressed in different terms, the maximum ratio between fissile:absorber values of different layers is a factor of 13 ( $\mathrm{Pu}$ in the bottom of 96-06 compared to the top layer). It should be recognized that even this value incorporates averaging within the upper and lower sections and may mask the extent of segregation actually present.

Although the data were very consistent for each sample, no clear trend in the direction of the segregation could be determined. In 96-04, U concentrated at the bottom while $\mathrm{Pu}$ concentrated at the top. For 96-06, $U$ and Pu concentrated at the bottom. For 96-11, U and Pu concentrated at the top. The reasons are not known, but probably relate to the characteristics of the individual samples. 


\section{A.3.10 Gas Generation And Expectations of Metallic Uranium}

Metallic uranium corroding in water generates hydrogen gas. If the metallic uranium is irradiated material, the corrosion of the metallic matrix may release fission gases that were trapped in the metallic matrix. Hydrogen gas generation has been observed for a number of KE canister sludge samples (96-05, 96-06, 96-13, 96-15). Gas samples analyzed by mass spectroscopy have been shown to contain fission gasses along with the hydrogen. This very strongly suggests that metallic uranium is present in some of the canister sludges. Metallic uranium has not been detected in XRD analyses of canister sludge. However, the samples are dried and ground in air prior to XRD analyses such that the metallic uranium may oxidize prior to analysis.

Gas generation has not been observed from floor and weasel pit sludge samples. However, these samples have much lower fissile inventory than is projected for the canister and fuel washing sludges. Gas release has also been observed from sandfilter backwash pits upon disturbing the sludge although the source and composition of this gas is uncertain. In any case, the majority of metallic uranium is expected to originate from canister sludge and fuel washing activities. Uranium metal removed from a damaged element by corrosion processes would most likely be present in canister sludge.

Additional metal uranium will be removed from the fuel elements during washing. In addition, the nominal projection for KE basin sludges indicates $80 \%$ of the total uranium and $82 \%$ of ${ }^{239} \mathrm{Pu} /{ }^{240} \mathrm{Pu}$ is expected to occur in the canister sludge and sludge produced by fuel washing. In KW basin sludges, the nominal projection is that $>99.5 \%$ of the uranium and plutonium will exist in the canister and fuel washing sludges (Pearce 1997). Thus, the major source of total uranium is canister sludge and fuel washing and other potential sources should be insignificant by comparison.

For purposes of this study, it has been assumed that when evaluating untreated sludge, it should be assumed that up to $4.5 \%$ of the uranium exists as metal or hydride ${ }^{5}$. This number was based on an assessment of how much metallic material could be present and still allow transport of the sludge to tank farms in a sealed vessel. The quantity does not have a basis in characterization measurements.

5 Personal communication, Kathleen L Pearce, 3/25/97 E-mai 1 correspondence, Assumption for metal/hydride in $\mathrm{K}$ basin S7udge 


\section{A.4 ADJUSTMENT OF SLUDGE PRIOR TO INTRODUCTION INTO TANK AW-105}

This chapter discusses the addition of iron to sludge prior to transfer to AW-105, the state of the iron added, the potential for beneficial coprecipitation effects and the mineralogic and solubility changes compared to $K$ basin conditions. It is possible that depleted uranium may be selected as the neutron absorber instead of iron. Depleted uranium has an advantage over iron in that once made homogeneous with the ${ }^{235} \mathrm{U}$, there is high confidence that no segregation of ${ }^{235} \mathrm{U}$ from ${ }^{238} \mathrm{U}$ would occur. Thus, only segregation of ${ }^{239} \mathrm{Pu}$ from uranium would need to be considered.

\section{A.4.1 Iron Addition}

Due to the high fissile content of the $K$ basin sludges, iron may be added to the sludges prior to transfer to tank AW-105. The iron is a neutron absorber which increases the margin of criticality safety. When homogeneously mixed with ${ }^{239} \mathrm{Pu}$, a ratio of $160 \mathrm{~g} \mathrm{Fe} / \mathrm{g} \mathrm{Pu}$ wi 77 assure subcriticality regardless of the amount or geometry of the mixture. A plutonium equivalent for the irradiated uranium can be obtained by assuming that the uranium enrichment in excess of natural uranium $\left(0.72 \%{ }^{235} \mathrm{~J}\right)$ is present as ${ }^{239} \mathrm{Pu}$. (The amount of ${ }^{235} \mathrm{U}$ up to the natural enrichment may be neglected because the presence of the neutron absorber ${ }^{238} U$ offsets the ${ }^{235} U$ in natural uranium.) This conservative approach was used for this appendix because $K_{\infty}$ calculations were not yet available for the sludge. The results of $K_{\infty}$ calculations indicate less iron would be needed than indicated using this approach (see appendix $B$ ).

For purposes of this appendix it was assumed that iron wil1 be added to each batch of sludge transferred to provide a minimum of three times the safe absorber mass ratio of iron to plutonium equivalent. The factor of three was arbitrarily selected to provide a resonably conservative value with which evaluations could be performed. This approach resulted in estimates of iron addition of $1.1 \mathrm{~kg} \mathrm{Fe} / \mathrm{kg} \mathrm{U}$ for sludge originating from $0.95 \%$ enriched fuel and $2.54 \mathrm{~kg} \mathrm{Fe} / \mathrm{kg} \mathrm{U}$ for sludge originating from $1.25 \%$ enriched fuel. Assuming that the $K$ East Basin contains a 11 the $0.95 \%$ enriched fuel and the $K$ West Basin contains only $1.25 \%$ enriched fuel, the amount of iron that would be added can be estimated by using the total estimated inventories of uranium in the basin sludges. If no credit is given for the iron already estimated to be within the basin sludges, the calculation is presented in Table A.4.1. If one takes credit for the iron that exists within the sludge. the quantity of iron needed drops as shown in Table A.4.2. The addition of iron to the sludge will result in a significant increase in sludge volume, particularly for the KW canister sludges. In addition, assuming the iron is added as ferric nitrate (to either dissolved or undissolved sludge) and then precipitated with sodium 
Table A.4.1. Calculation of the Quantity of Iron That Must Be Added to K East and $\mathrm{K}$ West Basin Sludge Without Considering Amount of Iron Already in Sludge.

\begin{tabular}{|c|c|c|c|c|c|}
\hline Total U (kg) & $\begin{array}{c}\text { Total Volume } \\
(1)\end{array}$ & $\begin{array}{c}\text { Fe:U Ratio } \\
\text { Required } \\
(\mathrm{kg} / \mathrm{kg})\end{array}$ & $\begin{array}{c}\text { Mass of } \\
\text { Fe } \\
\text { to Add } \\
(\mathrm{kg})\end{array}$ & $\begin{array}{c}\text { Mass of Fe to } \\
\text { Sludge } \\
\text { Volume }(\mathrm{g} / 1)\end{array}$ & $\begin{array}{c}\text { Concentration } \\
\text { of Fe Added } \\
\text { (mol/1) }\end{array}$ \\
\hline 9.845 & 44,400 & 1.1 & 10,830 & 244 & 4.37 \\
\hline \multicolumn{6}{|c|}{ K East Basin } \\
\hline 5.963 .7 & 8.635 & 2.54 & 15,148 & 1,754 & 31.41 \\
\hline
\end{tabular}

1 These conservative estimates were made prior to obtaining $K_{m}$ calculations for the sludge. The results of $K_{\infty}$ calculations indicate less iron would actually be needed (see appendix B).

Table A.4.2. Calculation of the Quantity of Iron That Must Be Added to K East and $K$ West Basin Sludge Taking into Account The Amount of Iron Already in Sludge

\begin{tabular}{|c|c|c|c|c|c|}
\hline Total U (kg) & $\begin{array}{c}\text { Mass of Fe } \\
\text { Needed }(\mathrm{kg})\end{array}$ & $\begin{array}{c}\text { Mass of Fe } \\
\text { Already in } \\
\text { Sludge }(\mathrm{kg})\end{array}$ & $\begin{array}{c}\text { Mass of Fe } \\
\text { to Add } \\
(\mathrm{kg})^{1}\end{array}$ & $\begin{array}{c}\text { Mass of Fe to } \\
\text { Sludge Volume } \\
(\mathrm{g} / 1)\end{array}$ & $\begin{array}{c}\text { Concentratio } \\
\text { n of Fe } \\
\text { Added } \\
(\mathrm{mol} / \mathrm{l})\end{array}$ \\
\hline \multicolumn{6}{|c|}{ K East Basin } \\
\hline 9,845 & 10,830 & $4,858.6$ & $5,971.4$ & 135 & 2.41 \\
\hline \multicolumn{6}{|c|}{ K West Basin } \\
\hline $5,963.7$ & 15,148 & 57.26 & 15,091 & 1,748 & 31.29 \\
\hline
\end{tabular}

1 These conservative estimates were made prior to obtaining $K_{.}$calculations for the sludge. The results of $K_{w} c a l c u l a t i o n s$ indicate less iron would actually be needed (see appendix $B$ ).

hydroxide solution, the volume of liquid added to the sludge will be significant relative to the sludge volume. The liquid volume will depend on the concentrations of ferric nitrate and sodium hydroxide (or other reagents) selected for the process so the actual liquid volume has not been estimated here.

The addition of iron has been used previously for wastes from PFP, but the amount of fissile material was much smaller. At PFP, the iron was added as $\mathrm{Fe}\left(\mathrm{NO}_{3}\right)_{3}$ and then precipitated by addition of potassium hydroxide 
(procedure 20-101-009. "perform batchwise chemical addition"). At K Basins, sodium hydroxide would likely be used to precipitate the iron added as ferric nitrate. Thus, although iron addition as dissolved ferric nitrate has been shown to be feasible for PFP wastes, the more concentrated Basin siudges (fissile uranium) warrant further study.

After transfer of the sludge into a shipping container and the addition of iron. the hydroxide and nitrite content wi 11 be adjusted to comply with corrosion specifications. The corrosion specification contained within the tank farm operating specification document (OSD-T-151-00007, Rev H 18) are reproduced below in Table A.4.3.

Table A.4.3. Corrosion Specifications For Waste to be Transferred to Tanks.

\begin{tabular}{|c|c|c|}
\hline$\left[\mathrm{NO}_{3}{ }^{-}\right]$Condition & Variable & Specification Limit \\
\hline \multirow{3}{*}{$\leq 1.0 \mathrm{M}$} & {$\left[\mathrm{OH}^{-}\right]$} & $0.010 \mathrm{M} \leq\left[\mathrm{OH}^{-}\right] \leq 5.0 \mathrm{M}$ \\
\hline & {$\left[\mathrm{NO}_{2}^{-}\right]$} & $0.011 \underline{\mathrm{M}} \leq\left[\mathrm{NO}_{2}^{-}\right] \leq 5.5 \mathrm{M}$ \\
\hline & & $\begin{array}{c}{\left[\mathrm{NO}_{3}^{-}\right] /\left(\left[\mathrm{OH}^{-}\right]+\left[\mathrm{NO}_{2}^{-}\right]\right)<} \\
2.5\end{array}$ \\
\hline \multirow{2}{*}{$\begin{array}{c}1.0 \underline{\mathrm{M}}<\left[\mathrm{NO}_{3}^{-}\right] \leq \\
3.0 \underline{\mathrm{M}}\end{array}$} & {$\left[\mathrm{OH}^{-}\right]$} & $0.1\left(\left[\mathrm{NO}_{3}^{-}\right]\right) \leq\left[\mathrm{OH}^{-}\right]<10 \mathrm{M}$ \\
\hline & & {$\left[\mathrm{OH}^{-}\right]+\left[\mathrm{NO}_{2}^{-}\right]>0.4\left(\left[\mathrm{NO}_{3}^{-}\right]\right)$} \\
\hline \multirow[b]{2}{*}[\mathrm{NO}_{3}^{-}]{$>3.0 \mathrm{M}$} & {$\left[\mathrm{OH}^{-}\right]$} & $0.3 \mathrm{M} \leq\left[\mathrm{OH}^{-}\right]<10 \mathrm{M}$ \\
\hline & & $\begin{array}{c}{\left[\mathrm{OH}^{-}\right]+\left[\mathrm{NO}_{2}^{-}\right] \geq 1.2 \underline{\mathrm{M}}} \\
{\left[\mathrm{NO}_{3}^{-}\right] \leq 5.5 \underline{\mathrm{M}}}\end{array}$ \\
\hline
\end{tabular}

The corrosion specifications are applied to the composition of the waste being considered for transfer, and not the composition of the current tank. Thus, the nitrate content of the tank receiving the waste does not enter into the evaluation for treating any new waste being added to that tank. It would appear that the nitrate concentration which would result after treating the $K$ Basin sludges, especially the $K$ West canister sludges, will be very high. The upper Timit 5.5 M may control the treated sludge and require significant 
dilution prior to transfer to the tank. That is, given the large quantity of iron that would be added to the basin sludges, the nitrate concentration of the treated basin sludge slurry would have to be kept below $5.5 \mathrm{M}$.

If no chemical processing of the $K$ Basin sludges is undertaken, then the amount of nitrate in the material to be transferred will be minor. For floor and pit sludge, the maximum nitrate measured in the water above a centrifuged sludge sample was $4.61 \mu \mathrm{g} / \mathrm{ml}$ or approximately $0.074 \mathrm{M}$. If equal amounts of free hydroxide and nitrite are assumed (and dilution effects during sludge transport, etc, are ignored), $0.015 \mathrm{M}$ nitrite and $0.015 \mathrm{M}$ free hydroxide would be needed to meet the specification. However, additional $\mathrm{NaOH}$ will be required to satisfy the caustic demand of the sludge. The caustic demand of $K$ East pit/floor sludge ranges from $4.9 \times 10^{-4}$ to $1.2 \times 10^{-4}$ moles of $\mathrm{OH}$ per gram of sludge. This would require addition of the equivalent of 0.2 to 0.6 moles of $\mathrm{NaOH}$ per liter of sludge. Similar values of caustic demand are obtained from K East canister sludge $\left(2.4 \times 10^{-4}\right.$ to $4.5 \times 10^{-4}$ with one value less than $2.5 \times 10^{-3}$ ). If a dilution of $1: 1$ is assumed in the transport container, the ionic strength of the transport container should be expected to be greater than $0.1 \mathrm{M}$.

However, nitrate wi 11 be added if iron is added to the sludge as $\mathrm{Fe}\left(\mathrm{NO}_{3}\right)_{3}$ or if the sludge is dissolved in nitric acid and then neutralized. In these cases, the nitrate content may be $>3 \mathrm{M}$ and the corrosion specification will require much higher levels of free hydroxide and nitrite to meet corrosion specifications. The actual ionic strength of the supernate for these transfers would depend on how the process were carried out, but would likely be greater than $1 M$ unless the solids are washed prior to transfer.

\section{A.4.2 State of Iron}

The state of the iron in the treated sludge will greatly depend on the specifics of the treatment. Assuming an oxidized system, the iron will exist in the +3 valence state. Dissolved $F e($ II) concentrations are typically quite low due to its tendency to precipitate or coprecipitate as hydroxide phases. Dissolved Fe(III) concentrations are especially low in high pH systems. For example, if the activity of dissolved iron is maintained by amorphous iron oxides $\left[\mathrm{Fe}(\mathrm{OH})_{3}\right]$, maghemite $\left(\gamma-\mathrm{Fe}_{2} \mathrm{O}_{3}\right)$, lepidocrocite $(\gamma-\mathrm{FeOOH})$, hematite $(\alpha-$ $\left.\mathrm{Fe}_{2} \mathrm{O}_{3}\right)$, or goethite $(\alpha-\mathrm{Fe} 0 \mathrm{OH})$, a 1000 -fold decrease in $\mathrm{Fe}^{3+}$ activity can be expected for each unit increase in pH (Lindsay 1979). Most of the dissolved Fe(III) species will likely exist as hydroxyl and possibly carbonate aqueous complexes.

A majority of the iron in the sludge system will be in the solid phase. The mineralogy of the iron is discussed below. The grain size of the iron 
HNF-SD-WM-ES-409, Rev. 0

phases wi11 vary greatly with mineralogy and the conditions under which the minerals are formed (Schwertmann and Taylor 1989). For example, goethite formed in high pH aqueous solutions is needle shaped and has a length of about $1 \mathrm{\mu m}$. When an iron phase is formed from oxidation of $\mathrm{Fe}(\mathrm{II})$, the precipitate is very poorly crystalline and has a diameter of about $0.05 \mu \mathrm{m}$. Hematite formed from ferrihydrite (nominally $5 \mathrm{Fe}_{2} \mathrm{O}_{3} \cdot 9 \mathrm{H}_{2} \mathrm{O}$ ) at $\mathrm{pH} 8$ has a diameter of about $0.1 \mu \mathrm{m}$. Lepidocrocite formed from oxidization of Fe(II) at pH 6 to 7 has a diameter of about $1 \mu \mathrm{m}$. On the other hand, ferrihydrite formed from the oxidation of $\mathrm{Fe}(\mathrm{II})$ has a diameter of $0.005 \mu \mathrm{m}$.

The extent to which these iron solid phases will aggregate will depend on a number of properties. including the size and surface charge of the colloids and the ionic strength, composition, and pH of the aqueous phase. These properties and how they influence aggregation and dispersion of colloidal suspensions are discussed in Section A.5.8.

A computer-assisted literature review was conducted to identify the range of possible zeta potentials of the iron phases that may form in the sludge. Zeta potential is a measure of the potential at the shear plane of a particle. Unfortunately, the location of the shear plane is difficult to define, but its potential is rather easy to measure. For that reason, the shear plane is commonly used to calculate the surface potential (Hiemenz 1986). Zeta potential values for various iron oxides are presented in Table A.4.4. At $\mathrm{pH} 7$, the zeta potentials for these iron oxides were generally positive, $+9.2 \pm 13 \mathrm{mV}$. At $\mathrm{pH} 11.5$, they were negative, $-23.8 \pm 15.8 \mathrm{mV}$. This trend is well documented (Stumm and Morgan 1981. Hiemenz 1986). The pH at which iron oxides have no charge, the zero-point-of-charge, is generally between pH 6.5 and 8.5 (Stumm and Morgan 1981). It is at the zero-point-ofcharge that the repulsive forces that reduce particle agglomeration are at a minimum. If the $\mathrm{pH}$ is changed from the the point of zero charge, the particle charge becomes more positive as the $\mathrm{pH}$ decreases or more negative as the $\mathrm{pH}$ increases. At the high pH of the tank waste environment. the iron oxides will have negative charges which contribute to repulsive forces (Table A.4.4). High dissolved salt contents effectively depress the repulsion due to the surface charge and encourage flocculation. For purposes of comparison. the zeta potentials of twelve sludge samples were $-19 \pm 4 \mathrm{mV}$ at $\mathrm{pH} 7$ and $-34 \pm 9$ $\mathrm{mV}$ at pH 11.5 (see Table A.5.21). 
HNF-SD-WM-ES-409, Rev. 0

Table A.4.4. Zeta Potential Values Reported for Iron Oxide Particles at pH Values of 7.0 and 11.5 .

\begin{tabular}{|c|c|c|l|}
\hline \multirow{2}{*}{ Sample } & \multicolumn{2}{|c|}{ Zeta Potentials $\mathrm{s}^{\mathrm{a}}$ (m) } & \multirow{2}{*}{ Reference } \\
\cline { 2 - 3 } & 7.0 & 11.5 & \\
\hline Fe-oxides & +10 & -40 & $\begin{array}{l}\text { Dumont et al. } \\
1976\end{array}$ \\
\hline Fe-oxides & +26 & -27 & $\begin{array}{l}\text { Dumont et al. } \\
1976\end{array}$ \\
\hline Fe-oxides & +22 & -- & $\begin{array}{l}\text { Dumont et a1. } \\
1976\end{array}$ \\
\hline Ferric hydroxide & +5 & -2 & Wang 1995 \\
\hline Goethite & 0 & -- & Hohl et a1. 1980 \\
\hline $\begin{array}{l}\text { Al-Ferric } \\
\text { hydroxide }\end{array}$ & -8 & -26 & Wang 1995 \\
\hline Average for Fe & $+9 \pm 13$ & $-24 \pm 16$ & \\
\hline $\begin{array}{l}\text { a In some cases the experimental data did not have zeta } \\
\text { potential values for pH levels as high as 11.5. In such } \\
\text { cases, the values were extrapolated. }\end{array}$ \\
\hline
\end{tabular}

\section{A.4.3 Potential Coprecipitation}

For the purposes of this appendix, two pretreatment options have been considered for $\mathrm{K}$ basin floor. pit and canister sludges. The principa? difference between the two options is that the sludge and iron (or other neutron absorber) are both dissolved and then reprecipitated together in one, whereas the addition of precipitated iron is conducted without dissolving the sludge in the second case. Iron is added to increase the neutron absorption cross section of the sludge. In both options. the final sludge is assumed to be adjusted by caustic and nitrite addition to meet AW-105 corrosion specifications.

In the sludge nondissolution case, there are two ways to increase the iron content of the sludges. One method is to add iron salt solutions to the basin. pit and canister sludges followed by titration with caustic ( $\mathrm{NaOH})$ to 
precipitate iron hydroxides: As the precipitated iron hydroxides age, they transform into oxyhydroxides and ultimately to oxidic phases. The precipitation and transformation pathways of these solid phases are described in Section A.2. Another method to increase the iron content of the sludge is to precipitate iron hydroxides separately and blend this slurry with the sludges to attain the designed absorber/fissionable material ratio. In either of these cases, no benefit from coprecipitation is obtained because the sludge particles are never dissolved.

However, the potential benefit of coprecipitation can be evaluated for the case where the sludge is dissolved and then precipitated along with the. iron. Coprecipitation phenomenon may influence the potential physical and chemical association of fissile phases with absorber material.

Coprecipitation is a phenomenon in which one or more of the constituents in a solution or suspension physically and/or chemically interact following induction of precipitation or adsorption reactions (Walton 1967. Sposito 1981). There are potentially four categories of coprecipitation. These are 1) solid solution formation in which two or more constituents precipitate as a single solid phase, 2) the precipitation of two or more components from a solution phase resulting in a mechanical mixture, 3) formation of inclusions in which particles of one or more trace constituent solid phases are physically encased by the precipitated solid phases of one or more major constituents, and 4) adsorption of a soluble trace constituent onto the surface functional groups of a precipitated major phase.

Solid solution formation, which is a type of coprecipitation, can occur if the constituent ions have ionic radii which do not differ significantly (within 15\%) from each other (Walton 1967). To assess the potential for coprecipitation of the fissile constituent uranium [U(IV) and U(VI)] in iron precipitates, the ionic radii for $U^{4+}$ and $U^{6+}$ can be compared to that for the adsorber constituent $\mathrm{Fe}^{+3}$. The ionic radii for $\mathrm{U}^{4+}$ and $\mathrm{U}^{6+}$ are 38 and $25 \%$. too large compared to the ionic radius of trivalent iron in octahedral coordination. Therefore, uranium ions in both valence states are too large to form solid solutions with any iron-containing solid phases such as hydroxides. oxyhydroxides, and oxides. Similarly, ionic radius constraint considerations likely precludes plutonium ions from forming any solid solution with ironcontaining adsorber solid phases.

Adsorption studies (e.g., Waite et al. 1994) show that U(VI) does not adsorb onto Fe(III) hydroxides at pH values exceeding 8 in the presence of carbon dioxide (carbonates). This nonadsorption behavior suggests that adsorption has no influence on the uranium and iron coprecipitation phenomenon under high alkaline conditions. 
The formation of inclusions occurs when one of the constituent is present in trace quantities. The pretreatment processes envisioned for sludges is unlikely to increase the absorber concentrations to the extent that the fissile material in the coprecipitated mass could be considered as a trace constituent. Therefore formation of mechanical mixtures would be the dominant physical phenomenon that would occur when fissiles and absorbers are coprecipitated during the pretreatment process. However. the types and rates of formation of each component in the mechanical mixtures would be controlled by the initial valence states of each constituent, the rate and amount of caustic addition, the rate of oxidation, and thermal treatment. These issues need to be examined during the development of the pretreatment process.

In conclusion it would appear that the precipitation of additional iron hydroxides within the existing $\mathrm{K}$ Basin sludges would not facilitate strong chemical bonding between the fissiles and added iron (neutron absorber) materials. However, the dissolution of sludge and iron and rapid reprecipitation will result in intimate mixing of the components and result in formation of very smal1 primary particulates for which agg 7 omeration should prevent differential settling. The existing sludges in both single-shell and double-shell tanks have been shown to be extremely fine grained primary particulates that readily agglomerate into larger clumps (see Whyatt et al. 1996). Tank sludge was formed by the same acid dissolution-rapid neutralization process proposed herein for the $K$ Basin sludges.

\section{A.4.4 Mineralogical/Solubility Changes Compared to $\mathrm{K}$ Basin Conditions}

As discussed in Section A.2.2.1, oxidation of uranium metal results in the formation of uraninite (nominal1y $\mathrm{UO}_{2}$ ) and its subsequent oxidation and hydration to produce the uranyl [U(VI)] oxide hydrates, such as schoepite $\left(\mathrm{UO}_{3} \cdot 2 \mathrm{H}_{2} \mathrm{O}\right)$ (Finch and Ewing 1990,1992$)$. Because schoepite always coexists with alkali and alkaline earth uranyl oxide hydrates (Finch and Ewing 1991). the addition of iron and caustic ( $\mathrm{NaOH}$ ) to the sludge should result in the transformation of uránium corrosion products, such as uranyl hydroxides like schoepite, to more complex solids, such as becquerelite $\left(\mathrm{CaU}_{6} \mathrm{O}_{19} \cdot 11 \mathrm{H}_{2} \mathrm{O}\right)$ and compreignacite $\left(\mathrm{K}_{2} \mathrm{U}_{6} \mathrm{O}_{19} \cdot 11 \mathrm{H}_{2} \mathrm{O}\right)$. As noted by Finch et a1. (1995) from studies of natural mineral specimens, becquerelite can remain stable for hundreds of thousands of years in geologic environments. Moreover, although sodium uranyl hydrates, such as clarkeite $\left[\left(\mathrm{Na}_{2}, \mathrm{Ca}, \mathrm{Pb}\right)_{2} \mathrm{U}_{2}(\mathrm{O}, \mathrm{OH})_{7}\right]$, are rare in nature. sodium uranates (e.g. $\mathrm{Na}_{2} \mathrm{U}_{2} \mathrm{O}_{7}$ ) have been identified as precipitates in laboratory experiments involving high $\mathrm{pH}$ and high alkali solutions containing dissolved uranium. Phases such as schoepite and becquerelite can in turn transform to more chemically complex minerals such as uranophane $\left(\mathrm{CaU}_{2} \mathrm{Si}_{2} \mathrm{O}_{11} \cdot 6 \mathrm{H}_{2} \mathrm{O}\right)$ and soddyite $\left(\mathrm{U}_{2} \mathrm{SiO}_{8} \cdot 2 \mathrm{H}_{2} \mathrm{O}\right)$ in the presence of dissolved silica. or the autunite series of uranyl phosphate minerals [e.g., $\left.\mathrm{Ca}\left(\mathrm{UO}_{2}\right)_{2}\left(\mathrm{PO}_{4}\right)_{2} \cdot 10 \mathrm{H}_{2} \mathrm{O}\right]$ 
in the presence of dissolved phosphate (Finch and Ewing 1992, Sowder et a1. 1996).

The solubilities of schoepite, uranophane, and other uranium minerals are very dependent on $\mathrm{pH}$. The addition of a caustic is Tikely to change the dissolved uranium concentrations by orders of magnitude so the dissolved uranium concentration will depend on the $\mathrm{pH}$ of the final waste slurry. Figure A.4.1 was adapted from Krupka and Serne (1997) who used MINTEQA2 to predict the solubilities of dissolved uranium in equilibrium with respect to schoepite and uranophane as a function of $\mathrm{pH}$ and oxidizing conditions. Their solubility calculations were based on geochemical conditions represented by the chemical evolution of a pore water composition changing from that of a highly alkaline cement porewater to that of a hypothetical near-neutral, carbonate-rich ground water. The predicted solubilities demonstrated the uranium solubilities are strongly dependent on the final $\mathrm{pH}$ and the composition of the final uranium precipitate.

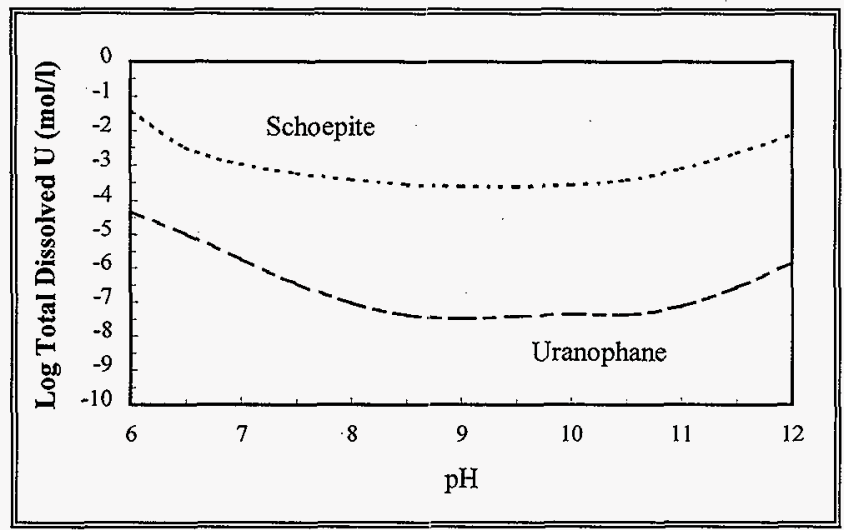

Figure A.4.1. Predicted Solubility of Dissolved Uranium with Respect to Schoepite and Uranophane as a Function of $\mathrm{pH}$. 
HNF-SD-WM-ES-409, Rev. 0

\section{A.5 Implications of Sludge Addition to Tank AW-105}

\section{A.5.1 Transfer of $K$ Basin Sludges to AW-105}

Sludge is proposed to be transferred from the KE and KW basins to Tank AW-105. In KE basin, the sludge is expected to come from a variety of sources including the main basin floor. canisters, cleaning of spent fuel, weasel pit, $\mathrm{N}$ loadout pit and channel (containing sand filter backwash), as well as minor amounts from other pits and channels connected to the basin. In KW basin. sludge is expected to come from sludge in canisters, the north loadout pit and channel (containing sand filter backwash), and sludge generated during fuel cleaning. The chemical composition of the sludges in KE basin floor and weasel pit have been characterized but most of the other sludges composition are estimates based on fuel and cladding compositions. KW Basin sludge wi11 be characterized in the next year. The KE basin floor and weasel pit sludges contain significant amounts of silica, alkali and alkaline earth cations and both inorganic and organic carbon besides the uranium, cladding ( $\mathrm{r}, \mathrm{A} 7$ ) and iron/steel hardware and canisters. The chemical composition of the KE basin floor and weasel pit sludges expressed as oxides are shown in Table A.3.1. The estimated total inventory of the sludge from KE and KW basins that would be transferred to Tank AW-105 or another new tank are shown in Table A.5.1 (based on masses estimated in internal memo DESH-9752731). The estimated mass after $K$ Basins sludge treatment (discussed below) and the current sludge contents of Tank AW-105 are also shown in Table A.5.1.

\section{A.5.1.1 K Basin Sludge Pretreatment and Transport}

The fate of the sludge in the KE and KW basins can be summarized as follows. The sludges will be consolidated via the integrated water treatment system into the Weasel Pit for KE basin with any particles $>1 / 4$ " removed and combined with fuel scrap. Plans for KW basin sludges are not as complete because it was initially believed that very little sludge would exist in the $\mathrm{KW}$ basin canisters. However, it is assumed for this analysis that $\mathrm{KW}$ sludge would be consolidated in the $\mathrm{N}$ loadout pit with a similar restriction on maximum particle size. 
Table A.5.1. Estimated Mass of Chemicals In Basin Sludges (As Is and After Treatment) Compared to STudge Mass Currentiy in Tank AW-105

\begin{tabular}{|c|c|c|c|c|c|}
\hline Constituent & Mass in $\mathrm{KE}$ & Mass in Treated & Mass in KW & Mass in Treated & Mass in Tank \\
\hline & Basin Sludge & KE Basin Sludge & Basin Sludge & KW Basin Sludge & AW-105 \\
\hline & $(\mathrm{Kg})$ & $(\mathrm{Kg})$ & $(\mathrm{Kg})$ & $(\mathrm{Kg})$ & $(\mathrm{Kg})$ \\
\hline U & 9.845 & 9,845 & 5,964 & 5,964 & 8.980 \\
\hline $\mathrm{Fe}$ & 4,859 & 10,830 & 57.3 & 15,148 & 26.600 \\
\hline 5102 & 3,639 & 3,639 & 0 & 0 & 0 \\
\hline $\mathrm{A}]$ & 832 & 832 & 23 & 23 & 0 \\
\hline $\mathrm{Zr}$ & 567 & 567 & 419 & 419 & 44,400 \\
\hline $\mathrm{Ca}$ & 232 & 232 & 13.8 & 13.8 & 4,840 \\
\hline $\mathrm{Na}$ & 57.5 & 57.5 & 1 & 1 & 104.000 \\
\hline TOC & 20.9 & 20.9 & NR & NR & 80 \\
\hline $\mathrm{Mg}$ & 39.7 & 39.7 & 1.9 & 1.9 & NR \\
\hline TIC & 36.6 & 36.6 & $\mathrm{NR}$ & NR & 1,550 \\
\hline $\mathrm{K}$ & 25.6 & 25.6 & 0 & 0 & 6,100 \\
\hline $2 n$ & 19.3 & 19.3 & 0.5 & 0.5 & NR \\
\hline $\mathrm{Cr}$ & 17 & 17 & 1.1 & 1.1 & 35 \\
\hline$M n$ & 10.9 & 10.9 & 0.92 & 0.92 & 27.8 \\
\hline $\mathrm{Cu}$ & 10.7 & 10.7 & 1.1 & 1.1 & NR \\
\hline $\mathrm{Pb}$ & 9.4 & 9.4 & 0.25 & 0.25 & 0.76 \\
\hline$T 1$ & 6.9 & 6.9 & 0 & 0 & $\mathrm{NR}$ \\
\hline $\mathrm{Ba}$ & 6 & 6 & 0.24 & 0.24 & NR \\
\hline$B$ & 4 & 4 & 0.002 & 0.002 & NR \\
\hline Se & 3.5 & 3.5 & 0.003 & 0.003 & $\mathrm{NR}$ \\
\hline$S m$ & 3.5 & 3.5 & 0 & 0 & 0 \\
\hline $\mathrm{Cd}$ & 1.6 & 1.6 & 0.13 & 0.13 & NR \\
\hline $\mathrm{Be}$ & 1.1 & 1.1 & 0.48 & 0.48 & $\mathrm{NR}$ \\
\hline $\mathrm{Ag}$ & 0.35 & 0.35 & NR & NR & $\mathrm{NR}$ \\
\hline $\mathrm{Hg}$ & NR & NR & $\mathrm{NR}$ & $\mathrm{NR}$ & 342 \\
\hline $\mathrm{Ni}$ & NR & NR & NR & NR & 621 \\
\hline $\mathrm{OH}$ & Low & 9,890 & Low & 13,800 & 80,700 \\
\hline $\mathrm{NO3}$ & Low & Some & Low & Some & 18,100 \\
\hline N02 & Low & Some & Low & Some & 383 \\
\hline $\mathrm{P} 04$ & 0 & 0 & 0 & 0 & 556 \\
\hline S04 & Low & Low & Low & Low & 33 \\
\hline$F$ & 0 & 0 & 0 & 0 & 81,700 \\
\hline $\mathrm{Cl}$ & Low & Low & Low & Low & 126 \\
\hline $\mathrm{NH} 3$ & 0 & 0 & 0. & 0 & 9.060 \\
\hline Reference & 1 & 3 & 1 & 3 & 2 \\
\hline
\end{tabular}


Tabie A.5.1. (continued)

Ref. 1 DESH-9752731 K Basins sludge Inventories to be Used in Sludge Disposal Evaluations - Preliminary Safety Assessment, Criticality Feasibility Report, Process Alternatives, Duke Engineering \& Services Company Letter, March 27, 1997, R. J. Lodwick to M. S. Madden, R. L. Schlosser and E. V. Morrey.

Ref. 2 Agnew, S. F. 1997, Hanford Tank Chemical and Radionuclide Inventories: HOW Model Ref. 3 Uses Reference 1 and the required Fe mass needed to make enriched $U$ mass subcritical. Amounts are based on 3 times a safe ratio using conservative estimates of iron addition requirements. This approach suggests addition of $1.1 \mathrm{~kg} \mathrm{Fe} / \mathrm{kg} \mathrm{U}$ for sludge originating from $0.95 \%$ enriched fuel and $2.54 \mathrm{~kg} \mathrm{Fe} / \mathrm{kg} \mathrm{U}$ for sludge originating from $1.25 \%$ enriched fue $\rceil$. Recent $K_{\infty}$ calculations for sludge indicate less iron than this may be acceptable.

Rev. 4, LA-UR-96-3860, Los Alamos National Laboratory, Los Alamos, New Mexico. $N R=$ Not Reported in the various references.

The $K$ Basin Process and Loadout System will retrieve the consolidated sludge and deliver it into the shipping package. At this point any required adjustments to the sludge will be made. These adjustments are assumed to include hydroxide and nitrite additions to comply with TWRS corrosion specifications, size reduction to assure particles are less than 0.05 in. diameter. addition of iron to meet criticality requirements, and any required treatments for removal of metal or hydride phases or PCB contamination. Any additional treatments required to make the sludge acceptable to TWRS would be performed at this point. The $K$ Basin Process and Loadout System may a 150 include the ability to reduce the water content of the sludge to maximize the sludge transferred per shipment. The system will include the capability to sample the sludge prior to shipment to TWRS (WHC-SD-SNF-FDC-006, Rev. 1). The shipping container will be mounted on a trailer and have a maximum volume capacity of $6 \mathrm{~m}^{3}$ [ 1600 gallons], which will contain slurry with 10 to $30 \mathrm{vo} . \%$ solids with the remainder being interstitial liquid (WHC-SD-TP-PDC-035, Rev 0 , WHC-SD-SNF-CDR-008, Rev 0.). The transport container includes HEPA filtered vents which are sealed during transport. The transport system also includes a pumping system to facilitate the offloading of sludge to the Siudge Receiving Station which consists of sloped. double-contained piping leading to a centra] riser in AW-105 and a spil1 retention basin to confine the transport system during the offload process (WHC-SD-WM-FDC-052, Rev 0 ). The sludge is discharged into the AW-105 via an existing slurry distributor at a maximum flow rate of $50 \mathrm{gpm}$. Thus a full shipping cask would take at least 31.7 hours to transfer into the tank. There will be a capability to flush the system through the transport container following sludge transfer. The flush system has a minimum capacity of 3200 gallons delivered at $20 \mathrm{gpm}$. The STudge Receiving Station wi71 accept up to $68 \mathrm{~m}^{3}$ of sludge beginning in January 2000 and finishing in December 2000 (WHC-SD-SNF-CDR-008, Rev 0). Based on the current estimates of sludge in $K$ East and $K$ West Basins, there are 44.4 (upper bound 59.3 ) $\mathrm{m}^{3}$ of sludge in $\mathrm{K}$ East Basin and 8.5 (upper bound 13.6) $\mathrm{m}^{3}$ of 
sludge in $K$ West Basin ${ }^{1}$. If the shipping cask contains between 10 and $30 \%$ vol of sludge and the rest is Basin waters it wi 11 take approximately 250 to 750 shipments to transfer all of the $K$ East sludge and 5 to 15 shipments to transfer all of the $K$ west sludge. These values do not include any additional volume increase caused by treating the sludge to incorporate more iron (neutron absorber) and to precondition the contents ( $\mathrm{OH}$ and nitrite) to be compatible with tank corrosion specifications.

\section{A.5.2 Tank AW-105}

\section{A.5.2.1 History of Tank 105-AW}

This double-shell tank located in the southeast portion of the 200 East Area was constructed and put into service in 1980. The tank has a design capacity of 1.16 million gallons but based on safety considerations is limited to holding $1: 14$ miliion gallons maximum. The first wastes placed in the tank were salt slurry from the 242-A evaporator and/or low level wastes from B Plant operations dependent upon references (DiCenso et al. 1994 and Agnew 1997). In late 1983 one transfer of dilute non-complexed sulfate waste (no organic complexing agents were present) originating from $100-\mathrm{N}$ was placed in the tank (225.000 ga7.). Since late 1983 through the present the main wastes transferred to the tank have been PUREX decladding (also called neutralized cladding removal waste-NCRW) and dilute, noncomplexed waste from miscellaneous waste streams at PUREX. In the Hanford Defined Waste (HDW) scheme (see Agnew 1997. 1995) the former waste is designated CWZr2 and the 1atter is designated PL2. According to Agnew (1997) during the first fiscal quarter of 1988 another batch of salt slurry concentrate from the 242-A evaporator was transferred into Tank 105-AW. This waste has been given the HDW designation SMMA2 and was previously labeled A2S1tSTr. At numerous times the supernatant liquid and sometimes some of the settled/suspended solids were removed from the tank and transferred to others or sent to the 242-A evaporator. Since 1994 the tank has been the active receiver tank for wastes from the following specific facilities within PUREX: tanks F-18, U-3, and U-4. The wastes in these facilities are process solutions such as sump water, steam condensate, rain water and minor amounts of laboratory waste and $\dot{U}$ and Pu nitrate solutions (see DiCenso et a1. 1994). Based on some assumptions on percentages of solids in the various HOW waste streams and the historical monitoring data on sludge levels in the tank. Agnew (1997) has estimated the sludge composition and supernate chemical nature as of December 1996. [Note that the

(1) Estimate includes the volume expected from fuel washing and is taken from a Duke Engineering and Services Hanford Inc. internal memo, R. B. Baker to K. L. Pearce, Current Estimates of STudge Volumes in K East and $K$ West Basins. March 19, 1997. 
transfer records used to perform the calculations do not show any entries after the fourth quarter of 1993 (see Agnew 1997. Appendix C, page C.53), yet the TWINS electronic data base does show significant transfers out occurred at the end of Nov. 1994 and Nov. 1995 and transfers in of more PL2 waste between Dec. 1994-Nov. 1995 and Jan. 1996-Feb. 1997.] We wi1l use Agnew (1997) as the primary source for estimates [to compare with actual analytical data] of the chemical nature of tank supernate solution and tank sludge despite this potential discrepancy. We will also compare actual chemical analyses data on solids and solutions taken from the tank to the estimated contents.

\section{A.5.2.2 Pu Content in Transfers to AW-1.05}

The Double Shel1 Tank Plutonium Inventory Tracking System has 1,306 waste transfers recorded for 241-AW-105 since the first quarter of 1981. Of those transfers. 456 batches contained either no plutonium or plutonium at a concentration so low that the cumulative plutonium inventory within the tank remained unchanged. The total quantity of plutonium sent to 241-AW-105, according to the inventory tracking system is $13.242 \mathrm{~g}$. Of the 850 plutonium bearing waste transfers 32 batches contained greater than 100 grams of plutonium and 29 of those batches were received between June 17, 1994 and April 25, 1995. During that time period the tank received approximately $60 \%$ of the plutonium currently contained in the tank. Therefore, the vertical portion of the waste with the highest plutonium concentration is expected to be near the top of the sludge layer. Transfers to AW-105 became less frequent after 1995.

The inventory tracking system records the source, volume and $\mathrm{Pu}$ concentration in the transfers. However, detailed compositional information is not recorded so it is difficult to predict the thickness of sludge layers resulting from transfers. For purposes of this scoping study, a11 transfers were assumed to have the same solids concentration and the solids in $1.15 \times 10^{7}$ Titers of transfers were assumed to be responsible for formation of $1.08 \times 10^{6}$ liters (286,000 gallons) of existing sludge in AW-105. Any solids content in liquid transfers out of the tank were neglected. Taking into account the sludge volume and $\mathrm{Pu}$ associated with each transfer, the concentration in the sludge deposited from each transfer was calculated. The results of this evaluation are shown in Figure A.5.1. The horizontal axis shows the estimated sludge volume accumulation from 1981 through February 1997. The left axis shows the estimated $\mathrm{Pu}$ content in solids resulting from each transfer. The right axis provides the accumulating total Pu inventory according to the inventory tracking system. The high-Pu layer near the top of the sludge can be seen by the sudden change in the Pu accumulation curve between 88 and 94 


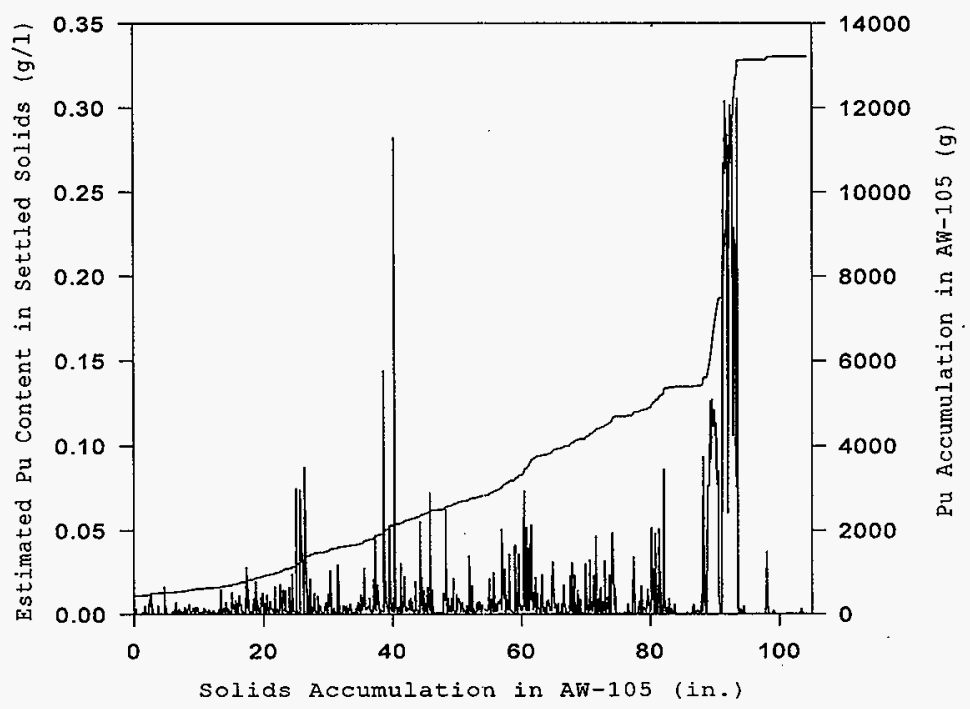

Figure A.5.1 Inventory Tracking System Estimates of Pu and Sludge Accumulation. The estimated Pu concentration in settled solids from each transfer and total Pu accumulation are plotted against the estimated accumulation of sludge in tank AW-105.

inches of sludge accumulation. The tank currently contains 104 inches of sludge so the concentrated layer is estimated to be approximately 10 inches below the surface.

It should be noted that several different estimates of the AW-105 Pu inventory are available. As discussed above, the DST Plutonium Inventory Tracking System provides an estimate of $13.2 \mathrm{~kg}$. Agnew et al. (1996) and Agnew (1997) present estimates of $12.6 \mathrm{~kg}$ and $18.7 \mathrm{~kg}$ respective $7 \mathrm{y}$ based on a combination of actual transfer records, waste stream chemistry assumptions and 
HNF-SD-WM-ES-409, Rev. 0

tank sludge and supernate volumes. Alternatively, an electronic version of the document by Tusler (1995) indicates $23.0 \mathrm{~kg}$.

\section{A.5.2.3. Current Tank Status}

Table A.5.2 contains current data on the amount of supernate liquid, sludge and free space in the tank over the past several years. More details on the tank contents versus time can be found in DiCenso et a 1 . (1994) and the TWINS electronic data base under the categories Tank Surface Leve 1 and Tank Transfer Events. There is some difference in the tank contents estimates between sludge and supernate designations between the TWINS electronic data base and DiCenso et a1. (1994).

Table A.5.2. Volume Contents in Tank AW-105 in Ga1lons (TWINS electronic database)

\begin{tabular}{|c|c|c|c|c|}
\hline Date & Supernate & Sludge & Total & Free Space \\
\hline June 1994* & $7.510 \mathrm{e}+05$ & $2.970 \mathrm{e}+05$ & $1.048 \mathrm{e}+06$ & $9.20 \mathrm{e}+04$ \\
\hline June 17,1994 & $6.600 \mathrm{e}+05$ & $3.880 \mathrm{e}+05$ & $1.048 \mathrm{e}+06$ & $9.200 \mathrm{e}+04$ \\
\hline Feb 28, 1997 & $1.520 \mathrm{e}+05$ & $2.860 \mathrm{e}+05$ & $4.380 \mathrm{e}+05$ & $7.020 \mathrm{e}+05$ \\
\hline
\end{tabular}

* DiCenso et a1. (1994)

The temperature history of the tank since 1990 has ranged from 50 to $75^{\circ}$ $\mathrm{F}$. The temperature has dropped down to 50 to $65^{\circ} \mathrm{F}$ since 1994 as more material was been removed from the tank in 1994-1995. Since early 1994 the majority of the waste transferred into the tank has come from tanks E6 and D5 in the PUREX facility that contained a rather purified U(VI) nitrate solution $(150 \mathrm{~g} / 7$ with minor amounts of $\mathrm{Pu}$ ) in $1 \mathrm{M}$ nitric acid. The total inventory was estimated to be $5,000 \mathrm{~kg}$ of $U$ that contained $9 \mathrm{~kg}$ of $\mathrm{Pu}$. The acid solution was neutralized with $50 \%$ sodium hydroxide in tank F18 and the resultant slurry was transferred to AW-105. Cadmium was either added at some point in the process or was originally present in the acid solution. Detailed measurements of $\mathrm{Pu}, \mathrm{U}$ and $\mathrm{Cd}$ for each batch of solution that was neutralized in tank F18 are available. The data reveal that $7.8 \mathrm{~kg}$ of Pu were transferred to the tank between May 21, 1994 and June 30,1996 . The $7.8 \mathrm{~kg}$ of Pu represents from $34 \%$ to $59 \%$ of the total Pu estimated to be in AW-105 dependent upon which estimate of tota] Pu inventory is selected (see section A.5.2.2 for more discussion). This portion is present in a relatively small volume of sludge compared to the total sludge content in the tank. The newest layers of sludge contains the $5,000 \mathrm{~kg}$ of $\mathrm{U}$ and more than $30 \mathrm{~kg}$ of $\mathrm{Cd}$. One might expect to see elevated $\mathrm{Pu}$ and $U$ concentrations in this uppermost sludge compared to 
HNF-SD-WM-ES-409, Rev. 0

the older sludge that is deeper in the tank. In the next section we explore this possibility by reviewing the analytical data from various sampling events.

\section{A.5.2.4 Sampling History of Tank.}

In reverse order the tank has been sampled in August 1996. August 1995 , 1990, 1988, and 1986. Over August 20-21, 1996 twenty bottle (grab samples) were taken through two risers [10A ( 9 samples) and 15A (11 samples)]. The analytical results from these samples are documented in Esch (1997). Table A.5.3 shows what phases were sampled. On August 29, 1995 three grab samples of supernate liquid were taken out of riser 10A. On May 14-17, 1990 samples were taken from riser 168 using a 1-inch diameter coring device that obtained successive 19-inch long segments. The first two segments contained only supernate liquid, while segments 3 through seven contained sludge and no free liquid. Depths within the tank at which the segments were obtained could not be established.

Table A.5.4 shows details on the material retrieved. In 1988 liquid grab samples were taken out of the tank. In late June or early July, 1986 a core sample was taken that contained 10 segments; the top 3 were solution, the fourth segment was empty and the 5th contained mostly liquid with 2 inches of white sludge. Segments 6 through 9 contained white sludge that was a runny s7urry in the upper segments and "tooth paste consistency" by segment 9 . The last segment (10) contained 7 inches of white sludge and 12 inches of black sludge in the bottom. The bottom segment containing the 12 inches of dark solids contained $70 \%$ of the Am and U inventory for the whole tank. The density of the sludge (wet) in segments 5 through 10 varied as follows: $1.22,1.34$, $1.28,1.36,1.41$, and $1.42 \mathrm{~g} / \mathrm{cm}^{3}$.

\section{A.5.2.5 Current Composition of Supernatant Liquid in Tank AW-105}

Twenty grab samples were collected from risers $10 \mathrm{~A}$ and $15 \mathrm{~A}$ on August 20 21, 1996. Twelve samples were used to perform various chemical analyses and 8 were used in K Basin sludge compatibility and mixing studies. All the data summarized herein was taken from Esch (1997). Samples 5AW-96-1 through 5AW96-9 were taken through Riser 10A and samples 5AW-96-10 through 5AW-96-20 were taken through Riser 15A. Table A.5.5 shows the details on the twelve samples 
Table A.5.3. Details on the Grab Samples Taken in Aug. 1996

\begin{tabular}{|c|c|c|c|}
\hline Sample \# & $\begin{array}{l}\text { Sampling } \\
\text { Depth } \\
\text { (in.) }\end{array}$ & \% Solids & Comments \\
\hline 5 AW-96-1 & 511 & Trace & clear yellow liquid. no organic layer \\
\hline 5 AW-96-2 & 529 & Trace & clear yellow liquid, no organic layer \\
\hline 5 AW $-96-4$ & 548 & Trace & clear yellow liquid, no organic layer \\
\hline $5 A W-96-5$ & 571 & 22 & $\begin{array}{c}\text { clear yellow Tiquid, no organic layer: } \\
\text { sludge soft, yellow with sma1l black } \\
\text { particles }\end{array}$ \\
\hline 5 AW-96-7 & 588 & 90 & $\begin{array}{c}\text { sludge soft, yellow/gray with smali black } \\
\text { particles }\end{array}$ \\
\hline 5 AW-96-9 & 589 & 90 & $\begin{array}{l}\text { sludge soft inhomogeneous, yellow and gray } \\
\text { with some smal1 black particles }\end{array}$ \\
\hline 5 AW $-96-10$ & 511 & Trace & clear yellow liquid, no organic layer \\
\hline 5 AW $-96-11$ & 529 & Trace & clear yellow liquid, no organic layer \\
\hline 5 AW-96-14 & 548 & Trace & clear yellow liquid, no organic layer \\
\hline 5 AW-96-15 & 571 & 90 & $\begin{array}{l}\text { sludge soft inhomogeneous, yellow and gray } \\
\text { with some small black particles }\end{array}$ \\
\hline 5 AW $-96-17$ & 593 & 90 & $\begin{array}{c}\text { sludge soft inhomogeneous, dark gray/black } \\
\text { with some yellow swirled within }\end{array}$ \\
\hline 5 AW $-96-20$ & 600 & 93 & $\begin{array}{c}\text { sludge soft inhomogeneous, yellow and gray } \\
\text { swirled together with some larger chunks } \\
\text { some black and some white }\end{array}$ \\
\hline
\end{tabular}

sample depth is measured from top of riser to mouth of sample bottle.

According to T. S. Vail the tank bottom is located at 666 inches from the top of the riser. Thus one can calculate the sample position from the bottom of the tank as 666- depth from top or riser. 
HNF-SD-WM-ES-409, Rev. 0

Table A.5.4. Description of the Core Samples Obtained in May 1990

\begin{tabular}{|c|c|c|c|c|c|}
\hline Segment & Weight (g) & $\begin{array}{c}\text { BuTk } \\
\text { Density } \\
\left(\mathrm{g} / \mathrm{cm}^{3}\right)\end{array}$ & $\begin{array}{c}\text { Calc. } \\
\text { Length of } \\
\text { Material } \\
\text { (in.) }\end{array}$ & $\begin{array}{c}\% \\
\text { Recovery }\end{array}$ & Comments \\
\hline 1 & 221 & & 15.2 & 80.0 & $\begin{array}{c}\text { opaque } \\
\text { 7iquid }\end{array}$ \\
\hline 2 & 265 & 1.08 & 18.2 & 95.7 & $\begin{array}{c}\text { opaque } \\
\text { liquid }\end{array}$ \\
\hline 3 & 294 & & 17.5 & 92.1 & $\begin{array}{c}\text { gray slurry } \\
\text { no shape }\end{array}$ \\
\hline 4 & 314 & 1.35 & 18.7 & 98.4 & white \\
\hline 5 & 307 & 1.40 & 17.5 & 92.6 & dry, white \\
\hline 6 & 323 & 1.44 & 18.0 & 94.7 & gray/white \\
\cline { 1 - 1 } & 122 & 1.50 & 6.52 & 34.3 & hard, dark \\
\hline 7 & & & & & \\
\hline
\end{tabular}

for which chemical analyses were performed. The specific gravity of the supernatant liquid decanted off the bulk samples ranged from 1.01 to 1.04 with a mean of $1.022 \mathrm{~g} / \mathrm{cm}^{3}$. Interstitial liouid removed from the settled solids after centrifugation had a specific gravity of 0.98 to 1.09 with a mean of $1.04 \mathrm{~g} / \mathrm{cm}^{3}$. The chemical composition of the supernate liquids, interstitial liquids removed from the wet sludge after centrifugation and the wet centrifuged sludge itself are shown in Tables A.5.5 through A.5.7. The density of the wet centrifuged sludges ranged from 1.15 to $1.32 \mathrm{~g} / \mathrm{cm}^{3}$. 
Table A.5.5. Chemical Composition of the Supernatant Liquids Removed From Tank in Aug. 1996 (mg/L)

\begin{tabular}{|c|c|c|c|c|c|c|}
\hline \multirow{2}{*}{$\begin{array}{c}\text { Distance above } \\
\text { tank bottom (in.) }\end{array}$} & \multicolumn{2}{|c|}{155} & \multicolumn{2}{|c|}{137} & \multicolumn{2}{|c|}{118} \\
\hline & 5 AW-96-1 & 5 AW $-96-10$ & $5 A W-96-2$ & 5AW-96-11 & 5 AW-96-4 & 5 AW-96-14 \\
\hline \multicolumn{7}{|l|}{ Constituent } \\
\hline $\mathrm{Al}$ & 16 & 16 & 17 & 17 & 17 & 89 \\
\hline$B$ & 3 & 3 & 5.5 & 2.7 & $<2$ & 2.8 \\
\hline $\mathrm{Ca}$ & $<4$ & $<4$ & 6 & 4.2 & $<4$ & $<4$ \\
\hline $\mathrm{Cr}$ & 0.6 & 0.6 & 0.6 & 0.6 & 0.6 & 4 \\
\hline $\mathrm{Fe}$ & $<2$ & $<2$ & $<2$ & $<2$ & $<2$ & $<4$ \\
\hline$k$ & 1.240 & 1.270 & 1.280 & 1,310 & 1,320 & 3,340 \\
\hline $\mathrm{Mg}$ & $<4$ & $<4$ & $<4$ & $<4$ & $<4$ & $<4$ \\
\hline $\mathrm{Mn}$ & $<0.4$ & $<0.4$ & $<0.4$ & $<0.4$ & $<0.4$ & $<0.4$ \\
\hline $\mathrm{Na}$ & 12,600 & 12.800 & 12.800 & 12.900 & 13.000 & 18.800 \\
\hline $\mathrm{OH}$ & 3.320 & 2,880 & 3.780 & 3.260 & 3.230 & 5.160 \\
\hline$P\left(\right.$ as $\left.\mathrm{PO}_{4}\right)$ & 43 & 40 & 41 & 36.6 & 41 & 168 \\
\hline $\mathrm{PO}_{4}$ & $<70$ & $594 *$ & $<130$ & $<130$ & $<70$ & $<130$ \\
\hline $\mathrm{S}\left(\right.$ as $\left.\mathrm{SO}_{4}\right)$ & 140 & 140 & 140 & 142 & 140 & 285 \\
\hline $\mathrm{SO}_{4}$ & 165 & $1630^{*}$ & 225 & 200 & 180 & 215 \\
\hline Si & 46 & 40 & 51 & 39 & 48 & 48 \\
\hline$F$ & 140 & $12600^{*}$ & 155 & 130 & 170 & 155 \\
\hline $\mathrm{Cl}$ & 225 & 410 & 245 & 210 & 220 & 250 \\
\hline $\mathrm{NO}_{3}$ & 24.000 & 28.100 & 24.600 & 24,700 & 24,100 & 28,800 \\
\hline $\mathrm{NO}_{2}$ & 1,100 & 4.690 & 1.170 & 1,080 & 1,110 & 1.270 \\
\hline TIC & 190 & 430 & 190 & 380 & 185 & 460 \\
\hline TOC & 4.620 & 1.520 & . 102 & 1.430 & 4,840 & 1.690 \\
\hline $\mathrm{pH}$ & 13.39 & 13.41 & 13.43 & 13.46 & 13.48 & 13.64 \\
\hline U & $<20$ & $<20$ & $<20$ & $<20$ & $<20$ & $<20$ \\
\hline $\mathrm{Pu}(\mu \mathrm{Ci} / \mathrm{L})$ & $<0.003$ & $\mathrm{NR}^{\star *}$ & $<0.004$ & $<0.004$ & $<0.004$ & $<0.004$ \\
\hline
\end{tabular}

* appears to be 10 times higher than probable, a dilution or transcription error is likely ** $N R=$ not reported 
HNF-SD-WM-ES-409, Rev. 0

Table A.5.6. Chemical Composition of Interstitial Water (mg/L) Sampled in Aug. 1996

\begin{tabular}{|c|c|c|c|c|c|c|}
\hline $\begin{array}{c}\text { Distance } \\
\text { above tank } \\
\text { bottom (in.) }\end{array}$ & 95 & 95 & 78 & 79 & 73 & 66 \\
\hline Sample \# & 5 AW- $96-5$ & $5 A W-96-15$ & $5 A W-96-7$ & $5 A W-96-9$ & 5AW-96-17 & 5 AW- $96-20$ \\
\hline \multicolumn{7}{|l|}{ Constituent } \\
\hline Al & 132 & 460 & 705 & 660 & 705 & 590 \\
\hline$B$ & 9 & $<5$ & 6 & $<5$ & $<5$ & $<5$ \\
\hline $\mathrm{Ca}$ & 57 & $<10$ & $<10$ & $<10$ & $<10$ & $<10$ \\
\hline $\mathrm{Cr}$ & 7.6 & $<1$ & 28.4 & 30.5 & 33 & 36 \\
\hline $\mathrm{Fe}$ & 17 & $<<5$ & $<5$ & $<5$ & $<5$ & $<5$ \\
\hline$k$ & 4,150 & 7.360 & 11,000 & 10.300 & 10,400 & 9,330 \\
\hline $\mathrm{Mg}$ & $<10$ & $<10$ & $<1.0$ & $<10$ & $<10$ & $<10$ \\
\hline Mn & $<1.5$ & $<1$ & $<1$ & $<1$ & $<1$ & $<1$ \\
\hline $\mathrm{Na}$ & 21,100 & 27.700 & 37.100 & 37,200 & 37,000 & 36.800 \\
\hline $\mathrm{OH}$ & 5,440 & 7.530 & 8.580 & 9,460 & 9.220 & 8,860 \\
\hline $\mathrm{P}\left(\right.$ as $\left.\mathrm{PO}_{4}\right)$ & 320 & 760 & 1,360 & 1.275 & 1.200 & 1,200 \\
\hline $\mathrm{PO}_{4}$ & $<130$ & 594 & 305 & 595 & 390 & 400 \\
\hline $\mathrm{S}\left(\mathrm{aS} \mathrm{SO}_{4}\right)$ & 450 & 1.050 & 1,760 & 1.630 & 1.590 & 1.375 \\
\hline $\mathrm{SO}_{4}$ & 405 & 950 & 1,560 & 1,630 & 1.510 & 1,260 \\
\hline Si & 104 & 33 & 58 & 54 & 51 & 54 \\
\hline$F$ & 1.500 & 4,230 & 9,610 & 12,600 & 10.500 & 9.850 \\
\hline $\mathrm{Cl}$ & 250 & 395 & 310 & 410 & 320 & 300 \\
\hline $\mathrm{NO}_{3}$ & 33.700 & 29,200 & 26,900 & 27.900 & 27,000 & 30.300 \\
\hline $\mathrm{NO}_{2}$ & 1,520 & 2,970 & 4,640 & 4.690 & 4,270 & 3.930 \\
\hline TIC & 425 & 580 & 845 & 740 & 780 & 680 \\
\hline TOC & 740 & 1,670 & 2,540 & 2.210 & 2.270 & 1,870 \\
\hline $\mathrm{pH}$ & 13.25 & 13.47 & 13.47 & 13.52 & 13.43 & 13.31 \\
\hline U & 270 & $<50$ & 137 & $<50$ & 67 & $<50$ \\
\hline $\mathrm{Pu}(\mu \mathrm{Ci} / \mathrm{L})$ & $N R^{\star \star}$ & $N R^{* *}$ & $N R * * *$ & $N R * *$ & $N^{* * *}$ & $\mathrm{NR}^{\star \star}$ \\
\hline
\end{tabular}


Three grab samples of supernate liquid were taken from riser $10 \mathrm{~A}$ on August 29, 1995 (see Esch 1995). Numerous chemical analyses were performed on all three samples. Although there has been a major transfer of liquid out of the tank since these supernates were taken the type of waste added since the removal is the same as that present when the samples were taken. Thus it is useful to see if the 1995 data agrees with the most recent samples taken in August 1996.

The chemical composition of the three supernatant grab samples from 1995 are shown in Table A.5.7. The first two samples in the table were described as being clear, colorless liquids while the third was a clear, yellow liquid. None of the samples showed evidence of a floating organic layer. The dose rate

Table A.5.7. Chemical Composition (mg/L) or (UCi/L) of Supernate--Aug 1995

\begin{tabular}{|c|c|c|c|}
\hline Constituent & $5 \mathrm{AW}-95-1$ & $5 \mathrm{AW}-95-2$ & $5 \mathrm{AW}-95-3$ \\
\hline $\mathrm{Na}$ & 9.860 & 10,400 & 17.300 \\
\hline $\mathrm{Al}$ & 36 & 43 & 145 \\
\hline $\mathrm{Fe}$ & $<1$ & $<1$ & $<2$ \\
\hline $\mathrm{K}$ & $\mathrm{NR}$ & $\mathrm{NR}$ & $\mathrm{NR}$ \\
\hline $\mathrm{NH}_{4}$ & 72 & 110 & 570 \\
\hline $\mathrm{OH}$ & 3.300 & 3.450 & 5.120 \\
\hline $\mathrm{NO}_{3}$ & 13,000 & 15,900 & 21.300 \\
\hline $\mathrm{NO}_{2}$ & 780 & 860 & 1.180 \\
\hline $\mathrm{F}$ & 440 & 540 & 1.590 \\
\hline $\mathrm{Cl}$ & 33 & 42 & 94 \\
\hline Inorganic C & 120 & 100 & 220 \\
\hline $\mathrm{SO}_{4}$ & 110 & 115 & 310 \\
\hline $\mathrm{PO}_{4}$ & $<60$ & $<60$ & 128 \\
\hline Organic C & 250 & 220 & 830 \\
\hline $\mathrm{pH}$ & 13.36 & 13.24 & 13.16 \\
\hline
\end{tabular}


HNF-SD-WM-ES-409, ReV. 0

from the third sample is much higher than the first two. The specific gravity of the three liquids was 1.00 to $1.01 \mathrm{~g} / \mathrm{cm}^{3}$. In general the solutions are very basic, sodium nitrate solutions with minor amounts of ammonia, nitrite. fluoride and carbonate. The cation anion balance is acceptable $(< \pm 10 \%$ out of balance). The nature of the dissolved organic carbon is not measured but likely is not dominating the Pu or U chemistry (see Serne et al. 1996 for discussions on the influence of dissolved organic carbon in SST wastes on Pu chemistry). Uranium concentrations in these supernates were not measured. There is no measurable dissolved iron in the solutions. It is not clear whether the three grab samples represent samples taken at ever increasing depths in the tank liquid but there does appear to be significant differences between the third sample and the first two. The third sample was yellow in color and contains much higher dissolved concentrations of all constituents including Pu. Thus there may be stratification within the liquids in Tank AW105. The chemical composition is similar to samples taken recently in 1996 as one might expect given the similarity in wastes transferred to the tank between samplings.

The supernate samples obtained in 1990 (shown in Table A.5.4 were composited as follows prior to any chemical analysis: the supernates [segments 1 and 2] were mixed together in equal proportions by weight. The supernate composite was filtered through 0.2 um prior to analysis. The results for the supernate liquids in early samplings are shown in Table A.5.8.

DiCenso et a1. (1994) quotes an internal letter [Mauss 1985] that suggests that a thin separate organic layer existed in the tank in 1985 that consisted of $30 \%$ tributyl phosphate and $70 \%$ normal paraffin hydrocarbon. the organic phase used to separate $P u$ and $U$ from the aqueous phase during the PUREX process. There is no other mention in the more recent sampling events of such a separate organic layer in the tank. To the contrary it is stated that no separated organic layer was observed in the liquid samples taken in 1995 and 1996. It is not clear that bottle grab samples would easily detect a thin separate organic phase floating on the top of the supernate unless the bottle was positioned precisely at the level where the two phases met. 
HNF-SD-WM-ES-409, ReV, 0

Table A.5.8. Chemical Composition (mg/L) of Supernate Sampled in 1990 or 1988

\begin{tabular}{|c|c|c|}
\hline Constituent & Composite Seg. 1 and 2 & 1988, (Coroneos 1990) \\
\hline $\mathrm{Na}$ & 34.200 & - \\
\hline Al & 906 & -- \\
\hline$B$ & 3.3 & - \\
\hline $\mathrm{Cr}$ & 32.5 & - \\
\hline $\mathrm{Fe}$ & 0.7 & -- \\
\hline K & 13,700 & -- \\
\hline $\mathrm{Mg}$ & 0.4 & -- \\
\hline Mn & 0.04 & -- \\
\hline $\mathrm{Na}$ & 34.200 & -- \\
\hline $\mathrm{Ni}$ & 1 & -- \\
\hline $\mathrm{P}$ as $\mathrm{PO}_{4}$ & 970 & $-\cdot$ \\
\hline Si & 210 & -- \\
\hline $\mathrm{NH}_{4}$ & 1.020 & 750 \\
\hline $2 r$ & 0.5 & -. \\
\hline $\mathrm{OH}$ & 12,900 & 6.550 \\
\hline $\mathrm{NO}_{3}$ & 24,000 & 15,900 \\
\hline $\mathrm{NO}_{2}$ & 4,900 & 1,480 \\
\hline $\mathrm{F}$ & 8,300 & 3,220 \\
\hline $\mathrm{Cl}$ & 440 & 150 \\
\hline Inorganic $\mathrm{C}$ & 1,940 & -- \\
\hline Inorganic $\mathrm{C}$ as $\mathrm{CO}_{3}$ & $6.480^{\circ}$ & 1,990 \\
\hline $\mathrm{SO}_{4}$ & 1.760 & 960 \\
\hline $\mathrm{PO}_{4}$ & 660 & 470 \\
\hline Organic C & 650 & $-\cdot$ \\
\hline $\mathrm{pH}$ & 13.2 & - \\
\hline$u$ & 17 & -- \\
\hline${ }^{239 / 240} \mathrm{Pu}(\mu \mathrm{Ci} / \mathrm{L})$ & 0.045 & -- \\
\hline
\end{tabular}


The chemical composition of supernate liquid and interstitial water within sludge slurry has changed with time. Back in 1986-1990 the solution was more concentrated than in recent years (1995-96 and presumably now).

This is likely caused by the change from active fuel reprocessing to a more dilute miscellaneous PUREX waste stream making up the tank contents. The average chemical composition of supernate solution currently in the tank that will be used in all further calculations is shown in the section A.5.2.8 which summarizes the characterization data. It should be pointed out that there is evidence of layering in the solution, especially within the liquid entrained in the sludge slurry. The deeper depths of the tank contain more concentrated pore liquids and even the supernate shows some stratification.

\section{A.5.2.6. Composition of the Sludge in Tank AW-105}

The most recent sampling of sludge was performed in Aug. 1996 using bottle (grab) sampling techniques: Earlier in 1990 a core was obtained from the tank. The core segments obtained in 1990 (shown in Table A.5.4 were composited as follows prior to any chemical analysis: the sludges in cores 3 and 4 were mixed in equal portions by weight., and the sludges in segments 3 . 4,5 , and 6 were mixed in equal portions. Segment 7 was analyzed separately. The sludges were fused to facilitate dissolution and completely dissolved to measure metals and radionuclides. Water leaches of the sludges at a ratio of $1 \mathrm{~g}$ solid to $100 \mathrm{mls}$ water were used to measure anions. The results of these two recent sludge samplings are shown in Tables A.5.9 and A.5.10

The two samples taken at 95 inches above the tank bottom are still 9 inches below the calculated interface between sludge and supernatant solution. Depending upon how many inches of sludge were added to the tank during the transfer of the U(VI)-rich slurries from tanks E6 and D5 between earTy 1994 and the August 1996 sampling the expected $\mathrm{Pu}$ and U-enriched upper sludge may be evident in the analysis of sample 96-15 but it is not evident in sample 9605. Further looking at tank transfer records we find two significant transfers out of Tank AW-105 to Tank AP'-108 between Nov 30 and Dec 01, 1994 and one transfer out between Nov 13 and 15, 1995 to Tank AP-104 that may have entrained some of the upper layer of sludge. Thus it is difficult to assert that the analytical data corroborate the expected enriched Pu/U sludge layer at the very top of the existing sludge layer.

The core taken in 1986 was analyzed for a few constituents and the results are shown in Table A.5.11. Both in 1986 and 1990 there is evidence of distinct layering in the sludge with the bottom-most 12 inches being very different than the uppermost sludge. 
Table A.5.9. Chemical Composition of Centrifuged Sludge $(\mathrm{mg} / \mathrm{kg})$ Sampled in Aug. 1996

\begin{tabular}{|c|c|c|c|c|c|c|}
\hline $\begin{array}{c}\text { Distance } \\
\text { above tank } \\
\text { bottom (in.) }\end{array}$ & 95 & 95 & 78 & 77 & 73 & 66 \\
\hline Sample \# & $5 A W \cdot 96-5$ & 5an-96-15 & 5Ali $-96-7$ & $5 A H-96-9$ & $5 A W-96-17$ & 5AW- $-96-20$ \\
\hline \multicolumn{7}{|l|}{ constituent } \\
\hline $\mathrm{Al}$ & $<1810$ & 1.150 & 1.110 & 1.210 & 1.680 & 1.530 \\
\hline$B$ & $<1810$ & $<1000$ & $<970$ & $<1020$ & $<1000$ & $<1000$ \\
\hline $\mathrm{Ca}$ & 9.300 & $<2000$ & $<1940$ & $<2010$ & $<2000$ & $<2000$ \\
\hline $\mathrm{Cr}$ & $<360$ & $<200$ & $<190$ & $<250$ & 730 & 210 \\
\hline $\mathrm{Fe}$ & 3.740 & 2.350 & 2.260 & 1.340 & 4.580 & 1.680 \\
\hline La & $<1800$ & 1.100 & 1.570 & 1.460 & 2.280 & 1.040 \\
\hline $\mathrm{Mg}$ & $<3630$ & $<2000$ & $<1940$ & $<2050$ & $<2000$ & $<2000$ \\
\hline Mn & $<360$ & 770 & $\$ 70$ & 840 & 4.140 & 740 \\
\hline $\mathrm{Na}$ & 78.800 & 62.900 & 95.000 & 91.100 & 79.400 & 69.600 \\
\hline $\mathrm{Zr}$ & 570 & 16.600 & 84,200 & 69.600 & 77.800 & 17.200 \\
\hline $\mathrm{OH}$ & $<40$ & $N^{*}$ & $<40$ & $<40$ & $<40$ & $<40$ \\
\hline$P\left(\right.$ as $\left.P_{4}\right)$ & $<2400$ & $<6000$ & $<1170$ & $<1300$ & $<12000$ & $<12000$ \\
\hline $\mathrm{PO}_{4}$ & 465 & $<620$ & $<1170$ & $<470$ & $<580$ & $<600$ \\
\hline $\mathrm{S}\left(\mathrm{aS} \mathrm{SO}_{4}\right)$ & $<10.000$ & $<5000$ & $<580$ & $<6000$ & $<6000$ & $<6000$ \\
\hline $\mathrm{SO}_{4}$ & 425 & $<700$ & 1.630 & 1.220 & 1.680 & 1.240 \\
\hline Si & $<1810$ & $<1000$ & 1.100 & 1.000 & 1.260 & $<1000$ \\
\hline $\mathrm{F}$ & 1.400 & 1.110 & 36.600 & 28,400 & 20.000 & 4.190 \\
\hline $\mathrm{Cl}$ & 205 & 307 & 170 & 200 & 120 & 365 \\
\hline $\mathrm{NO}_{3}$ & 26.300 & 29.100 & 17,800 & 18.300 & 18.700 & 22.700 \\
\hline $\mathrm{NO}_{2}$ & 1.280 & 1.710 & 3.600 & 2.990 & 3.440 & 2.560 \\
\hline TIC & 1.100 & 650 & 920 & 874 & 810 & 700 \\
\hline TOC & 1.770 & 1.340 & 1.740 & 1.670 & 2.200 & 1.600 \\
\hline $\mathrm{pH}$ & 11.68 & 12.34 & 12.25 & 12.46 & 12.31 & 12.48 \\
\hline $\mathrm{U}$ & 59.000 & 95.100 & 43.800 & 54,500 & 42.800 & 94.400 \\
\hline $\mathrm{Pu}(\mu \mathrm{Ci} / \mathrm{g})$ & 0.45 & 3.62 & 1.7 & 1.75 & 3.4 & 3.26 \\
\hline
\end{tabular}


HNF-SD-WM-ES-409, Rev. 0

Table A.5.10. Chemical Composition of Sludges Sampled in 1990 ( $\mu \mathrm{g} / \mathrm{g}$ Centrifuged Sludge)

\begin{tabular}{|c|c|c|c|c|}
\hline Constituent & $\begin{array}{c}\text { Composite of } \\
\text { Segments } 3 \\
\text { and } 4\end{array}$ & Segment 5 & Segment 6 & Segment 7 \\
\hline $\mathrm{Na}$ & 27.000 & 27,000 & 28.700 & 25,500 \\
\hline A1 & 3.240 & 2.520 & 3.320 & 36,600 \\
\hline B & $<1200$ & 470 & 470 & 470 \\
\hline $\mathrm{Ca}$ & 940 & 690 & 700 & 980 \\
\hline $\mathrm{Cr}$ & 680 & 520 & 480 & 17,500 \\
\hline $\mathrm{Fe}$ & 3.590 & 1.720 & 1,580 & 19,400 \\
\hline K & 20.200 & 23.700 & 10.300 & 4,710 \\
\hline $\mathrm{Mg}$ & 91 & 41 & 81 & 580 \\
\hline Mn & 950 & 106 & 152 & 5.500 \\
\hline $\mathrm{Na}$ & 27.000 & 27,000 & 28,700 & 25.500 \\
\hline $\mathrm{Ni}$ & 380 & 180 & 290 & 560 \\
\hline $\mathrm{P}$ as $\mathrm{PO}_{4}$ & 13.240 & 17.960 & 3.770 & 7,660 \\
\hline $\mathrm{Si}$ & 8.880 & 8.270 & 4,920 & 3,060 \\
\hline $\mathrm{NH}_{4}$ & 1.020 & 820 & 750 & 150 \\
\hline $2 r$ & 238,000 & 210.000 & 216,000 & 23.600 \\
\hline $\mathrm{OH}$ & -- & $-\cdot$ & -- & -. \\
\hline $\mathrm{NO}_{3}$ & 41.500 & 46.000 & 42,000 & 81,000 \\
\hline $\mathrm{NO}_{2}$ & 12.100 & 18.000 & 30.000 & 7.700 \\
\hline$F$ & 86.800 & 170.000 & 150,000 & 22,000 \\
\hline $\mathrm{Cl}$ & 1,820 & 2.800 & 2,500 & 1,900 \\
\hline Inorganic C & 19.000 & 6.500 & 7,700 & 36,800 \\
\hline $\begin{array}{c}\text { Inorganic } \mathrm{C} \text { as } \\
\mathrm{CO}_{3}\end{array}$ & 80.000 & 12,000 & 21,000 & 28,500 \\
\hline $\mathrm{SO}_{4}$ & 2.600 & 3,100 & 1.800 & 5,600 \\
\hline $\mathrm{PO}_{4}$ & 1,120 & 2,900 & 500 & 1,300 \\
\hline Organic C & 3,000 & 4,100 & 3.500 & 29,300 \\
\hline $\mathrm{pH}$ & -- & -- & -- & 12.8 \\
\hline$U$ & 3.100 & 24.400 & 30.600 & 12.500 \\
\hline${ }^{239 / 240} \mathrm{Pu}(\mu \mathrm{Ci} / \mathrm{g})$ & 3.04 & 2.98 & 1.78 & 0.24 \\
\hline
\end{tabular}


HNF-SD-WM-ES-409, Rev. 0

Table A.5.11. Chemical Composition of the Sludge Sampled in 1986--ug/g wet

\begin{tabular}{|c|c|c|c|c|c|c|}
\hline $\begin{array}{c}\text { Constitue } \\
\mathrm{nt}\end{array}$ & $\begin{array}{c}\text { Segment } \\
5\end{array}$ & $\begin{array}{c}\text { Segment } \\
6\end{array}$ & $\begin{array}{c}\text { Segment } \\
7\end{array}$ & $\begin{array}{c}\text { Segment } \\
8\end{array}$ & $\begin{array}{c}\text { Segment } \\
9\end{array}$ & $\begin{array}{c}\text { Segment } \\
10\end{array}$ \\
\hline $\mathrm{A} 7$ & $<500$ & 900 & $<900$ & 1,150 & 1,600 & 6.600 \\
\hline $\mathrm{Cr}$ & $<100$ & $<100$ & $<100$ & $<100$ & $<100$ & 3,400 \\
\hline $\mathrm{Fe}$ & 200 & 650 & 300 & 550 & 400 & 10,100 \\
\hline $\mathrm{K}$ & 13,000 & 12,000 & 10,000 & 8,000 & $<5000$ & $<2000$ \\
\hline $\mathrm{La}$ & 400 & 700 & 600 & 400 & $<100$ & $<100$ \\
\hline $\mathrm{Mn}$ & $<100$ & $<100$ & $<100$ & $<100$ & $<100$ & 5,650 \\
\hline $\mathrm{Na}$ & 65,700 & 98,000 & 90,200 & 100,000 & 125,000 & 107,000 \\
\hline $\mathrm{Sn}$ & 400 & 700 & 500 & 650 & 800 & 750 \\
\hline $\mathrm{Zr}$ & 50,900 & 75.700 & 65,300 & 73,800 & 82,000 & 30,100 \\
\hline $\mathrm{U}$ & 1,800 & 4,750 & 4.500 & 4.750 & 13,800 & 59,800 \\
\hline $\begin{array}{c}239 / 240 \mathrm{Pu} \\
(\mu \mathrm{Cj} / \mathrm{g})\end{array}$ & 0.27 & 0.52 & 1.14 & 0.38 & 0.67 & 0.54 \\
\hline
\end{tabular}

\section{A.5.2.7 Organics in AW-105}

The task of measuring organic species in the complex highly radioactive tank phases is truly difficult. To date the organic analyses attempted have emphasized measuring chelating agents; chelating agent fragments, butyl phosphates, low-molecular-weight water-soluble organic acids and normal paraffin hydrocarbons (NPH).

To evaluate how well the organic analyses have identified the major organic compounds present in the tank materials, organic chemists have tried to calculate mass balances by comparing the organic carbon mass in the species identified with the total organic carbon measured in bulk material removed from the tanks. The bulk material consists of supernate solutions and solids, mainly sludge slurries. 
HNF-SD-WM-ES-409, Rev. 0

Not a 11 organic carbon is "seen" by a11 the techniques used to measure total organic carbon. Two commonly used methods to measure total organic carbon in tank materials are as follows:

- Hot persulfate oxidation, which acidifies a tank sample to drive off inorganic carbon. The remaining sample is then oxidized using a silver catalyst, heat, and persulfate to form carbon dioxide gas, which is collected and analyzed. This method assumes that the acidification and sparging do not liberate volatile organic materia1. Long chain organics such as NPH, surfactants, acetone, butanol, benzene, and organic polymers do not react quantitatively using this technique.

- Combustion, where the sample is heated to $600{ }^{\circ} \mathrm{C}$ in the presence of oxygen gas. The resultant carbon dioxide is measured to quantify the organic carbon content.

Analysts believe that combustion may more accurately measure total organic carbon, but it is not generally used on actual tank samples. The hot persulfate method is favored, so the actual amount of organic carbon in the tanks may be $\sim 0.5$ to 2 percent by weight higher in tank solids and 0.5 to 1.5 percent higher in tank supernate than generally reported The types of organic carbon that have been found to predominate in aqueous phases in tank samples (chelators, chelator fragments, and low molecular weight organic acids) react fairly quantitatively using the persulfate technique, so we can compare the mass of carbon species identified with the total organic carbon value to estimate how much organic carbon has not yet been identified.

The results of the mass balance check for the amount of organic carbon identified using detailed speciation techniques versus total organic carbon is improving. The current range is between 50 and 90 percent, with an average of 80 to 90 percent. This improvement is most7y because cation exchange techniques are now used to remove radioactive constituents, especially cesium and strontium, from tank samples. After the radioactive constituents are removed, the samples can be transferred from the hot cell to fume hoods for analysis using techniques that are specific for extracting organic materials. Being able to perform detailed work in a fume hood instead of being limited to the crude operations that can be performed in a hot cell lead to significant improvement in mass balance on organic carbon.

There has been no organic speciation measurements on the organics in Tank AW-105 supernatant solution or sludge. Samples from Tank AW-101 have 
recentiy been obtained to initiate organic speciation measurements but no data are available at this time. The tank with PUREX wastes closest to those in Tank AW-105 is single-shel 7 tank $\mathrm{C}-103$. The organic speciation results are shown in Tables A.5.12 through A.5.14 (see Campbell et a1. 1995b).

Table A.5.12. Organic Compounds and Other Inorganic Species Found in Organic Layer of Tank C-103.

\begin{tabular}{|l|c|}
\hline \multicolumn{1}{|c|}{ Species } & Weight \% \\
\hline TBP & 47.2 \\
\hline Tridecane $\left(C_{13}\right)$ & 11.4 \\
\hline Tetradecane $\left(C_{14}\right)$ & 6.0 \\
\hline Dodecane $\left(C_{12}\right)$ & 2.8 \\
\hline DBBP & 1.9 \\
\hline Pentadecane $\left(C_{15}\right)$ & 0.9 \\
\hline Various branch alkanes & 3.5 \\
\hline Water & 1.3 \\
\hline Ammonia & $<0.003$ \\
\hline Water-soluble anions & $<0.005$ \\
\hline Water-soluble cations & $<0.010$ \\
\hline Gross Alpha Emitters & $550(\mathrm{pCi} / \mathrm{g})$ \\
\hline Plutonium & $2.43 \cdot 10^{-3} \mathrm{ppm}$ \\
\hline Gross Beta Emitters & $1.05 \cdot 10^{+5}(\mathrm{pCi} / \mathrm{g})$ \\
\hline 90Sr & $5.5 \cdot 10^{+5}(\mathrm{pCi} / \mathrm{g})$ \\
\hline 137Cs & $4.1 \cdot 10^{+4}(\mathrm{pCi} / \mathrm{g})$ \\
\hline Others & $\sim 1.0 \cdot 10^{+3}(\mathrm{pCi} / \mathrm{g})$ \\
\hline Total Mass Identified & 75.0 \\
\hline & \\
\hline
\end{tabular}


Table A.5.13. Analysis of Supernate Solution in Tank C-103.

\begin{tabular}{|c|c|}
\hline Constituent & $\begin{array}{c}\text { Concentration (units are ppm } \\
\text { unless specified) }\end{array}$ \\
\hline Gross Alpha Emitters & $4.35 \cdot 10^{+4} \mathrm{pCi} / \mathrm{mL}$ \\
\hline Gross Beta Emitters & $7.06 \cdot 10^{+7} \mathrm{pCi} / \mathrm{mL}$ \\
\hline${ }^{137} \mathrm{Cs}$ & $5.79 \cdot 10^{+7} \mathrm{pCi} / \mathrm{mL}$ \\
\hline${ }^{60} \mathrm{Co}$ & $5.11 \cdot 10^{+4} \mathrm{pCi} / \mathrm{mL}$ \\
\hline \multicolumn{2}{|l|}{ Cations } \\
\hline Ammonia & 0.23 \\
\hline Sodium & 32800 \\
\hline $\mathrm{U}$ & 2100 \\
\hline$k$ & 320 \\
\hline$Z r$ & 300 \\
\hline $\mathrm{Ni}$ & 72 \\
\hline $\mathrm{Cr}$ & 57 \\
\hline $\mathrm{Ca}$ & 5 \\
\hline $\mathrm{Fe}$ & 3 \\
\hline \multicolumn{2}{|l|}{ Anions } \\
\hline Nitrite & 24800 \\
\hline Sulfate & 3230 \\
\hline Nitrate & 2590 \\
\hline Phosphate & 2200 \\
\hline Fluoride & 1200 \\
\hline Chioride & 430 \\
\hline Inorganic Carbon & 5175 \\
\hline Organic Carbon & 7200 \\
\hline $\mathrm{pH}$ & 10 \\
\hline Density & $1.078 \mathrm{~g} / \mathrm{mL}$ @ $25^{\circ} \mathrm{C}$ \\
\hline
\end{tabular}

A5. 22 
HNF-SD-WM-ES-409, Rev. 0

Table A.5.14. Organic Carbon Analyses on Tank C-103 Samples.

\begin{tabular}{|c|c|c|}
\hline \multirow[t]{2}{*}{ Sample \# } & \multicolumn{2}{|c|}{ Solids } \\
\hline & TOC (mg C/g) & $\begin{array}{c}\text { Oxalate (mg } \\
\mathrm{C} / \mathrm{g})\end{array}$ \\
\hline Core 63-Seg. 2(upper) & 8.5 & 2.66 \\
\hline Core 63-Seg. 2(lower) & 10.2 & -- \\
\hline Core 63-Seg. 3(upper) & 7.6 & 1.94 \\
\hline Core 63 -Seg. 3(1ower) & 8.9 & -- \\
\hline Core 63-Seg. 4 & 4.5 & 2.32 \\
\hline Core 66 -Seg. 3 (upper) & 8.9 & 3.92 \\
\hline Core 66 -Seg. 3 (lower) & -- & 2.96 \\
\hline Core 66 -Seg. 4 & 9.2 & 2.96 \\
\hline Sample \# & \multicolumn{2}{|c|}{ Liquids } \\
\hline Solids & TOC (mg/mL) & Oxalate $(\mathrm{mg} / \mathrm{mL})$ \\
\hline Core $63-$ Seg. $1^{\circ}$ & 7.71 & 3.36 \\
\hline Core $63-$ Seg. 2 & 7.61 & - \\
\hline Core $63-$ Seg. 4 & -- & 3.36 \\
\hline Core 66 -Seg. 1 & - & 3.14 \\
\hline Core 66 -Seg. 2 & -- & 3.1 \\
\hline Core $66-$ Seg. 3 & -- & 2.96 \\
\hline Core 66 -Seg. 4 & -- & 2.73 \\
\hline
\end{tabular}

Single-shel1 tank $\mathrm{C}-103$ has a distinct organic solution layer floating on top. Some of this material was diluted 10,000 times with methylene chloride and analyzed by GC/MS using the chemical ionization mode to determine 
HNF-SD-WM-ES-409, Rev. 0

molecular weight. High-resolution mass spectrometry also was used to improve our ability to identify the compounds. Table A.5.12 lists the organic carbon species results for this organic layer. The relative weight of [TBP + DBBP] to [NPH] is about 2:1. The "missing" mass in the organic layer was mostly inorganic (perhaps colloidal suspension) matter that was identified by SEM to be metal-sulfate salts; alumino-silicate particles; calcium phosphate particles; and iron, chromium, and aluminum hydrous oxide particles.

A sample of tank C-103 aqueous supernate layer was mixed with equal portions of distilled water and extracted three times with methylene chloride. The organic extracts were then conditioned and evaporated to $1 \mathrm{ml}$ volume and analyzed by GC/MS. The only organics (water-insoluble) found in the liquid phase were TBP at $80 \mathrm{ppm}$, DBBP at $7 \mathrm{ppm}$, and NPH at $\sim 1$ to $3 \mathrm{ppm}$.

Data on the chemical composition of the aqueous phase (supernate solution) underlying the aforementioned discrete organic phase in Tank C-103 are shown in Table A.5.13. The aqueous phase was measured for inorganic cations, anions, carbon, and radionuclides and for some physical properties such as viscosity and density, as well as for the water-insoluble organics just noted and the water-soluble organics mentioned in the next paragraph. Other data currently available on the water-soluble portion of supernate tank solids from Tank C-103 are shown in Table A.5.14. The TOC values were determined using the persulfate oxidation method. The oxalate values were determined by ion chromatography. The TOC content of the tank Tiquids and solids from this single-shell tank is slightly lower than for the double-shell tank (see Serne et a1. 1996), but more oxalate is present in single-shell tank liquids than in double-shell tank liquids and less oxalate is present in single-shell tank solids than in double-shell tank solids.

From the few data available one can estimate that the tank supernate aqueous solutions may contain up to $3.8 \mathrm{mg}$ of $\mathrm{c} / \mathrm{g}$ of solution of EDTA, which is the strongest complexing agent for plutonium, iron, and aluminum, as we11 as most other metals present in the tanks One mole of EDTA contains 10 carbon moles, so the highest concentration of EDTA measured to date in supernate solution is $\sim 0.04 \mathrm{M}$. All other identified chelating agents are present at lower concentrations. The highest concentration of low-molecular weight acids (LMWA) (about $2.0 \mathrm{mg} \mathrm{C} / \mathrm{mL}$ ) found in tank supernate solutions occurs in singleshell tanks. One mole of oxalic acid contains two carbon atoms, thus the molarity of the supernate solution would be $0.15 \mathrm{M}$. The single-she 11 tank studied also had an immiscible liquid organic layer consisting primarily of TBP and degradation products. TBP is used to enhance the extraction of the neutral species $\mathrm{Pu}\left(\mathrm{NO}_{3}\right)_{4}{ }_{4}$ from the aqueous phase into the $\mathrm{NPH}$ organic phase 
during the PUREX process. The proportion of the Pu that exists as this neutral species is highest under strong nitric acid conditions: Upon destroying the acid via sodium hydroxide neutralization. the Pu speciation will change dramatical1y such that hydroxide and carbonate aqueous complexes wi 71 predominate and nitrate complexes will become insignificant. The strength of the TBP-organic phase to retain Pu will also decrease as $\mathrm{pH}$ is increased because the aqueous phase will "draw" the Pu-nitrate species back out to form other charged carbonate/hydroxide species that favor the aqueous phase and to form Pu insoluble solids. This decreasing TBP-NPH-actinide association with increasing $\mathrm{pH}$ may be the cause for the very low plutonium and other radionuclides activities in the discrete organic layer (see Table A.5.12) in Tank C-103 when compared to the aqueous phase. Further, the ability of TBP to enhance extraction of nuetral U(VI)-nitrate species is expected to be low compared to actinide (IV) complexes because U(VI) nitrate complexes are not as stable as actinide (IV) complexes. Because U(VI) is the expected form of $U$ in the tank solutions we would not expect much tendency for $\mathrm{U}$ or Pu to be present in a discrete organic phase (TBP and NPH) should such a phase actually exist in Tank AW-105. The concentration of plutonium in either the organic liquid (in Tank C-103 as a proxy for any possible organic layer in Tank AW-105) or the supernate is much lower than values needed to reach criticality. Therefore, the potential presence of this separated organic layer does not create a criticality concern.

Campbell et a1. (1995a, b) describe several aging mechanisms that should change the nature and quantity of organics in the discrete organic layers present in some tanks, and likely in aqueous layers, although this is not stated in the reports. The high caustic content of the Hanford Site tanks should result in saponification of TBP to DBP (dibutyl phosphate) and, because DBP is much more water soluble than TBP, it should be extracted from the discrete organic phase into the aqueous fluids. Further. TBP undergoes radiolytic decomposition.

The NPH in the discrete floating organic layers in a few tanks is somewhat volatile under tank heat conditions. NPH decomposes radiolytically to carboxylic acids that are much more water soluble than NPH. Therefore the carboxylic acids will migrate towards the aqueous layers and some of the for long-chained acids perhaps precipitate and coat the inorganic sludges. Also, the passive ventilation systems present in some tanks has allowed some NPH to escape from the tank headspace.

At present we believe that the organic ligands present in Hanford Site 
tanks that could influence plutonium and uranium solubility are found at relatively low concentrations compared to free hydroxide and carbonate and most are also chemically unstable and are continually being transformed into molecules with even weaker complex-forming capabilities.

Delegard and Gallagher (1983) show in an empirical fashion that relatively high concentrations of chelating agents [HEDTA to $0.1 \mathrm{M}$. EDTA to $0.05 \mathrm{M}$, hydroxyacetate to $0.1 \mathrm{M}$, and citrate to $0.03 \mathrm{M}$ ] did not increase the solubility of plutonium in tank environments.

Camaioni et a7. (1995) also discuss ongoing work that shows radiation can degrade the complexing agents. Babad (personal communication 1996) says that the half-7ife data for EDTA measured by Camaioni et al. (1995) as a function of gamma dose rate equals about half the EDTA that degrades every 15 years. We are presently consider the issue of organic constituents as insignificant to increasing plutonium and uranium solubility.

\section{A.5.2.8 Summary}

The chemical composition of supernate solution currently in Tank AW-105 is shown in Table A.5.15. The liquid is a sodium, potassium, ammonium. nitrate, hydroxide, nitrite, carbonate, fluoride solution with a very high pH value of 13.47. There is indications that the composition increases with depth within the tank suggesting that the tank liquid is stratified. There is no soluble $\mathrm{Fe}$ in the supernate but there is a small amount of $\mathrm{B}$. These are two popular neutron absorbers often used to moderate the criticality potential of such wastes. Uranium and plutonium are sparingly soluble in the liquid and are below detection limits. There is a significant amount of dissolved organic carbon in the supernate solution but it has not been speciated to determine what type. 
HNF-SD-WM-ES-409, Rev. 0

Table A.5.15. Chemical Composition of the Supernatant Liquids--mg/L

\begin{tabular}{|c|c|c|c|c|}
\hline Constituent & $\mathrm{mg} / \mathrm{L}$ & $\mathrm{mM}$ & $\begin{array}{c}\text { Agnew } \\
\text { Prediction } \\
\text { CWZr2, (mg/L) }\end{array}$ & $\begin{array}{c}\text { Agnew } \\
\text { Prediction } \\
\text { PL2. }(\mathrm{mg} / \mathrm{L})\end{array}$ \\
\hline AT & 30 & 1 & 0 & 0 \\
\hline$B$ & 3 & 0.3 & $\cdots$ & -- \\
\hline $\mathrm{Ca}$ & 4 & 0.1 & 355. & 350 \\
\hline $\mathrm{Cr}$ & 1 & 0.02 & 0 & 400 \\
\hline $\mathrm{Fe}$ & $<2$ & $<0.04$ & 110 & 110 \\
\hline$k$ & 1,630 & 4.2 & 8.630 & 260 \\
\hline $\mathrm{Mg}$ & $<4$ & $<0.2$ & -- & -- \\
\hline $\mathrm{Mn}$ & $<0.4$ & $<0.008$ & 0 & 320 \\
\hline $\mathrm{Na}$ & 13.800 & 600 & 11,110 & 14,410 \\
\hline $\mathrm{NH}_{4}$ & 275 & 15.3 & 13,080 & 0 \\
\hline $\mathrm{OH}$ & 3,600 & 210 & 1,880 & 625 \\
\hline $\mathrm{P}\left(\right.$ as $\left.\mathrm{PO}_{4}\right)$ & 60 & 0.6 & 0 & 6.470 \\
\hline $\mathrm{SO}_{4}$ & 190 & 2 & 0 & 380 \\
\hline Si & 45 & 1.6 & 0 & 0 \\
\hline$F$ & 335 & 1.8 & 4,480 & 0 \\
\hline $\mathrm{Cl}$ & 260 & 7.3 & 160 & 135 \\
\hline $\mathrm{NO}_{3}$ & 25.720 & 415 & 23,880 & 15,600 \\
\hline $\mathrm{NO}_{2}$ & 1.740 & 38 & 410 & 450 \\
\hline TIC & 305 & 25 & 0 & 105 \\
\hline TOC & 2.370 & -- & 0 & * \\
\hline $\mathrm{pH}$ & 13.47 & -- & $\cdots$ & -- \\
\hline$U$ & $<20$ & $<0.08$ & 940 & 930 \\
\hline $\mathrm{Pu}(\mu \mathrm{Ci} / \mathrm{L})$ & $<0.004$ & $<4 \times 10^{-8}$ & 0.008 & 0.008 \\
\hline $\begin{array}{l}\text { Specific } \\
\text { Gravity }\end{array}$ & $\begin{array}{l}1.01 \text { to } 1.04 \\
\text { with a mean } \\
\text { of } 1.022 \\
\mathrm{~g} / \mathrm{cm}^{3} \text {. }\end{array}$ & -- & -- & -- \\
\hline$T^{\circ} \mathrm{F}$ & 50 to 60 & $\cdots$ & -- & -- \\
\hline
\end{tabular}

* contains 700 ppm DBP and 250 ppm butảnol 
The chemical composition of the Sludge in Tank AW-105 is summarized in Table A.5.16. There is a distinctly different layer of sludge in the bottommost 12 inches of the tank that is treated as a separate type from the remainder of the sludge. Currently there is approximately 286.000 gallons of sludge that should equate to filling the bottom 104 inches of the tank. Thus, the unique 12 -inch strata at the tank bottom represents only $12 \%$ of the total sludge volume. The chemical composition of the sludge is difficult to evaluate because $a 17$ of the analyses available are measured on centrifuged or settled samples that still contain a large but unmeasured amount of water. Solids should be measured on a dry weight basis but no such measurements are available. The values in Table A.5.16 are thus biased low by the presence of an undetermined but substantial amount of interstitial fluid. In general the sludge is predominately $\mathrm{Zr}$. $\mathrm{Na}, \mathrm{F}$, nitrate, $\mathrm{K}$, carbonate, $\mathrm{Al}, \mathrm{Fe}, \mathrm{Si}$, and nitrite. The sludge contains between 0.6 and $6.4 \%$ by weight $U$ and 4.3 to $58.3 \mu \mathrm{g} / \mathrm{g}$ of $\mathrm{Pu}-239$. The presence of an enriched Pu/U layer in the top layer of sludge is not conclusively supported by the recent grab samples taken in August 1996. The uppermost sludge sample taken in August 1996 does show significantly less $\mathrm{Zr}$. F, sulfate, and nitrite then deeper sludges and significantly more nitrate. Because the waste disposed most recently was rather pure U(VI) nitrate the absence of cladding and cladding dissolution related constituents $[\mathrm{Zr}$ and $\mathrm{F}]$ makes sense. The elevated nitrate may represent the $1 \mathrm{M}$ nitric acid solution that was neutralized.

\section{A.5.3 Mixing the Basin and Tank Sludges}

The chemical composition of the Basin sludges after treatment will be quite similar to the existing AW-105 tank sludges (refer to Whyatt et al. 1996, for mineralogy of AW-105 tank sludges). Metal hydroxide/oxides such as U, Fe, $\mathrm{Zr}, \mathrm{Al}, \mathrm{Si}$, and alkaline earth carbonates/hydroxides ( $\mathrm{Ca}, \mathrm{Mg}$ ) predominate in both sludges. There should be no significant (and more importantly unsafe) chemical reactions induced by mixing the sludges together. The solution in the Basin sludge slurry will exhibit a high salt $\left(\mathrm{NaNO}_{3}\right)$ and high pH composition quite similar to the existing supernate solution in Tank AW-105. In fact, as just presented in Section A.5.1 the Basin sludge treatment process [Fe-nitrate/Na hydroxide] may need to be controlled by additional water dilution so that the slurry used to transport the treated sludge to the Tank remains below the upper limit nitrate specification of 5.5 $M$ for corrosion control in Hanford tanks. In summary, there does not appear to be any chemical incompatibility between the chemical composition of the treated basin sludges and their slurry water with the existing AW-105 Tank sludges and supernate solutions. Mixing the two waste streams should not significantly impact solubility of the fissiles or neutron absorbers present 
Table A.5.16. Chemical Composition of Sludge- $-\mu \mathrm{g} / \mathrm{g}$ wet sludge

\begin{tabular}{|c|c|c|c|c|}
\hline Constituent & $\begin{array}{l}\mu \mathrm{g} / \mathrm{g} \\
\text { bulk } \\
\text { sludge }\end{array}$ & $\begin{array}{c}\mu \mathrm{g} / \mathrm{g} \\
\text { for } \\
\text { distinct } \\
\text { bottom heel }\end{array}$ & $\begin{array}{c}\mu \mathrm{g} / \mathrm{g} \\
\text { Agnew } \\
\text { Prediction } \\
\text { CWZr2 }\end{array}$ & $\begin{array}{c}\mu \mathrm{g} / \mathrm{g} \\
\text { Agnew } \\
\text { Prediction } \\
\text { PL2 }\end{array}$ \\
\hline $\mathrm{Al}$ & $<1000-1,700$ & 36.600 & 0 & 0 \\
\hline B & $700-1,000$ & 470 & -- & -- \\
\hline $\mathrm{Ca}$ & 800 & 980 & 2,950 & 15.300 \\
\hline $\mathrm{Cr}$ & $<325-560$ & 17.500 & 0 & 310 \\
\hline $\mathrm{Fe}$ & $420-2.300$ & 19,400 & 15.740 & 88.210 \\
\hline$x$ & $9,000-18,000$ & 4,700 & 5.780 & 200 \\
\hline $\mathrm{La}$ & $400-1,550$ & -- & 0 & 0 \\
\hline $\mathrm{Mg}$ & $70-<2000$ & 580 & $\cdots$ & $\cdots$ \\
\hline$M n$ & $400-1,300$ & 5,560 & 0 & 240 \\
\hline $\mathrm{Na}$ & $28.000-82.000$ & 25.500 & 97,950 & 10,885 \\
\hline $\mathrm{Zr}$ & $51,0.00-238.000$ & 23,600 & 42,300 & 0 \\
\hline $\mathrm{NH}_{4}$ & 860 & 150 & 8.620 & 0 \\
\hline $\mathrm{OH}$ & $<40$ & -- & 1,260 & 470 \\
\hline $\mathrm{P}\left(\right.$ as $\left.\mathrm{PO}_{4}\right)$ & $<600-11,600$ & 7,660 & 0 & 290 \\
\hline $\mathrm{SO}_{4}$ & $1,350-2,500$ & 5,600 & 0 & 290 \\
\hline $\mathrm{Si}$ & $<1,200-6,300$ & 3.060 & 0 & 0 \\
\hline$F$ & $15,000-120,300$ & 22.000 & 77.800 & 0 \\
\hline $\mathrm{Cl}$ & $230-2,140$ & 1,900 & 110 & 100 \\
\hline $\mathrm{NO}_{3}$ & $22,000-43,200$ & 81,000 & 15,920 & 11,770 \\
\hline $\mathrm{NO}_{2}$ & $2,600-17,400$ & 7,700 & 330 & 340 \\
\hline $\mathrm{CO}_{3}$ & $4,200-37,700$ & 28,500 & 4.410 & 27.440 \\
\hline TOC & $1,780-3,500$ & 29.300 & 100 & 0 \\
\hline $\mathrm{pH}$ & 12.25 & 13 & $-\cdot$ & -- \\
\hline U & $6.000-64.900$ & 12.500 & 7.350 & 11.090. \\
\hline $\begin{array}{c}\mathrm{Pu} \\
(\mu \mathrm{Ci} / \mathrm{g})\end{array}$ & $0.27-3.62$ & 0.2 & 1 & 2.4 \\
\hline $\begin{array}{l}\text { Bulk } \\
\text { Density } \\
\left(\mathrm{g} / \mathrm{cm}^{3}\right)\end{array}$ & 1.22 to 1.42 & 1.5 & 1.29 & 1.24 \\
\hline
\end{tabular}


in both sludges.

\section{A.5.4 Prediction of Particle Segregation Using 1-Dimensional Settling Calculation}

This section evaluates the potential for particle segregation resulting from differences in the terminal settling velocities of different particles. The potential for segregation is evaluated using a simplified 1-dimensional analytical model. The equations used to calculate the settling velocity of particles are presented first followed by a description of the conceptual model and a discussion of the results of two scoping calculations.

\section{A.5.4.1 Theory}

The equations for settling of spherical particles in a viscous fluid are we11 established and are available from a variety of sources.. The pertinent equations below are taken from McCabe and Smith (1976). The selection of the proper relationship for estimation of the terminal settling velocity of a spherical particle depends on the Reynolds number of the particle. The

$$
N_{R e, p}=\frac{D_{p} u_{t} \rho}{\mu}
$$

particle Reynolds number at terminal velocity is defined as: where

$$
\begin{aligned}
& N_{\text {Re. }}=\text { particle Reynolds number } \\
& D_{p}=\text { particle diameter } \\
& u_{t}=\text { terminal settling velocity } \\
& \rho=\text { density of fluid } \\
& \mu=\text { viscosity of fluid }
\end{aligned}
$$

For very small particles the settling velocities are low resulting in small particle Reynolds numbers. When the particle Reynolds number is <2. Stokes' Law applies and can be solved for the terminal velocity to yield:

$$
U_{t}=\frac{a_{e} D_{p}^{2}\left(\rho_{p}-p\right)}{18 p}
$$


where

$a_{e}=$ gravitational acceleration

$\rho_{p}=$ density of the particle

For $2<N_{\text {Re.p }}<500$, the Intermediate Law applies:

$$
u_{t}=\frac{0.153 a_{e}^{0.71} D_{p}^{1.14}\left(\rho_{p}-\rho\right)^{0.71}}{\rho^{0.29} \mu^{0.43}}
$$

If $N_{\text {Re.p }}>500$, then Newton's Law applies:

$$
u_{t}=1.75 \sqrt{\frac{a_{e} D_{p}\left(\rho_{p}-\rho\right)}{\rho}}
$$

The settling velocity is a factor in the particle Reynolds number while the particle Reynolds number is needed to determine the relationship used to calculate terminal settling velocity. This can be resolved through trial and error. However, it can also be resolved by calculating the following parameter:

$$
K=D_{P}\left[\frac{a_{e} \rho\left(\rho_{p}-\rho\right)}{\mu^{2}}-\right]^{1 / 3}
$$

Where for ' $K<3.3$. Stokes' Law applies, for $3.3<K<43.6$ the Intermediate Law applies, for $43.6<\mathrm{K}<2360$, Newton's Law applies.

\section{A.5.4.2 Model Description}

The objective of the calculation is to evaluate the potential for segregation of uranium (or Pu) solids in $K$ basin sludge from iron which may be added as a neutron absorber to prevent criticality. The model calculates the. degree of segregation which occurs when a column of initially uniformly mixed slurry is allow to settle under stagnant conditions. The mass of each component in the system is assigned a particle size distribution. The distribution is divided into several particle size ranges which are. represented in the model as specific particle sizes. Thus, the mass of each 
component is divided among a number of specific particle sizes. Each particle. in addition to having a specific size, is assigned a single composition and corresponding density. Particles of mixed composition (for example containing both uranium and iron) would decrease the degree of segregation so assuming particles consisting of a single comporient is conservative. Each particle settles independently in the fluid at its terminal velocity which is calculated using the appropriate equation presented in the previous section. The mass and composition of particles that settle to the bottom of the cylinder over each time increment is used to calculate the composition of sludge which would be deposited over that time increment. By comparing the composition of each settled layer to the initial composition of the uniform slurry, an indication of the degree of segregation that may occur is provided. The comparison of compositions is performed on a mass fraction of solids basis which neglects the degree of sludge consolidation or neutron absorption from interstitial supernate in the sludge.

There are a number of phenomena the mode] does not simulate. No flow of the fluid is modeled. No agglomeration of the particles is assumed. Particle agglomeration can significantly interfere with segregation, especially at sizes $<10 \mu \mathrm{m}$. The model calculates the composition of solids reaching the coordinates of the bottom of the cylinder and does not model the moving boundary of settled solids. Also, no hindered settling effects are included in the model. In previous work. calculations performed with a model which included the formation of a sludge layer and hindered settling effects found that the added complexity had little impact on the resulting segregation (Whyatt et a1. 1996).

The parameters for particle size distribution, particle densities. initial slurry composition, fluid density and viscosity must be selected for the calculation. The selection of parameters for the initial scoping study are provided below:

\section{A.5.4.3 Case \#1. Scoping Calculation}

Uranium Oxide Size Distribution

In order to select a size distribution to represent uranium solids it was desired to select data from a sample which consists largely of uranium. Data for sludge from KW fuel is not available. However, analysis of sample 96-06M indicates it is $83 \mathrm{wt} \%$ uranium. which when the additional weight of oxides or hydrates is considered, implies it consists almost entirely of uranium compounds. The Microtrac particle size data for the upper, middle and lower sections of $96-06 \mathrm{M}$ show a trend with the lower section having the most 
larger particles and the upper section showing the fewest large particles. For this calculation, the size distribution for the middle sample was used as being most representative, although not necessarily conservative. The particle size distribution was discretized into 10 particle size ranges and an additional size range for uranium metal particles was added. The size distribution is shown in Table A.5.17. The first 2 columns show the actual size data while columns 3 and 4 illustrate how the size data was converted to specific particle sizes for modeling. For example, 99.1 vol\% is finer than 250 microns. The maximum size measurable with the Microtrac is $750 \mu \mathrm{m}$ so the 0.9 vol\% that is not finer than 250 microns is assumed to be between 250 and 750 microns and is modeled using a size of $500 \mu \mathrm{m}$. Each of the sizes in the last three columns represents a particle being modeled in the calculation so that there are a total of 14 different types of particles settling simultaneously (10 uranium oxide, 1 uranium metal and 3 iron)

Uranium 0xide Density

The possible densities for the uranium oxide compounds range from 3.6 to $11 \mathrm{~g} / \mathrm{cm}^{3}$ (see Table A.3.7). To be conservative a uranium oxide density of 11 was selected. For comparison, the measured dry particle densities for samples 96-06M and $96-06 \mathrm{~L}$ were 6.9 and $7.9 \mathrm{~g} / \mathrm{cm}^{3}$ respectively.

Uranium Metal Particulate

For the purposes of the evaluation, it is assumed that $4.5 \mathrm{wt} \%$ of the uranium exists as metallic uranium particulate (Pearce 1997). Uranium metal particles will initially be separated into $>1 / 4$ " pieces which are combined with scrap, and $<1 / 4$ " pieces that are combined with sludge. Some size reduction will be applied to the large metallic uranium pieces in the sludge. At a minimum, the size is assumed to be reduced to $0.05^{\prime \prime}$ diameter $(1270 \mu \mathrm{m})$ or less to assure that criticality calculations can treat the uranium-containing sludge as a homogeneous material. Thus, for this scoping calculation. $4.5 \%$ of the uranium is assumed to exist as metallic uranium at a size of $1270 \mu \mathrm{m}$. The density of the metaliic uranium is $19.1 \mathrm{~g} / \mathrm{cm}^{3}$.

\section{Fluid Properties}

The fluid was assumed to be water with a density of $1 \mathrm{~g} / \mathrm{cm}^{3}$ and a viscosity of $1 \mathrm{CP}$.

Iron Addition

It is expected that iron wi 11 be added for criticality control. Although the amount of iron needed has not been established, a draft value of $2.54 \mathrm{~kg} \mathrm{Fe}$ per $\mathrm{Kg} U$ has been proposed. This ratio is approximately 3 times the safe atomic ratio between the iron and uranium if the uranium is assumed 
to be unirradiated and enriched to $1.25 \% \mathrm{U}-235$. The iron is assumed to exist as hematite with a density of $5.26 \mathrm{~g} / \mathrm{cm}^{3}$ and is assumed to have been precipitated from acid solution resulting in small flocculated particles. The particle size of precipitated iron was measured by Wang (1995). Measurements were made using a Horiba CAPA particle size analyzer which works by measuring sedimentation velocities under centrifugal acceleration. Upon precipitation. the average particle (agglomerate) size was about 8 microns. Upon stirring and reacidification to $\mathrm{pH}$ of 2 , the particle size was reduced to the 1 to 3 micron size range. For the purposes of the this calculation, the sizes of iron particulate were selected as shown in Table A.5.17.

\section{Other Materials}

In addition to iron and uranium, other materials are present in some $K$ basin sludges. These materials are ignored in this evaluation because the sludges of the greatest concern from a criticality standpoint are the $K$ west canister sludges. Some of the $K$ west fuel was initially enriched to $1.25 \% \mathrm{U}$ 235. In addition the sludge is in sealed containers such that the sludge would be expected to consist primarily of uranium corrosion products with little material such as iron, aluminum and sand which is found in some KE floor and pit sludges.

\section{Case 1 Results}

The case 1 results suggest severe segregation. The Fe:U mass ratio decreases from 2.54 in the uniform slurry to $2.6 \times 10^{-3}$ in the first thin layers to settle. Within this layer $88 \%$ of the uranium is the result of the $1270 \mathrm{\mu m}$ metallic particles. The settling model would predict the same relative change in mass ratio if the iron addition were to be increased. Thus, by increasing the iron addition by 1000 times, the calculation would indicate that in the most concentrated regions the Fe:Pu mass ratio would be similar to that in the uniform slurry at the start of case la. However. addition of this much iron is not practical and would greatly expand the waste volume. Also, it would be difficult to defend a lack of segregation when the driving force for segregation is so large. Repeated partial disturbance of the sludge followed by resettling could result in higher enrichments than for a single settling cycle. Clearly, the addition of precipitated iron to a system with $1270 \mu \mathrm{m}$ metallic uranium particles does little to prevent the metallic uranium from concentrating. 
HNF-SD-WM-ES-409, Rev. 0

Table A.5.17 Particle Size and Density and Mass Inputs to Scoping Calculation Case 1a.

\begin{tabular}{|l|l|l|l|l|l|l|}
\hline \multicolumn{2}{|l|}{$\begin{array}{l}\text { Sample 96-06M } \\
\text { Microtrac Data }\end{array}$} & Size Discretization & $\begin{array}{l}\text { Uranium } \\
\text { Oxide Size } \\
\text { Distribution }\end{array}$ & $\begin{array}{l}\text { Uranium } \\
\text { Metal Size } \\
\text { Distribution }\end{array}$ & $\begin{array}{l}\text { Added Iron } \\
\text { Size } \\
\text { Distribution }\end{array}$ \\
\hline $\begin{array}{l}\text { Diameter } \\
(\mu \mathrm{m})\end{array}$ & $\begin{array}{l}\text { Vol\% } \\
\text { Passing }\end{array}$ & $\begin{array}{l}\text { Size Range } \\
(\mu \mathrm{m})\end{array}$ & $\begin{array}{l}\text { Modeled } \\
\text { Size }(\mu \mathrm{m})\end{array}$ & $\begin{array}{l}\text { Volume \% } \\
(96-06 \mathrm{M})\end{array}$ & Volume \% & Volume \% \\
\hline & & 1270 & 0 & 100 & 0 \\
\hline 250 & 99.1 & $250-750$ & 500 & 0.9 & 0 & 0 \\
\hline 125 & 98.5 & $125-250$ & 188 & 0.6 & 0 & 0 \\
\hline 75 & 94.2 & $75-125$ & 100 & 4.3 & 0 & 0 \\
\hline 50 & 92.4 & $50-75$ & 62.5 & 1.8 & 0 & 0 \\
\hline 25 & 70.3 & $25-50$ & 37.5 & 22.1 & 0 & 0 \\
\hline 20 & 68 & $20-25$ & 22.5 & 2.3 & 0 & 0 \\
\hline 10 & 58 & $10-20$ & 15 & 10 & 0 & 0 \\
\hline 5 & 34 & $5-10$ & 7.5 & 24 & 0 & 25 \\
\hline 1 & 4.9 & $1-5$ & 3 & 29.1 & 0 & 50 \\
\hline & & $0-1$ & 0.5 & 4.9 & 0 & 25 \\
\hline Mass (kg per $100 \mathrm{~kg}$ total Fe+U in slurry) & 26.98 & 1.27 & 71.75 \\
\hline Particle Density, $\mathrm{g} / \mathrm{cm}^{3}$ & & 11 & 19.1 & 5.6 \\
\hline
\end{tabular}

Case 1 Parametric Investigation of Maximum Size

The calculation above established that addition of iron to $K$ basin sludge solids in their current state is not sufficient to prevent segregation. It would be useful to know what degree of size reduction may be needed in order to assure that the degree of segregation is manageable. To do this the calculation was repeated assuming that size reduction on the sludge was performed to achieve a maximum size limit. The mass of any materials in the size distribution exceeding the upper size limit were reassigned to particles of the maximum size allowed. This treatment is somewhat conservative because the size reduction process would result in some size distribution of particles smaller than the maximum size. At the two smallest sizes $(3 \mu \mathrm{m}, 0.5 \mu \mathrm{m})$ both 
the iron and the uranium are subject to the size limits although in reality the iron particles in the model represent agglomerates of finer particles. However, for the purpose of a scoping calculation this treatment was deemed sufficient. The settling calculation was repeated for maximum sizes corresponding to each of the particle size groupings in Table A.5.17 (i.e. $500,187.5,100,62.5,37.5,22.5,15,7.5,3,0.5 \mu \mathrm{m})$.

The results are summarized in Figures A.5.2 and A.5.3. Figure A.5.2 presents the ratio between iron and uranium predicted to occur in the most uranium-rich layer formed by the settling slurry as the maximum particle size is varied. The ratio is expressed in terms of a multiple of the infinite geometry safe ratio for $\mathrm{Fe}: \mathrm{U}$ at $1.25 \%$ enrichment. The safe ratio is assumed to be $0.85 \mathrm{Kg} \mathrm{Fe}: \mathrm{Kg}$ total $U$. Thus, at a value of 1.0 , there are $0.85 \mathrm{~kg} \mathrm{Fe}$ per $\mathrm{Kg} \mathrm{U}$. The average sludge composition is $2.54 \mathrm{~kg} \mathrm{Fe}$ per $\mathrm{kg} \mathrm{U}$ or a ratio of 3. As can be seen, in Figure A.5.2, when the maximum particle sizes are large, the minimum absorber ratios occurring the most concentrated uranium layers are very sma11. This indicates that large metallic uranium particles settle with very few iron particles. As the maximum size is reduced (moving left on the horizontal axis) the minimum ratio becomes larger indicating more iron in the most $U$-concentrated settled layers. At 22.5 microns, the minimum ratio is 0.102 . It should be noted that the decision to add an average of 3 times the safe ratio to the initial mix is somewhat arbitrary. Addition of larger amounts of iron would increase the degree of segregation that could occur while still maintaining a safe Fe:U ratio. If the initial Fe:U mass ratio was set at 30 times the safe ratio and the sludge were size reduced to $22.5 \mu \mathrm{m}$, this calculation would indicate that the safe ratio would still be 
HNF-SD-WM-ES-409, Rev. 0

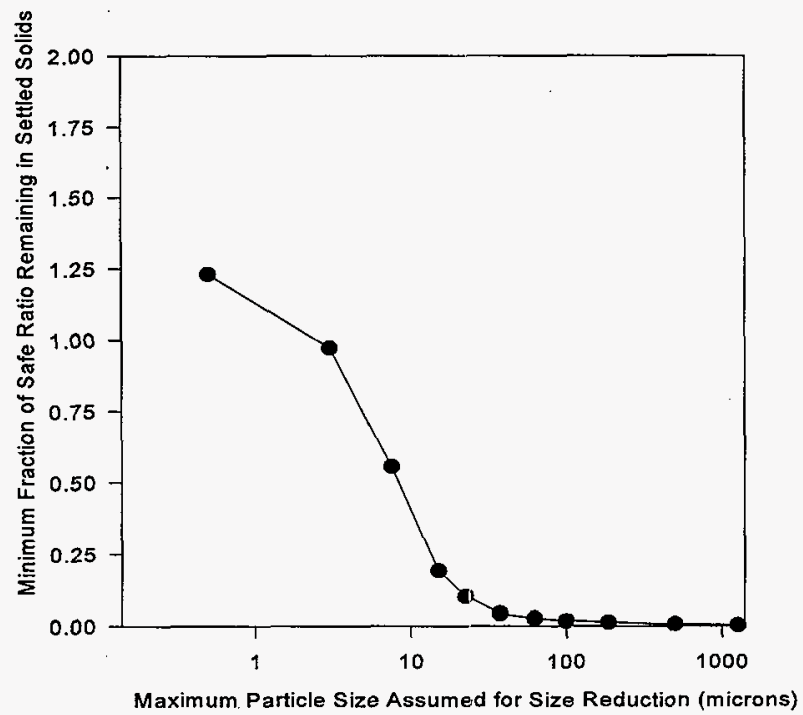

Figure A.5.2. Segregation During Settling vs. Upper Limit for Sludge Particle Size Reduction. The vertical axis represents the estimated multiple of the safe Fe:U ratio occurring in the settled layer with the minimum. Fe:U ratio. In all cases, the uniform slurry prior to settling was assumed to contain 3 times the safe ratio. The size reduction is plotted on the horizontal axis expressed as a maximum particle size criteria. Thus, moving to the left represents smaller size criteria for maximum particle size and greater size reduction. 
HNF-SD-WM-ES-409, Rev. 0

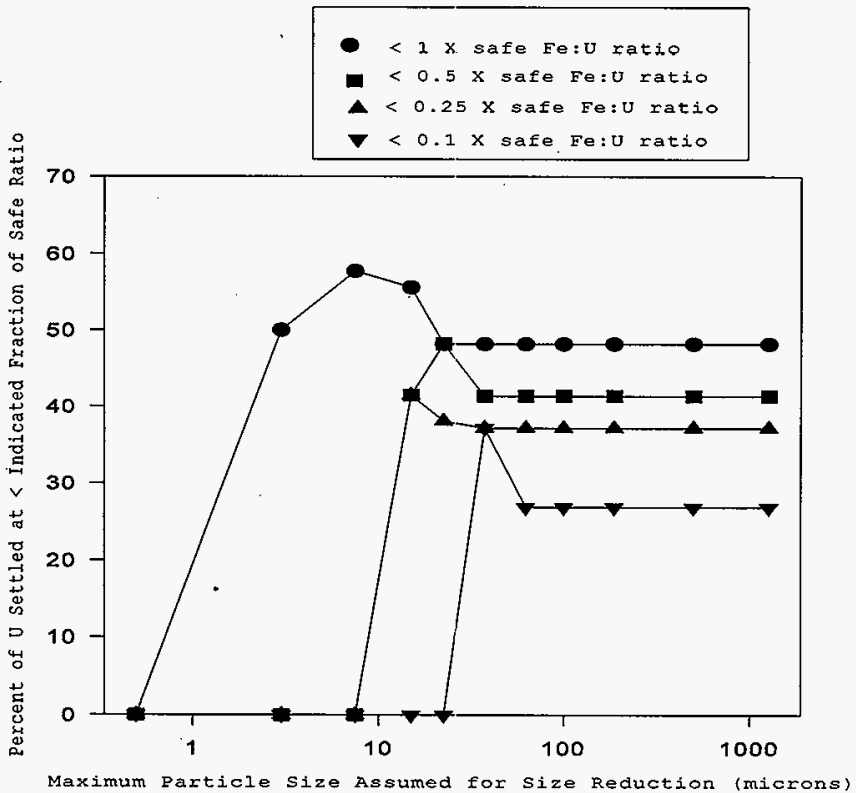

Figure A.5.3. Percent of Uranium Mass Failing to Maintain Specified Fraction of Safe Iron Ratio for Infinite Geometry as a Function of Maximum Sludge

Particle Size. The vertical axis indicates the mass percent of uranium which has settled in layers containing less than the specified fraction of the safe $\mathrm{Fe}: \mathrm{U}$ ratio. In a 11 cases the initially uniform slurry is assumed to contain 3 times the safe Fe:U ratio. The size reduction is plotted on the horizontal axis expressed as a maximum particle size criteria. Thus, moving to the left represents smaller size criteria for maximum particle size and greater size reduction. 
HNF-SD-WM-ES-409, Rev. 0

maintained even in thin layers containing the 22.5 micron metallic uranium particles. Addition of large amounts of iron is undesirable because it increases the waste volume. Thus, there is a trade off between size reduction and extent of iron addition. No attempt has been made to identify the optimum degree of size reduction. However, it appears fairly clear that the maximum size for which a safe ratio could reasonably be maintained is less than 50 microns when metallic uranium is present. It should be kept in mind that the model does not include particle interactions such as agglomeration. For sizes less than about 10 microns, agglomeration is expected to prevent any significant segregation.

Additional results of the calculations are shown in Figure A.5.3. These lines plot the fraction of uranium mass that is predicted to settle into layers containing less than the indicated fraction of a safe Fe:U ratio. For example, the lower line represents the mass fraction uranium which has settled into a layer with less than $1 / 10$ th of the safe ratio. If no size reduction is performed, about $27 \%$ of the uranium is associated with less than $1 / 10$ th of a safe ratio of iron. This line goes to zero at $22.5 \mathrm{~mm}$ where the minimum multiple of the safe Fe:U ratio occurring in any settled sludge layer (plotted in Figure A.5.2) is 0.102 , indicating all layers of settled sludge have more than 1/10th of the safe ratio. The local maximum in the line at sizes slightly larger than the value required to assure all sludge exceeds the ratio being plotted (where the line intersects the $X$ axis) may seem counterintuitive but is not unexpected behavior. As lower uranium content sludge settles along with a higher concentration layer, the mass of uranium settled with less than the plotted fraction of a safe ratio will increase by the amount of additional uranium in the less concentrated material until the dilution is sufficient to cause the layer to exceed the fraction of a safe ratio being plotted.

\section{A.5.4.4 Case \#2: Less Conservative Calculation}

A second set of parametric calculations were performed with the knowledge that a separate investigation (Precechtel.1997) had determined that no equipment vendor could commit to achieving a size reduction of the sludge to meet a $177 \mu \mathrm{m}$ maximum size criteria. With case 1 indicating that size reduction to a size much smaller size than $177 \mu \mathrm{m}$ (and probably somewhat less than $50 \mu \mathrm{m}$ )would be required to prevent segregation, it was desired to perform a reasonable but less conservative calculation to determine if the conclusions from case 1 might change appreciably with the assumptions. The differences between case 2 and case 1 are provided below. 
HNF-SD-WM-ES-409, Rev. 0

Uranium Oxide Size Distribution

The same sample size distribution data (96-06M, no sonication) was used but the distribution was divided into more particle size ranges in order to reduce potential errors due to concentration of material at specific particle sizes. While the previous calculation assumed some particles up to 0.05 in. $(1270 \mu \mathrm{m})$, this less conservative calculation assumes only the sizes indicated in the measured distribution for sample 96-06M. The particle size distribution used for modeling is summarized in Table A.5.18 in the same manner as for case 1 .

Uranium Densities

The breakdown of uranium phases was based on an evaluation of the dry particle density and XRD data (see section A.3.5) which suggested that uranium in sample 96-06M consists of roughly $65 \%$ schoepite with a density of 4.83 $\mathrm{g} / \mathrm{cm}^{3}$ and $35 \%$ as uraninite with a density of $10.98 \mathrm{~g} / \mathrm{cm}^{3}$. The potential presence of up to $4.5 \mathrm{wt} \%$ of the uranium in the form of metal or hydride, which was included in the previous calculation, was neglected in this calculation.

Fluid Properties

Fluid properties were not changed from the previous calculation. The fluid was assumed to be water with a density of $1 \mathrm{~g} / \mathrm{cm}^{3}$ and a viscosity of 1 CP.

Iron Addition

The amount of iron addition and the assumed density was not changed from the previous calculation. However, the size distribution was assumed to be more representative of the initial precipitated particle size measured by wang (1995). which results in a larger average particle size. Wang only reported average particle size so a size distribution was assumed. The distribution assumed is shown in Table A.5.18.

Other Materials

As in the previous calculation, materials other than iron and uranium were neglected. 
HNF-SD-WM-ES-409, Rev. 0

Table A.5.18. Particle Size and Density and Mass Inputs to Scoping Calculation Case 2.

\begin{tabular}{|c|c|c|c|c|c|c|}
\hline \multicolumn{2}{|c|}{$\begin{array}{l}\text { Sample 96-06M } \\
\text { Microtrac Data }\end{array}$} & \multicolumn{2}{|c|}{ Size Discretization } & \multirow{2}{*}{$\begin{array}{l}\text { Uranium as } \\
\text { Schoepite } \\
\text { Distribution } \\
\text { Volume \% } \\
(96-06 \mathrm{M})\end{array}$} & \multirow{2}{*}{$\begin{array}{l}\text { Uranium as } \\
\text { Uraninite } \\
\text { Distribution } \\
\text { Volume } \%\end{array}$} & \multirow{2}{*}{$\begin{array}{l}\text { Added Iron } \\
\text { Size } \\
\text { Distribution } \\
\text { Volume \% }\end{array}$} \\
\hline $\begin{array}{l}\text { Diameter } \\
(\mu \mathrm{m})\end{array}$ & $\begin{array}{l}\text { Vol\% } \\
\text { Passing }\end{array}$ & $\begin{array}{l}\text { Size Range } \\
(\mu \mathrm{m})\end{array}$ & $\begin{array}{l}\text { Modeled } \\
\text { Size }(\mu \mathrm{m})\end{array}$ & & & \\
\hline 250 & 99.1 & $250-750$ & 500 & 0.86 & 0.86 & 0 \\
\hline 125 & 98.5 & $125-250$ & 188 & 0.63 & 0.63 & 0 \\
\hline 105 & 97.0 & $105-125$ & 115 & 1.56 & 1.56 & 0 \\
\hline 88 & 95.2 & $88-105$ & 96.5 & 1.71 & .1 .71 & 0 \\
\hline 74 & 94.2 & $74-88$ & 81.0 & 1.01 & 1.01 & 0 \\
\hline 62 & 93.5 & $62-74$ & 68 & 0.71 & 0.71 & 0 \\
\hline 52 & 92.4 & $52-62$ & 57 & 1.1 & 1.1 & 0 \\
\hline 44 & 89.3 & $44-52$ & 48 & 3.09 & 3.09 & 0 \\
\hline 37 & 82.1 & $37-44$ & 40.5 & 7.23 & 7.23 & 0 \\
\hline 31 & 74.2 & $31-37$ & 34 & 7.9 & 7.9 & 0 \\
\hline 26 & 70.3 & $26-31$ & 28.5 & 3.89 & 3.89 & 0 \\
\hline 22 & 68.8 & $22-26$ & 24 & 1.5 & 1.5 & 0 \\
\hline 18.5 & 67.9 & $18.5-22$ & 20.25 & 0.95 & 0.95 & 0 \\
\hline 11 & 58.4 & $11-18.5$ & 14.75 & 9.45 & 9.45 & 0 \\
\hline 7.8 & 46.7 & $7.8-11$ & 9.4 & 11.71 & 11.71 & 20 \\
\hline 4.6 & 34.0 & $4.6-7.8$ & 6.2 & 12.68 & 12.68 & 50 \\
\hline 2.3 & 17.2 & $2.3-4.6$ & 3.45 & 16.78 & 16.78 & 15 \\
\hline 1 & 4.88 & $1-2.3$ & 1.65 & 12.36 & 12.36 & 10 \\
\hline 0 & 0 & $0-1$ & 0.5 & 4.88 & 4.88 & 5 \\
\hline \multicolumn{4}{|c|}{ Mass ( $\mathrm{kg}$ per $100 \mathrm{~kg}$ total $\mathrm{Fe}+\mathrm{U}$ in slurry) } & 18.36 & 9.89 & 71.75 \\
\hline \multicolumn{4}{|c|}{ Particle Density. $\mathrm{g} / \mathrm{cm}^{3}$} & 4.83 & 10.98 & 5.6 \\
\hline
\end{tabular}


HNF-SD-WM-ES-409, Rev. 0

Case 2 Results

The case 2 results indicate that while the degree of segregation is less, there is still rather severe segregation of $\mathrm{Fe}$ and $U$ if no size reduction is performed. In the most concentrated $U$ layer, the Fe:U ratio decreases from a value of 3 times the safe ratio to only 0.063 times a safe ratio. This implies that without size reduction, approximately 16 times more iron would be required in the calculation to result in a safe ratio at all times in the calculation.

Parametric calculations were performed for size reduction in the same manner as for case 1 . The results of the parametric evaluation are shown in Figure A.5.4 which combines the type of information that was previously plotted separately in Figures A.5.2 and A.5.3. As can be seen, the fractions of safe ratios are achieved at larger sizes than for case 1. To approximately double the calculated minimum Fe:U ratio occurring in a settled layer for no size reduction, the maximum size would have to be reduced to approximately 57 um where 0.136 times the safe ratio is estimated to occur in the most concentrated layer. At this point a dilution with 7.4 times more iron (initial uniform slurry composition containing 22.2 times a safe Fe:U ratio) would be needed to assure a safe ratio is maintained everywhere after settling.

Conclusions of Scoping Calculations

There is significant potential for segregation of precipitated iron from untreated sludge. Elimination of metallic uranium will reduce the extent of segregation but is not sufficient to avoid segregation. The specific size to which reduction must be achieved will depend on how much dilution with iron is considered acceptable. However, the size is clearly less than $177 \mu \mathrm{m}$ and is estimated to be $50 \mu \mathrm{m}$ or less. Reduction to some size less than $10 \mu \mathrm{m}$ would allow agglomeration arguments to be made which could assure that a safe ratio is maintained with the initial 3 times the safe ratio iron addition. Since a previous study (Precechtel and Packer, 1997) determined that commercial vendors could not commit to achieving the $177 \mu \mathrm{m}$ size criteria, it appears likely that dissolution followed by precipitation may be needed to assure that particle sizes are sufficiently small that agglomeration should prevent any significant segregation.

\section{A.5.5 Gravity Segregation}

A review of mining literature on gravity concentration was performed previously by whyatt et al. (1996) and is briefly summarized here. Gravity segregation separates minerals according to their relative density or particle 
HNF-SD-WM-ES-409, Rev. 0

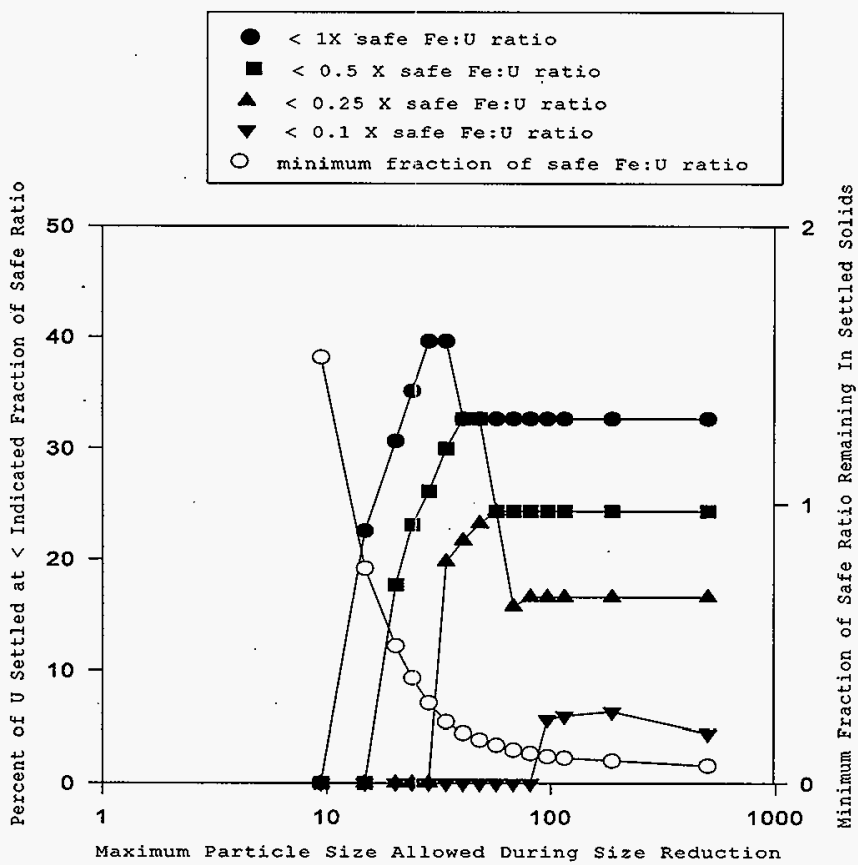

Figure A.5.4. Results for Case 2. Minimum ratio (right axis) and percent of sludge settled with less than the indicated fraction of safe Fe:U Ratio (left axis) plotted vs. maximum particle size in sludge. The right axis represents the estimated multiple of the safe Fe:U ratio occurring in the settled layer with the minimum Fe:U ratio. The left axis indicates the mass percent of uranium which has settled in layers containing less than the plotted fraction of the safe Fe:U ratio. In all cases the initially uniform slurry is assumed to contain 3 times the safe Fe:U ratio. The size reduction is plotted on the horizontal axis expressed as a maximum particle size criteria. Thus, moving to the left represents smalier size criteria for maximum particle size and greater size reduction. 
HNF-SD-WM-ES-409, Rev. 0

size. It is one of the earliest known methods of separating heavy minerals such as gold from the lighter ore components. Many gravity segregation devices, including a simple sluice box, can achieve segregation for particles which are substantially larger than $100 \mu \mathrm{m}$. Many separation devices become less and less effective as the particle size is reduced to $<100 \mu \mathrm{m}$. Specialized devices, incorporating centrifugal forces, thin flowing films, and/or shaking motions can achieve segregations for sizes less than $100 \mathrm{~mm}$. However, these devices begin to loose effectiveness rapidly for sizes less than $10 \mu \mathrm{m}$.

Many different factors can affect the degree of segregation obtained depending on the type of segregation device used. The most important factors are the relative sizes and densities of the minerals being segregated. The density of metallic gold (19.3) is very similar. to that of metallic uranium (19.1). The density of the iron is assumed to be $5.26 \mathrm{~g} / \mathrm{cm}^{3}$ which is higher than the usual density of minerals from which gold would normaliy be separated. However. in a typical gravity segregation of gold, the mineral sizes would be expected to be somewhat coarser than the precipitated iron. It is difficult to draw quantitative conclusions about the degree of segregation that may occur or what degree of size reduction is required. However. qualitative conclusions from mining literature are that:

1) If metallic uranium exists at sizes $>\approx 100 \mu \mathrm{m}$, the mining literature indicates gravity segregation would be feasible. The conditions under which the segregation occurs are sufficiently simple that significant unintentional segregation may be possible.

2) As the size is reduced from $\approx 100 \mu \mathrm{m}$ to $\approx 10 \mu \mathrm{m}$ the potential for unintentional segregation is significantly reduced. Towards the lower end of this particle size range, the fact that highly specialized equipment is required to achieve segregation in the commercial mineral segregation suggests that significant unintentional segregation is somewhat unlikely.

3). At sizes finer than $\approx 10 \mu \mathrm{m}$, even specialized equipment has difficulty achieving segregation which suggests that unintentional segregation to any significant degree is very unlikely. 


\section{A.5.6 Dissolution and Precipitation of K Basin Sludges}

One of the pretreatment options being considered for basin, pit and canister sludges involves the total dissolution of these sludges using nitric acid. Additional Fe would be added to the resulting solution in the form of an Fe salt followed by a caustic treatment to precipitate $U$ and Fe compounds and to increase the $\mathrm{pH}$ value to about 12 . The objectives of sTudge pretreatment are two fold. One of these objectives is to increase the neutron absorber to fissionable material ratio by adding iron compounds. Second, the chemistry of the resulting suspension is adjusted with caustic to reduce the corrosive potential of the treated sludge slurry.

The first step in the pretreatment process would consist of sludge dissolution. The proposed means of achieving this goal is to use $\mathrm{HNO}_{3}$. Assuming that fuming $\mathrm{HNO}_{3}$ would be usec to achieve oxidative dissolution of the sludge mass (except the silicate mineral residue) the resulting reactions in terms of identified crystalline U-bearing phases in basin, pit, and canister sludges can be represented as.

$$
\begin{aligned}
& \mathrm{UO}_{2} \text { (uraninite) } \rightarrow \mathrm{UO}_{2}{ }^{2+}(\mathrm{aq})+2 \mathrm{e}^{-} \\
& \mathrm{UO}_{3}\left(\mathrm{H}_{2} \mathrm{O}_{2}\right) 3 \mathrm{H}_{2} \mathrm{O} \text { (studtite) }+4 \mathrm{H}^{+}(\mathrm{aq})-\mathrm{UO}_{2}{ }^{2+}(\mathrm{aq})+6 \mathrm{H}_{2} \mathrm{O} \\
& \mathrm{UO}_{3} \cdot 2 \mathrm{H}_{2} \mathrm{O} \text { (schoepite/metaschoepite) }+2 \mathrm{H}^{+}(\mathrm{aq})-\mathrm{UO}_{2}{ }^{2+}(\mathrm{aq})+3 \mathrm{H}_{2} \mathrm{O} \\
& \mathrm{B}-\mathrm{U}_{3} \mathrm{O}_{8}+4 \mathrm{H}^{+}(\mathrm{aq}) \rightarrow 3 \mathrm{UO}_{2}^{2+}(\mathrm{aq})+2 \mathrm{H}_{2} \mathrm{O}+2 \mathrm{e}^{-} \\
& \mathrm{K}_{2} \mathrm{UO}_{4}+4 \mathrm{H}^{+}(\mathrm{aq})-2 \mathrm{~K}^{+}(\mathrm{aq})+\mathrm{UO}_{2}{ }^{2+}(\mathrm{aq})+2 \mathrm{H}_{2} \mathrm{O}
\end{aligned}
$$

Additionally. from hydrogen evolution studies it is estimated that there may a trace quantities of U-hydride (Abrefah et al., 1997). The oxidative dissolution of this phase can be shown as,

$$
\mathrm{UH}_{3}+2 \mathrm{H}_{2} \mathrm{O}-\mathrm{UO}_{2}^{2+}(\mathrm{aq})+7 \mathrm{H}^{+}(\mathrm{aq})+6 \mathrm{e}^{-}
$$

The dissolution of crystalline Fe- minerals that are part of the sludge matrix can be represented by.

$$
\begin{aligned}
& \alpha-\mathrm{FeOOH} \text { (goethite) }+3 \mathrm{H}^{+}(\mathrm{aq}) \rightarrow \mathrm{Fe}^{3+}(\mathrm{aq})+2 \mathrm{H}_{2} \mathrm{O} \\
& \gamma-\mathrm{FeOOH} \text { (7epidocrocite) }+3 \mathrm{H}^{+}(\mathrm{aq}) \rightarrow \mathrm{Fe}^{3+}(\mathrm{aq})+2 \mathrm{H}_{2} \mathrm{O}
\end{aligned}
$$




$$
\begin{gathered}
\text { HNF-SD-WM-ES-409, Rev. } 0 \\
\delta-\mathrm{FeOOH} \text { (Feroxyhyte) }+3 \mathrm{H}^{+}(\mathrm{aq}) \rightarrow \mathrm{Fe}^{3+}(\mathrm{aq})+2 \mathrm{H}_{2} \mathrm{O} \\
\gamma-\mathrm{Fe}_{2} \mathrm{O}_{3} \text { (maghemite) }+6 \mathrm{H}^{+}(\mathrm{aq}) \rightarrow 2 \mathrm{Fe}^{3+}(\mathrm{aq})+3 \mathrm{H}_{2} \mathrm{O} \\
\mathrm{Fe}_{3} \mathrm{O}_{4} \text { (magnetite) }+8 \mathrm{H}^{+}(\mathrm{aq}) \rightarrow 3 \mathrm{Fe}^{3+}(\mathrm{aq})+4 \mathrm{H}_{2} \mathrm{O}+e^{-}
\end{gathered}
$$

The second step of the process is to add $\mathrm{Fe}\left(\mathrm{NO}_{3}\right)_{3}$ to the solution and induce precipitation of dissolved $\mathrm{U}$ and $\mathrm{Fe}$ from the acid solutions by titrating with a caustic ( $\mathrm{NaOH}$ solution). When the titration reaches a pH value of about 6 , the dissolved $U$ which exists as hexavalent species, would precipitate as a sodium uranate hydrate phase (Wamser et al.,1952).

$$
7 \mathrm{UO}_{2}^{2+}(\mathrm{aq})+2 \mathrm{Na}^{+}(\mathrm{aq})+16 \mathrm{H}^{-}(\mathrm{aq})+8 \mathrm{H}_{2} \mathrm{O} \rightarrow \mathrm{Na}_{2}\left(\mathrm{UO}_{2}\right)_{7}(\mathrm{OH})_{16} \cdot 8 \mathrm{H}_{2} \mathrm{O} \text { (solid) }
$$

If the titration is continued beyond $\mathrm{pH}$ of about 10 . the precipitated phase will convert into a Na-rich uranate phase (Wamser et al.. 1952),

$$
\begin{aligned}
\mathrm{Na}_{2}\left(\mathrm{UO}_{2}\right)_{7}(\mathrm{OH})_{16} \cdot 8 \mathrm{H}_{2} \mathrm{O}(\mathrm{solid})+4 \mathrm{Na}^{+}(\mathrm{aq}) & +4 \mathrm{OH}^{\cdot}(\mathrm{aq}) \rightarrow \\
& \mathrm{Na}_{6}\left(\mathrm{UO}_{2}\right)_{7}(\mathrm{OH})_{20} \cdot 6 \mathrm{H}_{2} \mathrm{O}(\mathrm{solid})+2 \mathrm{H}_{2} \mathrm{O}
\end{aligned}
$$

From the known pathways formation of iron hydroxides, oxydroxides, and oxides, we can expect that upon caustic addition, trivalent Fe would hydrolyze and precipitate initially in the form of ferrihydrite. These reactions can be represented as,

$$
\begin{aligned}
& \mathrm{Fe}^{3+}(\mathrm{aq})+3 \mathrm{OH}^{-}(\mathrm{aq}) \rightarrow \mathrm{Fe}(\mathrm{OH})_{3}{ }^{0}(\mathrm{aq}) \\
& 5 \mathrm{Fe}(\mathrm{OH})_{3}{ }^{0}(\mathrm{aq}) \rightarrow \mathrm{Fe}_{5} \mathrm{HO}_{8} \cdot 4 \mathrm{H}_{2} \mathrm{O} \text { (ferrihydrite) }+3 \mathrm{H}_{2} \mathrm{O}
\end{aligned}
$$

Under highly alkaline conditions ( $\mathrm{pH} \sim 12$ ) that is expected to prevail as the end point for caustic titration. ferrihydrite would transform in to goethite via dissolution, nucleation and crystal growth as,

$$
\mathrm{Fe}_{5} \mathrm{HO}_{8} \cdot 4 \mathrm{H}_{2} \mathrm{O} \text { (ferrihydrite) } \rightarrow 5 \alpha-\mathrm{FeOOH} \text { (goethite) }+2 \mathrm{H}_{2} \mathrm{O}
$$

According to Schwertmann and Cornel1 (1991) initially precipitated ferrihydrite (density, 3.96) typically occurs as agglomerates of microcrystals with average particle sizes as smal1 as 1 to $2 \mathrm{~nm}$. When aged at room temperature (at $25^{\circ} \mathrm{C}$ ) under highly alkaline conditions, its transformation product, goethite (density, 4.26), normally occurs as acicular crystals that range from $0.05 \times 0.20 \mu \mathrm{m}$ to $0.15 \times 0.60 \mu \mathrm{m}$. However, goethite aged at higher temperatures $\left(70^{\circ} \mathrm{C}\right)$ under highly alkaline conditions ( $\mathrm{pH} 11.3$ - 
12.2) have been observed to reach particle sizes which range from $0.15 \times 0.4 \mu \mathrm{m}$ to $0.4 \times 3.0 \mu \mathrm{m}$. These observations show that $\mathrm{pH}$ and temperature are the two significant variables which control the particle size of aged goethite.

The advantages of this dissolution-rapid precipitation technique are 1) only two fine-grained solid phases would exist in the sludge, 2) because of the fine particle size these phases would exist as well mixed agglomerates, 3) the particle density differences between the fissile (schoepite, 4.86) and the absorber solid phases (ferrihydrite, 3.96; goethite, 4.26) would be minimized resulting in significantly reduced particle segregation effects.

It is important to note that the existing sludges in both single-shel1 and double-shell tanks have been shown to be extremely fine grained primary particulates that readily agglomerate into larger clumps (Whyatt et a1. 1996). Tank sludge was formed by the same acid dissolution-rapid neutralization process proposed herein for the $K$ basin sludges.

\section{A.5.7 Radiolysis}

Alpha emissions from spent fuel in aqueous media produce free radicals $\left(\mathrm{OH} \cdot \mathrm{H} \cdot, \mathrm{HO}_{2} \cdot\right)$, molecules $\left(\mathrm{H}_{2}, \mathrm{H}_{2} \mathrm{O}_{2}\right)$ and ions $\left(\mathrm{H}^{+}, \mathrm{OH}^{-}, \mathrm{e}^{-}{ }_{\mathrm{aq}}\right)$ which are powerful redox agents. The relative rates of interaction of these redox species will result in either overall reducing or oxidizing conditions. There is only limited data available in literature about effects of radiolysis in near neutral or alkaline solutions.

Sullivan (1983) showed that in the presence of ligands such as $\mathrm{Cl}, \mathrm{SO}_{4}$, $\mathrm{NO}_{3}, \mathrm{HCO}_{3}$, and $\mathrm{CO}_{3}$, radiolysis can result in oxidation of reduced actinide species. In contrast, gamma radiation induced radiolysis in alkaline media resulted in reduction of aqueous actinide species (Pikaev, 1996). Also, gamma irradiation tests conducted by Camaioni et al (1994) on simulated organic-rich Hanford waste tank supernatant indicated a net overall production of reductants. However, gamma irradiation experiments conducted on Pu(IV) hydrous oxide in simulated Hanford tank supernatants resulted in 5 to 10 fold increased solubility which indicates that irradiation produced overall oxidizing conditions (Karraker, 1994). This gamma radiation induced oxidizing reaction was attributed to the formation of $\mathrm{H}_{2} \mathrm{O}_{2}$, a powerful oxidizing agent in concentration exceeding of $10^{-4} \mathrm{M}$. These conflicting data indicate that radiolysis effects are not completely known for all combinations of electrolyte compositions. This conclusion is supported by the results of a review of radiolysis effects on solution chemistry conducted by Serne (1989). 


\section{A.5.7.1 Radiolysis Effects on KE Basin Sludges.}

We examined the available data on solid phases of fissionable material (U) in the sludges. and the solution chemistry indicators to deduce any effects of radiolysis occurring in the basin and canister environment. The sludge data show that basin floor, weasel pit sludges and fuel rod surfaces contain a $\mathrm{U}$-peroxide phase $\left[\mathrm{UO}_{3}\left(\mathrm{H}_{2} \mathrm{O}_{2}\right) 3 \mathrm{H}_{2} \mathrm{O}\right.$, studtite] (see Table A.3.6). The presence of a $\mathrm{H}_{2} \mathrm{O}_{2}$ bearing $\mathrm{U}$-solid phase would indicate that significant concentrations $\mathrm{H}_{2} \mathrm{O}_{2}$ may have formed from radiolysis reactions. Studtite can form either from oxidation of uraninite $\left(\mathrm{UO}_{2}\right)$.

$$
\left.\mathrm{UO}_{2} \text { (uraninite) }+\mathrm{H}_{2} \mathrm{O}_{2}+4 \mathrm{H}_{2} \mathrm{O}=\mathrm{UO}_{3}\left(\mathrm{H}_{2} \mathrm{O}_{2}\right) 3 \mathrm{H}_{2} \mathrm{O}\right) \text { (studtite) }+2 \mathrm{H}^{+}(\mathrm{aq})
$$

or by the peroxidation of schoepite or metaschoepite as follows:

$$
\mathrm{UO}_{3} \cdot 2 \mathrm{H}_{2} \mathrm{O} \text { (schoepite) }+\mathrm{H}_{2} \mathrm{O}_{2}+\mathrm{H}_{2} \mathrm{O}=\mathrm{UO}_{3}\left(\mathrm{H}_{2} \mathrm{O}_{2}\right) 3 \mathrm{H}_{2} \mathrm{O} \text { (studtite) }
$$

However, a report on $\mathrm{K}$ Basin Corrosion Program indicated that after 1978, $\mathrm{H}_{2} \mathrm{O}_{2}$ was added to the basin water as an algicide (Johnson and Burke. 1995). Therefore, the presence of U-peroxide solid phase in the sludge cannot be solely attributed to the effects of radiolysis.

In contrast, the composition of waters from KE canisters (see Table A.3.3) indicate that alpha radiolysis within the confined regions of the canisters may be intense enough to produce significant concentrations of. $\mathrm{HNO}_{3}$ resulting in up to three orders of magnitude increase in acidity, and from two to three orders of magnitude increase in $\mathrm{NO}_{3}$ concentrations as compared to the waters from the basin floor and weasel pit (see Table A.3.3). The most likely source of the acidity and dissolved nitrate concentrations in KE canister waters is alpha radiolysis which results in conversion of dissolved nitrogen from air in to nitric acid as described by Rai et al., (1980).

\section{A.5.7.2 Radiolysis Effects on Dissolved and Reprecipitated KE Basin Sludges}

Current7y, there are no data to forecast the degree and effects of radiolyis on dissolved and reprecipitated sludge. As discussed earlier in this section, available experimental data on simulated HLW show conflicting results as to the net production of either oxidants or reductants during the irradiation process. Clearly, the relative concentrations of these redox agents wi11 dictate whether oxidizing or reducing conditions wi11 dominate the chemistry of reprecipitated sludges. If radiolysis results in oxidizing conditions, the valence states of fissionable and absorber solid phases are 
not expected to change. However, depending on the intensity of alpha irradiation, solubilities may change due to solid phases altering in to less crystalline (more amorphous) states. However, if radiolysis results in reducing conditions overall. the fissionable and absorber solid phases in the reprecipitated sludge may alter in to reduced valent phases. The extent and rate of these reactions would depend on the rates, types, and concentrations of reducing agents produced from radiolysis.

The effects of radiolysis of reprecipitated $K$ Basin sludge can be assessed either by conducting irradiation experiments similar to those conducted on simulated Hanford wastes, or through use of models. Radiolysis models have been used to forecast the effects of radiolysis in repository environment (Carver et a1., 1979; Nicolosi, 1987). Reasonable forecasting of radiolysis effects by using models however depends mainly on including all potential types and rates of reactions that might occur in reprecipitated sludge matrix.

\section{A.5.8 Analysis of Flocculation and Dispersion of K Basin Sludige Particulate}

The objective of this analysis was to evaluate whether flocculation of sludge particles will likely occur during the sluicing and settling process. Understanding this is important because aggregated particles are less prone to settle differentially. The approach used in this analysis is similar to that reported by Serne et a1. (1996). They evaluated the question of whether Tank C-106 sludge could be safely sluiced into Tank AY-102. A number of simulations were conducted using Derjaguin, Landay, Verwey, and Overbeek (DLVO) theory, which describes colloid flocculation and dispersion processes. Similar calculations were conducted using parameter values from measurements made directly from K-Basin sludge or, when not avai lable, from the literature. The theory and the justification for the values used in these calculations are presented below.

\section{A.5.8.1 Overview of DLVO Theory}

The purpose of this section is to provide a brief overview of DLVO theory and has largely been condensed from three textbooks and review articles (Hiemenz 1986. Parsons 1990. Shaw 1980), and a previous treatment of this subject for criticality concerns of sludge by Serne et al. (1996. Appendix A). A description of how to interpret DLVO results is also presented.

When two particles approach each other in suspension, their diffuse counter-ion atmospheres, called the electric double layers, begin to interact. 
This interference leads to changes in the distribution of the ions in the double layer of both particles, which involves an increase in the free energy of the system. Work must therefore be performed to bring about these changes. In other words, there will be a repulsion between the particles. The amount of work required to bring the particles from infinite separation to a given distance between them can be calculated using Coulomb's Law (Parson 1990). The amount of work is the repulsive energy or the repulsive potential at a given distance. The repulsive potential decreases roughly inversely to the square of the particle separation.

Particle aggregation occurs by two distinct processes, depending on the nature of the interparticle attractive and repulsive forces. Particle flocculation occurs when particles are loosely bound together at a smal1, but nonzero distance. The interparticle distance corresponds to the distance where the magnitude of the attractive forces minus the magnitude of the repulsive forces is at a maximum. The particles are prevented from approaching closer than this distance by the repulsive forces. Particle coagulation occurs when the attractive forces are sufficient to overcome the repulsive forces at a11 possible interparticle separation distances. The surfaces of coagulated particles are in contact with each other.

Estimates of colloid suspension stability can be calculated using DLVO theory. This involves adding the attractive and the repulsive potential at each particle distance. By convention. attractive potentials are negative and repulsive potentials are positive. The work done by moving two spherical particles of radi $i a_{1}$ and $a_{2}$ together from an initially large separation distance, $h$, is given by the following equation (Shaw 1980):

$$
\Phi_{R}=\frac{64 \Pi \varepsilon a_{1} a_{2} k^{2} T^{2} Y_{1} Y_{2}}{\left(a_{1}+a_{2}\right) e^{2} z^{2}} \exp (-\mathrm{kh})
$$

where $\Phi_{R}$ is the repulsion potential (J), $\mathrm{K}$ is the Debye parameter as given by Equation A5.7 $(1 / \mathrm{m}), \varepsilon$ is the permittivity of the interparticle medium $\left(\mathrm{C}^{2} / \mathrm{Nm}^{2}\right), T$ is the absolute temperature $(K), Y$ is the charge-dependent parameter for particle $i$ as given by Equation A5.8. e is the electron charge $\left(1.6 \times 10^{-19} \mathrm{C}\right), z$ is the valence on the salt ions in solution (unitless), and $k$ is Boltzmann's Constant $\left(1.38 \times 10^{-23} \mathrm{~J} / \mathrm{K}\right)$.

The value of the Debye parameter, which is also called the inverse double-layer thickness, is given by 


$$
\begin{aligned}
& \text { HNF-SD-WM-ES-409, Rev. } 0 \\
& \mathrm{~K}=\left(\frac{2 e^{2} N_{A} C z^{2}}{\varepsilon k T}\right)^{0.5}
\end{aligned}
$$

where $N_{A}$ is Avogadro's number $\left(6.02 \times 10^{23}\right.$ molecules/mole), and $C$ is the concentration of a $z: z$ electrolyte (an electrolyte consisting of a univalent cation and a univalent anion; moles $/ \mathrm{m}^{3}$ ). The value of the charge-dependent parameter, $Y$, used in Equation A5.6 is :

$$
Y_{i}=\tanh \left(\frac{z \in \Psi_{i}}{4 k T}\right)
$$

Where $\psi_{i}$ is the surface charge ( $V$ ) of particle number $I$. Equations A5.6. A5.7. and A5.8 were used to estimate the repulsive force between particles of various sizes.

For spheres, the attractive potential ( $\Phi_{A}$, in units of joules) is:

$$
=-\frac{A}{6}\left[\frac{2 a_{1} a_{2}}{h^{2}+2 a_{1} h+2 a_{2} h}+\frac{2 a_{1} a_{2}}{h^{2}+2 a_{1} h+2 a_{2} h+4 a_{1} a_{2}}+\ln \left(\frac{h^{2}+2 a_{1} h+2 a_{2} h}{h^{2}+2 a_{1} h+2 a_{2} h+4 a_{1} a}\right.\right.
$$

where $A$ is the Hamaker constant in units of joules ( $\mathrm{J}$ ). Finai7y, the total potential. $\Phi_{T}$, can be calculated as the sum of the attractive and repulsive potentials:

$$
\Phi_{T}=\Phi_{A}+\Phi_{R}
$$

The interpretation of stability and flocculation in terms of the shapes of the net potential curves of particle interaction is based on a number of considerations. To help understand how to interpret the potential curves, an example of a dispersed, flocculated, and coagulated system is presented in Figure A.5.5. The curves in Figure A.5.5 were generated from Equations A5.6 through A5.7. First of a11, a convention has been established that attractive forces have a negative polarity whereas repulsive forces have a positive 
polarity. The net interaction potentials in this report are plotted in units of kT. i.e., Boltzmann's constant times temperature, resulting in units of joules. These units are used to directly compare the magnitude of the net force responsible for Brownian motion, which is the result of thermally induced molecular vibration forces. To ensure a reasonable stability of a suspension, the height of the energy barrier should be of the order of $15 \mathrm{kT}$ for a dilute suspension. For a more concentrated suspension, in which the rate of agglomeration in the absence of an energy barrier is already higher than that for dilute suspensions, the energy barrier should be as high as about $25 \mathrm{kT}$ to produce a reasonably stable suspension (van 01phen 1977). A7though the complete shape of the barrier should be taken into account, the maximum height appears to be the most important parameter. If two particles approach each other owing to their Brownian motion, they will aggregate when they reach the position at which the deep attraction minimum occurs, about 40 $\mathrm{nm}$. The aggregation of the particles is referred to as coagulation and the process is rapid and possibly irreversible. The curve representing flocculation has a positive net interaction potential at separations of about 5 to $10 \mathrm{~nm}$. At distances greater than about $20 \mathrm{~nm}$. the net force is negative, signifying attraction. Flocculation, but not coagulation, is predicted for this system. For the dispersed system in Figure A.5.5, the net interaction is positive at essentially all interparticle distances. No flocculation or coagulation is expected for this system. Hiemenz (1986) and van 0lphen (1977) present additional discussions describing how energy minimums, activation energy, and energy minimum "traps" related to net interaction potential curves.

\section{A.5.8.2 Justification of Input Parameters Used in DLVo Calculations}

Table A.5.19 presents the values used in the calculations. Baseline conservative estimates, "best" estimates, and a range of reported values for each parameter are presented. The baseline conservative estimates were selected to yield the most dispersed conditions (least amount of flocculation/coagulation). By being dispersed, the particles would be more likely to differentially settle as a result of their unique densities. These baseline estimates were also the values used to evaluate the sensitivity of a given parameter, e.g., when temperature was evaluated, its value was varied while the other values were the conservative estimates presented. The "best"estimates were provided in an attempt to provide some idea as to what may be expected to happen. As wi 11 be demonstrated, the use of conservative estimates may sometimes result in "washing out" the sensitivity of a calculation, thereby making it a less valuable tool for evaluating what will likely occur in disposing the sludge in AW-105. Finally, a range of values 
Table A.5.19. Justification for the Selection of Input Values for the DLVO Calculations.

\begin{tabular}{|c|c|c|c|c|l|}
\hline Parameter & Units & $\begin{array}{c}\text { Conservative } \\
\text { Baseline } \\
\text { Estimate }\end{array}$ & Best Estimate & Range & $\begin{array}{l}\text { Justification/ } \\
\text { Comments }\end{array}$ \\
\hline Hamaker, $\mathrm{A}$ & $\mathrm{J}$ & $8.30 \times 10^{-21}$ & $50 \times 10^{-21}$ & $8.3 \times 10^{-21}$ to $600 \times 10^{-21}$ & 1 \\
\hline Temp., $\mathrm{T}$ & $\mathrm{K}$ & 300 & 288 & 282 to 303 & 2 \\
\hline $\begin{array}{c}\text { Electrolyte } \\
\text { Conc., } \mathrm{c}\end{array}$ & $\mathrm{mo} / \mathrm{m}$ & 100 & 1000 & 1000 to 6000 & 3 \\
\hline $\begin{array}{c}\text { Surface } \\
\text { Charge, } \Psi\end{array}$ & $\mathrm{V}$ & -0.07 & -0.034 & -0.025 to -0.06 & 4 \\
\hline $\begin{array}{c}\text { Particle } \\
\text { Diameter, a }\end{array}$ & $\mathrm{nm}$ & 200 & 270 & 180 to 6260 & 5 \\
\hline
\end{tabular}

1) Conservative: Minimum value in range was selected to decrease attractive forces. Using such a low value is likely too conservative. Best: This value is based on reported values of $\mathrm{Al}_{2} \mathrm{O}_{3}, \mathrm{TiO}_{2}, \mathrm{ZnO}_{2}$, and elemental $-\mathrm{Au},-\mathrm{Ag}$, and $-\mathrm{Cu}$. Also, $\mathrm{Al}_{2} \mathrm{O}_{3}$ may be a reasonable analog; it has an average value of $13.3 \mathrm{e}-20 \mathrm{~J}$. The uncertainty of the Hamaker constant introduces a great deal of uncertainty in these calculations. See Table A.5:20.

2) Conservative: Highest value within range of reported temperatures in the AW-105. Best: Average temperature reported for AW-105.

3) Difficult values to estimate without detailed knowledge of the sludge treatment process. Presently, it appears that the sludge will be acid digested. Fe treated, and then the $\mathrm{pH}$ increased to reduce tank corrosion. The salt concentrations presently in the K-Basins are less than $10 \mathrm{~mol} / \mathrm{m}^{3}$.

4) Surface charge values are based on zeta potential measurements made on actual sludge samples collected from the K Basins. These values, which underestimate the actual surface charge, were corrected by an amount that depends on the salt concentration in the liquid phase (Hiemenz 1986, p. 768). Since the sludge may be totally digested and permitted to reprecipitate with Fe particles. literature values of the surface charge of Fe-oxides were also considered in these estimates. See Table A.5.21.

5) Values based on dynamic light scattering measurements of several K-Basin sludge samples. Conservative: A small particle size was selected as the baseline conservative estimate to provide the most likely scenario for colloid dispersion. Best: Based on dynamic light scattering measurements, the $270 \mathrm{~nm}$ value is representative of K-Basin sludge samples that had been sonicated ( $40 \mathrm{~W}$ for $300 \mathrm{~s}$ ). Such a value would represent the size of unaggregated particles. 
for each parameter is presented in Table A.5.19. The range of values was determined during the process of selecting the "best" and conservative estimates.

As will become apparent in the Results section, the value used for the Hamaker constant is very important to the outcome of the calculations. The Hamaker constant accounts for the portion of the attractive force that depends on the composition of the particles. It is a complicated function of the dielectric and polarizability properties of the particles and the surrounding liquid medium. A computer-assisted 1iterature search was conducted to identify Hamaker constants for this study. No values were found specifically for uranium or iron particles (Table A.5.20). This compromised the results of these DLVO calculations. The range of possible Hamaker constants ranged from $0.83 \mathrm{e}-20$ to $60 \mathrm{e}-20 \mathrm{~J}$. The range of constants for the metals, neglecting the silicates and aluminosilicates decreased substantially to5.3e-20 to $60 \mathrm{e}-20 \mathrm{~J}$ (Table A.5.20). The Hamaker constant for $\mathrm{Al}_{2} \mathrm{O}_{3}$ may be a reasonable analog for the iron and uranium particles based on its coordinate/solid-state chemistry. The average Hamaker constant for $\mathrm{Al}_{2} \mathrm{O}_{3}$ for three observations is $13.2 \mathrm{e}-20 \mathrm{~J}$.

Surface charge values used in the calculations were primarily based on zeta potential measurements made on K-Basin sludge (Table A.5.21). Zeta potentials do not actualiy measure the surface charge of a particle but the potential at the shear plane, a layer of water that approximately separates the mobile from immobile water. These zeta potential values were converted to surface charge values by an amount that depends of the salt concentration in the liquid. For the high ionic strength used in this scenario and the relatively low zeta potentials experimentally measured $(<60 \mathrm{mV})$, these ionic strength corrections were quite minimal, and in some cases, no correction was needed.

The zeta potentials of the 12 sludge samples did not vary greatly. The average zeta potential was $-19 \mathrm{mV}$ at $\mathrm{pH} 7$. The average zeta potential at $\mathrm{pH}$ 11.5 was $-34 \mathrm{mV}$. It is also important to have an idea about the surface charge of Fe-oxides because they are likely to be plentiful in the sludge. Should the K-Basin sludges be acid digested, treated with $\mathrm{Fe}^{3+}$ and then precipitated, then the Fe-oxide surface properties may be especially important. An important difference between Fe-oxide and $\mathrm{K}$-Basin sludge samples is that the former has a positive charge at $\mathrm{pH} 7$. At $\mathrm{pH} \mathrm{11.5,} \mathrm{the}$ iron particles charge properties are also negative and slightly less than those of the K-Basin sludge samples. Thus, at near-neutral pH levels, the iron particles would be expected to aggregate strongly with the sludge. In designing the sludge treatment, it may be possible to take advantage of this. 
HNF-SD-WM-ES-409, Rev. 0

Table A.5.20. Hamaker Constant for Materials in Water. Results from a Computer-Assisted Literature Search.

\begin{tabular}{|c|c|c|}
\hline $\begin{array}{l}\text { Hamaker Constant, } \mathrm{J} x \\
10^{-20}\end{array}$ & Material & Reference \\
\hline 1.59 & Mica & $\begin{array}{l}\text { Anandarajah and Chen 1995, p. } \\
\qquad 297\end{array}$ \\
\hline 1.3 & Quartz & $\begin{array}{l}\text { Anandarajah and Chen 1995, p. } \\
\qquad 297\end{array}$ \\
\hline 2.49 & pyrophyllite & $\begin{array}{l}\text { Anandarajah and Chen 1995, p. } \\
\qquad 297\end{array}$ \\
\hline 2.9 & Muscovite mica & Ackler et al. 1996, p. 462 \\
\hline 27.5 & $\mathrm{Al}_{2} \mathrm{O}_{3}$ & Ackler et a1. 1996, p. 462 \\
\hline 1.6 & $\mathrm{SiO}_{2}$ & Ackler et a]. 1996, p. 462 \\
\hline 60 & $\mathrm{TiO}_{2}$ & Ackler et al, 1996, p. 462 \\
\hline 5.3 & $\mathrm{Al}_{2} \mathrm{O}_{3}$ & Israelachvili 1991, p. 190 \\
\hline 0.83 & Quartz & Israelachvili 1991, p. 190 \\
\hline 6.7 & $\mathrm{Al}_{2} \mathrm{O}_{3}$ & Sabisky and Anderson 1973 \\
\hline 2 & Mica & Israelachvili 1991, p. 190 \\
\hline 2.2 & Mica & Isrealachvili and Adams 1978 \\
\hline 40 & Gold & Derjaguin et a1. 1978 \\
\hline 30 to 40 & $\begin{array}{c}\text { Elemental Ag, Au. } \\
\mathrm{Cu}\end{array}$ & Isrealachvili 1991, p. 190 \\
\hline 0.83 to 5.32 & $\mathrm{SiO}_{2}, \mathrm{CaCO}_{3}, \mathrm{CaF}_{2}$ & Russel et a1. 1989, p. 148. \\
\hline 13 & $\mathrm{n}-\mathrm{ZrO}_{2}$ & Horn et a1. 1988 \\
\hline 26 & $\mathrm{TiO}_{2}$ & Horn et a1. 1988 \\
\hline
\end{tabular}


Table A.5.21. Zeta Potential of K-Basin Sludge and Iron Oxide Particles

\begin{tabular}{|c|c|c|c|}
\hline Sample & \multicolumn{2}{|c|}{$\mathrm{pH}$} & Reference \\
\hline & 7 & 11.5 & \\
\hline M13T & -18 & -34 & Makenas et a1. 1996 \\
\hline M13T(dup) & -22 & -30 & Makenas et a1. 1996 \\
\hline M13B & -15 & -29 & Makenas et a1. 1996 \\
\hline$M 13 B(d u p)$ & -18 & -31 & Makenas et a1. 1996 \\
\hline T20T & -18 & -27 & Makenas et a]. 1996 \\
\hline T20T(dup) & -18 & -30 & Makenas et a1. 1996 \\
\hline $\mathrm{T} 20 \mathrm{~B}$ & -16 & -29 & Makenas et a 1. 1996 \\
\hline T20B(dup) & -18 & -25 & Makenas et a1. 1996 \\
\hline $96-6 M$ & -20 & -38 & Smith 1997 \\
\hline $96-06 \mathrm{~L}$ & -26 & -60 & Smith 1997 \\
\hline $96-04 \mathrm{~L}$ & -30 & -35 & Smith 1997 \\
\hline $96-11$ & -13 & -45 & Smith 1997 \\
\hline $\begin{array}{l}\text { Average for } \\
\text { Sludge }\end{array}$ & $-19+/-4$ & $-34+1 \cdot 9$ & \\
\hline Fe-oxides & +10 & -40 & Dumont et a1. 1976 \\
\hline Fe-oxides & +26 & -27 & Dumont et a 1.197 .6 \\
\hline Fe-oxides & +22 & -- & Dumont et a1. 1976 \\
\hline Ferric hydroxide & +5 & -2 & Wang 1995 \\
\hline Goethite & 0 & - - & Hohl et a1. 1980 \\
\hline $\begin{array}{l}\text { A1-Ferric } \\
\text { hydroxide }\end{array}$ & -8 & -26 & Wang 1995 \\
\hline Average for $\mathrm{Fe}$ & $+9+/ \cdot 13$ & $-24+/ \cdot 16$ & \\
\hline
\end{tabular}

a. In some cases the experimental data did not have zeta potential values for pH levels as high as 11.5. In such cases, the values were extrapolated. 
The particle sizes of the sludge have been measured by dynamic light scattering (Makenas et a1. 1996. Silvers 1995. Smith 1997). These measurements were made on untreated samples and samples that had been sonicated. The latter treatment provide information about whether the suspended colloids existed as separate or aggregated entities. The sonicated and nonsonicated samples were always less than $1 \mu \mathrm{m}$ in diameter (on a number of particles basis). The nonsonicated samples ranged from 0.3 to $0.7 \mu \mathrm{m}$. The sonicated samples ranged from 0.2 to $0.4 \mathrm{~mm}$. For all but one sample (KES-T20T), a difference in colloid size was observed upon sonication. This suggests that the sludge colloids, as they were taken from the K-Basins were likely aggregated. Uranium particle sizes based on TEM and $x$-ray diffraction analysis (determined indirectly from peak width of diffractograms) indicate that uranium and iron particles from the sludge have diameters within the range of 10 and $1500 \mathrm{~nm}$; most phases having a diameter between 100 and $500 \mathrm{~nm}$ (see sections A.3.7, A.3.8.4).

\section{A.5.8.3 DLVO Results}

A series of simulations using Equations A5.6 though A5.10 are described in this section The input values for these simulations are presented in Table A5.19. The "Conservative Baseline Values" in Table A5.19 were used in a11 cases except when stated. Parameters that were systematically varied include:

1) particle size (Figure A.5.6),

2) solution salt concentration (Figure A.5.7),

3) temperature (Figure A.5.8),

4) Hamaker constant (Figure A.5.9).

Additional7y, analyses based on "best" estimates were compared to those based on "conservative baseline" estimate (Figure A.5.10).

\section{A.5.8.3.1 Particle Size}

Particle size is an especially important parameter affecting colloid suspension stability. It appears in both the attractive (Equation A5.6) and repulsive (Equation $A 5.10$ ) equations. The propensity of a colloid to remain in suspension is inversely related to its size. This can be seen in Figure A.5.6. As mentioned above, negative potentials indicate a net attraction between the particles, whereas positive potentials indicate a net repulsion between particles. Another important feature of these figures is the magnitude of the energy barrier. A stable dilute suspension of colloids has an energy barrier greater than about $15 \mathrm{kT}$. 
A stable concentrated suspension of colloids is expected to have an energy barrier greater than about $25 \mathrm{kT}$. Thus, none of the colloid sizes in Figure A.5.6 is expected to be dispersed, i.e., to form stable colloid suspensions. A suspension of $200-\mathrm{nm}$ colloids would likely form weakly electrostatically bonded aggregates. Since the energy barriers of the 2000-, 4000-, and 20,000$\mathrm{nm}$ colloid suspensions are greater (more negative) than $15 \mathrm{kT}$, they would be expected to form strongly bonded aggregates, i.e, they would be coagulated. Another indication that these suspensions would flocculate or coagulate is that the net interaction potentials never are positive (except at extremely short distances where Bond and London forces are especially important).

\section{A.5.8.3.2 Solution Salt Concentration}

The salt concentration effects the repulsive forces while having no effect on attractive forces (Equations $A 5.10$ and A5.11). As the salt concentration increases, the double layer thickness decreases. A compressed double layer has lower repulsive forces. Based on the results presented in Figure A.5.7-A, $100 \mathrm{~mol} / \mathrm{m}^{3}$ (which is equal to $100 \mathrm{mM}$ ) will likely result in weak aggregation of $400-\mathrm{nm}$ diameter particles. The $100 \mathrm{~mol} / \mathrm{m} 3 \mathrm{curve}$ represents the conservative baseine estimate in this figure. The 1 - and 10$\mathrm{mol} / \mathrm{m}^{3}$ suspension are highly dispersed, whereas the $100-$ and $1000-\mathrm{mol} / \mathrm{m}^{3}$ suspension is 1ikely to aggregate. Both the AW-105 and the transfer shipping casks will have solution concentrations well above $10 \mathrm{~mol} / \mathrm{m}^{3}$, thus the slurries should promote particle aggregation. For very small colloids with a diameter of $20 \mathrm{~nm}$. concentrations as high as $10.000 \mathrm{~mol} / \mathrm{m}^{3}$ were unabie to flocculate the system (Figure A.5.7B). Another interesting feature of Figure A.5.7-B is that the repulsion forces of even the most dilute system only reaches $4 \mathrm{~nm}$ from the colloid surface.

\section{A.5.8.3.3 Temperature}

Temperature was varied in these simulations between $260 \mathrm{~K}$ to $320 \mathrm{~K}$, the approximate range of temperatures reported in Tank AW-105. The slight correction for changes in viscosity were not made in these calculations. The temperature parameter occurs in four terms in the repulsive force equation and not at all in the attractive force equation (Equations A5.6, A5.7, and A5.8). Temperature had little effect on the outcome of the net interaction potentials (Figure A.5.8). This is an important result and not intuitive based on general principles of chemistry or by looking at the equations.

\section{A.5 8.3.4 Hamaker Constant}


The value selected for the Hamaker constant had a profound effect on the outcome of these calculations (Figure A.5.9). The range of possible values is greater than an order of magnitude and unfortunately no values exist for uranium or iron materials. The inability to accurately predict this value compromises the accuracy of these calculations. Thus, in using the lowest value obtained from a literature search. we are very likely to underestimate the attractive potential of the colloids. The sensitivity analysis of the Hamaker constant shows that the conservative baseline value, $8.3 \times 10^{-21} \mathrm{~J}$, predicts a weakly flocculated system. When the "best estimate" of the Hamaker constant, $5 \times 10^{-20} \mathrm{~J}$, was used, coagulation (strong aggregation) was predicted.

\section{A.5.8.3.5 "Best Estimates" versus "Conservative Baselines Estimates"}

The purpose of conducting this calculation was to evaluate the extent to which our "best" and "conservative" estimates affected the outcome of the net interaction potential curves. As shown in Figure A.5.10, the two sets of input values suggest that the particles are rikely to aggregate. For the conservative set of input values, the system is expected to be very weakly aggregated. In the case of the "best estimate," the system is expected to be strongly aggregated.

\section{A.5.8.3.6 Suspension of Colloids with Different Sizes}

When two different size particles $\left(a_{1}: a_{2}\right)$ were simulated, the curves took on a form that was somewhere in between the forms of the separate particles $\left(a_{1}: a_{1}\right)$.

\section{A.5.8.4 Kinetic Considerations of Aggregation: Theory and Initial Results}

The rate of particle aggregation depends on the frequency of collisions and on the efficiency of particle contacts. The efficiency of particle contacts is the subject of the above discussion in which DLVO calculations were made to determine the net interactive energy of two approaching particles. The frequency of collisions in the subject of this section.

Particles in suspension collide with each other as a consequence of at least three mechanisms of particle transport: Brownian motion (perikinetic), advective or shear (orthokinetic), and differential settling velocities (Friedlander 1977. 0'Melia 1978. Stumm and Morgan 1981). The time-dependent decrease in the concentration of particles $(N=$ number of particles per cubic meter) in a suspension due to collisions can be represented by a second-order rate law: 
HNF-SD-WM-ES-409, Rev. 0

$$
-\frac{d N}{d t}=k N^{2}
$$

(A.5.6)

where $k$ is the second order rate constant and $t$ is time. $k$ can be rewritten in a more mechanistic manner such that a term for collision efficiency, $\alpha_{p}$, and the rate of particle reactions for a specific process, $k_{i}$, is included in the formulation:

$$
k=\alpha_{p} k_{i}
$$

The collision efficiency term is difficult to predict, however considerable effort has been directed at relating it to DLVO theory. The reaction rate of each process is better understood. The rate constant for Brownian motion $\left(k_{b}\right)$. is:

$$
k_{b}=\frac{2 k T\left(d_{1}+d_{2}\right)^{2}}{3 n d_{1} d_{2}}
$$

where $\eta$ is the absolute viscosity $\left(\mathrm{Ns} / \mathrm{m}^{2}\right)$ and $d_{1}$ and $d_{2}$ are the diameters of particles 1 and 2, respectively. The rate constant for laminar shear $\left(k_{s h}\right)$ is

$$
k_{s h}=\frac{\left(\alpha_{1}+d_{2}\right)^{3}}{6}-G
$$

where $G$ is the mean velocity gradient $(1 / s)$ : The rate constant for differential settling $\left(k_{5}\right)$ is 
HNF-SD-WM-ES-409, Rev. 0

$$
k_{s}=\frac{\pi g(\rho-1)}{72 v}\left(d_{1}+d_{2}\right)^{3}\left(d_{1}-d_{2}\right)
$$

where $g$ is gravitational acceleration $\left(\mathrm{m} / \mathrm{s}^{2}\right), v$ is the kinematic viscosity $\left(\mathrm{m}^{2} / \mathrm{s}\right)$ and $\rho$ is the particle density $\left(\mathrm{kg} / \mathrm{m}^{3}\right)$. The overall rate constant of decrease in concentration of particles (Equation A5.11) can then be rewritten as:

$$
-\frac{d N}{d t}=\alpha_{b} k_{b} N^{2}+\alpha_{s h} k_{s h} N^{2}+\alpha_{s} k_{s} N^{2}
$$

Rewriting the rate equation in this manner, it is possible to account for different processes in the rate reaction. Unfortunately, collision efficiency, $\alpha_{i}$, is poorly understood (Friedlander 1977, O'Melia 1978). One exception, is that the rate collision efficacy via Brownian motion, $\alpha_{b}$, has been rather successfully calculated based on DLV0 theory. Such calculations may be valuable for future reports related to criticality concerns of K-Basin sludge. An attribute of this approach is that it may permit calculations on selective aggregation (e.g., uranium particles selectively aggregating with other uranium particles instead of with the more abundant iron particles) and help identify the important flocculation/dispersion processes.

Calculations using Equations A5.13, A5.14, and A5.15 are presented in Figure A.5.12. Figure A.5.12 is modeling a scenario in which two colloid sizes are present in a system. The first colloid, $d_{1}$, is $1-\mu \mathrm{m}$ in diameter. The second colloid is the size indicated on the x-axis. When the colloid is $0.01-\mu \mathrm{m}$ in diameter. differential settling is the most important process occurring. Laminar shear becomes important when the second particle is $>1$ $\mu \mathrm{m}$. The mean velocity gradient used in this simulation was purposely set quite low, $5 \mathrm{~s}^{-1}$. This rate corresponds to slow stirring in a beaker. about one revolution per second. Thus, its importance to the rate of aggregation is unexpected. Brownian motion is a less important process. When the first colloid's diameter was set to $0.01-\mu \mathrm{m}$ instead of $1 \mu \mathrm{m}$. Brownian motion was the most important process controlling aggregation (results not presented).

\section{A.5.8.5 DLVO Conclusions}

Some uncertainty is introduced in these calculations because the actual 
sludge pretreatment approach is not known. However, it is assumed that the sludge is completely dissolved in acid, a neutron absorber added (iron or depleted uranium) and then the mixture is rapidly precipitated by caustic addition. In this case, it is expected that the precipitates would nonselectively agglomerate. This non-selective agglomeration is expected to dramatically reduce the degree of segregation that can occur as the result of differing crystallite densities, sizes or shapes.

Parameter values used in the simulations were based on references from PNNL reports and references obtained from a computer-assisted literature search. Several laboratory measurements made at the Hanford Site of the particle size and zeta potential of K-Basin sludge have been conducted. These results were quite consistent. They suggested that the particles were weakly aggregated. The flocs were $<1-\mu \mathrm{m}$ in diameter. The elementary particle size was generally about 200 to $300 \mathrm{~nm}$ in diameter. The zeta potential values of the sludge were also quite similar. A collection of values at pH 7 and 11.5 was presented. The average at pH 11.5 was about $-0.03 \mathrm{~V}$. Among the input parameters used in these calculations, the Hamaker constant had the greatest uncertainty, ranging from $8.3 \times 10^{-21}$ to $600 \times 10^{-21} \mathrm{~J}$.

The model used in these simulations predicts the net interactive potential of two colloids as a function of distance as they approach each other. The shape of the calculated curves and the magnitude of the energy barrier were used to evaluate whether a given system would likely flocculate (form weakly held together clusters), coagulate (form strongly held together clusters), or disperse. This is important because a dispersed system is more likely to promote differential settling. If the particles' diameters were larger than about $200 \mathrm{~nm}$, flocculation or coagulation was predicted. At: particle sizes greater than about 2000-nm, coagulation was predicted. The fact that most K-Basin sludge was found to be made up of elementary particles between 200 and $300 \mathrm{~nm}$ suggests that this material would likely flocculate. According to dynamic light scattering measurements, these elementary particles tend to aggregate into effective sizes of $>1000 \mathrm{~nm}$. The solution salt concentration also had a profound effect on dispersion and flocculation. But even in the most conservative estimates ( $100 \mathrm{mM}$; a low value), flocculation is expected. Based on these calculations, dispersion is not likely to become important for $400-\mathrm{nm}$ particles until the solution salt concentration decreased below about $10 \mathrm{mM}$. This concentration is not likely in light of the fact that the inhibitor treatment alone is expected to have a salt concentration of 20 $\mathrm{mM}$. The salt concentration in Tank AW-105 is in the $1000 \mathrm{mM}$ range. Temperature had essentially no effect on colloid suspension stability. 
In conclusion, these calculations support the notion that K-Basin sludge particles will likely either weakly flocculate or more strongly coagulate in a high $\mathrm{pH}$ system with a dissolved salt concentration greater than $100 \mathrm{mM}$.

Experimental evidence supports the conclusion that the particles presently in the K-Basins are aggregated. 
HNF-SD-WM-ES-409, Rev. 0

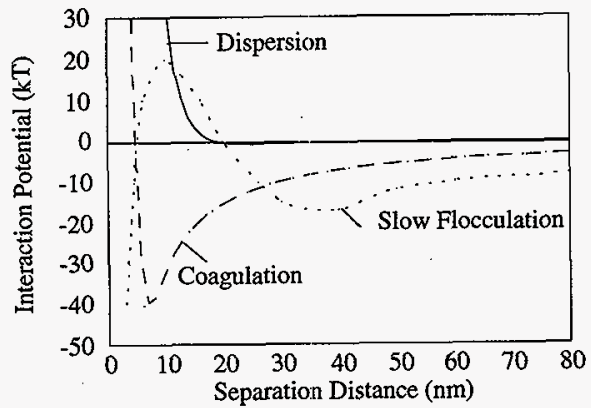

Figure A.5.5. Example of Net Interaction Potential Curves for Dispersed, Flocculated, and Coaggulated Colloidal systems.

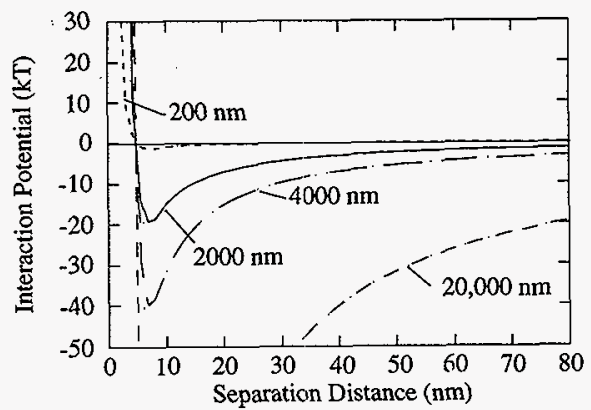

Figure A.5.6. Effect of Particle Diameter on Interaction Potential (Input Parameter values in Table A.5.19) 
HNF-SD-WM-ES-409, Rev. 0
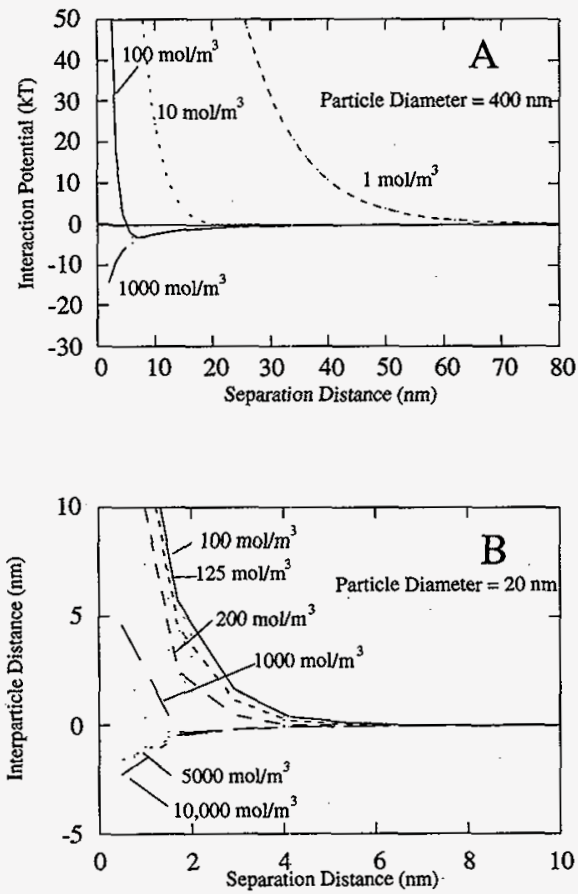

Figure A.5.7. Effect of Solution Salt Concentration on Interaction Potential for particles (A) $400 \mathrm{~nm}$ and (B) $20 \mathrm{~nm}$ (Input Parameter values in Table A.5.19) 
HNF-SD-WM-ES-409, Rev, 0

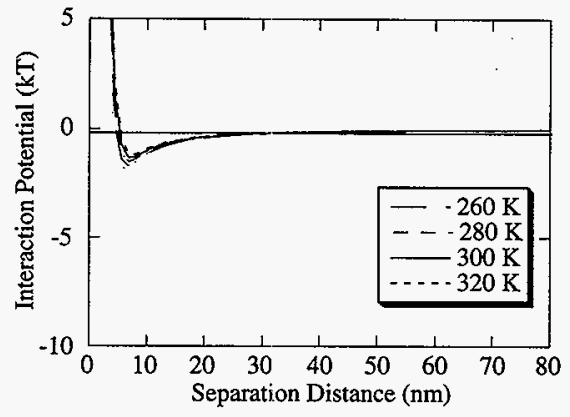

Figure A.5.8. Effect of Temperature on Interaction Potential (Input Parameter Values in Table A.5.19) 
HNF-SD-WM-ES-409, Rev. 0

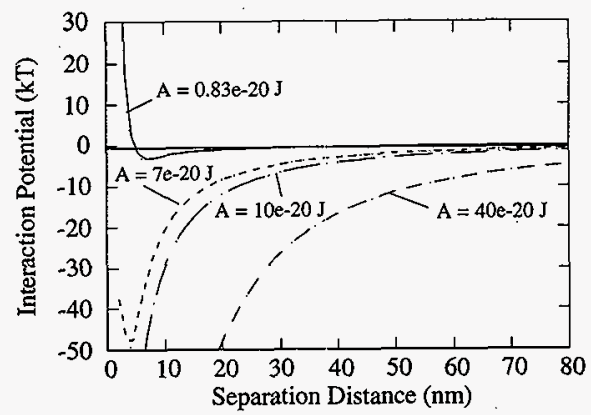

Figure A.5.9. Effect of Hamaker Constant on Interaction Potential (Input Parameter Values in Table A.5.19, Particle Diameter $=400 \mathrm{~nm}$ )

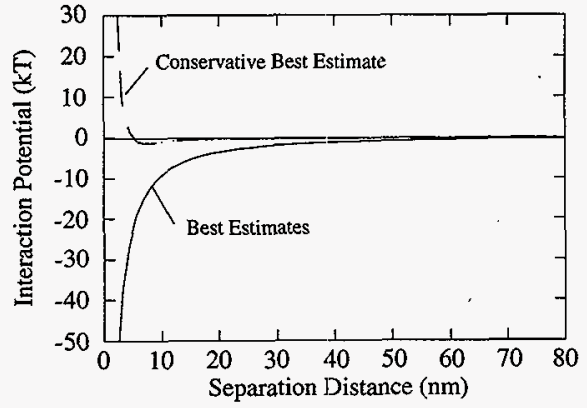

Figure A.5.10. "Best Estimates" Versus "Conservative Baseline Estimates" on Interaction Potential (Input Parameter Values in Table A.5.19) 
HNF-SD-WM-ES-409, Rev. 0
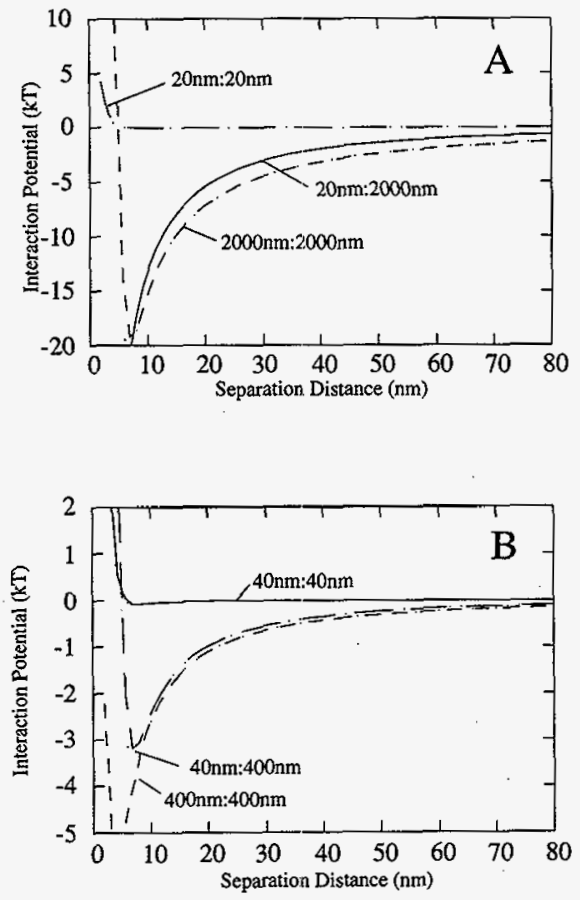

Figure A.5.11. Effect of Having Two Particles of Varying Diameter on Net Interaction Potential (Input Parameter Values in Table A.5.19) 
HNF-SD-WM-ES-409, Rev. 0

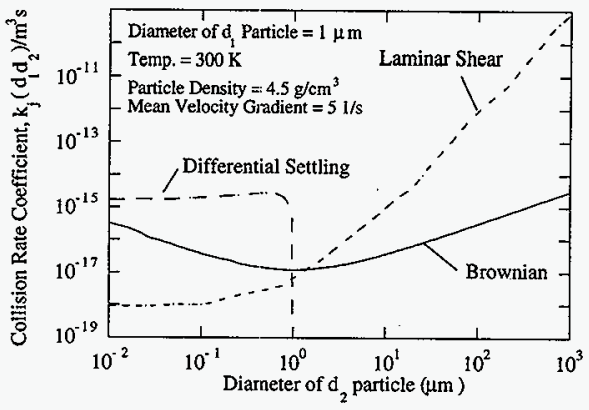

Figure A.5.12. Effects of Particie Size on Collision Rate Constants for a Suspension Containing 1- $\mu \mathrm{m}$ Colloids. 
HNF-SD-WM-ES-409, Rev. 0

\section{A.6 REFERENCES}

AckTer, H. D., R. H. French, and Y. Chiang. 1996. "Comparisons of Hamaker Constants for Ceramic Systems with Intervening Vacuum or Water: From Force Laws and Physical Properties." Journal of Colloid and Interface Science, 179:460-469.

Agnew, S. F. 1995. Hanford Defined Wastes: Chemical and Radionuclide Compositions. LA-UR-94-2657, Rev. 2, Los Alamos National Laboratory, Los Alamos. New Mexico.

Agnew. S. F., J. Boyer, R. A. Corbin, T. B. Duran, J. R. FitzPatrick, K. A. Jurgensen, T. P. Ortiz, and B. L. Young. 1996. Hanford Tank Chemical and Radionuclide Inventories: HDW Mode7 Rev. 3. . LA-UR-96-858, LoS Alamos Nationa 1 Laboratory, Los Alamos. New Mexico.

Allison, J. D., D. S. Brown, and K. J. Novo-Gradac. 1991. MINTEQA2/PRODEFA2, A Geochemical Assessment Model for Environmental Systems: Version 3.0 User's Manua 7. EPA/600/3-91/021, U.S. Environmental Protection Agency, Athens, Georgia.

Amaia Sandino, M. C., and B. Grambow. 1994. "Solubility Equilibria in the U(VI) - Ca-K-Cl- $\mathrm{H}_{2} \mathrm{O}$ System: Transformation of Schoepite into Becquerelite and Compreignacite," Radiochimica Acta, 66/67:37-43.

Anandarajah. A. and J. Chen. 1995. "Single Correction Function for Computing Retarded van der Waals Attraction." Journa 7 of Co7loid and Interface Science, 176:293-300.

Babad. H. 1996. personal communication, Westinghouse Hanford Company, Richland. Washington.

Bain, D., and B. F. L. Smith. 1987. "Chemical Analysis." In A Handbook of Determinative Methods in Clay Mineralogy, ed. M. J. Wilson, Chapman and Ha17. New York. New York.

Ba17. J. W., E. A. Jenne, and M. W. Cantrel1. 1981. WATEQ3: A Geochemical 
HNF-SD-WM-ES-409, Rev. 0

Mode7 with Uranium Added. Open-File Report 81-1183, U.S. Geological Survey, Mento Park, California.

Bates, J. K., B. S. Tani, E. Veleckis, and D. J. Wronkiewicz. 1990. "Identification of Secondary Phases Formed during Unsaturated reaction of $\mathrm{UO}_{2}$ with $\mathrm{EJ}-13$ Water." In Scientific Basis for Nuclear Waste Management XIII, eds. V. M. Oversby and P. W. Brown, pp. 499-506. Materials Research Society Symposium Proceedings, Volume 176. Materials Research Society, Pittsburgh. Pennsylvania.

Bolt, G. H., and M. G. M. Bruggenwert (eds.). 1978. Soi7 Chemistry.

A. Basic Elements. Developments in Soil Science 5A. Elsevier Scientific Publishing Company, New York. New York.

Bragg. R. H. 1967. 'Quantitative Analysis by Powder Diffraction.' In Handbook of X-Rays. Ed. E. F. Kaeble. McGraw Hi11., New York.

Brisbin, S. A., and K. L. Pearce. October 1996. Functional Design Criteria for the S7udge Receiving Station. WHC-SD-WM-FDC-052. Rev 0., Westinghouse Hanford Company, Richland, Washington.

Brown, D. S., and J. D. Allison. 1987. MINTEQA1, an Equil.ibrium Metal Speciation Mode 7: User's Manua 7. EPA/600/3-87/012, U.S. Environmental Protection Agency, Athens, Georgia.

Bruno, J., I. Casas, B. Lagerman, and M. Munoz. 1987. "The Determination of the Solubility of Amorphous $\mathrm{NO}_{2}(\mathrm{~s})$ and the Mononuclear Hydrolysis Constants of Uranium(IV) at $25^{\circ} \mathrm{C}$." In Scientific Basis for Nuclear Waste Management X, eds. J. K. Bates, and W. B. Seefeldt, pp. 153-160. Materials Research Society Symposium Proceedings, Volume 84, Materials Research Society. Pittsburgh. Pennsylvania.

Bruno, J. and A. Sandino. 1989. "The Solubility of Amorphous and Crystalline Schoepite in Neutral to Alkaline Aqueous Solution." In Scientific Basis for Nuclear Waste Management VXII. eds. W. Lutze and R. C. Ewing. pp. 871-878. Materials Research Society Symposium Proceedings, volume 127, Materials Research Society, Pittsburgh, Pennsylvania.

Camaioni, D. M., W. D. Samue1s, B. D. Lenihan, S. A. Clauss, K. L. Wah1, and 
HNF-SD-WM-ES-409, Rev. 0

J. A. Campbe11. 1994. Organic Waste Tank Safety Program Waste Aging Studies. PNL-10161. Pacific Northwest Laboratory. Richland. Washington.

Campbe11, J. A., R. M. Bean, K. L. Wahi, G. M. Mong, K. E. Be11, K. B. Wehner, A. D. Rick, R. J. Ray, D. B. Bechtold, B. R. Wels, R. W. Schroeder, J. W. Bal1, B. D. Valenzuela, J. M. Frye, S. L. Fitzgerald, P. P. Bachelor, B. Griffin, R. K. Fuller. A. B. Banally, and S. M. Parong. 1995b. Analysis of Samples from Hanford Waste Tank 241-C-103. PNL-10531. Pacific Northwest Laboratory, Richland, Washington.

Campbe11, J. A., S. A. Clauss, K. E. Grant, F. V. Hoopes, G. M. Mong, J. K. Rau. R. Scheele, and K. L. Wah1. 1995a. Flammab7e Gas Safety Program Organic Analysis and Analytical Methods Development: FY 1995 Progress Report. PNL-10776. Pacific Northwest Laboratory, Richland, Washington.

Carver, M. B., D. V. Hanley, and K. R. Chaplin. 1979. MAKSIMA-CHEMIST: A Program for Mass Action Kinetics Simulation by Automatic Chemical Equation Manipulation and Integration Using Stiff Techniques. AECL6413. Whiteshel1 Nuclear Research Establishment. Atomic Energy of Canada. Ltd. Research Company. Pinawa, Manitoba, Canada.

Casas, I., J. Bruno, E. Cera, R. J. Finch, and R. C. Ewing. 1994. Kinetic and Thermodynamic Studies of Uranium Minerals. Assessment of the LongTerm Evolution of Spent Nuclear Fue7. SKB Technical Report 94-16. Svensk Kärnbränslehantering AB (Swedish Nuclear Fuel and Waste Management Company), Stockholm, Sweden.

Cordfunke, E. H. P. 1969. The Chemistry of Uranium. Elsevier Publishing Company. New York. New York.

Cordfunke, E. H. P., and A. A. Van Der Giessen. 1963. Pseudomorphic Decomposition of Uranium Peroxide into $\mathrm{UO}_{3}$. Journal of Inorganic and Nuclear Chemistry, 25:553-555.

Delegard, C. H. 1987. "Solubility of $\mathrm{PuO}_{2} \cdot \mathrm{xH}_{2} \mathrm{O}$ in Alkaline Hanford HighLevel Waste Solution." Radiochimica Acta, 41:11-21. 
HNF-SD-WM-ES-409, Rev. 0

Delegard, C. H. 1995. "Carbonate Complexes of Plutonium in Alkaline Solution." In Calcination/Dissolution Chemistry Development Fisca 7 Year 1995. WHC-EP--0882, pp. 4-25 to 4-31, Westinghouse Hanford Company. Richland, Washington.

Delegard, C. H. and S. A. Gallagher. 1983. Effects of Hanford High-Level Waste Components on the Solubility of Cobalt. Strontium. Neptunium. P7utonium, and Americium. RHO-RE-ST-3P, Rockwell Hanford Company. Richland, Washington.

Dennis, R. (ed.). 1976. Handbook on Aeroso7s. U.S. Energy Research and Development Administration. Technical Information Center. Springfield, Virginia.

DESH Interna7 Memo. March 19, 1997. "Current Estimates of Siudge Volumes In K East and K West Basins." R. B. Baker to K. L. Pearce.

DESH-9752731. March 27, 1997. "K Basins sludge Inventories to be Used in Sludge Disposal Evaluations - Preliminary Safety Assessment. Criticality Feasibility Report, Process Alternatives." Duke Engineering \& Services Company Letter, R. J. Lodwick to M. S. Madden, R. L. Schlosser and E. V. Morrey.

Díaz-Arocas, P., J. Quiñones, C. Maffiotte, J. Serrano, J. Garcia, J. R. A7mazán, and J. Esteban. 1995. "Effect of Secondary Phases Formation in the Leaching of $\mathrm{UO}_{2}$ under Simulated Radiolytic Products." In Scientific Basis for Nuclear Waste Management XVIII. eds. T. Murakami and R. C. Ewing, pp. 614-646. Materials Research Society Symposium Proceedings, Volume 353, Materials Research Society. Pittsburgh. Pennsylvania.

DiCenso, A. T., L. C. Amato, J. D. Frarkitin, R. W. Lambie, R. H. Stephens, and B. C. Simpson. 1994. Tank Characterization Report for Doub7e-She 7 Tank 241-AW-105. WHC-SD-WM-ER-364. Rev 0, Westinghouse Hanford Company. Richland, Washington.

Dumont, F., D. Van Tan, and A. Wati17on. 1976. "Study of Ferric Oxide Hydrosols from Electrophoresis, Coagulation and Peptization Measurements." Journal of Colloid and Interface Science. 55:678-687. 
HNF-SD-WM-ES-409, Rev. 0

Erda1. B. R., Chairman. 1985. Workshop on Fundamental Geochemistry Needs for Nuclear Waste Isolation. US DOE CONF8406134. National Technical Information Service, Springfield, Virginia.

Erikson, R. L., C. J. Hostetler, R. J. Serne, J. R. Divine, M. A. Parkhurst. 1993. Geochemica7 Factors Affecting Degradation and Environmenta7 Fate of Depleted Uranium Penetrators in Soi7 and Water. PNL-8527. Pacific Northwest Laboratory, Richland, Washington.

Esch. R. A. 1995. 60-Day Waste Compatibility Safety Issue and Final Resu7ts for Tank 241-AW-105; Grab Sample 5AW-95-1. 5AW-95-2, and 5AW-95-3. WHCSD-WM-DP-146, REV 0. Westinghouse Hanford Company, Richland, Washington.

Esch. R. A. 1997. Tank 241-AW-105 Grab Samples. Analytical Results for the Final Report. HNF-SD-WM-DP-214, REV 0, Rust Federal Services of Hanford, Inc., Richland, Washington.

Falck. W. E. 1992. CHEMVAL Project: Critical Evaluation of the CHEMVAL Thermodynamic Database with Respect to its Content and Relevance to Radioactive Waste Disposal at Sellafield and Dounreay. DoE/HMIP/RR/92.064, WS Atkins Science and Technology, Epsom, Surrey, England.

Felmy, A. R., D. C. Girvin, and E. A. Jenne. 1984. MINTEQ: A Computer Program for Calculating Aqueous Geochemical Equilibria.

EPA-600/3-84-032 (NTIS PB84-157148), Pacific Northwest Laboratory, Richland, Washington.

Finch. R., and R. Ewing. 1990. Uraninite A7teration in an Oxidizing Environment and its Relevance to the Disposal of Spent Nuclear Fuel. SKB Technicai Report 91-15. Svensk Kärnbränslehantering AB (Swedish Nuclear Fuel and Waste Management Company). Stockholm. Sweden.

Finch. R. J., and R. C. Ewing. 1991a. "Alteration of Natural $\mathrm{UO}_{2}$.under Oxidizing Conditions from Shinkolobwe, Katanga, Zaire: A Natural Analogue for the Corrosion of Spent Fuel." Radiochimica Acta. 52/53:395-401.

Finch, R. J., and R. C. Ewing. 1991b. "Phase Relations of the Uranyl Oxide 
HNF-SD-WM-ES-409, Rev. 0

Hydrates and Their Relevance to the Disposal; of Spent Fuel." In Scientific Basis for Nuclear Waste Management XIV, eds. T. A. Abrajano, $\mathrm{Jr}$. and L. H. Johnson, Materials Research Society Symposium Proceedings, Volume 212, pp. 373-386. Materials Research Society. Pittsburgh, Pennsylvania.

Finch. R. J., and R. C. Ewing. 1992a. "Alteration of Natural Uranyl Oxide Hydrates in Si-Rich groundwaters: Implications for Uranium Solubility." In Scientific Basis for Nuclear Waste Management XV, ed. C. G. Sombret. Materials Research Society Symposium Proceedings, Volume 257, pp. 465472. Materials Research Society, Pittsburgh. Pennsylvania.

Finch, R. J., and R. C. Ewing. 1992b. "The Corrosion of Uraninite under Oxidizing Conditions." Journa7 of Nuclear Materia7s, 190:133-156.

Finch, R. J., M. L. Miךler, and R. C. Ewing. 1992." "Weathering of Natural Uranyl Oxide Hydrates: Schoepite Polytypes and Dehydration Effects." Radiochimica Acta, 58/59:433-443.

Finch, R. J., J. Suksi, K. Rasilainen, and R. C. Ewing. 1995. "The Long-Term Stability of Becquerelite." In Scientific Basis for Nuclear Waste Management XVIII, eds. T. Murakami and R. C. Ewing. Materials Research Society Symposium Proceedings, Volume 353, pp. 647-652. Materials Research Society, Pittsburgh. Pennsylvania.

Friedlander, S. K. 1977. Smoke, Dust, and Haze. Fundamenta 75 of Aeroso7 Behavior. Wiley-Interscience, New York, New York.

Fronde1. C.. 1958. Systematic Mineralogy of Uranium and Thorium. U.S. Geological Survey Bulletin 1064, U.S. Geological Survey, Washington, D.C.

Garrels, R. M., and C. L. Christ. 1965. Solutions, Minera7s, and Equilibria. Fréeman, Cooper, and Company, San Francisco. California.

Gayer, K. H., and H. Leider. 1955. "The Solubility of Uranium Trioxide, $\mathrm{UO}_{3} \cdot \mathrm{H}_{2} \mathrm{O}$ in Solutions of Sodium Hydroxide and Perchloric Acid at $25^{\circ} \mathrm{C}$." Journal of the American Chemical Society, 77:1448-1450. 
HNF-SD-WM-ES-409, Rev. 0

Gayer, K. H., and H. Leider. 1957. "The Solubility of Uranium(IV) Hydroxide in Solutions of Sodium Hydroxide and Perchloric Acid at $25^{\circ} \mathrm{C}$." Canadian Journal of Chemistry, 35:5-7.

Grambow, B. 1989. Spent Fue7 Dissolution and Oxidation. An Evaluation of Literature Data. SKB Technical Report 89-13, Svensk Kärnbränslehantering $A B$ (Swedish Nuclear Fuel and Waste Management Company), Stockholm. Sweden.

Gray, W. J., and G. L. McVay, 1985, "Nitric Acid Formation during Gamma Irradiation of Air/Water Mixtures." Radiation Effects, 89:257-262.

Hem. J. D. 1985. Study and Interpretation of the Chemical Characteristics of Natural Water. Water Supply Paper 2254, U. S. Geological Survey. Alexandria, Virginia.

Hesketh, H. E. 1986. Fine Particles in Gaseous Media. Second Edition, Lewis Publishers. Inc., location of publisher?.?.?.

Hiemenz, P. C. 1986. Principles of Colloid and Surface Chemistry. Second Edition, Marcel Dekker, Inc., New York, New York.

Hobbs, D. T. 1995. Effects of Coprecipitation on the Concentrations of Uranium and Plutonium in A7kaline Salt Solutions. WSRC-TR-95-0462, Westinghouse Savannah River Company, Aiken, South Carolina.

Hobbs, D. T.. T. B. Edwards, and S. D. Fleischman. 1993. Solubility of P7utonium and Uranium in A7ka7ine Sa7t Solutions. WSRC-TR-93-056. Westinghouse Savannah River Company, Aiken, South Carolina.

Hoh 1, G., L. Sigg, and W. Stumm. 1980. "Characterization of Surface Chemical Properties of 0xides in Natural Waters." In Particles in Water, eds. M. C. Kavanaugh and J. 0. Leckie, pp. 1-30. Advances in Chemistry Series 189. American Chemical Society, Washington, D.C.

Horn, R. G., D. R. Clarke, and M. T. Clarkson. 1988. "Hamaker Constants for A7-, Zn-, and Ti-Oxides." Journal of Materia7s Research, 3:413-416.

Israelachvili, J. 1991. Intermolecular and Surface Forces. Second Edition, 
HNF-SD-WM-ES-409, Rev. 0

Academic Press, London, England.

Israelachvili, J. N., and G. E. Adams. 1978. "Deposition of Brown and Particles." Journal of the Chemistry Society Faraday Transactions. 74:975-1001.

Jackson, K. J., and W. L. Bourcier (technical organizers), 1986. Proceedings of the Workshop on Geochemica7 Modeling. CONF-8609134, National Technical Information Service. Springfield, Virginia.

Jacobs, G. K., and S. K. Whatley (eds.). 1985. Proceedings of the Conference on the Application of Geochemica7 Mode7s to High-level Nuclear Waste Repository Assessment. NUREG/CR-0062 (ORNL/TM-9585), Oak Ridge Nationa 1 Laboratory, Oak Ridge. Tennessée.

Janeczek. J., and R. C. Ewing. 1992a. "Structural Formula of Uraninite." Journal of Nuclear Materials, 190:128-132.

Janeczek. J., and R. C. Ewing. 1992b. "Dissolution and Alteration of Uraninite under Reducing Conditions." Journal of Nuclear Materia7s. $190: 157-173$.

Jenne, E. A. (ed.). 1979. Chemical Modeling in Aqueous Systems. Speciation, Sorption. Solubility, and Kinetics. Symposium Series 93. American Chemical Society, Washington, D.C.

Jenne, E. A. 1981. Geochemical Modeling: A Review. PNL-3574, Pacific Northwest Laboratory. Richland, Washington.

Johnson, Jr., A. B. and S. P. Burke. 1995. K Basin Corrosion Program Report. WHC-EP-0877. Westinghouse Hanford Company, Richland, Washington.

Karraker. O. G. 1994. Radiation Effects on the Solubility of Plutonium in A7ka7 ine High Leve7 Waste Supernate. WSRC-MS-94-0278X (Rev. 2), Westinghouse Savannah River Company, Aiken. South Carolina.

Katz, J. J. And E. Rabinowitch. 1951. The Chemistry of Uranium. Part I. McGraw Hi11., New York. 
HNF-SD-WM-ES-409, Rev. 0

Kincaid, C. T., J. R. Morrey, and J. E. Rogers. 1984. Geohydrochemica7 Models for Solute Migration. Volume 1: Process Description and Computer code Selection. EPRI EA-3417, Volume 1, Battelle. Pacific Northwest Laboratories, Richland, Washington.

Krauskopf, K. B. 1979. Introduction to Geochemistry. McGraw-Hi11 Book Company, New York, New York.

Krupka, K. M., D. Rai, R. W. Fuiton, and R. G. Strickert. 1985. "Solubility Data for U(VI) Hydroxide and Np(IV) Hydrous Oxide: Application of MCC-3 Methodology. In Scientific Basis for Nuclear Waste Management VIII, eds. C. M. Jantzen, J. A. Stone, and R. C. Ewing, pp. 753-760. Materials Research Society Symposium Proceedings, Volume 44, Materials Research Society, Pittsburgh. Pennsylvania.

Krupka, K. M. and R. J. Serne. 1997 (in publication). Effects on Radionuclide Concentrations by Cement/Ground-Water Interactions to Support Performance Assessment of Low-Leve7 Radioactive Waste Disposa 7 Facilities. NUREG/CR-6377. Pacific Northwest National Laboratory, Richland, Washington.

Langmuir, D. 1978. "Uranium Solution-Mineral Equilibria at Low Temperatures with Applications to Sedimentary Ore Deposits." Geochimica et Cosmochimica Acta, 42:547-569.

Lemire. R. J.. and P. R. Tremaine. 1980. "Uranium and Plutonium Equilibria in Aqueous Solutions to $200^{\circ} \mathrm{C}$." Journal of Chemical and Engineering Data, 25:361-370.

Lewis, G. N., and M. Randa11. 1961. Thermodynamics. Revised by K. S. Pitzer and L. Brewer. MCGraw-Hil 1 Book Company. New York. New York.

Lindsay, W. L., 1979. Chemical Equilibria in Soi7s. John Wiley and Sons, New York, New York. 
HNF-SD-WM-ES-409, Rev. 0

Loeppert. R. H., A. P. Schwab, and S. Goldberg (eds.). 1995. Chemical Equilibrium and Reaction Mode7s. Special Publication Number 42, Soil Science Society of America, Inc., Madison, Wisconsin.

Makenas, B. J., T. L. Welsh, R. B. Baker, D. R. Hansen, and G. R. Golcar. 1996. Analysis of Sludge from Hanford K East Basin Floor and Wease 7 Pit. WHC-SP-1182, Westinghouse Hanford Company, Richland, Washington.

Marschman, S. C., and J. Abrefah. 1997. Highlight Report: Water Content of Film Coatings on K-East Fuel Surfaces. SNFCT97:040:R00, Pacific Northwest National Laboratory. Richland. Washington.

Mauss, B. M. June 10, 1985. "Chemical Analysis for 105-AW Sample." Letter No. 65453-85-115 to R. A. Kaldor, Rockwel1 Hanford Company, Richland. Washington.

McCabe, W. L., and J. C. Smith. 1976. Unit Operations of Chemical Engineering. Third Edition. McGraw-Hill Book Company, New York. New York.

Meichior, D. C., and R. L. Bassett (eds.). 1990. Chemical Modeling in Aqueous Systems II. Symposium Series 416. American ChemicaT Society, Washington, D.C.

Mercer, J. W., C. R. Faust, W. J. Miller, and F. J. Pearson, Jr. 1981. Review of Simulation Techniques for Aquifer Thermal Energy Storage (ATES). PNL-3769, Pacific Northwest Laboratory, Richland, Washington.

Miller. G. L. (project coordinator). 1995. Interim Chemical and Radiochemical Analytical Report for 105-K East Basin S7udge. WHC-SD-SNF-DP-004, Rev. 1, Westinghouse Hanford Company, Richland, Washington.

Mi11er, G. L. (project coordinator). 1997. Chemical and Radiochemical Characterization of 105-K East Basin Canister S7udge. HNF-SD-WM-DP-228, Rev. 0, Rust Federal Services of Hanford Inc. (222-S Laboratory), Richland, Washington. 
HNF-SD-WM-ES-409, Rev. 0

Morel. F. M. M. 1983. Principles of Aquatic Chemistry. John Wiley and Sons, New York. New York.

Nicolosi.S. L. 1987. "A Generalized Model for the Radiolysis of Groundwater: Bicarbonate Chemistry and Influences." In Scientific Basis for Nuclear Waste Management X, eds. J. K. Bàtes, and W. B. Seefeldt. pp. 671-679. Materials Research Society Symposium Proceedings, Volume 84, Materials Research Society, Pittsburgh, Pennsylvania.

Nordstrom, D. K., and J. W. Ba11. 1984. "Chemical Models, Computer Programs and Metal Complexation in Natura] Waters." In Complexation of Trace Metals in Natural Waters, eds. C. J. M. Kramer and J. C. Duinker, pp. 149-169. Martinus Nijhoff/Dr. J. W. Junk Publishing Co., Netherlands.

Nordstrom. D. K., and J. L. Munoz. 1985. Geochemical Thermodynamics. The Benjamin/Cummings Publishing Co., Inc., Menlo Park, California.

Nordstrom, D. K., L. N. Plummer, T. M. L. Wigley, T. J. Woley, J. W. Ball, E. A. Jenne, R. L. Bassett, D. A. Crerar, T. M. Florence, B. Fritz, M. Hoffman, G. R. Holdren, Jr., G. M. Lafon, S. V. Mattigod, R. E. McDuff, F. More1, M. M. Reddy, G. Sposito, and J. Thrailki11. 1979.

"Comparison of Computerized Chemical Models for Equilibrium Calculations in Aqueous Systems." In Chemical Modeling in Aqueous Systems. Speciation, Sorption, Solubility, and Kinetics, ed. E. A. Jenne, pp. 857-892. American Chemical Society Symposium Series 93. Washington. D.C.

OSD-T-151-00007, Rev H-18. November 14, 1996 (release date). Unclassified Operating Specifications for the 241-AN, AP. AW. AY. AZ and SY Tank Farms.

0'Melia. C. R. 1978. "Rate Constants in a Polydispersed System." In The Scientific Basis of Flocculation, ed. K. J. Ives, pp. xx-xx. Sijthoff and Noordhoff. Alphen aan den Ri.jm. The Netherlands.

Parson R. 1990. "Electric Double Layer: Recent Experimental and Theoretical Developments." Chem. Rev., 90:813-826.

Payne, T. E., K. Sekine, J. A. Davis, and M. J. Frissel.. 1992. Mode7ing of 
HNF-SD-WM-ES-409, Rev. 0

Radionuclide Sorption Processes in the Weathered Zone of the Koongarra Ore Body. A7ligator River Analogue Project. Annual Report, 1990-1991. ed.. P. Duerden.. pp 57-85. Aus. Nuc. Sci. Tech. Org. Australia.

Pearce. K. L. March 27, 1997. K Basins S7udge Inventories to be Used in S7udge Disposa7 Evaluations-Preliminary Safety Assessment, Criticality Feasibility Report. Process Alternatives. Duke Engineering and Services Hanford. Inc. . Correspondence number DESH-9752731.

Pearce 1997 email with $4.5 \%$ U value

Peters. B. B. 1986. "Analysis of Neutralized Coating Removal Waste (NCRW) Core Samples From Tank 105-AW." Letter No. 65453-86-124, Rockwe11 Hanford Company, Richland, Washington.

Peterson. S. R., C. J. Hostetler, W. J. Deutsch, and C. E. Cowan. 1987. MINTEQ User's Manua 7. NUREG/CR-4808 (PNL-6106). Pacific Northwest Laboratory, Richland, Washington.

Pikaev. A. 1996. Gamma Radiolysis of A7kaline Aqueous Solutions of Neptunium and Plutonium. Poster at Chemistry of the Actinides and Technetium in Alkaline Media Meeting. Battelle Auditorium. April 2, 1996. Richland, Washington.

Precechtel, D. R. October 1996. Functional Design Criteria for the K Basins S7udge Process and Loadout System. WHC-SD-SNF-FDC-006, Rev 1., Westinghouse Hanford Company, Richland, Washington.

Precechtel, D. R., and M. J. Packer. 1997. Evaluation of Process for S7udge Particle Size Reduction. HNF-SD-SNF-TI-051. Rev 0.. Duke Engineering and Services Hanford, Inc., Richland, Washington.

Rai, D., A. R. Felmy, and J. L. Ryan. 1990. “Uranium(IV) Hydrolysis Constants and Solubility Product of $\mathrm{UO}_{2} \times \mathrm{XH}_{2} \mathrm{O}(\mathrm{am})$." Inorganic Chemistry, 29:260-264.

Rai, D., and J. L. Ryan. 1982. "Crystallinity and Solubility of Pu(IV) Oxide and Hydrous Oxide in Aged Aqueous Suspensions." Radiochimica Acta, $30: 213-261$. 
HNF-SD-WM-ES-409, Rev. 0

Rai, D., R. J. Serne, and D. A. Moore. 1980a. "Solubility of Plutonium Compounds and Their Behavior in Soils." Soil Science Society of America Journa 7, 44:490-495.

Rai, D., R. J. Strickert and J. L. Ryan. 1980b. "Alpha Radiation-Induced Production of $\mathrm{HNO}_{3}$ During Dissolution of Pu Compounds." Inorganic and Nuclear Chemistry Letters, 16:551-555.

Ryan, J. L., and D. Rai. 1983. "The Solubility of Uranium(IV) Hydrous Oxide in Sodium Hydroxide Solutions Under Reducing Conditions." Polyhedron. 2:947-952.

Sabisky, E. S., and C. H. Anderson. 1973. "Review of Intermolecular and Surface Forces." Phys. Rev. A., 7:790-806.

Schwertmann, U., and R. M. Taylor. 1989. "Iron Oxides." In Minerals in Soit Environments, Second Edition, eds. J. B. Dixon and S. B. Week, pp. 379438. Soil Science Society of America, Madison. Wisconsin.

Schwertmann, U., and R. M. Corne11. 1989. "Iron Oxides." In Minerals in Soi7 Environments, eds. $x x x x$. pp. xx-xx. Soil Science Society of America, Madison, Wisconsin.

Schwertmann, U., and R. M. Corne11. 1991. Iron Oxides in the Laboratory. Verlagsgesellschaft mbH, VCH Publishing, New York, New York.

Serne, R. J., G. A. Whyatt, S. V. Mattigod, Y. Onishi, P. G. Doctor, B. N. Bjornstad, M. R. Powe 17, L. M. Li1jegren, J. H. Westsik, Jr., N. J. Aimo, K. P. Recknagle, G. R. Golcar, T. B. Miley, G. R. Holdren, D.W. Jeppson. R.K. Biyani, and G. S. Barney. 1996. Fluid Dynamic Particulate Segregation. Chemica7 Processes, and Natural Ore Analog Discussions that Relate to the Potential for Criticality in Hanford Tanks. Westinghouse Hanford Company, WHC-SD-WM-TI-757, Revision 0., Westinghouse Hanford Company, Richland, Washington.

Serne. R. J. 1989. "Radiation Effects on Chemistry." Engineering Geology, 26:319-329.

Shaw. D. J. 1980. Introduction of Colloid and Surface Chemistry. Third 
HNF-SD-WM-ES-409. Rev. 0

Edition, Butterworths, Boston, Massachusetts.

Shoesmith, D. W., S. Sunder, L. H. Johnson, and M. G. Bailey. 1985. "Oxidation of CANDU $\mathrm{CO}_{2}$ Fuel by the Alpha-Radiolysis Products of Water." In Scientific Basis for Nuclear Waste Management IX, ed. L. 0. Werme, pp. 309-316. Materials Research Society Symposium Proceedings, Volume 50. Materials Research Society, Pittsburgh. Pennsylvania.

Silvers, K. L. 1995. KE Basin S7udge Sample Analysis. Basin Floor and Weasel Pit Samples. Pacific Northwest National Laboratory, Richland. Washington.

Silvers, K. L. 1997. KE Basin Canister S7udge Sample Ana7ysis. Pacific Northwest National Laboratory, Richland, Washington.

Smith. P. 1997. "Colloid Data Summary and Particle Size Data." Personal Communication with G. A. Whyatt on March 28, 1997, Pacific Northwest National Laboratory, Richland, Washington.

Smith, D. K. 1989. "Computer Analysis of Diffraction Data." In Modern Powder Diffraction, eds. D. L. Bish and J. E. Post, pp. 183-216. Mineralogical Society of America, Reviews in Mineralogy, Volume 20. Washington, D.C.

Sowder, A. G., S. B. Clark, and R. A. Fjeld. 1996. "The Effect of Silica and Phosphate on the Transformation of Schoepite to Becquerelite and Other Uranyl Phases." Radiochimica Acta, 74:45-49.

Sposito, G. 1981. The Thermodynamics of Soi7 Solutions, 0xford, Clarendon Press, Oxford, England.

Sposito, G. 1989. The Chemistry of Soi7s. Oxford University Press, New York. New York.

Sposito, G. 1994. Chemical Equilibria and Kinetics in Soils. Oxford University Press, New York. New York.

Stumm, W. and J. J. Morgan. 1981. Aquatic Chemistry. An Introduction Emphasizing Chemical Equilibria in Natural Waters. John Wiley and Sons. 
HNF-SD-WM-ES-409, Rev. 0

New York, New York.

Sullivan, J. C. 1983. "Reaction of Plutonium Ions with Products of Water Radiolysis." In Plutonium Chemistry, eds. W. T. Carnall and G. R. Choppin, pp 241-249. American Chemical Society. ACS Symposium Series 216. Washington, D.C.

Sunder, S., D. W. Shoesmith, H. Christensen, M. G. Bailey, and N. H. Miller. 1989. "Electrochemical and X-ray Photoelectron Spectroscopic Studies of $\mathrm{UO}_{2}$ Fuel Oxidation by Specific Radicals Formed during Radiolysis of Groundwater." In Scientific Basis for Nuclear Waste Management XII, eds. W. Lutze and R. C. Ewing, pp. 317-324. Materials Research Society Symposium Proceedings, Volume 127, Materials Research Society, Pittsburgh. Pennsylvania.

Sunder, S., D. W. Shoesmith, H. Christensen, and N. H. Mi17er, 1992, "Oxidation of $\mathrm{UO}_{2}$ Fuel by the Products of Gamma Radiolysis of Water." Journal of.Nuclear Materials, 190:78-86.

Sunder, S., D. W. Shoesmith, H. Christensen, N. H. Miller, and M. G. Bailey. 1990. "Oxidation of $\mathrm{UO}_{2}$ Fuel by Radicals Formed during Radiolysis of Water." In Scientific Basis for Nuclear Waste Management XIII. eds. V. M. Oversby and P. W. Brown. pp. 457-464. Materials Research Society Symposium Proceedings, Volume 176. Materials Research Society, Pittsburgh. Pennsylvania.

Sunder. S., D. W. Shoesmith, L. H. Johnson, G. J. Wallace, M. G. Bailey, and A. P. Snaglewski. 1987. "Oxidation of CANDU' Fuel by the Products of the Alpha Radiolysis of Groundwater." In Scientific Basis for Nuclear Waste Management X, eds. J. K. Bates and W. B. Seefe1t. pp. 103-113. Materials Research Society Symposium Proceedings, Volume 84, Materials Research Society, Pittsburgh, Pennsylvania.

Tomaszewski, T. A. July 1996. Packaging Design Criteria for the K East Basin STudge Transportation System. WHC-SD-TP-PDC-035, Rev 0., Westinghouse Hanford Company; Richland, Washington. 
HNF-SD-WM-ES-409, Rev, 0

Trimble. D. J. 1995a. Data Compilation Report: Gas and Liquid Samples from $K$ West Basin Fuel Storage Canisters. WHC-SD-SNF-DP-001, Rev. 0 (Engineering Data Transmittal 610169), Westinghouse Hanford Company. Richland. Washington.

Trimble, D. J. 1995b. Data Compilation Report: $K$ West Basin Fuel Storage Canister Liquid Samples. WHC-SD-SNF-DP-003, Rev. O (Engineering Data Transmittal 610186), Westinghouse Hanford Company, Richland, Washington.

Trimble. D. J. 1996a. Data Analysis of Gas and Liquid from K West Basin Fue 7 Canisters; 1995 Samples. WHC-SD-SNF-ANAL-008, Rev. 0, Westinghouse Hanford Company, Richland, Washington.

Trimble, D. J. 1996b. Data Ana7ysis, K West Basin Canister Liquid and Gas Samples, Gamma Energy Analysis and Mass Spectrometry Data. Westinghouse Hanford Company, WHC-SD-SNF-ANAL-007, Rev. 0 ( Engineering Data Transmittal 610193), Richland, Washington.

Trimble, D. J. 1997a. Analysis of $K$ West Basin Canister Gas. HNF-SD-SNF-TI-049, Rev. O (Engineering Data Transmittal 620782), Duke Engineering and Services Hanford, Inc., Richland, Washington.

Trimble, D. J. 1997b. Analysis of Water from $K$ West Basin Canisters (Second Campaign). Duke Engineering and Services Hanford. Inc. .

HNF-SD-SNF-TI-048, Rev. O (Engineering Data Transmittal 620780), Richland, Washington.

Trimble, D. J., and T. L. Welsh. 1997. Cesium-137 in K West Basin Canister Water. HNF-SD-SNF-ANAL-014, Rev. O (Engineering Data Transmittal 617439); Duke Engineering and Services Hanford, Inc., TLW: B\&W Protect, Inc., Richland, Washington. .

Tusler, L. A. 1995. Double Shel7 Tanks Pu Inventory Assessment. WHC-SD-WM-TI-640 Rev 0, Westinghouse Hanford Company, Richland. Washington.

Tyfield, S. P. 1988. "Corrosion of Reactor Grade Uranium in Aqueous Solutions Relevant to Storage and Transport." Nuclear Energy, 27:91-98. 
HNF-SD-WM-ES-409, Rev. 0

Van 01phen. H., and J. J. Fripiat. 1979. Data Handbook for Clay Materia7s and other Non-Metal7ic Minerals. Pergamon Press, Oxford.

Vdovenko, V. M. 1960. The Chemistry of Uranium and Transuranium Elements. Academy of Sciences, Moscow, USSR.

Waite, T: D., J. A. Davis, T. E. Payne, G. A. Waychunas, and N. Xu. 1994. "Uranium(VI) Adsorption to Ferrihydrite: Application of a Surface Complexation Mode1." Geochimica et Cosmochimica Acta, 58:5465-5478.

Walton. A. G. 1967. The Formation and Properties of Precipitates. Interscience Publishers. New York. New York.

Wamser, C. A. J. Belle, E. Bernsohn, and B. Williamson. 1952. “The Constitution of the Uranates of Sodium." J. Am. Chem. Soc. 74:10201022.

Wang, X. 1995. Effect of Zeta Potential on the Entrainment of Col7oidal Particles in a Submerged Jet. Unpublished M.S. Thesis, Washington State University. Pullman. Washington.

Wanner, H, and I. Forest (eds.). 1992. Chemical Thermodynamics Series. Volume 1: Chemical Thermodynamics of Uranium. (I. Grenthe, J. Fuger, R. J. M. Konings, R. J. Lemire, A. B. Muller, C. Nguyen-Trung, and H. Wanner, review team). North-Holland, Elsevier Science Publishing Company, Inc., New York. New York.

Weast. R. C. (ed.). 1980. CRC Handbook of Chemistry and Physics. CRC Press. Inc., Boca Raton, Florida.

Wellner, A. F., and D. W. Crass. September 1996. Conceptual Design Report for the Sludge Receiving Station. WHC-SD-SNF-CDR-008, Rev 0., Westinghouse Hanford Company, Richland, Washington.

Westa11, J. C., J. L. Zachary, and F. M. M. More]. 1976. MINEQL, A Computer Program for the Calculation of Chemical Equilibrium Composition of Aqueous Systems. Technical Note 18, Department of Civil Engineering, Massachusetts Institute of Technology, Cambridge, Massachusetts. 
HNF-SD-WM-ES-409, Rev. 0

Whyatt, G. A., R. J. Serne, S. V. Mattigod, Y. Onishi, M. R. Powel1, J. H. Westsik. Jr., L. M. Liljegren, G. R. Golcar, K. P. Recknagle, P. M. Doctor, V. G. Zhirnov. J. Dixon. D. W. Jeppson, and G. S. Barney. 1996. The Potential for Criticality in Hanford Tanks Resulting from Retrieval of Tank Waste. PNNL-11304, Pacific Northwest National Laboratory, Richland, Washington.

Wronkiewicz, D. J., J. K. Bates, T. J. Gerding, E. Veleckis, and B. S. Tani. 1991. Leaching Action of EJ-13 Water on Unirradiated $10_{2}$ Surfaces Under Unsaturated Conditions at $90^{\circ} \mathrm{C}$ : Interim Report. ANL-91/11. Argonne Nationai Laboratory, Argonne, I17inois.

Wronkiewicz, D. J., J. K. Bates, T. J. Gerding, E. Veleckis, and B. S. Tani. 1992. Uranium Release and Secondary Phase Formation during Unsaturated Test of $\mathrm{UO}_{2}$ at $90^{\circ} \mathrm{C}$ : Journal of Nuclear Materials, 190:107-127.

Yamaguchi, T., Y. Sakamoto, and T. Ohnuki. 1994. "Effect of the Complexation on Solubility of P. (IV) in Aqueous Carbonate System." Radiochimica Acta, 66/67:9-14. 
HNF-SD-WM-ES-409, Rev. 0

APPENDIX B

\section{CRITICALITY SAFETY}

OF

DISPOSING OF $K$ BASINS SLUDGE

Prepared by

C. A. Rogers 
HNF-SD-WM-ES-409, Rev. 0

This page intentionally left blank. 
HNF-SD-WM-ES-409, Rev. 0

\section{CONTENTS}

1.0 INTRODUCTION . . . . . . . . . . . . . . . . . B-1

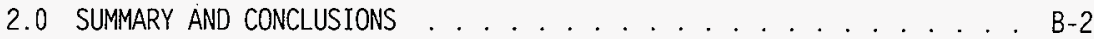

2.1 CRITICALITY SAFETY EVALUATION REPORT . . . . . . . . . . B B-2

2.2 CHEMISTRY EVALUATION $\ldots \ldots \ldots$

2.3 ADDITION OF SOLID MATERIAL $\ldots \ldots$

2.4 OPTION 1: DISPOSAL IN DST AW-105 $\ldots$ B-3

2.5 OPTION 2: DISPOSAL IN DST AW-105 WITH ISOLATION $\cdots . . . \quad$.

2.6 OPTION 3: DEDICATED TANK $\ldots \ldots$

2.7 OPTION 4 : DEDICATED CRITICALLY SAFE TANKK $\cdots \cdots$

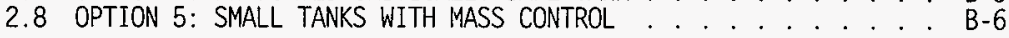

3.0 CRITICALITY PARAMETERS . . . . . . . . . . . B-7

3.1 URANIUM PARAMETERS

3.2 ABSORBER-TO-URANIUM MINIMUM SUBCRITICAL MASS RATIOS $\cdots . . \quad$ B-9

3.3 PLUTONIUM PARAMETERS . . . . . . . . . . . . . . . . . . . . . . B-9

3.4 ABSORBER-TO-PLUTONIUM MINIMUM SUBCRITICAL MASS RATIOS $\cdots$ B-10

3.5 COMBINING THE EFFECT OF ABSORBERS . . . . . . . B-12

3.6 IMPORTANCE OF PARTICLE SIZE

3.7 IRRADIATION EFFECTS ON CRITICAL MASS $\ldots \ldots . . . \cdots \cdots$

4.0 SLUDGE DESCRIPTION . . . . . . . . . . . . . . . . . . . . . . . . .

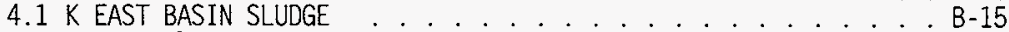

4.1.1 Sludge Component Inventories . . . . . . . . . . . B-15

4.1.2 Analyzed Samples . . . . . . . . . . . . . . B-15

4.1.3 $k_{\infty}$ of Sludge . . . . . . . . . . . . . . . . . . . . B-18

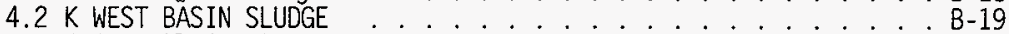

4.2.1 Sludge Component Inventories . . . . . . . . . . . B-19

4.3 DST AW-105 SLUDGE . . . . . . . . . . . . . . . . . . . B-19

4.3.1 Controls of Incoming Transfers . . . . . . . . . . B-21

4.3.2 Tank Contents Origin . . . . . . . . . . . . B-21

4.3.3 Zircalloy Decladding Waste Process Records : . . . . . B-22

4.3.4 Mass Ratios and Subcritical Fractions . . . . . . . . . B-22

$4.3 .5 k_{\infty}$ of Sludge . . . . . . . . . . . . B-23

4.4 SLUDGE TRANSPORTATION SYSTEM $\ldots \ldots \ldots$

5.0 OPTION 1: DISPOSAL IN DST AW-105 . . . . . . . . . . . . B-25

5.1 ACCEPTABLE MARGIN OF SAFETY . . . . . . . . . . . . . . . . B-25

5.1.1 Tank Farms CPS Requirements . . . . . . . . . . . B-25

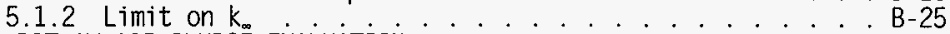

5.2 DST AW-105 SLUDGE EVALUATION . . . . . . . . . . . . . . B-27

5.2.1 Stratification . . . . . . . . . . . . . B-27

5.2.2 PUREX Transfers Based upon Cadmium Presence . . . . . . B-28

5.2.3 Mass Ratios and Subcritical Fractions . . . . . . . B-28

5.3 K BASIN SLUDGE EVALUATION . . . . . . . . . . . . . B-29

5.3.1 Absorber/plutonium Mass Ratios . . . . . . . . . . . B-29

5.3.2 Neutron Absorbing Solids Addition . . . . . . . . . . . B-31

5.3.2.1 Depleted Uranium . . . . . . . . . . . . . . B-31

5.3.2.2 Iron . . . . . . . . . . . . . B-32

5.3.2.3 Boron in Solution . . . . . . . . . . . . . 
5.3.2.4 Boron in Rods ... . . . . . . . . . . . . B-33

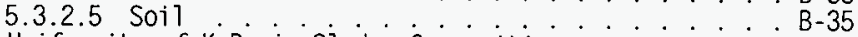

5.3.3 Uniformity of $\mathrm{K}$ Basin siudge Composition

5.4 COMBINING K BASIN AND TANK AW-105 SLUDGE ......... . B-36

5.4.1 Supernatant Liquid . . . . . . . . . . . . B-36

5.4 .2 Contribution of KW Sludge . . . . . . . B-37

5.4 .3 Pockets of Higher Plutonium Concentration . . . B-37

5.4 .4 Interaction with contents of DST AW-105 . . . . . B-37

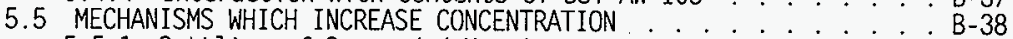

5.5 .1 Settling of Suspended Uranium . . . . . . . . B-38

5.5 .2 Removing Liquid . . . . . . . . . B-38

5.5.3 Chemical Separation of Components . . . . . . B-39

5.5 .4 Mixing . . . . . . . B-39

5.5 .5 Conditions that Preverit Plutonium Accumulation . . . . B-39
5.6 CHEMISTRY

5.6.1 Plutonium Chemistry . . . . . . . . . . . . . . : : B-40

5.6.2 Uranium Chemistry . . . . . . . . . . . . . . . . B-41

5.6.3 Particles Size Restrictions . . . . . . . . . B-41

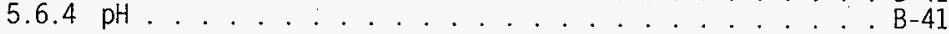

6.0 OPTION 2: DISPOSAL IN DST AW-105 WITH ISOLATION . . . . . . . . B-42

7.0 OPTION 3: DEDICATED TANK . . . . . . . . . B-43

7.1 ACCEPTABLE MARGIN OF SAFETY ............... B-43

7.2 OPTION 3 A: LIMIT ${ }^{235}$ U ENRICHMENT $\cdots$

7.3 OPTION 3B: NEUTRON ABSORBING SOLIDS ADDITION $\cdots \cdots$

7.3.1 Depleted Uranium . . . . . . . . . . . . . B-44

7.3 .2 Iron . . . . . . . . . . . . . . . . . B-44

7.3 .3 Boron . . . . . . . . . . . B-44

7.3 .4 Soil

7.4 CHEMISTRY REQUIREMENTS $\ldots \ldots \ldots$

8.0 OPTION 4: DEDICATED CRITICALLY SAFE TANK . . . . . . . . . B-46

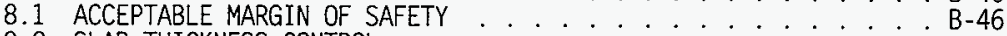

8.2 SLAB THICKNESS CONTROL . . . . . . . . . . . . . . . . B-46

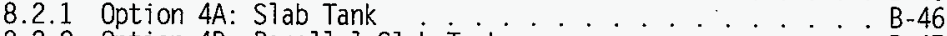

8.2.2 Option 4B: Parallel Slab Tanks . . . . . . . . B-47

8.2.3 Option 4C: Depth Control . . . . . . . . . . . B-47

8.3 CYLINDER DIAMETER CONTROL $\ldots \ldots \ldots$. . . . . . . . . . B-47

8.3.1 Option 4D: Cylindrical Tanks . . . . . . . . B-47

8.4 EARTHQUAKE . . . . . . . . . . . . . . . . . B-48

9.0 OPTION 5: SMALL TANKS WITH MASS CONTROL .......... B-49

9.1 ACCEPTABLE MARGIN OF SAFETY . . . . . . . . . . . . . . . . . . . B-49

9.2 BATCH LIMITS

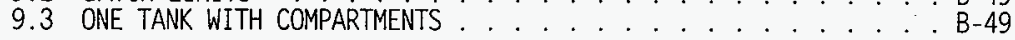

10.0 REFERENCES ....................... . . . . . . . . . . . . 
HNF-SD-WM-ES-409, Rev. 0

\subsection{INTRODUCTION}

Sludge containing uranium from damaged $N$ Reactor fuel elements is to be removed from large water-filled basins located in facilities 105-KE and 105-KW and placed in a storage tank for disposal. Much of the fuel stored in the $K$ Basins was subject to the stress of irradiation and discharge operations. Cracking of elements has allowed contact of the uranium metal with water. leading to deterioration, and in some cases partial disintegration. Oxidized uranium and broken fuel pieces have fallen away from the elements. Some of this broken fuel has found its way to the basin floor where it has mixed with debris to form "K Basin Sludge." A large fraction of broken fuel remaining within canisters, both sealed and open, will also be sent to disposal as K Basin sludge.

Disposal options are reviewed from the perspective of criticality safety to provide a basis for selection of a final disposal option. 


\subsection{SUMMARY AND CONCLUSIONS}

This appendix examines options for the disposal of $K$ Basin s7udge from the perspective of criticality safety. K Basin sludge differs from sludge already at tank farms in several important ways. The size of particles in $\mathrm{K}$ Basin sludge is larger, the uranium content is higher, and the content of neutron absorbing solids is lower. K Basin sludge has not been subjected to the chemical processes by which tank waste was generated, and there is a potential for the presence of uranium metal or hydride. The metal in tank waste was dissolved in a nitric acid solution and then reprecipitated with sodium hydroxide. Nevertheless, characterization data indicates that after adjustment to meet corrosion specifications, the chemistry of K Basin sludge will be similar to and compatible with tank sludge chemistry.

\subsection{CRITICALITY SAFETY EVALUATION REPORT}

A Criticality Safety Evaluation Report (CSER) must be completed that requires an evaluation of the chemical and physical concentrating (segregation) mechanisms and an estimate of the margin of subcriticality. This appendix does not meet the requirements for a CSER. Although limits and controls are proposed to facilitate the selection of a disposal option, complete justification may not be provided. These limits and controls are subject to change according to the basis provided in a CSER.

Oxidation of uranium underwater can generate hydrogen gas and can produce considerable heat. Although heat generation and hydrogen gas production are important safety issues, they are not part of a criticality safety evaluation as they do not increase the potential for a criticality.

\subsection{CHEMISTRY EVALUATION}

A review of the chemistry of $K$ Basin sludge and the implications of adding these siudges to Double-Shell Tank (DST) AW-105 is provided in Appendix A of this feasibility study. K Basin sludge contains larger particles than tank sludge and may contain some dense metallic uranium. Segregation according to particle size is a process capable of concentrating the uranium. To prevent segregation, a small particle size is required. An important question is whether dissolution and reprecipitation is required to prevent unacceptable segregation of the fissile material from iron, or any other component, added as a neutron absorber. When K Basin and DST AW-105 s7udges are combined. the chemistry of both plutonium and uranium must be examined. Other studies of plutonium chemistry of tank waste are documented by Serne et a1. (1996) and by Whyatt et al. (1996).

\subsection{ADDITION OF SOLID MATERIAL}

The following neutron absorbing solids are considered as possible additives to ensure subcriticality. 
HNF-SD-WM-ES-409, Rev. 0

(1) Depleted uranium - This reduces the ${ }^{235} \mathrm{U}$ enrichment.

(2) Iron - This provides neutron absorption and tends to remain associated with uranium and plutonium.

(3) Boron - This is a very effective neutron absorber.

(4) Soit - This is plentiful and cheap.

Use of neutron absorbing solids requires assurance that they are and will remain distributed throughout the sludge.

\subsection{OPTION 1: DISPOSAL IN DST AW-105}

Disposal Option 1 is to combine K Basin sludge with the contents of DST AW-105. To meet the requirement in the tank farms Criticality Prevention Specification (CPS) that limit the plutonium concentration in settled solids to $1 \mathrm{~g} / \mathrm{L}$ a large volume of solid material would have to be added. An alternative is to provide justification in the CSER for a revised limit based on the following proposed limits. With justification, the quantity of solids which must be added can be reduced.

Proposed limits to permit discharges of $K$ Basin sludge into DST AW-105 are provided in Section 5.1.2. These limits include the following:

(1) The quantity of neutron absorbing solids well mixed with the uranium must be at least enough to ensure that $k_{\infty}$ will not exceed 0.95 with optimal moderation and full reflection, after taking into account uranium segregation through gravity settling and chemical processes.

(2) No separated plutonium is permitted to be added to $K$ Basin sludge.

(3) Particle size for both uranium and other solids must not exceed 50 microns.

(4) When combined with tank wastes, $k_{\text {eff }}$ of the combined sludge shall not exceed 0.95 . under the worst credible conditions of storage and operations, including optimal moderation and ful1 reflection.

When the ${ }^{235} \mathrm{U}$ enrichment is $0.84 \mathrm{wt} \%$, or less, $k_{\infty}$ for uranium in water solution can not exceed 0.95 (See Section 5.3.2.1). No other neutron absorbing solids.

$K$ Basin sludge wi1l be well characterized when it is sent to DST AW-105. However, the distribution of components in DST AW-105 sludge is less welT defined. Under conditions defined by historic discharge limits and by characterization data the neutronic interaction between $\mathrm{K}$ Basin sludge and DST AW-105 sludge has a negligible impact towards increasing neutron multiplication. However, the possibility, however unlikely. must be considered that a pocket of higher plutonium concentration might exist for which the localized neutron multiplication might be higher than expected. It 
is necessary to maintain the neutron multiplication in $\mathrm{K}$ Basin sludge low enough to compensate for uncertainties.

Estimiated component masses in $\mathrm{K}$ Basin sludge are provided by Pearce (1997). Unless shown to be unnecessary, enough iron, or other solid material, must be added uniformly to the sludge as it is pumped into each transport container to meet the requirement on $k_{\alpha}$.

$\mathrm{KE}$ Basin sludge on the basin floor, in the Weasel/Tech View/Dummy Pits, and in the North Loadout Pit contains enough neutron absorbers to ensure a $k_{\infty}$ less than 0.60 . provided it is homogeneously distributed.

Whyatt et a1. (1996) reports that an increase in fissile concentration of a factor of 3 is possible as a result of segregation of waste components according to differences in particle size and density. If one assumes a segregation factor of 3 and negligible interaction with DST AW-105 sludge, the neutron absorbing solids must be 3 times that required to ensure a $k_{\infty}$ of 0.95 . If uniform mixing can not be demonstrated, a larger fraction of neutron absorbing solids will be required.

For 0.95 wt\% enriched uranium sludge in canisters and in the Wash Pit the addition of $0: 18 \mathrm{~kg}$ of iron per kilogram of uranium will meet this limit (see Table 5-4). For 1.25 wt\% enriched uranium sludge in the KW Basin, the addition of $0.54 \mathrm{~kg}$ of iron per kilogram of uranium is required. After addition of iron to meet the above requirement, $k_{\infty}$ can not exceed 0.85 , provided the uranium and iron is homogenized.

DST AW-105 sludge has a larger ratio of absorbers to fissile material. both soluble and insoluble, than does sludge from either the KE or the KW Basin. Sludge from the KW Basin contains uranium of a higher enrichment and also contains a lower fraction of absorbers than KE Basin sludge. For these reasons, the $\mathrm{KW}$ Basin sludge determines the margin of subcriticality when $K$ Basin sludge is combined with DST AW-105 sludge.

Waste was discharged into DST AW-105 from PUREX as a large number of batches. The official plutonium inventory is $22.9 \mathrm{~kg}$, based on sample data. The transfers which contained the largest content of fissile material form the top layers in DST AW-105 sludge. Whyatt et al (1996) conclude that the plutonium in tank waste primarily resides in the solid phase and that the saturation concentrations of plutonium in supernatant liquid are at least 30 times lower than needed to support criticality.

\subsection{OPTION 2: DISPOSAL IN DST AW-105 WITH ISOLATION}

Disposal Option 2 is to combine $K$ Basin sludge with the contents of DST AW-105 with restriction of further use for waste acceptance and storage until final retrieval for other waste storage. The criticality safety requirements for Disposal option 2 are seen as being identical to those of Disposal Option 1. 
HNF-SD-WM-ES-409, Rev. 0

\subsection{OPTION 3: ONE DEDICATED TANK}

Disposal Option 3 is the construction of a tank for storage of a 17 $K$ Basin sludge, but without permitting any other waste. With the exception that there is no other sludge with which to interact, criteria for Option 1 above apply. No neutronic interaction with other sludge makes Option 3 simpler to justify.

This option is divided into two possibilities:

Option $3 \mathrm{~A}$ Limit ${ }^{235} \mathrm{U}$ enrichment of uranium to $0.84 \mathrm{wt} \%$. Uniform mixing of depleted uranium with the enriched uranium is required. No other neutron absorbing solids need be added.

Option 3B Add neutron absorbing solids to ensure subcriticality for an unlimited volume. Sirice the sludge is not mixed with DST AW-105 sludge, questions associated with neutron interaction are eliminated.

If a segregation factor of 3 is assumed, KE Basin sludge in canisters and in the Wash Pit require the addition of a minimum of $0.18 \mathrm{~kg}$ of iron per kilogram of uranium (see Table 5-4). For sludge in the KW Basin the addition of a minimum of $0.54 \mathrm{~kg}$ of iron per kilogram of uranium is required. However, unless the iron must be shown to be mixed reasonably homogeneously with the uranium, a larger fraction will be required to ensure the same margin of subcriticality.

\subsection{OPTION 4: DEDICATED CRITICALLY SAFE TANK}

Disposal Option 4 is to construct: a critically safe tank. A revision of the CPS is. needed to permit storage in tanks based upon controi of geometry. Guarantees must be provided that the controlled dimension can not be increased above the limit value.

For a slab tank the thickness shall not exceed the minimum critical thickness multiplied by 0.90 ; or, $k_{\text {eff }}$ shall not exceed 0.97 . For a cylindrical tank the diameter shall not exceed the minimum critical diameter multiplied by 0.90 ; or. $k_{\text {eff }}$ shall not exceed 0.98 .

This option is divided into four possibilities:

Option 4A Siab tank of limited thickness. All K Basin sludge can be stored with no restriction of piece (particle). size in a slab tank of $30.0 \mathrm{~cm}$ (11.8 in.) maximum thickness. As $0.13 \mathrm{~cm}$ (0.05 in.) diameter particles, a slab tank of $43.9 \mathrm{~cm}$ (17.3 in.) maximum thickness can be used.

Option 4B Parallel slab tanks separated by walls which provide neutronic isolation.

Option 4C Limit depth of sludge in tank. The depth must be limited to no more than the thickness of a slab tank. This would be an 
administrative limit requiring verification of compliance. The consequences of an earthquake need careful consideration.

Option 40 Cylindrical tanks of limited diameter.

For 1.25 wt\% enriched uranium pieces the subcritical limit cylinder diameter is $48.3 \mathrm{~cm}$ (19.0 in.). For a particle size less than $0.13 \mathrm{~cm}$, the subcritical limit diameter is $65.5 \mathrm{~cm}(25.8 \mathrm{in}$.$) . If the { }^{235} \mathrm{U}$ enrichment is limited to $0.95 \mathrm{wt} \%$, a cylinder diameter of $222.8 \mathrm{~cm}(87.7$ in.) may be used. The total cylinder length needed to accommodate a $17 \mathrm{~K}$ Basin sludge is large. A reduction in the length of cylinder can be realized by not combining the KE Basin sludge with the KW Basin sludge. KE Basin sludge could be placed in cylinders of larger diameter.

Justification is required that a design basis earthquake would not be capable of changing the configuration such that a criticality would be possible. Concerns associated with an earthquake can be mitigated by mixing the sludge with neutron absorbing solid material. Loss of liquid from a storage tank (i.e., a leak into the ground) must not be able to contribute to a criticality.

\subsection{OPTION 5: SMALL TANKS WITH MASS CONTROL}

Disposal Option 5 is construction of small tanks to hold critically safe batches of sludge without requiring processing. A safe batch of sludge is limited to no more than one-half of a subcritical limit mass of uranium. Assurances must be provided that the batch limit can not be exceeded.

This option can be divided into possibilities:

Option 5A Construct a number of smail tanks.

Option $5 B$ Construct a tank with compartments to separate the batches from each other.

For uranium as pieces the batch limit for $0.95 \mathrm{wt} \%$ and $1.25 \mathrm{wt} \%$ enriched uranium are $975 \mathrm{~kg}\left(9.2 \mathrm{~kg}{ }^{235} \mathrm{U}\right)$ and $266 \mathrm{~kg}\left(3.3 \mathrm{~kg}{ }^{235} \mathrm{U}\right)$. respectively. When particles are limited to less than $0.13 \mathrm{~cm}(0.05 \mathrm{in}$.) diameter, the batch limit for 0.95 wt\% uranium increases to $33.320 \mathrm{~kg}$, and the batch limit for $1.25 \mathrm{wt} \%$ enriched uranium increases to $682 \mathrm{~kg}$ uranium $\left(8.5 \mathrm{~kg}{ }^{235} \mathrm{U}\right)$.

For KE Basin sludge the maximum estimated inventory is $26.281 \mathrm{~kg}$ of uranium enriched to $0.95 \mathrm{wt} \%{ }^{235} \mathrm{U}$. As uranium pieces this represents 27 batches, but as $0.13 \mathrm{~cm}$ diameter particles it represents a single batch. For $\mathrm{KW}$ Basin sludge the maximum estimated inventory is $12,969 \mathrm{~kg}$ of uranium enriched to 1.25 wt\% ${ }^{235} \mathrm{U}$. As uranium pieces this represents 49 batches, but as $0.13 \mathrm{~cm}$ diameter particles it represents 19 batches. 
HNF-SD-WM-ES-409, Rev. 0

\subsection{CRITICALITY PARAMETERS}

A compilation of criticality information and parameters is provided to support this feasibility study.

\subsection{URANIUM PARAMETERS}

For low enriched uranium the minimum critical mass for a heterogeneous lattice of optimal diameter rods in water is smaller than that for a homogenized solution. For optimized pieces criticality is possible for enrichments as low as the $0.72 \mathrm{wt} \%$ content in natural uranium. For a homogeneous mixture of uranium in water criticality can not occur unless the ${ }^{235} \mathrm{U}$ enrichment is at least $1.03 \mathrm{wt} \%$.

Table 3-1 shows critical masses provided by Schwinkendorf (1995) for low enriched uranium. Critical masses for uranium pieces (scrap) are based on optimally sized pieces at an optimal spacing in water. Critical masses for uranium pieces (scrap) are the smallest for which criticality is possible under any condition. The parameter shown for cylinders is the minimum critical mass per unit length and for slabs is the minimum critical mass per unit area.

A subcritical limit value based on a $k_{\text {eff }}$ of 0.98 is provided in Table 3-1. This defines the limit which is assured of being subcritical and is often used in setting operating limits for low enriched uranium. although sometimes a more conservative value based on a $k_{\text {eff }}$ of 0.95 is used.

For 0.95 wt\% enriched uranium pieces the minimum critical mass is 2886 $\mathrm{kg}$ uranium $\left(27 \mathrm{~kg}{ }^{235} \mathrm{U}\right)$. When $k_{\text {eff }}$ is limited to 0.98 . the minimum mass is $1951 \mathrm{~kg}$. The large change in mass for a small change in $k_{\text {eff }}$ clearly shows that the mass is a sensitive function of $k_{\text {eff }}$ for $0.95 \mathrm{wt} \%$ enriched uranium. The minimum critical areal density is $2124 \mathrm{~kg} / \mathrm{m}^{2}$, and the minimum areal density for which $k_{\text {eff }}$ can be 0.98 is $1763 \mathrm{~kg}$ of uranium. Criticality is precluded for $0.95 \mathrm{wt} \%$ uranium in the form of particles with dimension (diameter) less than $0.13 \mathrm{~cm}(0.05 \mathrm{in.}$ ).

For $1.25 \mathrm{wt} \%$ enriched uranium pieces the minimum critical mass is $672 \mathrm{~kg}$ uranium $\left(8.4 \mathrm{~kg}{ }^{235} \mathrm{U}\right)$. When $\mathrm{k}_{\text {eff }}$ is 7 imited to 0.98 , the minimum mass is $532 \mathrm{~kg}$ of uranium. The minimum critical areal density is $967 \mathrm{~kg} / \mathrm{m}^{2}$, and the minimum areal density for which $k_{\text {eff }}$ can be 0.98 is $864 \mathrm{~kg} / \mathrm{m}^{2}$ of uranium. For 1.25 wt\% enriched uranium criticality is possible no matter how smali the particle size. However, $1364 \mathrm{~kg}$ of uranium $\left(17.0 \mathrm{~kg}{ }^{235} \mathrm{U}\right)$ is required to reach a $\mathrm{k}_{\text {eff }}$ of 0.98 when particles are smaller than $0.13 \mathrm{~cm}$. 
Table 3-1. Critical Masses for Low Enriched Uranium (Schwinkendorf 1995)

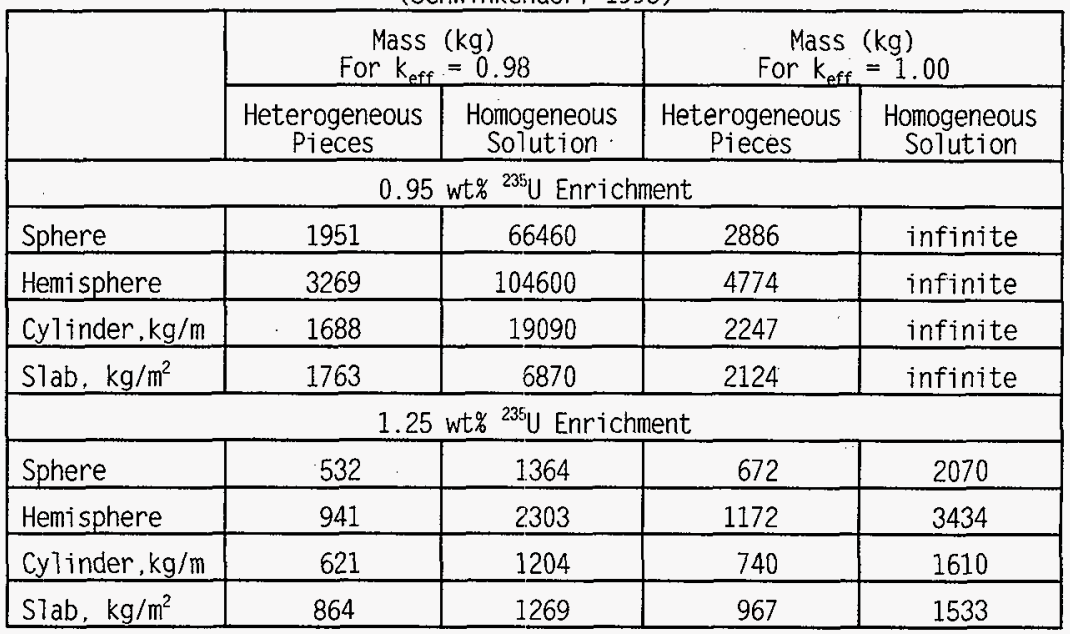

Table 3-2 shows critical dimensions provided by Schwinkendorf (1995) for low enriched uranium. For $0.95 \mathrm{wt} \%$ enriched uranium pieces the minimum critical sphere diameter is $101.3 \mathrm{~cm}$ (39.8 in.). The minimum sphere diameter for which $k_{\text {eff }}$ is 0.98 is $91.4 \mathrm{~cm}(36.0 \mathrm{in}$.). For a slab the minimum critical thickness is $48.0 \mathrm{~cm}$ (18.9 in.) and the minimum thickness for which $k_{\text {eff }}$ can be 0.98 is $46.5 \mathrm{~cm}$ (18.3 in.). A homogeneous mixture of 0.95 wt\% enriched uranium can not be made critical.

For $1.25 w$ t\% enriched uranium pieces the minimum critical sphere diameter is $69.6 \mathrm{~cm}\left(27.4\right.$ in.). The minimum sphere diameter for which $k_{\text {eff }}$ can be 0.98 is $64.5 \mathrm{~cm}(25.4 \mathrm{in}$.$) . For a slab the minimum critical thickness is$ $33.5 \mathrm{~cm}$ (13.2 in.) and the minimum thickness for which $k_{\text {eff }}$ can be 0.98 is 30.0 $\mathrm{cm}$ (11.8 in.).

As a homogeneous mixture, the minimum critical sphere diameter for $1.25 \mathrm{wt} \%$ enriched uranium is $103.4 \mathrm{~cm}$ (40.7 in.). The minimum sphere diameter for which $k_{\text {eff }}$ is can be 0.98 is $89.9 \mathrm{cml}(35.4 \mathrm{in}$.). For a slab the minimum critical thickness is $48.8 \mathrm{~cm}$ (19.2 in.) and the minimum thickness for which $k_{\text {eff }}$ can be 0.98 is $45.2 \mathrm{~cm}$ (17.8 in.). 
Table 3-2. Critical Dimensions for Low Enriched Uranium (Schwinkendorf 1995)

\begin{tabular}{|l|c|c|c|c|}
\hline \multirow{2}{*}{} & \multicolumn{2}{|c|}{$\begin{array}{c}\text { Dimension }(\mathrm{cm}) \\
\text { For } \mathrm{k}_{\mathrm{eff}}=0.98\end{array}$} & \multicolumn{2}{c|}{$\begin{array}{c}\text { Dimension } \\
\text { For } \mathrm{k}_{\text {eff }}=1.00\end{array}$} \\
\cline { 2 - 5 } & $\begin{array}{c}\text { Heterogeneous } \\
\text { Pieces }\end{array}$ & $\begin{array}{c}\text { Homogeneous } \\
\text { Solution }\end{array}$ & $\begin{array}{c}\text { Heterogeneous } \\
\text { Pieces }\end{array}$ & $\begin{array}{c}\text { Homogeneous } \\
\text { Solution }\end{array}$ \\
\hline \multicolumn{5}{|c|}{0.95 wt\% ${ }^{235}$ U Enrichment } \\
\hline Sphere Diameter & 91.4 & 295.9 & 101.3 & infinite \\
\hline Hemisphere Dia. & 136.9 & 433.8 & 151.1 & infinite \\
\hline Cylinder Dia. & 69.9 & 222.8 & 77.0 & infinite \\
\hline Slab Thickness & 46.5 & 140.5 & 48.0 & infinite \\
\hline & 1.25 wt\% 235 U Enrichment & 103.4 \\
\hline Sphere Diameter & 64.5 & 89.9 & 69.6 & 154.2 \\
\hline Hemisphere Dia. & 98.3 & 134.9 & 105.7 & 75.7 \\
\hline Cylinder Dia. & 48.3 & 65.5 & 52.8 & 48.8 \\
\hline Slab Thickness & 30.0 & 45.2 & 33.5 & \\
\hline
\end{tabular}

Although not part of Table 3-2, calculations of masses and dimensions for a $k_{\text {eff }}$ of 0.95 have been completed by Schwinkendorf and can be found in Appendix $C$.

\subsection{ABSORBER-TO-URANIUM MINIMUM SUBCRITICAL MASS RATIOS}

Appendix $C$ contains graphs showing the effect of adding neutron absorbing solids to uranium-water solutions. Summation of these calculations are provided in Section5.3.2. These calculations do not conservatively assume that ${ }^{235} \mathrm{U}$ is equivalent to ${ }^{239} \mathrm{Pu}$ and also take into account the presence of a 7arge ${ }^{238} \mathrm{U} /{ }^{235} \mathrm{U}$ mass ratio. For these reasons, they more closely represent $K$ Basin sludge than the more conservative approach of assuming all fissile material is plutonium.

\subsection{PLUTONIUM PARAMETERS}

In most evaluations of tank waste, uranium is assumed to be natural or depleted, and critical parameters are defined in terms of plutonium content. In the past. the ${ }^{235} \mathrm{U}$ in uranium enriched to $1.0 \mathrm{wt} \%$ has not been included in the fissile (plutonium) inventory. When enriched uranium is present, the ${ }^{235} \mathrm{U}$ is usually replaced by its "plutonium equivalence." The fissile component of $K$ Basin sludge is primarily enriched uranium, and the ${ }^{235} \mathrm{U}$ must be taken into account. In this evaluation the ${ }^{235} \mathrm{y}$ in uranium above an enrichment of $0.72 \mathrm{wt} \%$ (i.e. , that of natural uranium) is treated as if it were plutonium 
and is added to the "plutonium equivalent" inventory. Usually this is referred to as the plutonium inventory.

For the evaluation of tank waste, plutonium concentration is a key parameter. When the plutonium concentration is everywhere less than the minimum critical concentration for the waste composition, subcriticality is assured. A Conservative Waste Model (CWM) with reduced neutron absorption and optimized water was developed by Rogers (1993) to provide a waste composition for which critical concentrations and critical dimensions are conservative relative to any real waste. The complexity of waste and the lack of knowledge of the distribution of waste types can be overcome by replacing an entire configuration of waste layers and mixtures with the CWM. Based on the CWM. the subcritical limit for plutonium concentration in waste solids is $2.6 \mathrm{~g} / \mathrm{L}$. When applied to $K$ Basin sludge, the subcritical limit on the sum of the ${ }^{235} \mathrm{U}$ and plutonium concentrations is $2.6 \mathrm{~g} / \mathrm{L}$.

The experimentally determined plutonium minimum critical concentration of $7.2 \mathrm{~g} / \mathrm{L}$ in water (Paxton and Pruvost 1987) and the minimum critical plutonium areal density provided by Carter et al. (1970) as $240 \mathrm{~g} \mathrm{Pu} / \mathrm{ft}^{2}$ $\left(2,582 \mathrm{~g} / \mathrm{m}^{2}\right)$ are larger than the corresponding subcritical limit values reported by Rogers. However, these parameters are supported by authoritative documentation and are used as subcritical limits.

The subcritical limit for plutonium concentration. based on the CWM with optimal water content (i.e.. completely dry), is $2.6 \mathrm{~g} / \mathrm{L}$. When the plutonium concentration is $3.6 \mathrm{~g} / \mathrm{L}$, criticality requires at least $250 \mathrm{~kg}$ of plutonium in a spherical volume of $69,400 \mathrm{~L}$. When the plutonium concentration is $10 \mathrm{~g} / \mathrm{L}$. criticality requires $3.0 \mathrm{~kg}$ of plutonium in a $300 \mathrm{~L}$ sphere. If no restriction is placed on the plutonium concentration, the smallest mass of plutonium that can be made critical is $520 \mathrm{~g}$ at a plutonium concentration of about $30 \mathrm{~g} / \mathrm{L}$ in pure water.

The most probable geometry for a waste stream is a slab. The minimum critical plutonium mass in a uniform slab covering the entire area of a 22.9m-diameter tank at a uniform depth was calculated to be slightly less than $1,000 \mathrm{~kg}$. When Carter's less conservative minimum critical areal density of $2.582 \mathrm{~g} / \mathrm{m}^{2}$ is used, the minimum critical mass is $1,060 \mathrm{~kg}$. This quantity exceeds the total inventory for tank farms and is considerably larger than the projected inventory of DST AW-105 after K Basin sludge has been added.

The addition of solids to a plutonium-water solution increases the minimum critical plutonium areal density. Therefore, a subcritical limit on the areal density of $2.582 \mathrm{~g} / \mathrm{m}^{2}$ derived from plutonium in pure water is conservative for a11 compositions of waste solids and water.

\subsection{ABSORBER-TO-PLUTONIUM MINIMUM SUBCRITICAL MASS RATIOS}

Subcriticality is ensured by a plutonium concentration below the minimum for which criticality is possible or by a high mass ratio of absorbers to plutonium. A set of minimum subcritical absorber-to-plutonium (X/Pu) mass ratios is defined. where $X$ is used to designate the absorber type. The actual $\mathrm{X} / \mathrm{Pu}$ mass ratio for a waste component divided by its corresponding minimum subcritical mass ratio is referred to as the actual-to-minimum subcritical 
mass fraction (usually shortened to subcritical fraction). When the sum of the subcritical fractions for components is greater than unity, the waste is subcritical.

Uranium, iron, and manganese have a very low solubility under conditions found in tank waste. These are important waste components for which detailed studies have been made. Table $3-3$ presents the $X / P U$ and $X /{ }^{235} U$ minimum subcritical mass ratios for these elements.

Table 3-3. Absorber-to-Fissile Mass Ratios to Ensure Subcriticality.

\begin{tabular}{|l|c|c|}
\hline \multicolumn{1}{|c|}{$\begin{array}{c}\text { Element or } \\
\text { compound }\end{array}$} & $\begin{array}{c}\text { Minimum subcritical } \\
\text { X/Pu mass ratio }\end{array}$ & $\begin{array}{c}\text { Minimum subcritical } \\
X / 235\end{array}$ \\
\hline${ }^{238} \mathrm{U}$ & -- & $\begin{array}{c}\text { Heterogeneous } 139 \\
\text { Homogeneous } 100\end{array}$ \\
\hline Natural uranium & 770 & $-\cdots$ \\
\hline Iron & 160 & 77 \\
\hline Manganese & 32 & 30 \\
\hline
\end{tabular}

The minimum subcritical $X / P u$ mass ratios were calculated for waste components shown in Table 3-4. These elements were chosen because of their high neutron absorption cross sections, or because of their relative abundance in the waste.

$A{ }^{238} \mathrm{U} /{ }^{235} \mathrm{U}$ mass ratio of 139 is based upon the 0.72 wt\% ${ }^{235} \mathrm{U}$ content in natural uranium being the lowest enrichment which can be made critical in a lattice of uranium rods. For a homogenous mixture of uranium and water criticality is not possible for an ${ }^{235} \mathrm{U}$ enrichment less than 1.0 wt\% (Carter et a1. 1969). The ${ }^{238} \mathrm{U} /{ }^{235} \mathrm{U}$ mass ratio for a homogeneous mixture is therefore 100 .

Whyatt et al (1996) conclude that plutonium primarily resides in the solid phase of the tank waste in the form of agglomerates. The solubility of plutonium in alkaline salt solution is low enough that saturation concentrations in waste liquids are at least 30 times lower than the minimum concentration needed to support a criticality. Tank waste is maintained alkaline to ensure that the uranium and plutonium remains combined with the solids. K Basin sludge is to be made alkaline with a pH of at least 8 before transfer into DST AW-105. 
Table 3-4. Absorber-to-Plutonium Mass Ratios to Ensure Subcriticality.

\begin{tabular}{|l|c|}
\hline \multicolumn{1}{|c|}{ Component } & $\begin{array}{c}\text { Subcritical limit X/Pu } \\
\text { mass ratio }\end{array}$ \\
\hline Aluminum & 910 \\
\hline Calcium & 770 \\
\hline Chromi um & 135 \\
\hline Copper & 130 \\
\hline Lanthanum & 121 \\
\hline Nickel & 105 \\
\hline Nitrogen & 61 \\
\hline Nitrate & 270 \\
\hline Sodium & 360 \\
\hline Thorium & 243 \\
\hline Zirconium & 4,000 \\
\hline
\end{tabular}

\subsection{COMBINING THE EFFECT OF ABSORBERS}

The contributions of different components to the total absorption cross section can be combined by adding their individual contributions. The following rules can be used to evaluate a waste composition (Rogers et al 1996).

- Calculate the actual absorber-to-plutonium mass ratio $(\mathrm{X} / \mathrm{Pu})$ for each waste component. Divide each actual mass ratio by its corresponding minimum subcritical mass ratio to obtain a fraction. This fraction will be referred to as the actual-to-minimum subcritical mass fraction or simply as the subcritical fraction.

- When the sum of the actual-to-minimum subcritical mass fractions for individual components is greater than unity, the waste is subcritical.

When the following expression is satisfied, the waste is subcritical:

$$
\sum_{j=1}^{N} \frac{\left(\frac{X_{j}}{P u}\right)_{\text {actual }}}{\left(\frac{X_{j}}{P u}\right)_{\text {suberitical }}} \geq 1
$$

When the sum of fractions is greater than 1.0 , the total neutron absorption is sufficient to ensure subcriticality in an infinite system of 
homogeneous waste. The greater the sum of the fractions, the greater the margin of safety.

\subsection{IMPORTANCE OF PARTICLE SIZE}

A sma11 particle size increases the margin of criticality safety. This is true because ${ }^{238} \mathrm{U}$ is a strong resonance absorber for epithermal neutrons. When uranium particles are large, neutrons can escape absorption by being moderated outside of the fuel and reentering as thermal neutrons. When particles are smal1 neutrons are not able to reach thermal energies outside of the presence of ${ }^{238} U$. There is an optimal particle size for which the critical mass can be made smallest. When particle size is decreased, the mass of uranium required for criticality will increase. The minimum critical mass for water moderation is smaller than that of any other material with which the uranium might be mixed.

The average size of particles in $K$ Basin sludge is several times larger than in tank farm sludge, and the largest particles are orders of magnitude larger. Limiting the largest particle to a dimension no greater than $0.13 \mathrm{~cm}$ (0.05 in.) provides assurance of subcriticality for 0.95 wt\% enriched uranium. but not for 1.25 wt\% uranium.

Accumulation of uranium at high concentration can result in an unacceptably high neutron multiplication. This is true both for $1.25 \mathrm{wt} \%$ and for 0.95 wt\% enrichment. Gravity separation of uranium particles from other sludge may be possible for particles larger than $10 \mu \mathrm{m}$. A very sma 77 particle size would preclude gravity separation.

Particles should be limited to a size small enough to preclude significant separation during settling after mixing. Although a maximum particle size (diameter) of $0.13 \mathrm{~cm}$ ensires that homogeneous critical parameters apply, it cannot ensure that the neutron multiplication is not unacceptably high, even for $0.95 \mathrm{wt} \%$ errriched uranium. A discussion of how small a particle size is required to preclude significant gravity separation is provided in Appendix A.

\subsection{IRRADIATION EFFECTS ON CRITICAL MASS}

Toffer (1976) calculates the critical mass for 0.95 and 1.25 wt\% $\mathrm{N}$ Reactor fuel as a function of irradiation history. According to Toffer, the critical mass of uranium in KE and KW Basin sludge would be expected to be at least $30 \%$ larger than the critical mass for unirradiated (green) fuel. For the evaluation of disposing of K Basin sludge, the effect of fuel burnup is not taken into account because it cannot be shown that the less highly irradiated elements have not contributed to the sludge.

On the surface of fuel elements composed of low enriched uranium plutonium is produced faster than ${ }^{235} \mathrm{U}$ is burned. However. as the ${ }^{235} \mathrm{U} /{ }^{238} \mathrm{U}$ ratio increases, the ratio of plutonium production to ${ }^{235} \mathrm{~J}$ burnup decreases. Schwinkendorf (1997a. Appendix G) looks at the radial isotopic evolution during burnup of $0.95 \mathrm{wt} \%$ and $1.25 \mathrm{wt} \%$ enriched uranium and reaches the following conclusion: 
In a11 burnup calculations reported in this appendix, the production of plutonium is enhanced at the outer surfaces of the fuel: there is increased exposure near the surfaces because of self-shielding. However, this effect is at least partially mitigated by the fact that enhanced fissile uranium depletion also occurs near the fuel surfaces. In addition, the increased plutonium production near the surface also has a higher ${ }^{240} \mathrm{Pu}$ content, again, because of the increased exposure at the surface. The number of neutrons produced per fission is higher for ${ }^{239} \mathrm{Pu}$ than ${ }^{235} \mathrm{U}$, and so the plutonium is worth more than the fissile uranium, but the effect is not large. Scrap material composed of the outer skin of the fuel is more reactive than the average fuel, but not to a significant degree.

Based only upon consideration of the concentrations of ${ }^{235} \mathrm{U}$ and ${ }^{239} \mathrm{Pu}$. the outer $0.05-\mathrm{cm}$ thick layer of each $0.95 \mathrm{wt} \%$ element is found to increase in. reactivity worth during irradiation. Below the surface of the element the total fissile concentration decreases with fuel exposure. For the fuel element as a whole, the loss of $235 \mathrm{~J}$ is 1.6 to 1.8 times greater than the production of ${ }^{239} \mathrm{Pu}$. Because the surface layer is protected by cladding and so much interior uranium would have to be removed to permit removal of the surface layer, sludge would not contain an elevated fraction of surface uranium. For 1.25 wt.\% enriched uranium, the sum of the ${ }^{235} \mathrm{U}$ and ${ }^{239} \mathrm{Pu}$ concentrations does not exceed that of green fuel at any radial position. regardless of exposure time. 
HNF-SD-WM-ES-409, Rev. 0

\subsection{SLUDGE DESCRIPTION}

A description is provided of $\mathrm{K}$ Basin sludge and of sludge in DST AW-105.

\subsection{K EAST BASIN SLUDGE}

Spent N Reactor fuel elements have been stored in the KE Basin in unsealed fuel canisters with open bottoms. Disintegrated uranium found its way to the basin floor and is mixed with other debris. The bounding (upper limit) estimate of the uranium in KE Basin sludge is $26,281 \mathrm{~kg}$ (Pearce 1997), and the maximum ${ }^{235} \mathrm{U}$ enrichment is $0.95 \mathrm{wt} \%$. The expected quantity of uranium is estimated at $9,845 \mathrm{~kg}$.

\subsubsection{Sludge Component Inventories}

Recent estimates of the sludge volume and its uranium content reported by Pearce (1997) for KE Basin are shown in Tables 4-1. The various columns in the table show the sludge estimates for the basin floor. the Weasel Pit, the North Loadout Area, canisters in the storage array, and the Wash Area. The total quantity of uranium in KE Basin sludge is estimated to be $9,845 \mathrm{~kg}$, with a bounding estimate of $26,281 \mathrm{~kg}$.

\subsubsection{Analyzed Samples}

Welsh et al. (1996) reported 20 representative sludge samples from the KE Basin and from the Weasel Pit adjoining the basin. Sampling locations were selected to facilitate characterization of the sludge over the entire basin.

The density of most settled sludge was found to be between 1.0 to $1.8 \mathrm{~g} / \mathrm{cm}^{3}$. After centrifuging the density remained in about the same range. The highest density found was $3.9 \mathrm{~g} / \mathrm{cm}^{3}$ in a dry sample with a high uranium content.

The ${ }^{235} \mathrm{U}$ enrichment in uranium from analyzed samples ranged from 0.695 to $0.734 \mathrm{wt} \%$. This enrichment is very nearly the same as that of natural uranium. Although this value is low enough to ensure subcriticality, the sludge covered by these samples represents only a small fraction of the total sludge in the K Basins.

The plutonium/235 $\mathrm{U}$ mass ratio was found to range from a low of 0.21 to a high of 1.69 . with a mean value of 0.39 . Values much larger than the mean value are suspect because the plutonium generated during irradiation is nearly always less than the ${ }^{235} \mathrm{U}$ burned. This result is not reasonable and may be caused by measurement errors. 
Table 4-1. KE Basin STudge Component Mass Estimates (Pearce 1997)

\begin{tabular}{|c|c|c|c|c|c|c|}
\hline Component & $\begin{array}{l}\text { Basin } \\
\text { Floor }\end{array}$ & $\begin{array}{l}\text { Weasel Pit } \\
\text { Tech View } \\
\text { Dummy Pit }\end{array}$ & N.Loadout & Canisters & Wash & Total \\
\hline \multicolumn{7}{|c|}{ KE Basin Nominal Values $(\mathrm{kg})$} \\
\hline A1 & 372 & 424 & 30 & 3.7 & 2.7 & 832 \\
\hline $\mathrm{B}$ & 1.5 & 2.4 & $\cdots$ & 0.0 & 0.0 & 3.9 \\
\hline $\mathrm{Cd}$ & 0.8 & 0.5 & 0.2 & 0.0 & 0.0 & 1.5 \\
\hline $\mathrm{Fe}$ & 1505 & 3260 & 89.8 & 2.0 & 1.5 & 4859 \\
\hline$U$ & 1387 & 499 & 39 & 4570 & 3350 & 9845 \\
\hline $\mathrm{Pu}$ & 3.4 & 1.7 & 0.1 & 13.1 & 9.6 & 27.9 \\
\hline Total & 5103 & 6407 & 191 & 4899 & 3591 & 20192 \\
\hline Volume, $\mathrm{m}^{3}$ & 21.6 & 11.8 & 6.2 & 3.0 & 2.4 & 45.0 \\
\hline $\begin{array}{l}\text { Mass/Vol }{ }^{2} \\
\mathrm{~g} / \mathrm{cm}^{3}\end{array}$ & 0.24 & 0.54 & $0 . \overline{030}$ & 1.63 & 1.50 & 0.45 \\
\hline $\mathrm{U}, \mathrm{g} / \mathrm{cm}^{3}$ & 0.064 & 0.042 & 0.006 & 1.52 & 1.39 & 0.22 \\
\hline \multicolumn{7}{|c|}{ KE Basin Bounding Values (kg) } \\
\hline A7 & 1520 & 863 & 36.3 & 4.6 & 6.8 & 2430 \\
\hline$B$ & 19.9 & 11.3 & $\cdots$ & 0.0 & 0.0 & 31.2 \\
\hline $\mathrm{Cd}$ & 2.0 & 1.1 & 0.2 & 0.0 & 0.0 & 3.3 \\
\hline $\mathrm{Fe}$ & 13600 & 7670 & 109 & 2.5 & 4.7 & 21385 \\
\hline $\mathrm{U}$ & 11100 & 1110 & 47.2 & 5643 & 8380 & 26281 \\
\hline $\mathrm{Pu}$ & 18.9 & 3.5 & 0.2 & 32.3 & 24.0 & 78.9 \\
\hline Total & 37546 & 16541 & 231 & 6048 & 8983 & 69351 \\
\hline Volume, $\mathrm{m}^{3}$ & 26.0 & 14.7 & 7.5 & 7.4 & 6.0 & 61.6 \\
\hline $\begin{array}{l}\text { Mass/Vol. } \\
\mathrm{g} / \mathrm{cm}^{3}\end{array}$ & 1.44 & 0.71 & 0.030 & 0.817 & 1.50 & 1.12 \\
\hline $\mathrm{U}, \mathrm{g} / \mathrm{cm}^{3}$ & 0.42 & 0.075 & 0.006 & 0.762 & 1.39 & 0.43 \\
\hline
\end{tabular}

"Mass/volume is total mass of components shown divided by volume. This may not be actual density of sludge. since water and some components may not be included. 
To overcome inconsistencies and uncertainties associated with these sample analyses, the sludge should be evaluated using the assumption that the uranium is "green" fuel. A11 uranium in K East Basin had an enrichment of 0.95 wt\% before irradiation. The plutonium content is determined by the irradiation history of the uranium. The increase in plutonium during irradiation is more than compensated for by the decrease in ${ }^{235} \mathrm{U}$ and in the build up of neutron absorbing fission products.

\subsubsection{Subcritical Fractions}

Subcritical mass fractions were determined for the representative sludge samples reported by welsh et al. (1996). In determining these subcritical fractions the "plutonium equivalent" inventory is used. The $235 \mathrm{y}$ content in natural uranium is not included in the inventory. The "plutonium equivalent" inventory is the sum of the ${ }^{235} \mathrm{U}$ above that in natural uranium and the plutonium content. This is usually referred to as the plutonium inventory.

Table 4-2 summarizes subcritical fractions for KE Basin sludge based upon uranium and neutron absorber concentrations obtained from centrifuged sludge samples. When the fractions are added, the smallest sum is 2.65, and the mean value is 9.38 . When a subcritical fraction exceeds 1.0 , the sludge is subcritica T, if homogeneous.

Table 4-2. Actual-to-Minimum Subcritical Mass Fractions in KE Basin and Weasel Pit Centrifuged Sludge (Based on data from Welsh et a1. (1996))

\begin{tabular}{|l|c|c|}
\hline \multirow{2}{*}{} & \multicolumn{2}{|c|}{ Subcritical Mass Fraction } \\
\cline { 2 - 3 } & Sma7lest & Median \\
\hline Aluminum & 0.13 & 0.28 \\
\hline Iron & 0.92 & 8.32 \\
\hline Boron & 0.88 & 2.58 \\
\hline Uranium & 0.11 & 0.26 \\
\hline Sum of fractions & 2.68 & 9.38 \\
\hline
\end{tabular}

There is a wide variation in subcritical fractions from sample to sample. The sum of subcritical fractions varies from 2.7 to 43.6 , with a mean value of 9.4. For iron, the most important component of KE Basin sludge towards.ensuring subcriticality, the mean subcritical fraction is 8.32 . In $78 \%$ of the samples the iron content by itself is adequate to ensure subcriticality for both the ${ }^{235} \mathrm{U}$ and the plutonium in a homogeneous mixture.

In a11 cases, the combined effect of the iron and ${ }^{238} \mathrm{U}$ is sufficient to maintain subcriticality. However, for 4 samples the sum of the iron and uranium subcritical fractions is less than 2.0. 
Iron and uranium are the only two components in KE Basin sludge providing a significant contribution to subcriticality and whose presence can be relied upon. The margin of safety for K Basin sludge should be based solely upon the mass ratio of iron to uranium. The contribution of other components in the analyzed waste samples are viewed as an added margin of safety, but these components will not be used as a basis for ensuring subcriticality.

A]though half of the samples have sufficient boron to maintain subcriticality, the presence of boron cannot be considered guaranteed. Nevertheless, its presence does provide assurances that an evaluation of the subcritical margin based only on the uranium and iron content is conservative.

This sample data does not indicate what volume of waste each sample represents. However, using the maximurn inventory data in Table 4-1. the iron/uranium mass ratio for sludge on the basin floor is 1.2, in the Weasel/Tech View/Dummy Pits is 6.9, and in the North Loadout Area is 2.3. When the sludge in these areas are combined, the average iron/uranium mass ratio is 2.3. This quantity of iron will guarantee a $k_{\infty}$ less than 0.60 (see Table 5-4), provided the sludge in these areas is homogenized.

\subsection{3 $k_{\infty}$ of Sludge}

Estimates of $k_{\infty}$ have been made for sludge in the Discharge Chute and in the Weasel Pit. The Discharge Chute is located at one end of the basin in front of the reactor. Fuel assemblies fell into the discharge chute after being pushed out of the reactor. After sliding down the discharge chute the assembiies came to rest at the bottom of the basin in the pickup area in front of the chute. The Weasel Pit is a gallery off one side of the basin where fuel was handled.

\subsubsection{Sludge in Discharge Chute}

Wittekind and Schwinkendorf (1993) calculated $k_{\infty}$ for representative KE Basin sludge. Sludge compositions were obtained from chemical analysis of samples from various locations within the 105-KE Discharge Chute and from the Tech View Pit. Calculations were made for both homogeneous and heterogeneous sludge, assuming the uranium is enriched to $0.947 \mathrm{wt} \%$ in ${ }^{235} \mathrm{U}$. For compositions exactly as reported, the two largest neutron multiplication constants from among five sludge samples were 0.12 and 0.03 . The water content was that for normal sludge conditions. Additional calculations were made for sludge from the 100-KE Basin West Discharge Chute where the largest values of $k_{\infty}$ were found. The maximum $k_{\infty}$ over the entire range of water moderation for sludge from the 100-KE Discharge Chute and from the Tech View Pit is 0.38 .

\subsubsection{Sludge in Weasel Pit}

Erickson (1997) performed calculations of $k_{\infty}$ for sludge samples from the Weasel Pit reported by Makenas (1996). Sludge in the weasel Pit arrived there after passing through a $0.635-\mathrm{cm}(0.25-\mathrm{in}$.$) mesh over the inlet portion of the$ pump to protect the pump from damage by larger particles. For a homogeneous mixture of 0.95 wt\% uranium oxide in water. Erickson determined that the maximum $k_{\infty}$ over the entire range of water content is 0.98 , and this occurs 
when the $\mathrm{UO}_{2}$ density is about $4.0 \mathrm{~g} / \mathrm{cm}^{3}$. For $0.635-\mathrm{cm}$ diameter, unirradiated $\mathrm{UO}_{2}$ spheres in pure water, the maximum possible $\mathrm{k}_{\infty}$ is 1.05 . When the spheres are placed in sludge taken from the KE Basin, the maximum $k_{\infty}$ drops to 0.96 . When placed in Wease? Pit sludge, the maximum $k_{\infty}$ drops to 0.85 .

\subsection{K WEST BASIN SLUDGE}

Fuel elements and sludge in KW Basin are contained within sealed canisters. In this way, the KW Basin was spared the buildup of uraniumbearing sludge on the basin floor. There is no significant volume of sludge on the main basin floor or in the Weasel Pit. Tech View, and the Dummy Pit.

\subsubsection{Sludge Component Inventories}

Recent estimates of the sludge volume and its uranium content reported by Peace (1997) for KW Basin are shown in Table 4-3. The columns in the table show the primary locations within the basin where sludge is located. The bounding estimate of the sludge inventory in $\mathrm{KW}$ Basin is $12,969 \mathrm{~kg}$ of uranium oxide enriched between 0.95 and $1.25 \mathrm{wt} \%$. No analytical data is avajlable on the actual ${ }^{235} \mathrm{U}$ enrichment of uranium ir $\mathrm{KW}$ basin sludge. In the absence of analyses showing otherwise, uranium in KW Basin sludge must be considered enriched to $1.25 \mathrm{wt} \%$.

$\mathrm{KW}$ Basin sludge is formed within sealed containers and should contain only debris originating from the fuel elements and from canister internals. Cladding material might be iron, zircalloy, or aluminum. However, the mass ratio of zircalloy and aluminum required to assure subcriticality is very high. For this reason, only the iron will be used in evaluating the degree of subcriticality. For most of this sludge the iron content is low. The assurance of subcriticality is therefore dependent upon the addition of iron.

\subsection{DST AW-105 SLUDGE}

DST AW-105 is $35.4 \mathrm{~m}$ (75 ft) in diameter and contains $1,665,000 \mathrm{~L}$ (440.000 ga7) of waste from the processing of fuel at the Plutonium Uranium Reduction Extraction Plant (PUREX) (Hanion 1996). The Double Shell Tank PTutonium Inventory System shows the December 1996 inventory for DST AW-105 to be $22.95 \mathrm{~kg}$, based on sample analysis. The largest measured plutonium concentration for this tank is $0.024 \mathrm{~g} / \mathrm{L}$ (Braun et a1. 1994), less than $1 \%$ of the minimum required for criticality under the most idealized conditions. The average plutonium areal density is estimated to be $61.0 \mathrm{~g} / \mathrm{m}^{2}\left(5.75 \mathrm{~g} / \mathrm{ft}^{2}\right)$. a value only $2.3 \%$ of the minimum critical areal density. 
Table 4-3. KW Basin Sludge Component Mass Estimates (Pearce 1997)

\begin{tabular}{|c|c|c|c|c|}
\hline Component & N.Loadout & Canisters & Wash & Total \\
\hline \multicolumn{5}{|c|}{$\mathrm{KW}$ Basin Nominal Values $(\mathrm{kg})$} \\
\hline$\overline{A l}$ & 18.2 & 2.1 & 2.7 & 23.0 \\
\hline$B$ & 0.0 & 0.0 & 0.0 & 0.0 \\
\hline$\overline{\mathrm{Cd}}$ & 0.1 & 0.0 & 0.0 & 0.1 \\
\hline $\mathrm{Fe}$ & 54.6 & 1.1 & 1.5 & 57.3 \\
\hline $\mathrm{U}$ & 23.7 & 2590 & 3350 & 5964 \\
\hline $\mathrm{Pu}$ & 0.1 & 7.9 & 10.2 & 18.2 \\
\hline Total & 115.8 & 2777 & 3591 & 6484 \\
\hline Volume, $\mathrm{m}^{3}$ & 3.8 & 1.7 & 2.4 & 7.9 \\
\hline Mass/Volume ${ }^{\mathrm{a}}, \mathrm{g} / \mathrm{cm}^{3}$ & 0.030 & 1.63 & 1.5 & 0.82 \\
\hline $\begin{array}{l}U \text { Concentration } \\
\mathrm{g} / \mathrm{cm}^{3}\end{array}$ & 0.006 & 1.52 & 1.39 & 0.75 \\
\hline \multicolumn{5}{|c|}{ KW Basin Maximum Values $(\mathrm{kg})$} \\
\hline A1 & 21.8 & 3.7 & 6.8 & 32.3 \\
\hline$B$ & 0.0 & 0.0 & 0.0 & 0.0 \\
\hline$\overline{c d}$ & 0.1 & 0.0 & 0.0 & 0.1 \\
\hline $\mathrm{Fe}$ & 65.2 & 2.0 & 3.7 & 71.0 \\
\hline U & 28.3 & 4560 & 8380 & 12968 \\
\hline $\mathrm{Pu}$ & 0.1 & 13.9 & 25.5 & 39.5 \\
\hline Total & 138.4 & 4889 & 8983 & 14011 \\
\hline Volume, $\mathrm{m}^{3}$ & 4.5 & 3.0 & 6.0 & 13.5 \\
\hline Mass/Volume ${ }^{\mathrm{a}}, \mathrm{g} / \mathrm{cm}^{3}$ & 0.030 & 1.63 & 1.5 & 1.04 \\
\hline $\begin{array}{l}\text { U Concentration } \\
\mathrm{g} / \mathrm{cm}^{3}\end{array}$ & 0.006 & 1.52 & 1.39 & 0.96 \\
\hline
\end{tabular}

'Mass/volume is total mass of components shown divided by volume. This may not be actual density of sludge, since water and some components may not be included. 
HNF-SD-WM-ES-409, Rev. 0

\subsubsection{Controls on Incoming Transfers}

For waste presently in DST AW-105, discharges were made under two basic CPS limits. First, the plutonium concentration in the holdup vessel at the facility from which the waste originated was required to be less than $0.013 \mathrm{~g} / \mathrm{L}(0.05 \mathrm{~g} / \mathrm{gal})$ at the time of discharge. This is an average over the entire waste batch volume after being stirred just prior to discharge. Sometimes caustic and water were added to ensure that this limit was not exceeded. Second. the waste had sufficient solids such that after settling the plutonium concentration would not exceed $1.0 \mathrm{~g} / \mathrm{L}$.

The PUREX tank from which most plutonium bearing waste was discharged has a volume of $18.900 \mathrm{~L}(5,000 \mathrm{ga} 1)$. To meet the discharge limit of 0.013 $\mathrm{g} / \mathrm{L}$ (maximum), the total mass of plutonium discharged at one time could therefore not exceed $250 \mathrm{~g}$. Since there was a period of at least several days between discharges, the solids in each discharge had time to settle before the next discharge.

In 1995 waste was sent to DST AW-105 from PUREX under discharge limits requiring the presence of cadmium to compensate for allowing an increase in the plutonium concentration in settled solids. The cadmium concentration in these transfers was well above that required to maintain subcriticality at a plutonium concentration of $30 \mathrm{~g} / \mathrm{L}$, although the actual plutonium concentration was less than $0.05 \mathrm{~g} / \mathrm{L}$. The mass of plutonium in a transfer did not exceed $500 \mathrm{~g}$, and the uranium/plutonium mass ratio was high enough to ensure subcriticality. This was the last waste sent to DST AW-105, and it lies at the top of the sludge layer. These were the only transfers ever where cadmium was added to allow a higher concentration of plutonium to be transferred.

\subsubsection{Tank Contents Origin}

Properties of Generated Waste Relevant to Criticality Hazard, a detailed review of the contents of waste storage tanks, based upon historic records of discharges to tank farms, is provided both as Appendix A of Whyatt et al. (1996) and as Chapter 9 of Serne et al. (1996).

Whyatt et a1. provide two estimates of plutonium inventory. The first estimate is based upon Basel ine Report WHC-SD-WM-TI-640 as of January 1. 1995 , with updates to Apri1 1996, which reports that DST AW-105 contains 1,124,000 L of sludge, 288,000 L of liquid, and $22,947 \mathrm{~g}$ of plutonium. This is the official tank inventory. The second estimate is contained in Revision 3 of the Hanford Defined Waste (HOW) Model which provides a plutonium inventory of $12,600 \mathrm{~g}$.

The HDW model estimates a significantly smaller plutonium inventory than the official inventory. This difference reflects the fact that the official inventory conservatively assumes that the largest measured plutonium concentration applies to the entire volume of the tank.

Serne et a1. (1996. Appendix D) characterizes waste streams to DST AW-105 as follows:

(1) the primary stream was low-level waste from PUREX; 
HNF-SD-WM-ES-409, Rev. 0

(2) the secondary stream was aluminum and zircalloy cladding waste from the REDOX process;

(3) the tertiary stream was slurry product from the evaporator; and

(4) other waste was primarily decontamination waste from the T Plant containing mainly $0.24 \mathrm{M} \mathrm{NaNO}_{2}$ solution.

\subsubsection{Zircalloy Decladding Waste Process Records}

According to Serne et a7. (1996. Appendix E), a total of $729.550 \mathrm{~L}$ of decladding waste sludge was added to DST AW-105. This contained $8.64 \mathrm{~kg}$ of plutonium and $11.697 \mathrm{~kg}$ of uranium.

At PUREX before being discharged from the TK-E5 tank, a batch of waste was verified to contain less than $500 \mathrm{~g}$ of plutonium, to have an average plutonium concentration less than $0.013 \mathrm{~g} / \mathrm{L}$, and to have a pH greater than 12 . This sludge comprises 68.8 vol\% of the sludge in the tank. Averaged over the entire volume, the uranium concentration was determined to be $0.525 \mathrm{~g} / \mathrm{L}$ and the plutonium concentration was $0.00039 \mathrm{~g} / \mathrm{L}$.

Zircalloy decladding waste contains 1.4 times as much iron and 7.1 times as much zirconium than required to ensure subcriticality when the waste is homogenized. The quantity of uranium is reported to be 1.346 times larger than the quantity of plutonium.

\subsubsection{Mass Ratios and Subcriticat Fractions}

Using process records. Agnew (1995) determined the sum of the insoluble absorber actual-to-minimum subcritical fractions to be 18.6 and the sum of subcritical fractions for the soluble components to be 54.4. A fraction of 1.0 will ensure subcriticality in a homogeneous solution.

Table 4-4 shows component-to-minimum subcritical fractions provided by Whyatt et a1. (1996) from analysis of a core analyzed by Tingey (1994). For iron and zirconium, process records provides values which are 2 and 5 times larger than the corresponding value based upon analysis of core samples. For process records, the sum of subcritical fractions for these two components is 8.4, as compared to 2.1, based on analysis of core samples.

Based upon process records, Whyatt et al. (1996) conclude that zirconium is the most accurately known constituent in the waste stream sent to DST AW105. These records show there to be 7.1 times as much zirconium as is required to maintain subcriticality.

No actual-to-minimum subcritical fraction was found for uranium because the ${ }^{235} \mathrm{U}$ enrichment was not reported. Without including uranium, the sum of the subcritical fractions is 2.72 . The sum of fractions obtained from the analysis of a core sample is significantly smaller than the sum reported by Agnew. The largest mass fractions for individual elements are 1.28 for zirconium, 0.78 for iron, and 0.46 for lanthanum. 
Table 4-4. Component-to-Minimum Subcritical Fractions (From whyatt et al. (1996). Table A.32)

\begin{tabular}{|c|c|c|}
\hline Component & $\begin{array}{c}\text { Fraction Based on } \\
\text { Process Records }\end{array}$ & $\begin{array}{c}\text { Fraction Based on } \\
\text { Core Sample Analysis }\end{array}$ \\
\hline zirconium & 7.1 & 1.28 \\
\hline iron & 1.4 & 0.78 \\
\hline lanthanum & --- & 0.46 \\
\hline chromium & --- & 0.14 \\
\hline aluminum & --- & 0.06 \\
\hline sum of fractions & 8.4 & 2.72 \\
\hline
\end{tabular}

Braun et a7. (1994) reports data from eight waste samples taken from DST AW-105. The largest measured plutonium concentration is $0.024 \mathrm{~g} / \mathrm{L}$. Based upon a plutonium concentration of $0.024 \mathrm{~g} / \mathrm{L}$, the solids-to-plutonium mass ratio is estimated to be at least 50,000 . The fraction of the actual-tominimum subcritical mass ratio for this waste is estimated to be 64 . In other words, the mass of solids is estimated to be 64 times larger than required to ensure subcriticality when homogenized.

Braun et al. (1994) provides a listing of the actual-to-minimum subcritical mass fractions for waste components, based upon analyzed concentrations from samples taken from waste storage tanks. Waste is separated into soluble and insoluble components. One sample shows the sum of the fractions for the insoluble components to only be 0.50 . However, the soluble fraction is 15 , a value far greater than required to assure subcriticality. In addition, the plutonium concentration in al7 samples is less than $0.025 \mathrm{~g} / \mathrm{L}$, a value less than $1 \%$ of the minimum required for criticality under the most idealized conditions. Even if a large fraction of the soluble components were to be removed, it would be unlikely for the plutonium concentration to increase sufficiently for criticality to occur. The areal density of plutonium is $61 \mathrm{~g} / \mathrm{m}^{2}$, a value 41.7 times smaller than the minimum required for criticality.

\subsection{5 $k_{\infty}$ of Sludge}

Braun et al. (1994) provides calculations of the neutron multiplication constant $\left(k_{\infty}\right)$ for waste samples from DST AW-105 selected because of "their relatively low neutron absorber content." Calculations of $k_{\infty}$. for water content between 600 and $35 \mathrm{~g} / \mathrm{L}$ shows a monotonic increase as the water content is decreased. A water content of $50 \mathrm{~g} / \mathrm{L}$ represents waste which is drier than considered possible in practice.

Using the measured water content (normal conditions), $k_{\infty}$ was calculated to be less than 0.03 . Under hypothetical conditions with water content reduced to $50 \mathrm{~g} / \mathrm{L}$ plutonium concentration arbitrarily increased to $3 \mathrm{~g} / \mathrm{L}, K_{\infty}$ was found to increase to 0.38 . This is an extreme condition with less water 
HNF-SD-WM-ES-409, Rev. 0

content than would actually ever occur and with a plutonium concentration more than 100 times greater than measured. Even under these hypothetical conditions, the waste remains subcritical.

\subsection{SLUDGE TRANSPORTATION SYSTEM}

The Sludge Transportation System wil1 move K Basin sludge to tank farms. A precise description of the transport container is not available for this review. Before $\mathrm{K}$ Basin sludge is placed in the transport container it must first be assured that criticality is not possible in an unlimited volume of the sludge. If an adequate margin of subcriticality cannot be demonstrated, solids might be added to the sludge as it is pumped into the container.

S7udge will arrive at tank farms in the transport container on a flatbed trailer. The trailer will be positioned at the Sludge Receiving Station where the sludge wi17 be transferred into DST AW-105. S7udge will be transferred through a flexible $3.8 \mathrm{~cm},(1.5 \mathrm{in}$.) diameter hose at a maximum rate of $3 \mathrm{~L} / \mathrm{sec}$ $(50 \mathrm{gpm})$. 
HNF-SD-WM-ES-409, Rev. 0

\subsection{OPTION 1: DISPOSAL IN DST AW-105}

Disposal Option 1 is to combine K Basin sludge with the contents of DST AW-105 with unrestricted usage for storage of other waste. Before $K$ Basin waste is sent to DST AW-105 for storage, a CSER must be completed.

Oxidation of uranium underwater can generate hydrogen gas and can produce considerable heat. Although heat generation and hydrogen gas production are important safety issues, they are not part of a criticality safety evaluation as they do not increase the potential for a criticality.

\subsection{ACCEPTABLE MARGIN OF SAFETY}

Transfers of waste into tank farms is governed by limits in the Criticality Prevention Specification (CPS). However, $K$ Basin sludge does not meet these requirements and a revision of discharge 1 imits wi 11 be required to permit receipt of $\mathrm{K}$ Basin sludge, unless an adequate volume of solids is added.

\subsubsection{Tank Farms CPS Requirements}

The tank farms CPS limits the plutonium in incoming waste to no more than $1 \mathrm{~g} / \mathrm{L}$ in settled waste solids. For waste already in DST AW-105 the ${ }^{235} \mathrm{U}$ in uranium enriched to $1.0 \mathrm{wt} \%$ has not been included in the fissile inventory. For this evaluation the ${ }^{235} U$ content in excess of the $0.72 \mathrm{wt} \%$ in natural uranium is assumed to be added to the fissile inventory. The sum of the excess ${ }^{235} \mathrm{U}$ and the plutonium is known as the "plutonium equivalent" inventory. For $0.95 \mathrm{wt} \%$ and $1.25 \mathrm{wt} \%$ enriched uranium, the excess ${ }^{235} \mathrm{~J}$ is equal to 0.23 wt\% and $0.53 \mathrm{wt} \%$ of the uranium, respectively. If one assumes an uranium density in sludge of $1.5 \mathrm{~kg} / \mathrm{L}$, the ${ }^{235} \mathrm{U}$ concentration can be as high as $3.4 \mathrm{~g} / \mathrm{L}$ for $0.95 \mathrm{wt} \%$ and $7.9 \mathrm{~g} / \mathrm{L}$ for $1.25 \mathrm{wt} \%$ enriched uranium. If a higher uranium density is assumed, a proportionately higher ${ }^{235 \mathrm{U}}$ concentration is found.

A criticality safety evaluation would provide justification for a higher ${ }^{235} \mathrm{U}$ concentration and would become the basis for revising the CPS limit.

\subsubsection{Limit on $k_{\infty}$}

A revision of CPS limits is proposed to permit discharges of $K$ Basin sludge based on the following criteria:

(1) The quantity of neutron absorbing solids well mixed with the uranium must be at least enough to ensure that $k_{\infty}$ will not exceed 0.95 with optimal moderation and full reflection. after taking into account uranium segregation through gravity settiing and chemical processes.

(2) The enrichment (before irradiation) for a 71 uranium in a batch is assumed to be either $0.95 \mathrm{wt} \%$ or $1.25 \mathrm{wt} \%$ according to the following: 
(a) When a batch contains no uranium enriched to more than $0.95 \mathrm{wt} \%$ (before irradiation). then all uranium is assumed to have been enriched to $0.95 \mathrm{wt} \%{ }^{235} \mathrm{U}$ (before irradiation).

(b) When a batch contains uranium enriched above $0.95 \mathrm{wt} \%{ }^{235} \mathrm{U}$ (before irradiation), then a 11 uranium is assumed to have been enriched to. $1.25 \mathrm{wt} \%{ }^{235} \mathrm{U}$ (before irradiation).

(3) The plutonium must not occur in greater proportion to the uranium than when discharged from the reactor. In other words, no separated plutonium is permitted in K Basin sludge.

(4) When depleted uranium is added to lower the ${ }^{235} U$ enrichment:

a. The proportion of plutonium to uranium must not exceed that in the uranium to which it is added.

b. The combined uranium shall be mixed (blended). to ensure a uni form enrichment.

c. The stated enrichment of blended uranium shall be increased by an amount which compensates for uncertainties in ${ }^{235} \mathrm{U}$ content of the uraniums which were blended and in possible variations in enrichment.

(5) Particle size for both uranium and other solids must not exceed 50 microns.

(6) When combined with tank farms sludge, $k_{\text {eff }}$ of the combined sludge shall not exceed 0.95 , under the worst credible conditions of storage and operations. including optimal moderation and full reflection.

\subsubsection{Discussion}

When the ${ }^{235} \mathrm{U}$ enrichment is $0.84 \mathrm{wt} \%$, or less, $\mathrm{k}_{\infty}$ for $\mathrm{UO}_{3}$ in water solution can not exceed 0.95 (See Section 5.3.2.1). It is impossible under tank waste storage conditions to separate isotopes of uranium from each other. No other neutron absorbing solids are needed to ensure that $k_{\infty}$ wi 11 not exceed 0.95 .

Uranium enriched to $0.95 \mathrm{wt} \%{ }^{235} \mathrm{U}$ can be made critical in a lattice of pieces whose size falls within a narrow range. For a homogeneous solution of $0.95 \mathrm{wt} \%$ enriched uranium, the maximum possible $k_{\infty}$ is $0.98 . k_{\infty}$ can be reduced to 0.95 by adding iron until the iron/uranium mass ratio is 0.06 . Addition of 3 times this quantity of iron provides a mass ratio of 0.18 , and $k_{\infty}$ is reduced to about 0.85 (See Table 5-4).

For $1.25 \mathrm{wt} \%$ enriched uranium in a homogeneous solution $k_{\infty}$ can be reduced to 0.95 by adding iron at an iron/uranium mass ratio of 0.18 . When 3 times this quantity of iron is added to provide a mass ratio of $0.54, k_{\infty}$ wi 17 be about 0.85 . 
K Basin sludge wi1l be well characterized when it is sent to DST AW-105. However, the distribution of components in DST AW-105 sludge is less wel1 defined. Since the expected maximum neutron multiplication for DST AW-105 sludge is 0.05 , the neutron interaction is expected to have a negligible impact towards increasing neutron multiplication. However, the possibility must be considered that a pocket of higher plutonium concentration might exist for which the localized neutron multiplication might be higher than expected. It is necessary to maintain the neutron multiplication in $\mathrm{K}$ Basin sludge low enough to compensate for uncertainties.

Whyatt et a1. (1996) reports that an increase in fissile concentration of a factor of 3 is possible as a result of segregation of waste components according to differences in particle size and density.

Uncertainties in the analytical measurement of the plutonium content sometimes results in a reported plutonium/uranium mass ratio higher than expected. Since an upper limit on the plutonium/uranium mass ratio can be determined with high accuracy from knowledge of the irradiation history, the official plutonium content should be determined from the irradiation history. As irradiation time is increased, the content of plutonium increases, but at the same time the content of ${ }^{235} U$ decreases. Also, neutron absorbing fission products increase. During irradiation, the overall reactivity of the uranium decreases.

\subsection{DST AW-105 SLUDGE EVALUATION}

Characterization data is now used to describe sludge in DST AW-105, and information required for a criticality safety evaluation is summarized.

\subsubsection{Stratification}

Differences in particle size and density will cause differences in the rate at which particles settle. This difference in settling rates can result in particle segregation into layers according to size. Whyatt et a1. (1996) concluded that particles are flocculated under norma 7 tank conditions and this flocculent waste contains agglomerates in which the plutonium is tightly bound with other solids. This agglomeration counteracts any tendency of the plutonium to separate from other solids. Whyatt et a1. report using the Transient Energy Momentum and Pressure Equations in Three Dimensions (TEMPEST) code to model fiuid dynamics and to estimate the degree by which the plutonium concentration might increase upon settling. Their simulations indicated that the concentration increase should not exceed a factor of 2.5 .

Waste was discharged into DST AW-105 from PUREX as a large number of batches. Transfer records and a measurement of the total depth of sludge presently in this tank provide a means of modeling the plutonium concentration as a function of waste depth. Since a period of days elapsed between discharges, the solids of each batch had time to settle before the next batch was introduced. Even if particles containing plutonium settled at a different velocity. each plutonium-rich layer would be sandwiched between layers of neutron absorbing solids. The mass of plutonium in a layer is the same as in the discharge. If the plutonium concentration is high, then the thickness of the layer is smail. 
HNF-SD-WM-ES-409, Rev. 0

Vail (1997) examines the variation in plutonium concentration in sludge in DST 241-AZ-101 formed from discrete discharges of waste from PUREX. Each discharge formed a layer on top of the existing waste surface. The final waste configuration is one of stratification. Vail reaches the conclusion for DST AZ-101 that elevated plutonium concentrations as high as $2 \mathrm{~g} / \mathrm{L}$ might be possible, but only in layers less than one millimeter thick. Over a thicker slice of waste the average plutonium concentration will be considerably less. The largest concentration in DST AZ-101 averaged over a one-inch thick layer was found to be less than $0.35 \mathrm{~g} / \mathrm{L}$.

\subsubsection{PUREX Transfers Based upon Cadmium Presence}

Between January and Apri7 1995, 18 transfers of waste were made to DST AW-105 from PUREX using discharge Timits requiring the presence of cadmium to compensate for allowing an increase in the plutonium concentration. During these transfers the plutonium inventory increased by $5,613 \mathrm{~g}$ from $17,230 \mathrm{~g}$ to $22,843 \mathrm{~g}$. The increase in "plutonium inventory" was partly ${ }^{235} \mathrm{U}$. The average plutonium content was $311 \mathrm{~g}$, while the largest transfer contained $446 \mathrm{~g}$. The average plutonium concentration in these discharges was $0.018 \mathrm{~g} / \mathrm{L}$, and the highest value for a single transfer was $0.031 \mathrm{~g} / \mathrm{L}$.

The cadmium to fissile atom ratio in the solution varied between 2.6 and 11. This quantity of cadmium ensures subcriticality under all conditions, regardless of what other components are present in the solution. However, even if the presence of cadmium is ignored (ie., assumed not to remain with the enriched uranium), the content of uranium was sufficiently high to ensure subcriticality.

Inside of DST AW-105 each batch of this waste should have spread out into a layer. The ${ }^{235} \mathrm{U}$ and plutonium would be expected to remain with the ${ }^{238} \mathrm{~J}$ in their original proportions. Since this waste was transferred in 18 batches, each layer of enhanced fissile concentration would be sandwiched between layers containing higher concentrations of natural uranium and cadmium. Any movement of waste would remix these enriched layers with the intervening depleted layers. No scenarios can be postulated in which the ${ }^{235} \mathrm{U}$ and/or plutonium reaches a high enough concentration in a volume large enough and compact enough for criticality to occur.

These 18 transfers form the top layers in DST AW-105 and these layers contain the highest plutonium concentration anywhere in this tank. $K$ Basin sludge added to this tank wi11 form the next layer above this waste.

\subsubsection{Mass Ratios and Subcritical Fractions}

Using process records, Agnew (1995) determined the sum of the insoluble absorber actual-to-minimum subcritical fractions to be 18.6 and the sum of subcritical fractions for the soluble components to be 54.4 .

Whyatt et a1. (1996) conclude that zirconium is the most accurately known constituent in the waste stream sent to DST AW-105. Process records show there to be 7.0 times as much zirconium as is required to maintain subcriticality. In addition, there is 1.4 times as much iron as required to maintain subcriticality. However. the fractions obtained from the analysis of 
a core sample are found significantly smaller. Using one core sample, the mass fractions are 1.28 for zirconium, 0.78 for iron, and 0.46 for lanthanum.

Braun et al. (1994) reports data from eight waste samples taken from DST AW-105. The largest measured plutonium concentration is $0.024 \mathrm{~g} / \mathrm{L}$, and the areal density of plutonium is $61 \mathrm{~g} / \mathrm{m}^{2}$. a value 41.7 times less than the minimum required for criticality. The solids-to-plutonium mass ratio is estimated to be at least 50,000. The fraction of the actual-to-minimum subcritical mass ratio for this waste is estimated to be 64 . From eight samples the smallest sum of the fractions for the insoluble components was found to be only 0.50 , and the smallest sum of fractions for soluble components was 15.

\subsection{K BASIN SLUDGE EVALUATION}

A summary is provided of component/plutonium mass ratios for absorbers found in $\mathrm{K}$ Bas in sludge. Information is also provided on the quantity of absorbers which must be added to ensure that a specified $k_{\infty}$ wi 17 not be exceeded.

\subsubsection{Absorber/plutonium Mass Ratios}

Twenty sludge samples reported by welsh et al. (1996) are summarized in Section 4.1.2. These samples taken from the floor of the KE Basin and Weasel Pit showed a wide variation in the content of the various components, and the absorber content for several samples was less than required to assure an adequate margin of subcriticality. However. using the maximum inventory data the iron/uranium mass ratio for siudge on the basin floor is 1.22, in the Weasel/Tech View/Dummy Pits is 6.9. and in the North Loadout Area is 2.3 (see Table 5-1). When this sludge is combined, the average iron/uranium mass ratio is 1.7 . This quantity of iron will guarantee a $k_{\infty}$ less than 0.60 (see. Table 5-4), provided the sludge in these areas is homogenized. The margin of subcriticality is adequate, and no additional iron needs to be added to this sludge.

Pearce (1997) estimates component masses in sludge from all locations. The most important component in this sludge for ensuring subcriticality is iron. The average iron/ $\left({ }^{235} \mathrm{U}+\mathrm{Pu}\right)$ mass ratio for the KE Basin is shown in Table 5-1 to be 153. This mass ratio is too small to provide an adequate margin of subcriticality for all of the sludge. About two thirds of KE Basin sludge contains almost no iron. The sludge without sufficient neutron absorbers to guarantee an adequate margin of subcriticality is found in the canisters and in the Wash Area. 
Table 5-1. KE Basin Sludge Containing 0.95 wt\% Enriched Uranium (Based on Pearce (1997))

\begin{tabular}{|l|c|c|c|c|c|c|}
\hline Parameter & Basin Floor & Weasel Pit & N.Loadout & Canisters & Wash & Total \\
\hline \multicolumn{7}{|c|}{ Maximum Inventory (kg) } \\
\hline Iron & 13600 & 7670 & 109 & 2.5 & 3.7 & 21385 \\
\hline Uranium & 11100 & 1110 & 47.2 & 5643 & 8380 & 26281 \\
\hline Total ${ }^{235} \mathrm{U}$ & 105.4 & 10.5 & 0.5 & 53.6 & 79.6 & 249.7 \\
\hline $\begin{array}{l}\text { 235U in } \\
\text { Inventory }\end{array}$ & 25.5 & 2.5 & 0.1 & 13.0 & 21.6 & 60.4 \\
\hline Pu & 18.9 & 3.5 & 0.2 & 32.3 & 24.0 & 78.9 \\
\hline Inventory & 44.4 & 6.0 & 0.3 & 45.3 & 45.6 & 139.3 \\
\hline \multicolumn{7}{|c|}{ Missile Concentration Based on Inventory $(\mathrm{g} / \mathrm{L})$} \\
\hline 235U+Pu & 1.7 & 0.5 & 0.0 & 6.1 & 7.6 & 2.26 \\
\hline \multicolumn{7}{|c|}{ Mass Ratios for Iron } \\
\hline Iron/Uranium & 1.22 & 6.91 & 2.31 & 0.00 & 0.00 & 0.81 \\
\hline $\begin{array}{l}\left.\text { Fe/ }{ }^{235} \mathrm{U}+P u\right) \\
\text { Inventory }\end{array}$ & 306 & 1278 & 363 & 0.0 & 0.1 & 153 \\
\hline
\end{tabular}

Table 5-2. KW Basin Sludge Containing 1.25 wt\% Enriched Uranium (Based on Pearce (1997))

\begin{tabular}{|c|c|c|c|c|}
\hline Parameter & N.Loadout & Canisters & Wash & Total \\
\hline \multicolumn{5}{|c|}{ Maximum Inventory $(\mathrm{kg})$} \\
\hline Iron & 65.2 & 2.0 & 3.7 & 71.0 \\
\hline Uranium & 28.3 & 4560 & 8380 & 12968 \\
\hline $235 \mathrm{U}$, Total $\mathrm{kg}$ & 0.4 & 57.0 & 104.7 & 162.1 \\
\hline${ }^{235} \mathrm{U}$ in Inventory & 0.2 & 24.2 & 44.4 & 68.7 \\
\hline $\mathrm{Pu}$ & 0.1 & 13.9 & 25.5 & 39.5 \\
\hline Inventory & 0.3 & 38.1 & 69.9 & 108.2 \\
\hline \multicolumn{5}{|c|}{ Fissile Concentration Based on Inventory $(\mathrm{g} / \mathrm{L})$} \\
\hline${ }^{235} \mathrm{U}+$ Plutonium & 0.07 & 12.7 & 11.7 & 8.0 \\
\hline \multicolumn{5}{|c|}{ Mass Ratios for Iron } \\
\hline Iron/Uranium & 2.3 & 0.0 & 0.0 & 0.0 \\
\hline $\begin{array}{l}\text { Iron/ }\left({ }^{235} \mathrm{~J}+\mathrm{Pu}\right) \\
\text { Inventory }\end{array}$ & 217 & 0.05 & 0.05 & 0.65 \\
\hline
\end{tabular}


The average iron/ $\left({ }^{235} \mathrm{U}+\mathrm{Pu}\right)$ mass ratio for sludge from the $\mathrm{KW}$ Basin is shown in Table 5-2 to be only 0.65. Nearly all KW Basin sludge is composed almost entirely of uranium and is not combined with any significant quantity of iron. Only a small fraction of the uranium is combined with a high mass ratio of iron.

Because a large fraction of the sludge is composed almost entirely of uranium, the assurance of subcriticality is dependent upon the addition of iron. No credit can be taken for the iron already present because of its highiy non-uniform distribution. Even if all of the sludge were to be mixed and made homogeneous, its iron content would be less than required to ensure an adequate margin of subcriticality.

\subsubsection{Neutron Absorbing Solids Addition}

Subcriticality can be assured by mixing solids with the sludge provided: (1) the solids are sufficient to provide adequate neutron absorption: (2) the solids and sludge are uniformly mixed: and (3) there are no processes capable of separating the solids from the uranium. Although any solid material fulfilling these conditions can ensure subcriticality, only four are considered: depleted uranium, iron, boron, and soil.

\subsubsection{Depleted Uranium}

Clayton and Brown (1995) state that the minimum critical ${ }^{235} \mathrm{U}$ enrichment for $\mathrm{UO}_{3}$ in a water solution is $1.030 \pm 0.010 \mathrm{wt} \%$. Extrapolating their data shows that when the ${ }^{235} \mathrm{U}$ enrichment is $0.88 \mathrm{wt} \%$. or less. $\mathrm{k}_{\mathrm{o}}$ for $\mathrm{UO}_{3}$ in water solution can not exceed 0.95 . Based upon calculations for uranium metal using computer code WIMS-E, a conservative enrichment of 0.84 wt $\%$ is obtained. For this discussion the more conservative value will be used. In reality. finely divided uranium, and especially uranium in solution. would be expected to be oxidized, and the higher enrichment value would apply.

Addition of depleted uranium to reduce the uranium enrichment below 0.84 wt\% provides a high level of assurance of subcriticality. There are no chemical or physical processes in the tank waste storage environment capable of separating the ${ }^{238} \mathrm{U}$ from the ${ }^{235} \mathrm{U}$. However, it is important that the depleted uranium be well mixed (blended) with the enriched uranium. No other neutron absorbing solids are needed to ensure that $k_{\infty}$ will not exceed 0.95 . In addition, this enrichment provides a very high level of assurance that no heterogeneous configurations can be constructed for which criticality would be possible.

The highest ${ }^{235} \mathrm{U}$ enrichment in $\mathrm{K}$ Basin sludge is $1.25 \mathrm{wt} \%$. Table $5-3$ shows the quantity of depleted uranium which must be blended with both 0.95 $w t \%$ and $1.25 w t \%$ enriched uranium to reduce the enrichment to $0.84 \mathrm{wt} \%$. 
Table 5-3. Depleted Uranium Required to Reduce Uranium Enrichment to $0.84 w t \%$

\begin{tabular}{|c|c|c|}
\hline $\begin{array}{c}{ }^{235} \mathrm{U} \text { Content in } \\
\left.\text { DepTeted Uranium (wt\% }{ }^{235} \mathrm{U}\right)\end{array}$ & $\begin{array}{c}\text { Mass Ratio to Reduce } \\
0.95 \text { wt\% to } 0.84 \text { wt\% }\end{array}$ & $\begin{array}{c}\text { Mass Ratio to Reduce } \\
1.25 \text { wt\% to } 0.84 \text { wt\% }\end{array}$ \\
\hline 0.20 & 0.145 & 0.540 \\
\hline 0.30 & 0.203 & 0.756 \\
\hline 0.40 & 0.250 & 0.932 \\
\hline 0.50 & 0.323 & 1.20 \\
\hline 0.60 & 0.458 & 1.71 \\
\hline 0.72 (natura1) & 0.916 & 3.41 \\
\hline
\end{tabular}

\subsubsection{Iron}

Iron is a good material to add to sludge because it tends to remain associated with the uranium. When in solution with uranium, iron wi 77 coprecipitate with the uranium. The purpose of adding iron is to ensure that the neutron multiplication remains acceptably low by preventing the uranium and plutonium from segregating into regions of high concentration.

Calculations of the quantity of iron which must be combined with enriched uranium to ensure a specified $k_{\text {on }}$ are summarized in Table 5-4. For 1.25 wt\% enriched uranium criticality can not occur. when the iron/uranium mass ratio exceeds 0.12 .

Table 5-4. Iron Needed to Ensure a Limiting $k_{\infty}$ in Homogeneous Uranium Oxide with Optimal Moderation

(Data from Appendix C)

\begin{tabular}{|c|c|c|c|c|c|}
\hline Fissile Content & $\begin{array}{l}k_{\infty}= \\
1.00\end{array}$ & $\begin{array}{l}k_{\infty}= \\
0.90\end{array}$ & $\begin{array}{l}k_{\infty}= \\
0.80\end{array}$ & $\begin{array}{l}k_{\infty}= \\
0.70\end{array}$ & $\begin{array}{l}k_{\infty}= \\
0.60\end{array}$ \\
\hline \multicolumn{6}{|c|}{$\mathrm{Fe} /(\mathrm{Pu}+\mathrm{U})$ atom ratio } \\
\hline $0.95 w t \%{ }^{235} U$ & 0.0 & 0.5 & 1.0 & 2.1 & 3.0 \\
\hline 1.25 wt\% $235 \mathrm{U}$ & 0.5 & 1.0 & 2.0 & 3.0 & 4.5 \\
\hline $\begin{array}{l}0.53 \text { wt\% }{ }^{239} \mathrm{Pu} \\
0.72 \text { wt\% }{ }^{235} \mathrm{U}\end{array}$ & 1.1 & 2.0 & 3.5 & 5.0 & 7.0 \\
\hline \multicolumn{6}{|c|}{$\mathrm{Fe} /(\mathrm{Pu}+\mathrm{U})$ Mass Ratio } \\
\hline 0.95 wt\% ${ }^{235} \mathrm{U}$ & 0.0 & 0.12 & 0.23 & 0.49 & 0.70 \\
\hline 1.25 wt\% ${ }^{235} \mathrm{U}$ & 0.12 & 0.23 & 0.47 & 0.70 & 1.05 \\
\hline $\begin{array}{l}0.53 \text { wt\% }{ }^{239} \mathrm{Pu} \\
0.72 \text { wt\% }{ }^{235} \mathrm{U}\end{array}$ & 0.26 & 0.47 & 0.82 & 1.17 & 1.64 \\
\hline
\end{tabular}


To ensure a maximum $k_{\infty}$ of 0.95 requires an iron/uranium mass ratio of 0.06 and 0.18 for $0.95 \mathrm{wt} \%$ and $1.25 \mathrm{wt} \%$ enriched uranium, respectively. Three times this ratio is 0.18 and 0.54 for 0.95 wt\% and 1.25 wt\% enriched uranium. respectively. When $0.54 \mathrm{wt} \%$ iron is uniformly mixed with $1.25 \mathrm{wt} \%$ enriched uranium, $k_{\infty}$ will not exceed 0.80 . However, when 0.18 wt\% iron is uniformly mixed with 0.95 wt\% enriched uranium. $k_{\infty}$ can be as high as 0.85 .

During irradiation plutonium is produced. A conservative assumption which bounds plutonium production is to assume that the plutonium produced is equal to the ${ }^{235} \mathrm{U}$ burned. An upper limit on reactivity is found by assuming that a $17{ }^{235} \mathrm{U}$ above $0.72 \mathrm{wt} \%$ is replaced by plutonium. When this assumption is made, the iron/heavy metal mass ratio to ensure $k_{\infty}$ of 0.95 is 0.36 . Three times this mass ratio is 1.08 . Heavy metal refers to the sum of the uranium and plutonium. The iron/heavy metal mass ratio of 0.54 required for 1.25 wt\% enriched uranium will ensure that $k_{\infty}$ will not exceed 0.88 , if this more conservative assumption for plutonium is used.

An important chemistry question is whether the iror can be added as finely divided particles or whether it is necessary to dissolve the uranium and plutonium and coprecipitate them with the iron.

\subsubsection{Boron in Solution}

Boron is a very effective neutron absorber. Natural boron composed of $20 \mathrm{wt} \%{ }^{10} \mathrm{~B}$ and $80 \mathrm{wt} \%{ }^{11_{\mathrm{B}}}$ is assumed in this discussion.

Calculations of the quantity of natural boron which must be combined with enriched uranium to ensure a specified $k_{\infty}$ are summarized in Table 5-5. For 1.25 wt\% enriched uranium criticality can not occur when the iron/uranium mass ratio exceeds 0.00014 . When the mass ratio exceeds $0.00045, k_{\infty}$ will not exceed 0.70 , and when the mass ratio exceeds $0.00077, k_{\infty}$ wi 17 not exceed 0.60 . maintain these values of $k_{\infty}$ is reduced by $35 \%$.

Table 5-5. Natural Boron Needed to Ensure a Limiting $k_{\infty}$ in Homogeneous Uranium Oxide with Optimal Moderation

(Data from Appendix $C$ )

\begin{tabular}{|c|c|c|c|c|c|}
\hline Fissile Content & $\begin{array}{l}k_{\infty}= \\
1.00\end{array}$ & $\begin{array}{l}\mathrm{k}_{\infty}= \\
0.90\end{array}$ & $\begin{array}{l}\mathrm{k}_{\infty}= \\
0.80\end{array}$ & $\begin{array}{l}k_{\infty}= \\
0.70\end{array}$ & $\begin{array}{l}k_{\infty}= \\
0.60\end{array}$ \\
\hline \multicolumn{6}{|c|}{$\mathrm{B} /(\mathrm{Pu}+\mathrm{U})$ atom ratio } \\
\hline 0.95 wt\% ${ }^{235} \mathrm{U}$ & 0.0 & 0.002 & 0.004 & 0.006 & 0.011 \\
\hline $1.25 w t \%{ }^{235} \mathrm{U}$ & 0.003 & 0.005 & 0.007 & 0.010 & 0.017 \\
\hline $\begin{array}{l}0.53 \text { wt\% }{ }^{239} \mathrm{Pu} \\
0.72 \text { wt\% }{ }^{235} \mathrm{U}\end{array}$ & 0.004 & 0.008 & 0.011 & 0.019 & 0.030 \\
\hline \multicolumn{6}{|c|}{$\mathrm{B} /(\mathrm{Pu}+\mathrm{U})$ Mass Ratio } \\
\hline $0.95 w t \%$ 235 & $\overline{0.0}$ & 0.00009 & 0.00018 & 0.00027 & 0.00050 \\
\hline $1.25 w t \%{ }^{235} \mathrm{U}$ & 0.00014 & 0.00023 & 0.00032 & 0.00045 & 0.00077 \\
\hline $\begin{array}{l}0.53 \text { wt\% }{ }^{239} \mathrm{Pu} \\
0.72 \text { wt\% }{ }^{235} \mathrm{U}\end{array}$ & 0.00018 & 0.00036 & 0.00050 & 0.00086 & 0.00136 \\
\hline
\end{tabular}


An upper limit on reactivity is found by assuming that al1 ${ }^{235} \mathrm{U}$ above 0.72 wt\% is replaced by plutonium. When this assumption is made, the boron/heavy metal mass ratio to ensure a $k_{\infty}$ of 0.60 is 0.00136 .

A difficulty in using boron is the need to provide assurance that boron is present throughout the sludge in sufficient quantity to ensure subcriticality. The quantity of boron added needs to be considerably greater than required to maintain subcriticality in a homogeneous system to compensate for changes that might occur. A detailed study of the solubility of boron and of its tendency to precipitate or otherwise remain associated with other chemical constituents in tank waste and $\mathrm{K}$ Basin sludge is required. This study would determine whether the boron would distribute homogeneously in the supernatant liquid or preferentially precipitate with certain sludge components that might be physically separable from the fissile isotopes.

\subsubsection{Boron in Rods}

If boron were to be used as a fixed poison, the most acceptable form would be rods or parallel slabs. Although rods are discussed, the separation distances for parallel slabs would be expected to be only a little larger.

The size of the region over which a borated rod is effective at influencing the neutron multiplication is roughly equal to the diffusion length for a neutron. In water the diffusion length is $2.7 \mathrm{~cm}$, while in graphite, which has one of the largest values, it is $54 \mathrm{~cm}$. In very dry waste the diffusion length should not exceed $15 \mathrm{~cm}$. For poison rods to be effective they would have to be placed in a lattice with a separation on the order of $15 \mathrm{~cm}$, or less. Poison rods farther than $30 \mathrm{~cm}$ (1 ft) apart would not significantly reduce the neutron multiplication.

Calculations by Schwinkendorf in Appendix $C$ to determine the distance over which poison rods are effective are summarized in Table 5-6. For 1.25 wt\% uranium with an optimized water content rods must be placed less than 12 $\mathrm{cm}$ edge-to-edge apart to ensure that $k_{\infty}$ is less than 0.90 . To ensure a $k_{\infty}$ of 0.70 the separation must be less than $8 \mathrm{~cm}$. This applies to borated rods with diameters up to $7.5 \mathrm{~cm}(3.0$ in.).

In conclusion, a large number of poison rods, spaced less than $20 \mathrm{~cm}$ apart. center-to-center, would be required to ensure subcriticality. These rods would have to be fixed rigidly in place and would most likely hinder future processing or removal activities. Use of poison rods does not appear to be a viable option for ensuring subcriticality. 
Table 5-6. Separation of Borated Stainless Steel Rods in Uranium and Water Solution ${ }^{\mathrm{s}}$

(Data from Appendix C)

\begin{tabular}{|c|c|c|c|c|c|}
\hline \multirow{2}{*}{$\begin{array}{c}\text { Rod Diameter } \\
\mathrm{Cm}\end{array}$} & \multicolumn{5}{|c|}{ Separation, center/center $(\mathrm{cm})$} \\
\cline { 2 - 6 } & $\begin{array}{c}\mathrm{k}_{\infty}= \\
1.0\end{array}$ & $\begin{array}{c}\mathrm{k}_{\infty}= \\
0.9\end{array}$ & $\begin{array}{c}\mathrm{k}_{\infty}= \\
0.8\end{array}$ & $\begin{array}{c}\mathrm{k}_{\infty}= \\
0.7\end{array}$ & $\begin{array}{c}\mathrm{k}_{\infty}= \\
0.6\end{array}$ \\
\hline 2.5 & 17 & 10 & 7.5 & 6.8 & 6.3 \\
\hline 5.0 & 22 & 15 & 12 & 10 & 8 \\
\hline 7.5 & 30 & 19 & 17 & 15 & 12 \\
\hline
\end{tabular}

$w t \%{ }^{235} \mathrm{U}$. $\mathrm{H} / \mathrm{U}$ atom ratio set at 5 to maximize $k_{\infty}$.

\subsubsection{Soil}

Soil is easy and cheap to obtain. In addition, it is possible to postulate accident conditions in which soil might be combined with sludge. Silicon dioxide, a major component of sandy soil, has an extremely low neutron absorption cross section. With a minimum critical plutonium concentration as low as $1 \mathrm{~g} / \mathrm{L}$ (Sanchez et a]. 1996), silicon dioxide sand is one of the most conservative forms of soil which might be used.

Although the minimum critical plutonium concentration is reduced in silicon dioxide, the mass of plutonium required for criticality is increased. In fact, the minimum critical mass in silicon dioxide is about $40 \mathrm{~kg}$ plutonium, as compared to $0.52 \mathrm{~kg}$ plutonium in water.

Calculations of the mass ratio of silicon dioxide which must be combined with enriched uranium to ensure a specified $k_{\infty}$ are summarized in Table 5-7. For 1.25 wt\% enriched uranium criticality can not occur when the silicon dioxide/uranium mass ratio exceeds 1.3 . When the mass ratio exceeds $1.9, k_{\infty}$ wi 11 not exceed 0.95 , and when the mass ratio exceeds 5.0 , $k_{\infty}$ will not exceed 0.80 . For a ${ }^{235} U$ enrichment of 0.95 , the quantity of silicon dioxide required to maintain these values of $k_{\infty}$ is reduced by about half. 
Table 5-7. Silicon Dioxide Needed to Ensure a Limiting $k_{\infty}$ in Homogeneous Uranium Oxide with Optimal Moderation

(Data from Appendix C)

\begin{tabular}{|c|c|c|c|c|c|}
\hline Fissile Content & $\begin{array}{l}\mathrm{k}_{\infty}= \\
1.00\end{array}$ & $\begin{array}{l}k_{\infty}= \\
0.90\end{array}$ & $\begin{array}{l}k_{\infty}= \\
0.80\end{array}$ & $\begin{array}{l}k_{\infty}= \\
0.70\end{array}$ & $\begin{array}{l}k_{\infty}= \\
0.60\end{array}$ \\
\hline \multicolumn{6}{|c|}{$\mathrm{SiO}_{2} /(\mathrm{Pu}+\mathrm{U})$ atom ratio } \\
\hline $0.95 w t \%{ }^{235} \mathrm{U}$ & 0.0 & 4 & 10 & 20 & 35 \\
\hline $1.25 w t \%{ }^{235} U$ & 5 & 10 & 20 & 40 & 50 \\
\hline $\begin{array}{l}0.53 \text { wt\% }{ }^{239} \mathrm{Pu} \\
0.72 \text { wt } \%{ }^{235} \mathrm{U}\end{array}$ & 10 & 20 & 40 & 60 & 88 \\
\hline \multicolumn{6}{|c|}{$\mathrm{SiO}_{2} /(\mathrm{Pu}+\mathrm{U})$ Mass Ratio } \\
\hline $0.95 w t \%{ }^{235} \mathrm{U}$ & 0.0 & 1.0 & 2.5 & 5.0 & 8.8 \\
\hline $1.25 w t \%{ }^{235} \mathrm{U}$ & 1.3 & 2.5 & 5.0 & 10.1 & 12.6 \\
\hline $\begin{array}{l}0.53 \text { wt\% }{ }^{239} \mathrm{Pu} \\
0.72 \text { wt\% }{ }^{235} \mathrm{U}\end{array}$ & 2.5 & 5.0 & 10.1 & 15.1 & 22.2 \\
\hline
\end{tabular}

\subsubsection{Uniformity of K Basin Sludge Composition}

Mixing $K$ Basin sludge thoroughly would remove spatial variation in composition and would reduce regions of low absorber content. However, it would be difficult to mix the entire volume together homogeneously. To ensure criticality safety in DST AW-105, it is necessary to ensure each transport container load has an adequate margin of subcriticality. This can be accomplished by adding enough iron to each transport container to meet the required limit. Iron should be added as sludge is pumped into the container to facilitate mixing.

For highly fluid sludge, the process of transfer into DST AW-105 wi 17 have a strong tendency to mitigate variations in transport container contents. The contents of each container when emptied will spread out into a layer within the storage tank. Normally this layer would be thin. Variations in sludge composition would translate into variations within thin layers in DST AW-105. If formed into a uniform layer over the entire area of a storage tank, the total volume of $\mathrm{K}$ Basin sludge would form a layer less than $20 \mathrm{~cm}$ (7.9 in.) thick.

\subsection{COMBINING K BASIN AND TANK AW-105 SLUDGE} evaluated.

The interaction of $K$ Basin sludge with DST AW-105 sludge must be

\section{4:1 Supernatant Liquid}

Whyatt et al (1996) conclude that the plutonium in tank waste primarily resides in the solid phase. The solubility of plutonium in tank supernatant 7 iquid is low enough that saturation concentrations are at least 30 times 
HNF-SD-WM-ES-409, Rev. 0

lower than the values needed to support criticality. For this reason, criticality in the supernatant liquid is not credible.

\subsubsection{Contribution of KW Sludge}

Uranium in KW Basin sludge is more highly enriched than uranium in KE Basin sludge, and the fraction of absorbers in KW Basin sludge is lower. For these reasons. KW Basin sludge is capable of greater neutron multiplication. Sludge in DST AW-105 has a Tower fissile concentration and a larger absorber fraction than does either KE or KW Basin sludge. When these siudges are combined, the margin of subcriticality is determined primarily by $\mathrm{KW}$ Basin sludge.

\subsubsection{Pockets of Higher Plutonium Concentration}

Since there is no evidence for pockets of high fissile concentration in DST AW-105, the neutron multiplication for combined sludge, either mixed or unmixed, will not exceed that of $\mathrm{KW}$ Basin sludge alone.

However, if it is assumed that a small volume with high plutonium concentration exists in DST AW-105 and this is surrounded by $K$ Basin sludge. the resulting $k_{\text {ff }}$ could increase significantly, unless $K$ Basin sludge also has low neutron multiplication $\left(k_{\text {eff }}\right)$. Uncertainties in the composition of DST AW105 sludge makes it impossible to define the highest $k_{\text {eff }}$ possible for the combined sludge. For this reason, $K$ Basin sludge must be assured of having a low neutron multiplication.

\subsubsection{Interaction with Contents of DST AW-105}

Chemical compatibility of the $K$ Basin sludge with the existing contents of DST AW-105 need only be addressed in so far as it causes concern for criticality safety. For this evaluation, it is assumed that the evaluation of chemistry documented by Serne et al. (1996) and by Whyatt et al. (1996) will apply to DST AW-105, both before and after the transfer of $K$ Basin sludge.

DST AW-105 contains 729,550 L of sludge from the PUREX zircalloy decladding waste stream. This is 68.8 v07\% of the total sludge volume. Subcritical fractions reported by whyatt et a1.., based on process records, are shown in Table 4-4. The sum of subcritical fractions for iron, zirconium, and uranium is 10.1 , as compared to 2.6. based on analysis of core samples.

Agnew (1995) calculated the sum of the absorber actual-to-minimum subcritical fractions to be 18.6 for insoluble components and 54.4 for soluble components. Braun et al. (1994) estimates the solids/plutonium mass ratio to be 50,000 , and the fraction of the actual-to-minimum subcritical fraction to be at least 64 . This value, which includes both soluble and insoluble components, is in good agreement with Agnew's value. For several samples Braun et ai. reports the sum of subcritical fractions for the insoluble components to be less than unity. This sample showed a sum of insoluble subcritical fractions of 0.50 . The smallest subcritical fractions found for soluble components was 15 . The sum of these two values is smaller (more conservative) than the sum shown above derived from the total mass of solids. 
The largest plutonium concentration reported by Braun et al. was $0.024 \mathrm{~g} / \mathrm{L}$, a value 20 times higher than indicated by the process records. For this evaluation, the larger value of $0.024 \mathrm{~g} / \mathrm{L}$ wi 11 be assumed to apply to all sludge in DST AW-105. Assuming this higher plutonium concentration, the plutonium areal density is $61 \mathrm{~g} / \mathrm{m}^{2}$, a value 41.7 times smaller than the minimum required for criticality.

DST AW-105 sludge has a larger ratio of absorbers, both soluble and insoluble, than does either KE or KW Basin sludge. Sludge from the KW Basin contains uranium of a higher enrichment and also contains a lower fraction of absorbers than KE Basin sludge. For this reason, the KW Basin sludge determines the margin of subcriticality when the sludges are combined. The highest achievable neutron multiplication (i.e., with optimized moderation and geometry) for the combined sludge will not be any greater than that of $\mathrm{KW}$ Basin sludge before transfer. If the sludges are mixed, the combined sludge wi 71 contain a larger fraction of absorbers than KW Basin siudge and the neutron multiplication will be less than for unmixed KW Basin sludge. The characteristics of the combined sludge and the associated chemistry should be very much the same as that of each of the individual sludge types. Mixing the sludge should not reduce the margin of subcriticality.

\subsection{MECHANISMS WHICH INCREASE CONCENTRATION}

For criticality to occur. the plutonium concentration must exceed $2.6 \mathrm{~g} / \mathrm{L}$. the minimum concentration for which criticality is possible. To achieve such a high concentration, mechanisms capable of greatly increasing the plutonium concentration must be operating.

\subsubsection{Settling of Suspended Uranium}

The most obvious, and also perhaps the most effective, mechanism for concentrating uranium and/or plutonium is settling. Solids content and particle size distribution are the primary limiters of concentration by settling. If uranium particles settle faster than other waste particles, this would lead to the formation of layers containing an elevated concentration of uranium.

The fissile areal density is the total mass of fissile material above a unit of floor area. Criticality is not possible unless the plutonium equivalent areal density exceeds $240 \mathrm{~g} / \mathrm{ft}^{2}\left(2.582 \mathrm{~g} / \mathrm{m}^{2}\right)$. This areal density over the area of a storage tank would require more than $1,000 \mathrm{~kg}$ of plutonium.

\subsubsection{Removing Liquid}

Evaporation and pumping can remove liquid from waste. As liquid is removed the solids wi7l consolidate and their density will increase. However, the solids/plutonium mass ratio will remain unchanged. If this mass ratio exceeds the minimum subcritical value. subcriticality will be assured, no matter how dry the waste becomes. 
HNF-SD-WM-ES-409, Rev. 0

\subsubsection{Chemical Separation of Components}

A chemical process capable of concentrating uranium (or plutonium) can be postulated: the uranium (or plutonium) would first be dissolved and then precipitated. For dissolution to occur, followed by precipitation, the chemical environment of the tank must change. Dissolution requires a change from high alkalinity (i.e., present tank conditions) to high acidity, and precipitation requires the reverse. These changes can only be possible when wastes of considerably different compositions are mixed. This would require a major deviation from normal operating procedures.

If chemicals were to dissolve and remove neutron-absorbing components, there are several natural controls preventing criticality. First, the low plutonium areal density would preclude criticality even if all absorbers were removed. Second, the variety of chemicals that compose waste would mitigate the impact of removing a specific absorber. Components removed chemically would tend to be remixed with the waste.

\subsubsection{Mixing}

When small particles are mixed, the concentration of each component in waste tends to become closer to an average value. The overall waste mixture becomes increasingly uniform in composition as the mixing continues. When particles of varying size and density are mixed, however, they are capable of settling into layers of similarly sized (or dense) particles. This segregation process is described in more detail for natural geologic processes and ore benefaction processes by Serne et a1. (1996). They also address segregation in tank operations such as sluicing, mixing, and salt well pumping.

\subsubsection{Conditions that Prevent Plutonium Accumulation}

There are several conditions that tend to prevent the accumulation of plutonium in a sma11. compact volume. First. alkaline conditions limit the mass of plutonium and uranium that can be found in solution (dissolution). Second. the bulk of the plutonium and uranium would be present as precipitates amongst a large mass of other metal hydrous oxide particulates that are neutron absorbers. These other materials would be capable of mixing with the fissile components during any mechanical disturbance which might lead to segregation. Third, once the brief periodic transfers of new waste are complete there are no physical forces disturbing the sludge and causing particle segregation or forcing precipitates of a particular type to a localized portion of the waste. The transfer of small volumes of waste slurry into the tank is not expected to cause major mixing of the existing sludge. especially that near the bottom under the weight of the overlying material. 
HNF-SD-WM-ES-409, Rev. 0

\subsection{CHEMISTRY}

Chemical processes capable of changing the uranium or plutonium concentration in K Basin and DST AW- 105 sludges are of concern to criticality safety. Chemical processes may be capable of either increasing or inhibiting the segregation of uranium and plutonium.

In alkaline waste. plutonium solubility is low and the plutonium is bound within the solids. Waste sent to tank storage is maintained alkaline to ensure that the plutonium remains combined with the solids. The upper limit of the concentration of dissolved plutonium in liquid waste should not exceed $0.017 \mathrm{~g} / \mathrm{L}$ (Hobbs et a1. 1993)

The origin of $k$ Basin sludge is different from that of waste already in tank storage. This sludge is not the product of operations in a separations plant in which the uranium and plutonium has been precipitated, after having first been dissolved. K Basin sludge contains particles of enriched uranium metal, and the chemistry associated with it is not as described in the earlier studies. When K Basin and DST AW-105 sludges are combined, the chemistry of both plutonium and uranium must be examined. The possible chemical changes that might occur upon mixing $\mathrm{K}$ Basin sludge with DST AW-105 sludge are discussed in Appendix A.

\subsubsection{Plutonium Chemistry}

Evaluations of plutonium chemistry as it concerns tank waste is documented by Bratzel et al. (1996). Tank Farm Nuclear Criticality Review, by Serne et a1., Fluid Dynamics, Particulate Segregation, Chemical Processes, Natura 7 Ore Analog and Tank Inventory Discussions that Relate to the Potential for Criticality in Hanford Tanks. and by Whyatt et al. (1996). The Potential for Criticality in Hanford Tanks Resulting from Retrieval of Tank Waste. These documents provide a comprehensive review of the chemistry of waste produced by the plants which extracted plutonium from the waste. A17 waste sent to tank farms in the past was the product of processes in which the uranium and plutonium was first dissolved and then precipitated.

Bratzel et al. (1996) identify three potential chemical mechanisms which cause plutonium to enter the sludge:

- Sorption onto precipitated hydrated metal oxide sludge particles

- Precipitation as pure plutonium oxide crystals

- Formation of solid-solid solutions with non-neutron absorbers such as $\operatorname{Zr}(\mathrm{IV})$.

Bratzel et a1. conclude that "no physical or chemical phenomena or mechanism has been identified that could concentrate fissile material at sufficient quantities or concentrations to result in an accidental nuclear criticality." 
HNF-SD-WM-ES-409, Rev. 0

\subsubsection{Uranium Chemistry}

The uranium in fuel elements is in the form of metal. When uranium metal comes into contact with water, it readily oxidizes into uranium oxide. The oxidation process occurs on the surface of the metal where the oxidized metal sloughs off and falls into the basin water. This process reduces the size of uranium metal particles and increases the fraction of particles of micron size. Two important questions to be answered by a chemistry study are: what is the rate of transformation of the uranium metal particles to micron size uranium oxide particles and to what degree is this process completed over time.

\subsubsection{Particles Size Restrictions}

Particle size is of interest to criticality safety for two reasons: smaller particles exhibit a larger minimum critical mass and larger particles can lead to stratification during settling. On the average, particle size for $K$ Basin sludge is several times larger than in tank sludge, and the largest particles are orders of magnitude larger. Tank waste was generated from chemical processes that dissolved metals in a nitric acid solution and reprecipitated them with sodium hydroxide. This resulted in a precipitate of very small particles.

A maximum particle dimension of $0.13 \mathrm{~cm}(0.05 \mathrm{in}$.) is adequately small to ensure that mixtures and solutions containing $0.947 \mathrm{wt} \%$ enriched uranium can not be made critical, even with optimal moderation. A small size, however, does not ensure subcriticality for 1.25 wt\% enriched uranium.

The ability to concentrate particles during agitation and/or mixing is related to particle size and density. When dense particles are suspended through mixing or pumping, the larger particles wi 11 more rapidly settle and might therefore form a layer of higher uranium concentration. The question of how smal1 particles must be to provide assurance that separation wi1l not occur is discussed in Appendix A.

\subsection{4 pH}

Criticality safety requires that waste sent to tank storage be alkaline with a minimum $\mathrm{pH}$ of 8 . A higher $\mathrm{pH}$ maly be required for other reasons, such as corrosion control. 
HNF-SD-WM-ES-409, Rev. 0

\subsection{OPTION 2: DISPOSAL IN DST AW-105 WITH ISOLATION}

Disposal Option 2 is to combine $K$ Basin sludge with the contents of DST AW-105 with restriction of further use for waste acceptance and storage until final retrieval for other waste storage.

The requirements for Disposal Option 2 are identical to those of Disposal Option 1. Even if no new waste is added, the question of interaction with sludge already stored in DST AW-105 must be addressed. 


\subsection{OPTION 3: DEDICATED TANK}

Disposal Option 3 is the construction of one or more tanks which comply with the Resource Conservation and Recovery Act of 1976 (RCRA) for interims storage of the sludge prior to vitrification. These tanks would be used exclusively for storage of $K$ Basin sludge.

\subsection{ACCEPTABLE MARGIN OF SAFETY}

Limits for discharge into a tank dedicated to storage of $K$ Basin sludge are similar to those for discharge into a tank containing tank waste. The difference is that for this option there is no interaction with other wastes.

A revision of CPS limits is proposed to permit discharges of $K$ Basin sludge based on the following criteria:

(1) The quantity of neutron absorbing solids well mixed with the uranium must be at least enough to ensure that $k_{\infty}$ will not exceed 0.95 with optimal moderation and full reflection. after taking into account uranium segregation through gravity settling and chemical processes.

(2) The enrichment (before irradiation) for a 11 uranium in a batch is assumed to be either 0.95 wt: or $1.25 \mathrm{wt} \%$ according to the following:

(a) When a batch contains no uranium enriched to more than $0.95 \mathrm{wt} \%{ }^{235} \mathrm{U}$ (before irradiation). then all uranium is assumed to have been enriched to $0.95 \mathrm{wt} \%{ }^{235 \mathrm{U}}$ (before irradiation).

(b) When a batch contains uranium enriched above $0.95 \mathrm{wt} \%{ }^{235} \mathrm{U}$ (before irradiation), then a 11 uranium is assumed to have been enriched to $1.25 \mathrm{wt} \%{ }^{235} \mathrm{U}$ (before irradiation).

(3) The plutonium must not occur in greater proportion to the uranium than when discharged from the reactor. In other words, no separated plutonium is permitted in K Basin sludge.

(4) When depleted uranium is added to a batch of enriched uranium to lower the average ${ }^{235} \mathrm{U}$ enrichment:

a. The proportion of plutonium to uranium must not exceed that in the uranium to which it is added.

b. The combined uranium shall be mixed (blended) to ensure a uni form enrichment.

c. The stated enrichment of blended uranium shall be increased by an amount which compensates for uncertainties in ${ }^{235} \mathrm{U}$ 
content of the uraniums which were blended and in possible variations in enrichment.

(5) Particle size for both uranium and other solids must not exceed 50 microns.

\subsection{OPTION 3A: LIMIT ${ }^{235} \mathrm{U}$ ENRICHMENT}

For a homogeneous mixture of uranium in water a maximum $k_{\infty}$ of 0.95 can be assured by limiting the ${ }^{235} \mathrm{U}$ enrichment in the uranium to $0.84 \mathrm{wt} \%$ (maximum). Homogeneity requires that the particle size to be less than $0.13-\mathrm{cm}(0.05-\mathrm{in}$.) diameter.

When reducing the ${ }^{235} \mathrm{U}$ enrichment to $0.84 \mathrm{wt} \%$, uniform mixing of depleted uranium with the enriched uranium is required. No other neutron absorbing solids need be added.

\subsection{OPTION 3B: NEUTRON ABSORBING SOLIDS ADDITION}

Subcriticality can be assured by mixing solids with the sludge provided the quantity is sufficient, the solids and sludge are uniformly mixed, and there are no processes capable of separating solids from the uranium. Four solid materials are considered in this study as candidates for addition: depleted uranium, iron, boron, and soil. The discussion in Section 5.3.2 concerning the addition of neutron absorbing solids to $K$ Basin sludge applies here.

\subsubsection{Depleted Uranium}

Table $5-3$ shows the quantity of depleted uranium which must be blended with 0.95 wt\% and 1.25 wt\% enriched uranium to reduce the enrichment to 0.84 wt\%. See Section 5.3.2.1.

\subsubsection{Iron}

Assurance of subcriticality can be obtained by adding iron to each transport container load in proportion to the uranium present, but independent of the iron and other components already present. Calculations for iron combined with 1.25 wt\% enriched uranium show that criticality can not occur when the iron/uranium atom ratio exceeds 0.5 (See Appendix $C$ ). See Section 5.3.2.2 for additional information.

\subsubsection{Boron}

Natural boron composed of $20 \mathrm{wt} \%{ }^{10} \mathrm{~B}$ and $80 \mathrm{wt} \%{ }^{11} \mathrm{~B}$ is a very effective neutron absorber. Boron would be added in solution form. The boron would have to maintain subcriticality in a homogeneous system after taking into account processes which might remove boron. Use of poison rods is not a viable option. See Section 5.3.2.3 and 5.3.2.4 for additional information. 


\subsubsection{Soi1}

Soil is easy to obtain and cheap. Silicon dioxide, a major component of sandy soil, is the most conservative form of soil. Although the minimum critical plutonium concentration is reduced in silicon dioxide, the mass of plutonium required for criticality is increased. Other soil components present would increase the margin of safety. See Section 5.3.2.5 for additional information.

\subsection{CHEMISTRY REQUIREMENTS}

A chemistry study will be required with about the same level of detail as a study required for sending the sludge to DST AW-105. The primary question is whether the uranium can be separated from other components. Segregation of uranium is prevented by limiting the maximum particle size to 10 micron or to a larger. size justified by a study of the physical and chemical characteristics of particle segregation. Segregation of uranium must be prevented in any tank that does not use dimension or batch control to preclude criticality. 
HNF-SD-WM-ES-409, Rev. 0

\subsection{OPTION 4: DEDICATED CRITICALLY SAFE TANK}

Disposal Option 4 is the construction of a new critically safe tank which complies with the Resource Conservation and Recovery Act of 1976 (RCRA) for interims storage of the sludge prior to vitrification. This tank would be used exclusively for storage of $K$ Basin sludge.

\subsection{ACCEPTABLE MARGIN OF SAFETY}

A revision of the CPS is needed to permit storage in tanks based upon the following criteria.

(1) The controlled dimension shall be governed by one of the following (Nuclear Criticality Safety Manua 7, FDH 1996):

(a) The thickness for a siab tank or the diameter for a cylindrical tank shall not exceed their minimum critical value multiplied by 0.90 ;

or

(b) $k_{\text {eff }}$ shall not exceed 0.97 for a slab tank or 0.98 for a cylindrical tank.

(2) Guarantees must be provided that the dimension limit can not be exceeded.

(3) Unless particle size is limited to 50 microns, critical parameters for an optimized lattice (heterogeneous values) shall be used.

\subsection{SLAB THICKNESS CONTROL}

A slab tank may be used to store $K$ Basin sludge without requiring any processing of the waste. The controlled dimension will be limited to 0.90 times its minimum critical value. No climensions have been calculated for a $k_{\infty}$ of 0.97 .

\subsubsection{Option 4A: Slab Tank}

Safe limit slab thicknesses are obtained by multiplying the critical thickness in Table 3-2 by 0.90 . With no control on the size of particles, it is acceptable to store a $11 \mathrm{~K}$ Basin sludge in a slab tank of $30.0 \mathrm{~cm}$ (11.8 in.) maximum thickness. With particle size limited to a maximum of $0.13 \mathrm{~cm}$ $(0.05$ in.) diameter, it is acceptable to use a $43.9 \mathrm{~cm}(17.3$ in.) thick slab tank. These values are slightly smaller than the thicknesses for which $k_{\infty}$ is equal to 0.98 .

A larger slab thickness may be used for 0.95 wt\% enriched uranium stored separately. With no control on the size of particles, it is acceptable 
HNF-SD-WM-ES-409, Rev. 0

to store 0.95 wt\% enriched uranium in a slab tank of $43.2 \mathrm{~cm}(17.0 \mathrm{in}$. maximum thickness.

A homiogeneous mixture of 0.95 wt\% enriched uranium can not be made critical, and the safe limit is undefined when determined in this fashion. For this reason the safe thickness is obtained by multiplying the subcritical 7 imit by 0.90 . This results in a safe slab thickness of $126 \mathrm{~cm}(49.8 \mathrm{in}$.) With particle size limited to a maximurn of $0.13 \mathrm{~cm}(0.05$ in.) diameter, it is acceptable to use an 126-cm (49.8-in.) thick slab tank. Assurances must be provided that no uranium enriched above $0.95 \mathrm{wt} \%$ is combined with this uranium.

\subsubsection{Option 4B: Parallel Slab Tanks}

A compact storage system can be constructed using parallel slab tanks separated by walls of concrete. The walls would have to be thick enough to neutronically isolate the tank from each other. For concrete a $2 \mathrm{ft}$ thickness would be acceptable, and a smaller thickness could be used if supported by calculations.

\subsubsection{Option 4C: Depth Control}

A standard design. non-critically safe tank could be used to store sludge by limiting the depth of sludge to a critically safe depth. The depth must be limited to no more than the thickness of a slab tank. This would be an administrative limit requiring verification of compliance. Assurance would have to be provided that the sludge will not form mounds which exceed the required slab height. The criticality safety evaluation would have to consider whether an earthquake would be able to reconfigure the sludge into a critical configuration (See Section 8.4).

\subsection{CYLINDER DIAMETER CONTROL}

A cylindrical tank may be used to store $K$ Basin sludge without requiring any processing of the waste.

\subsubsection{Option 4D: Cylindrical Tanks}

When the uranium is maintained within a cylinder with a diameter less than the subcritical limit (defined by $k_{\infty}$ equal to 0.98 ). criticality is not possible. For $1.25 \mathrm{wt} \%$ and $0.95 \mathrm{wt} \%$ enriched uranium pieces the subcritical limit on cylinder diameter is $48.3 \mathrm{~cm}(19.0 \mathrm{in}$.) and $69.9 \mathrm{~cm}(27.5 \mathrm{in}$.$) .$ respectively.

As a homogeneous mixture, the subcritical limit on cylinder diameter for $1.25 \mathrm{wt} \%$ enriched uranium is $65.5 \mathrm{~cm}$ (25.8 in.). The subcritical limit cylinder diameter for a homogeneous mixture of $0.95 \mathrm{wt} \%$ enriched uranium is $222.8 \mathrm{~cm}(87.7$ in.).

A cylindrical tank would be constructed so as to maintain a guaranteed diameter. The orientation of the tank can be horizontal or vertical. In order to have a capacity capable of holding all of the sludge, the tota? length would have to be long. If particle size is less than $0.13 \mathrm{~cm}$, the 
required length is significantly reduced. A reduction in the total length of cylinder required could be achieved by storing 0.95 wt\% uranium in cylinders of larger diameter.

\subsection{EARTHQUAKE}

The consequences of an earthquake must be evaluated. If a limit is placed on sludge depth, an earthquake might tilt the tank and change the geometry of the sludge from a slab of uniform thickness to a wedge having greater thickness at one end. The maximum credible tilt of the tank would determine whether criticality would be credible. If the sludge is mixed with solid material which limits the concentration of the uranium and provides neutron absorption, concerns associated with an earthquake might be mitigated. The proportion of solids must be great enough to preclude criticality if reconfigured, shaken for a period of time, and flooded.

Reconfiguration, shaking, and flooding are accident conditions limited by the frequency and magnitude of earthquakes. Shaking might cause segregation of solid absorbers from the uranium through gravity separation. However, an earthquake is a low probability event and the duration of the shaking would be limited. For the degree of particle segregation should be more Timited than assumed for mixing operations. If justification were provided for a limited degree of segregation, siab storage could be permitted with a larger particle size.

The possibility must be considered of a leak which drains liquid from the sludge. Criticality must not be possible as a result of loss of liquid. 


\subsection{OPTION 5: SMALL TANKS WITH MASS CONTROL}

Disposal Option 5 is construction of smali tanks for the exclusive storage of $\mathrm{K}$ Basin sludge. The contents of each tank would be limited to a critically safe quantity. The only restriction placed on a receiver tank would be to limit the total mass of uranium permitted.

\subsection{ACCEPTABLE MARGIN OF SAFETY}

A batch limit is defined as one-half of the subcritical mass limit. The subcritical mass limit is the largest mass for which $k_{\text {eff }}$ does not exceed 0.98 . Subcritical limits values are provided in Table 3-1.

\subsection{BATCH LIMITS}

For $0.95 \mathrm{wt} \%$ enriched uranium pieces, the batch limit is $975 \mathrm{~kg}$ uranium $\left(9.2 \mathrm{~kg}{ }^{235} \mathrm{U}\right)$. For $1.25 \mathrm{wt} \%$ enriched uranium, the subcritical mass limit is about $266 \mathrm{~kg}$ uranium $\left(3.3 \mathrm{~kg}{ }^{235} \mathrm{U}\right)$. A batch 1 imit may be used without requiring processing of sludge and without addition of iron oxide. Assurances must be provided that the batch limit can not be exceeded.

Criticality is precluded for $0.95 \mathrm{wt} \%$ uranium in the form of particles with dimension (diameter) less than $0.13 \mathrm{~cm}(0.05 \mathrm{in.}$ ). Nevertheless, a batch limit of $33,230 \mathrm{~kg}$ is defined, based on the subcritical limit. For $1.25 \mathrm{wt} \%$ enriched uranium the batch size is $682 \mathrm{~kg}$ when particles are smaller than 0.13 $\mathrm{cm}$ diameter.

The maximum estimated uranium mass in KE Basin sludge is $26,281 \mathrm{~kg}$ of 0.95 wt\% enrichment. No uranium in the KE Basin has an enrichment greater than $0.95 \mathrm{wt} \%$. As pieces with no restriction on particle size, this represents 27 batches. When particle size is restricted to less than $0.13 \mathrm{~cm}$ diameter, this entire mass can be placed in a single batch.

The maximum estimated uranium mass in KW Basin sludge is $12,969 \mathrm{~kg}$ of $1.25 \mathrm{wt} \%$ enrichment. As pieces with no restriction on particle size this represents 49 batches. When particle size is restricted to less than $0.13 \mathrm{~cm}$ diameter, the number of batches can be reduced to 19 .

The total number of batches required to store sludge from both basins is 76 batches for uranium as pieces. When particle size is restricted to less than $0.13 \mathrm{~cm}$ diameter, the number of batches can be reduced to 20 .

\subsection{ONE TANK WITH COMPARTMENTS}

Instead of individual tanks, an alternative would be to use a large tank with compartments. Each compartment would be limited to one safe batch of $K$ Basin sludge. Walls between compartments would guarantee that the individual batches remain separated by a fixed distance, estimated to be at least $1 \mathrm{ft}$ if concrete and $2 \mathrm{ft}$ if air. If this option is adopted. calculations would be required to confirm the actual spacing to be acceptable. 


\subsection{REFERENCES}

Agnew, S. F., 1995, Hanford Defined Wastes: Chemical and Radionuclide Compositions, LA-UR-94-2657, Rev. 2, Los Alamos National Laboratory, Los Alamos. New Mexico.

Bratzel, D. R., W. W. Schulz, R. Vornehm, and A. E. Waltar, 1996. Tank Farm Nuclear Criticality Review, WHC-SD-WM-TI-725, Westinghouse Hanford Company, Richland, Washington.

Braun, D. J., L. D. Muhlestein. T. B. Powers, and M. D. Zentner, 1994. High-Level Waste Tank Subcriticality Safety Assessment. WHC-SD-WM-SARR-003. Rev. 0. Westinghouse Hanford Company, Richland, Washington.

Carter, R. D., G.R. Kiel, and K. R. Ridgway. 1969, Criticality Handbook, ARH-600, Vol. II, Atlantic Richfield Hanford Company, Richland, 7 Washington.

Clayton, E. D., and C. L. Brown, 1965. Criticality and Nuclear Safety of Slightly Enriched Uranium. Chemical Enqineering Progress. Symposium Series, Vol. 61. No.60, pp. 33-43.

Erickson. D. G., 1997. CSER 97-003: Analysis of the Criticality Safety of the 100K East Basin Wease7 Pit, HNF-SD-NR-CSER-008 Rev 2, Fluor Daniel Northwest, Richland. Washington.

Hanton, B. M., 1996. Waste Tank Summary Report for Month Ending June 30. 1996. WHC-EP-0182-89. Westinghouse Hanford Company, Richland. Washington.

Higley, B. A., 1997. Compatibility of J Basin S7udge with TWRS Treatment and Disposa 7 Particle Size Criteria. Attachment 1. Correspondence No. 9750522 , H. L. Boston to F. G. Hudson, Lockheed Martin Hanford Corporation. Richland, Washington.

Hobbs, D. T., T. B. Edwards, and S. D. Fleischman. 1993, Solubility of Plutonium and Uranium in A7kaline Salt Solutions (U). WSRC-TR-93-056. Savannah River Technology Center. Westinghouse Savannah River Company. Aiken. South Carolina.

FDH, 1996, Nuclear Criticality Safety Manua7, HNF-CM-4-29. Fluor Daniel Hanford Company, Richland, Washington.

Makenas, B. J., 1996. Analysis of S7udge from Hanford K East Floor and Wease 7 Pit. WHC-SP-1182. Westinghouse Hanford Company, Richland. Washington

Meichie. R. H, 1996, K Basins Safety Analysis Report. WHC-SD-WM-SAR-062, Rev. 3, Westinghouse Hanford Company, Richland, Washington.

Pearce. K. L., 1997, K Basins S7udge Inventories to be Used in S7udge 
Disposa7 Evaluations, DESH-9752731, Duke Engineering and Services Hanford, Inc., Richland, Washington.

Rogers, C. A., 1993, CSER 92-009: An Analytical Model for Evaluating Subcritical Limits for Waste in Hanford Site Storage Tanks.

WHC-SD-SQA-CSA-20356. Rev. 0. Westinghouse Hanford Company, Richland, Washington.

Rogers, C. A., K. N. Schwinkendorf, and H. Harris, 1996. Criticality Parameters for Tank Waste Evaluation. WHC-SD-SQA-CSA-507, Westinghouse Hanford Company, Richland. Washington.

Sanchez, Rene, Williams Myers, David Hayes, Robert Kimpland, Peter Jaegers, Richard Paternoster. Stephen Rojas, Richard Anderson, and Wi Tliam Stratton, 1996, Criticality Characteristics of Mixtures of Plutonium. Silicon Dioxide, Nevada Tuff, and Water. LA-UR-96-3738, Los Alamos National Laboratory. Los Alamos. New Mexico.

Serne, R. J.. G. A. Whyatt, S. V. Mattigod, Y. Onishi, P. M. Doctor, B. N. Bjornstad, M. R. Powel1, L. M. Liljegren, J. H. Westsik, Jr., N. J. Aimo, K. P. Recknagle, G. R. Golcar, T. B. Miley, G. R. Holdren, D. W. Jeppson. R. K. Biyani, and G. S. Barney, 1996. Fluid Dynamics, Particulate Segregation. Chemical Processes, Natural Ore Analog and Tank Inventory Discussions that Relate to the Potential for Criticality in Hanford Tanks, WHC-SD-WM-TI-757. Rev. 0, Westinghouse Hanford Company, Richland, Washington.

Schwinkendorf, K. N., 1995, Criticality Safety Evaluation for 300 Area N Reactor Fuel Fabrication and Storage Facility, WHC-SD-NR-CSER-010. Rev. 1, Westinghouse Hanford Company, Richland, Washington.

Schwinkendorf, K. N., 1997a. Criticality Safety Evaluation for Spent Nuclear Fuel Processing and Storage Facilities. HNF-SD-SNF-CSER-005. Rev. 3, Fluor Daniel Northwest, Richland, Washington.

Toffer. H. . 1976, Nuclear Criticality Safety Analysis and Technical Basis For the Storage of N Reactor Fuels in K Reactor Basins - 1900 Ton Capacity, UNI-283 ADD1, United Nuclear Industries, Inc., Richland, Washington.

We1sh, T. L., R. B. Baker, D. R. Hansen, G. R. Golcar, and B. J. Makenas, 1996. Analysis of Sludge from Hanford K East Basin Floor and Weasej Pit. WHC-SP-1182, Westinghouse Hanford Company, Richland, Washington.

Wittekind, W. D., and K. N. Schwinkendorf, 1993, MCNP Ca7culations of K-Infinity for $100 \mathrm{KE}$ Basin S7udge Samples. WHC-SD-NR-CSER-008 Rev 1. Westinghouse Hanford Company, Richland. Washington.

Whyatt, G. A., R. J. Serne, S. V. Mattigod, Y. Onishi, M. R. Powel1, J. H. Westsik, Jr., L. M. Liljegren, G. R. Golcar. K. P. Recknagle, P. M. Doctor, V. G. Zhirnov, J. Dixon, D. W. Jeppson, and G. S. Barney, 1996. The Potential for Criticality in Hanford Tanks Resulting from Retrieval of Tank Waste, PNNL-11.304, Pacific Northwest National Laboratory, Richland, Washington. 
HNF-SD-WM-ES-409, Rev. 0

\section{APPENDIX C}

PARAMETRIC CALCULATIONS OF REACTIVITY REDUCTION WITH ADDITION OF VARIOUS NEUTRON ABSORBERS 
HNF-SD-WM-ES-409, Rev. 0

This page intentionally left blank 


\subsection{INTRODUCTION}

The uranium metal scrap now in K Basin sludge will be processed until the piece size is less than that which is required to ensure that absorbers added to the system will not separate from the fissile material. Fluid dynamics simulation using the TEMPEST code shows that a particle size of less than 10-20 microns is sufficient to prevent fissile material/absorber segregation. Particles of this size are sufficiently small that neutronics calculations may assume a homogeneous solution. This appendix contains the results of a number of parametric calculations which show the reactivity effects of adding a number of different absorbers. These calculations can be divided into two parts. In the first part, three different absorber materials were added to fissile solutions, and the water content was adjusted to find the maximum reactive hydrogen-to-heavy metal atom ratio. Comparison to previous calculations show that if the dissolved fissile solid had been uranium metail instead of uranium oxide, reactivity could have been up to $10 \mathrm{mk}$ higher. One set of calculations also addressed the slight increase in reactivity seen when the uranium is in the form of 0.25 -inch outer diameter (OD) uranium metal rods. In the second set of calculations, the added neutron absorber was in the form of rods.

\subsection{SUMMARY OF FIGURES}

This appendix contains 17 figures. The first three figures show families of curves for the addition of iron to a homogeneous fissile water solution. The first figure is for 1.25 wt\% ${ }^{235} \mathrm{U}$ enriched uranium. The second figure is for $0.95 \mathrm{wt} \%{ }^{235} \mathrm{U}$. The third figure is a hypothetical. bounding conservative model for uranium and plutonium. The uranium component is natural (i.e. . the ${ }^{235} U$ content is $0.72 \mathrm{wt} \%$ ). The plutonium content was set to $0.53 \mathrm{wt} \%$ in heavy metal to bring the total fissile mass fraction up to the 1.25 wt\% enriched case. This results in a more reactive system than 1.25 wt\% enriched solutions, and it is known that exposed. Jow-enriched uranium fuel is less reactive than is unexposed fuel. The fourth figure collects the maxima from the first three figures and plots them as a function of the iron-to-heavy metal atom ratio.

Figures $\mathrm{C}-5$ through $\mathrm{C}-8$ repeat Figures $\mathrm{C}-1$ through $\mathrm{C}-4$, but for the addition of naturat boron as the absorber material. Figures $\mathrm{C}-9$ through $\mathrm{C}-12$ repeat this same sequence again, but for the addition of $\mathrm{SiO}_{2}$, which is intended to represent sandy soit. Figure $\mathrm{C}-13$ illustrates the 0.25 -inch uranium metal rod results.

Figures $\mathrm{C}-14$ and $\mathrm{C}-15$ show result:s for the addition of 1 wt\% natural boron in stainless steel rods of various diameters. The abscissa in Figure C14 is the volume ratio, and it is the center-to-center spacing in Figure C-15. These figures compare using very smal1 rods versus larger rods. Figures C-16 and $\mathrm{C}-17$ show the comparison between using the larger rods of Figures $\mathrm{C}-14$ and C-15 with annular absorber "tubes" with the same outer dimensions as the rods. The larger solid rods are less effective compared to tubes (on a per unit mass or volume basis) because of self-shielding. The abscissa in Figure $\mathrm{C}-16$ is the volume ratio, and the abscissa in Figure $\mathrm{C}-17$ is the spacing. 


\subsection{RESULTS}

\subsection{Homogeneous Neutron Absorbers}

Calculations were performed for homogeneous mixtures of uranium, iron. and water. Both $0.95 \mathrm{wt} \%$ and $1.25 \mathrm{wt} \%{ }^{235} \mathrm{U}$, and various atom ratios of iron to uranium (Fe/U), were analyzed $(0.0,0.5,1.0,2.0,4.0,10.0$, and 20.0$)$. For each combination, the hydrogen-to-uranium atomic ratio (H/U) was varied to find the maximum $k_{\infty}$. These calculations were also performed for the mixed oxide (U.PU) $\mathrm{O}_{2}$ system. The ${ }^{235} \mathrm{U}$ content in $\mathrm{U}$ was $0.72 \mathrm{wt} \%$ and the $\mathrm{Pu} /(\mathrm{U}+\mathrm{Pu})$ fraction was $0.53 \mathrm{wt} \%$. The notation $\mathrm{H} / \mathrm{M}$ and $\mathrm{Fe} / \mathrm{M}$ is used to denote the hydrogen-to-heavy metal and iron-to-heavy metal atom ratios, where $M$ is the total heavy metal (i.e., $M=U+P u$ ).

These calculations were performed using the WIMS-E lattice transport computer code (Gubbins 1982). For blending. the following formulae were used. The basis for weight fractions is one rnole of heavy metal oxide. For a given $H / M$ ratio (and for a given Fe/M ratio), the weight fraction of iron is:

$$
f_{F e}=\frac{55.847\left(\frac{F e}{M}\right)}{M_{M}+2(15.9994)+55.847\left(\frac{F e}{M}\right)+\frac{1}{2}\left(\frac{H}{M}\right) M_{H_{2} O}}
$$

where: $M_{M}=$ average heavy metal atomic mass

$M_{\mathrm{H}_{2} \mathrm{O}}=$ molecular weight of water

The numerical value 55.847 in Equation (C.1) is the atomic mass of iron. and when a different neutron absorber is added (such as boron or $\mathrm{SiO}_{2}$ ), the appropriate atomic or molecular masses must be used. The atomic mass of oxygen is 15.9994 .

The metal oxide weight fraction is:

$$
f_{M O_{2}}=\frac{M_{M}+2(15.9994)}{M_{M}+2(15.9994)+55.847\left(\frac{F e}{M}\right)+\frac{1}{2}\left(\frac{H}{M}\right) M_{H_{2} O}}
$$

The average heavy metal atomic mass is calculated from:

$$
M_{M}=\left[\sum_{i=1}^{n} \frac{f_{i}}{M_{i}}\right]^{-1}
$$

where: $f_{i}=$ weight fraction for species $i$

$$
M_{i}=\text { atomic mass for species } i
$$

The mixture density is: 
HNF-SD-WM-ES-409, Rev. 0

$$
\bar{\rho}=\left[\frac{f_{M O_{2}}}{10.96}+\left(1-f_{M O_{2}}-f_{F e}\right)+\frac{f_{F e}}{7.86}\right]^{-1}
$$

where: $f_{\mathrm{MO}_{2}}=$ mass fraction of heavy metal oxide

$f_{F e}=$ mass fraction of iron

The numerical values 10.96 and 7.86 in Equation (C.4) are the solid densities of the heavy metal oxide and of iron, respectively. For natural boron and $\mathrm{SiO}_{2}$ addition, the appropriate densities were used, 2.34 for boron and 2.33 for $\mathrm{SiO}_{2}$.

These blending equations were programed into an input generator program that created the input files for WIMS-E. The results are shown in Figures $\mathrm{C}-1$ through $\mathrm{C}-4$. Figures $\mathrm{C}-1$ through $\mathrm{C}-3$ show $\mathrm{K}_{\infty}$ as a function of $\mathrm{H} / \mathrm{M}$ for 1.25 wt\% enriched ${ }^{235} \mathrm{U}, 0.95 \mathrm{wt} \%$ enriched uranium, and for the mixed oxide system. respectively. Figure $\mathrm{C}-4$ plots the maximum $\mathrm{k}_{\infty}$ values from Figures $\mathrm{C}-1$ through $\mathrm{C}-3$ as a function of $\mathrm{Fe} / \mathrm{M}$ for each system. Exposed production reactor fuel (i.e., that which contains plutonium) is less reactive than unexposed fuel (Schwinkendorf 1997). The assumption of Pu/M $=0.53$ wt\% and ${ }^{235} U$ content in uranium equal to 0.72 wt\% is known from burnup calculations as well as measurements to be conservative.

Figures $\mathrm{C}-5$ through $\mathrm{C}-8$ i1lustrate the same homogeneous configurations as Figures $C-1$ through $C-4$, but the iron is replaced by natura? boron.

Figures $\mathrm{C}-9$ through $\mathrm{C}-12$ show these results for the addition of $\mathrm{SiO}_{2}$. which is intended to simulate soil. The amount of absorber added varied depending upon the type of absorber. Far less boron was added than was iron, and yet, as expected, the reactivity suppression was still greater. Silicon dioxide does not significantly suppress reactivity unless large quantities are added. 
Figure $\mathrm{C}-1 . \quad \mathrm{k}_{\infty}$ vs. H/U Atom Ratio.

Iron Added to 1.25 wt: $235 \mathrm{U}$ Uranium Oxide Solution.

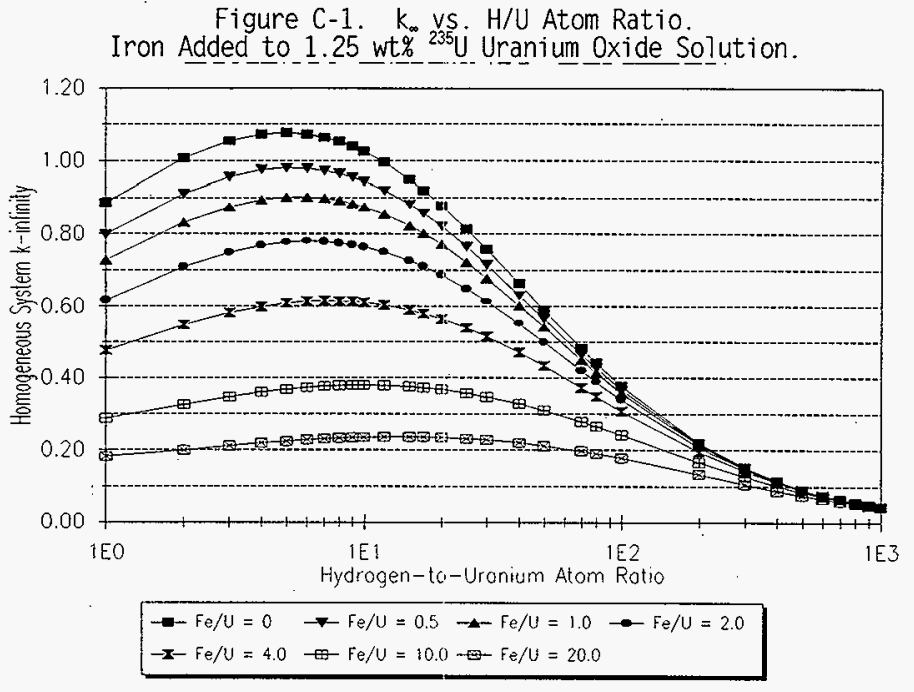

Fig

ure

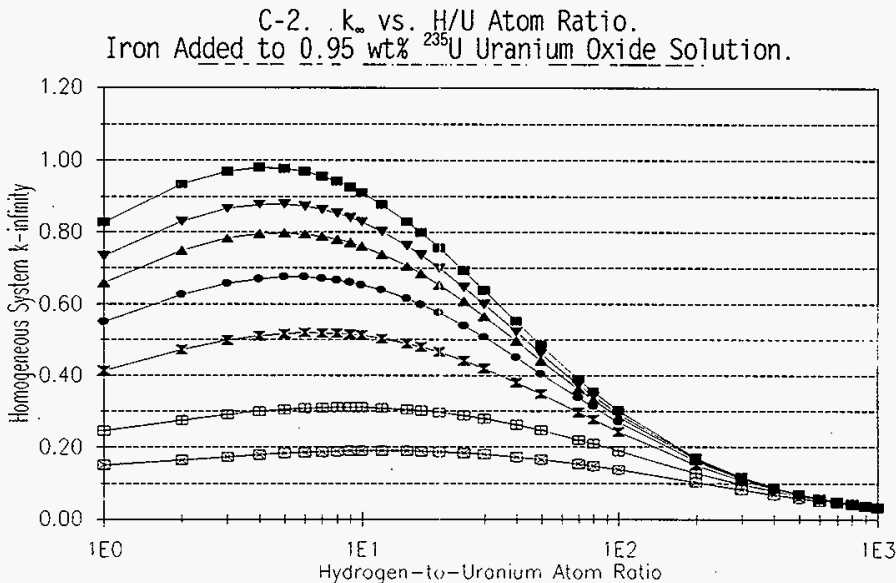

Fig

ure

$\rightarrow \mathrm{Fe} / \mathrm{U}=0 \rightarrow \mathrm{Fe} / \mathrm{U}=0.5 \rightarrow \mathrm{Fe} / \mathrm{U}=1.0 \rightarrow \mathrm{Fe} / \mathrm{U}=2.0$
$\rightarrow \mathrm{Fe} / \mathrm{U}=4.0 \rightarrow \mathrm{Fe} / \mathrm{U}=10.0 \rightarrow \mathrm{Fe} / \mathrm{U}=20.0$

C-

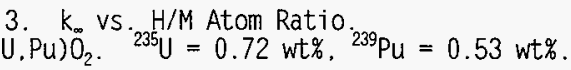




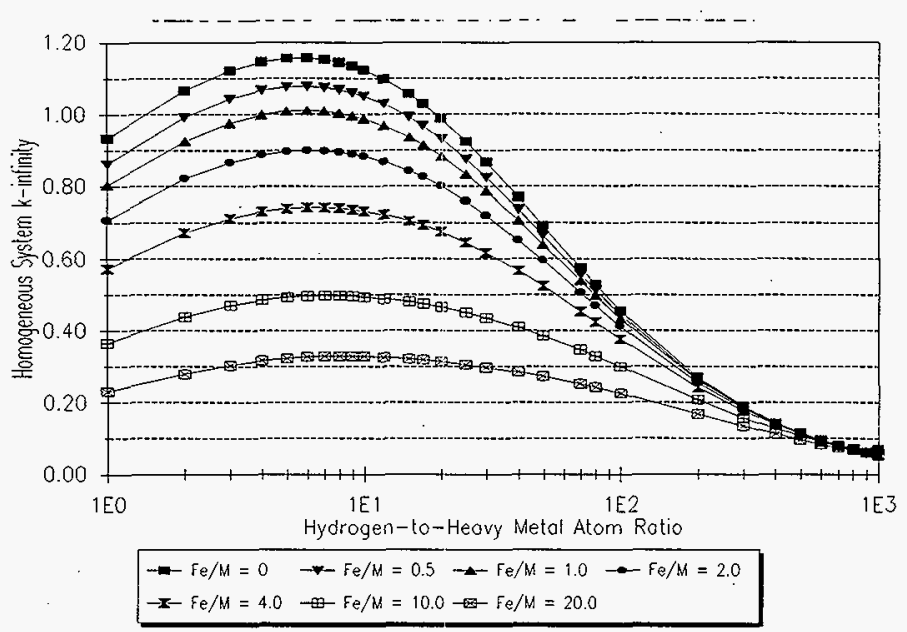

Fig

ure

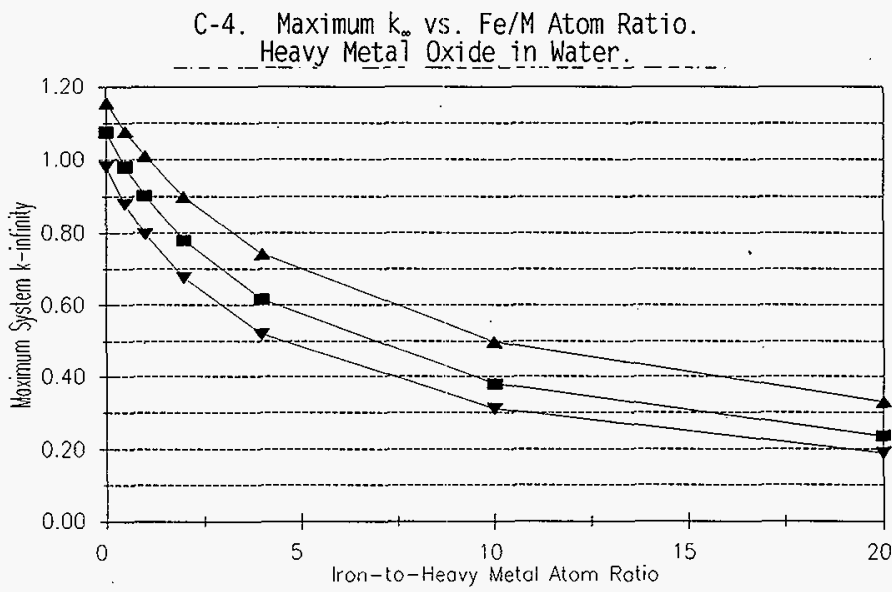

ure C-

5. $k_{\infty}$ vs. H/U Atom Ratio.

Natural Boron Added to 1.25 wt\% ${ }^{235}$ U Uranium Oxide Solution. 
HNF-SD-WM-ES-409, Rev. 0

Fig

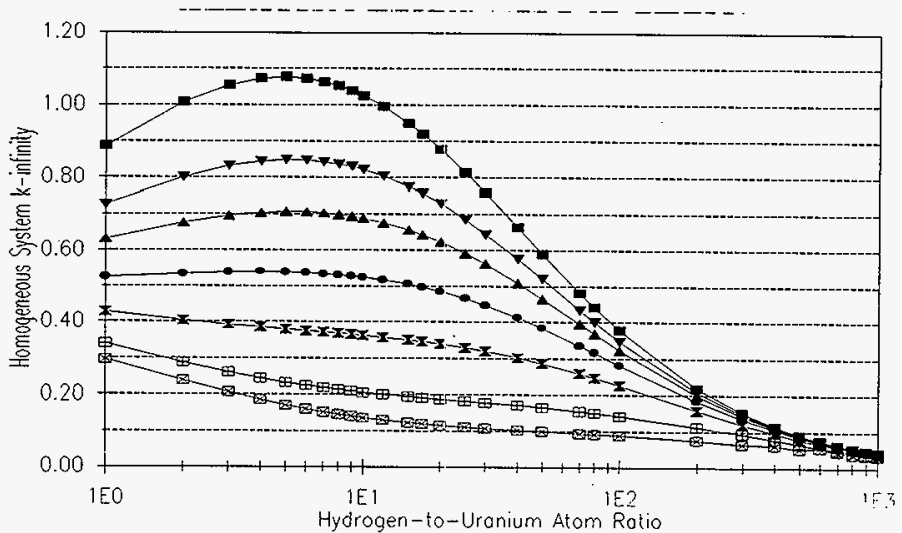

Hyorogen-to-Uranium Atom Ratio

$$
\begin{aligned}
& \rightarrow-B / U=0 \rightarrow B / U=0.005-B / U=0.01 \rightarrow B / U=0.02 \\
& \rightarrow-B / U=0.04 \rightarrow B / U=0.1 \rightarrow B / U=0.2
\end{aligned}
$$

ure

C-6. $\mathrm{K}_{\infty}$ VS. H/U Atom Ratio.

Natural Boron Added to 0.95 wt\% ${ }^{235} \mathrm{U}$ Uranium Oxide Solution.

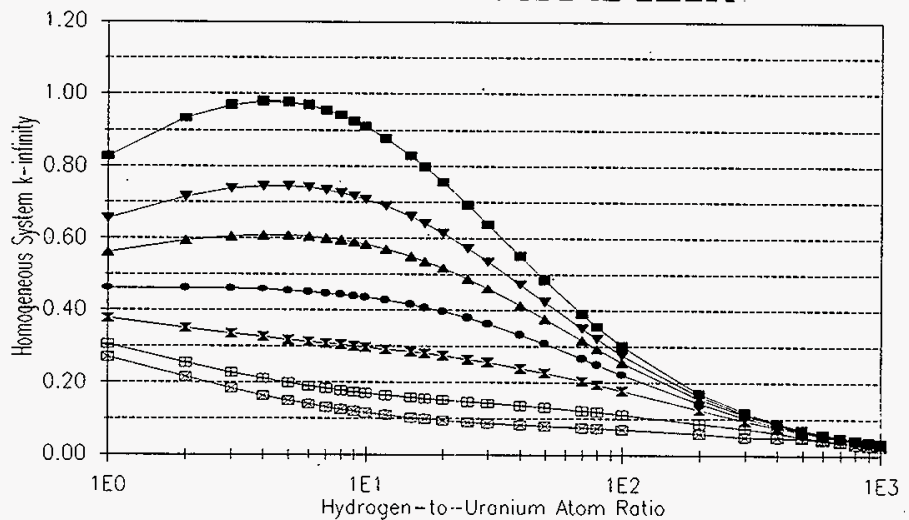

Fig

Etom Rotio

Fig $\quad \begin{aligned} & \rightarrow-B / U=0 \quad \rightarrow B / U=0.005-B / U=0.01 \rightarrow-B / U=0.02 \\ & -B / U=0.04 \rightarrow B / U=0.1 \rightarrow-B / U=0.2\end{aligned}$

C-

7. $K_{\infty}$ vs. H/M Atom Ratio.

Natural Boron Added to (U, $\mathrm{Pu}) \mathrm{O}_{2} .{ }^{235} \mathrm{U}=0.72$ wt\%. ${ }^{239} \mathrm{Pu}=0.53$ wt\%. 
HNF-SD-WM-ES-409, Rev. 0

Fig

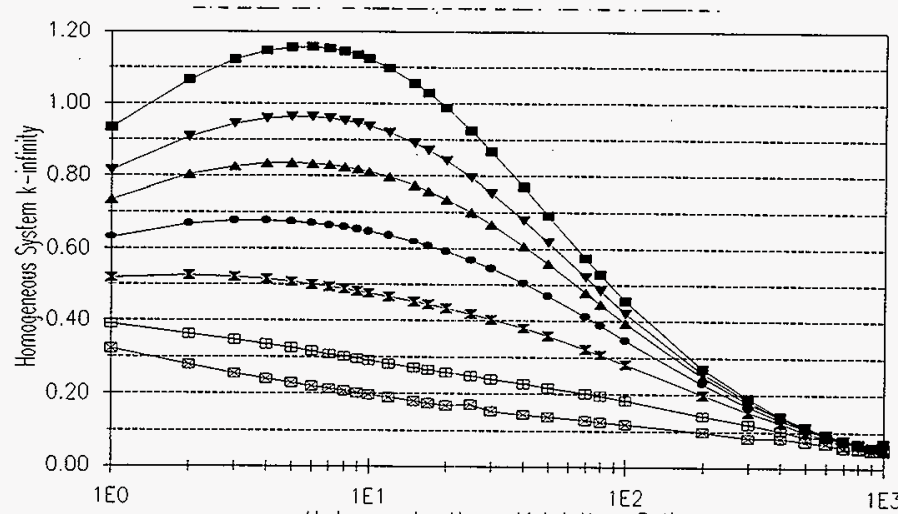

Hydrogen-to-Heovy Metol Atom Rotio

$\rightarrow B / M=0 \quad-W-B / M=0.005-B / M=0.01 \quad \rightarrow B / M=0.02$

$\rightarrow B / M=0.04 \rightarrow B / M=0.1 \rightarrow B / M=0.2$

ure

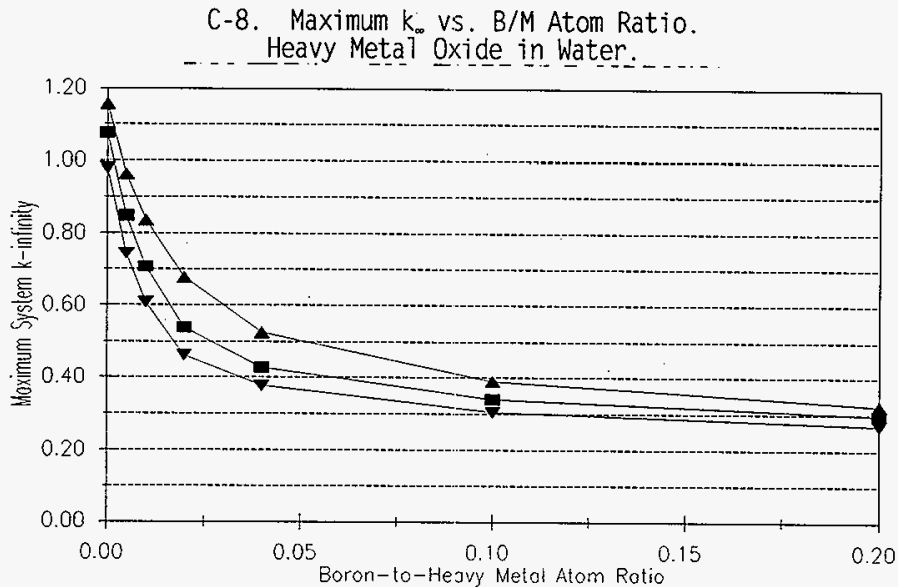

Fig

ure

$-E=1.2491$ wt\% $U-235-\nabla-E=0.9471 w t \% U-235-1-$ Mixed (U.PU) Oxide

C-

$k_{\infty}$ vs. H/U Atom Ratio.

$\mathrm{SiO}_{2}$ Added to 1.25 wt\% ${ }^{235} \mathrm{U}$ Uranium Oxide Solution. 
HNF-SD-WM-ES-409, Rev. 0

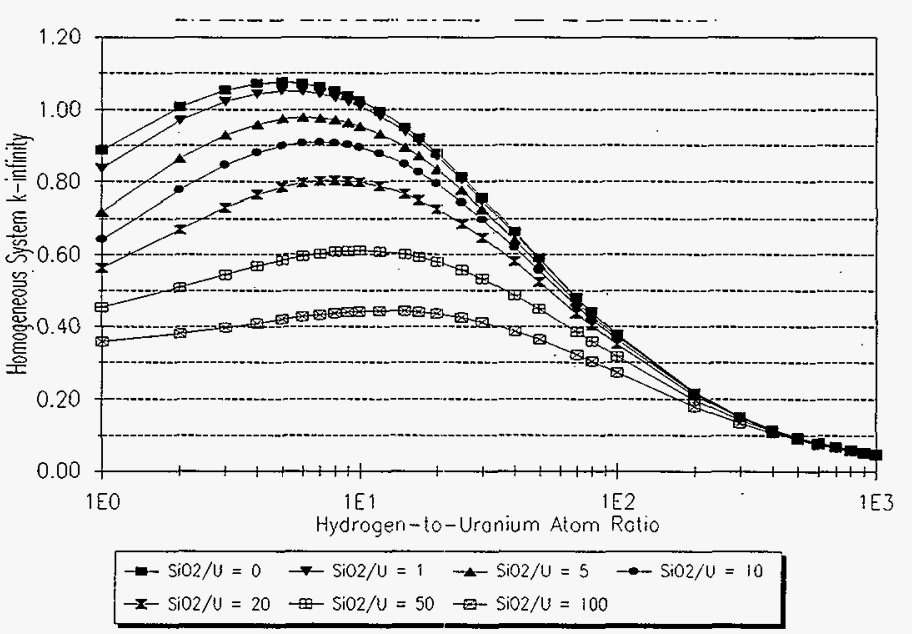

Fig

ure

C-10. $k_{\infty}$ vs. $H / U$ Atom Ratio.

$\mathrm{SiO}_{2}$ Added to $0.95 \mathrm{wt} \%$.235 Uranium Oxide Solution.

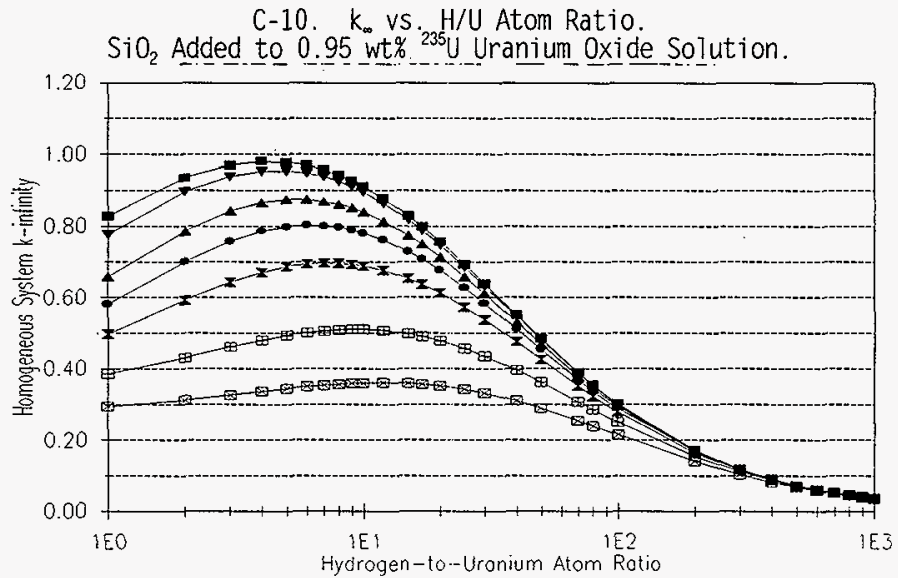

Fig

ure

c-

11.

$k_{\infty}$ vs. H/M Atom Ratio.

$\mathrm{SiO}_{2}$ Added to $(\mathrm{U}, \mathrm{Pu}) \mathrm{O}_{2} .{ }^{235} \mathrm{U}=0.72$ wt\%. ${ }^{239} \mathrm{Pu}=0.53$ wt\%. 
HNF-SD-WM-ES-409, Rev. 0

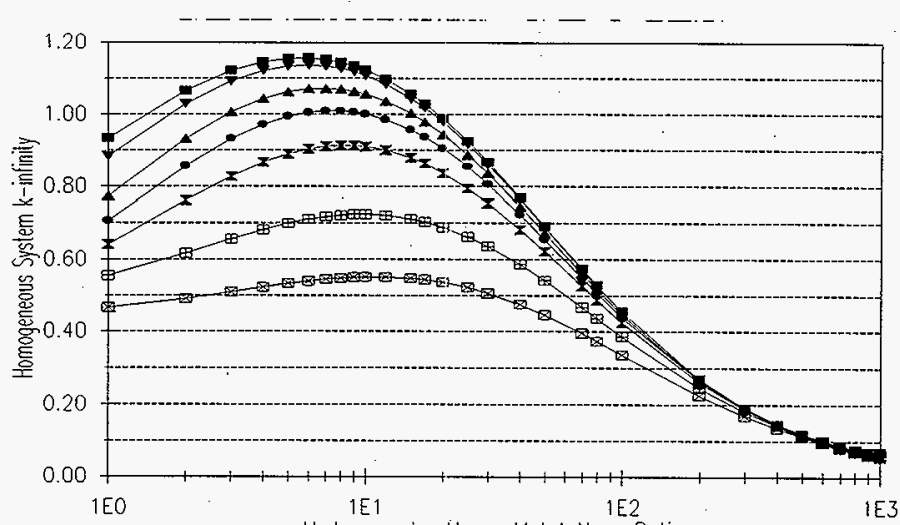

Hydrogen-to-Heavy Metol Atom Rotio

Fig

ure

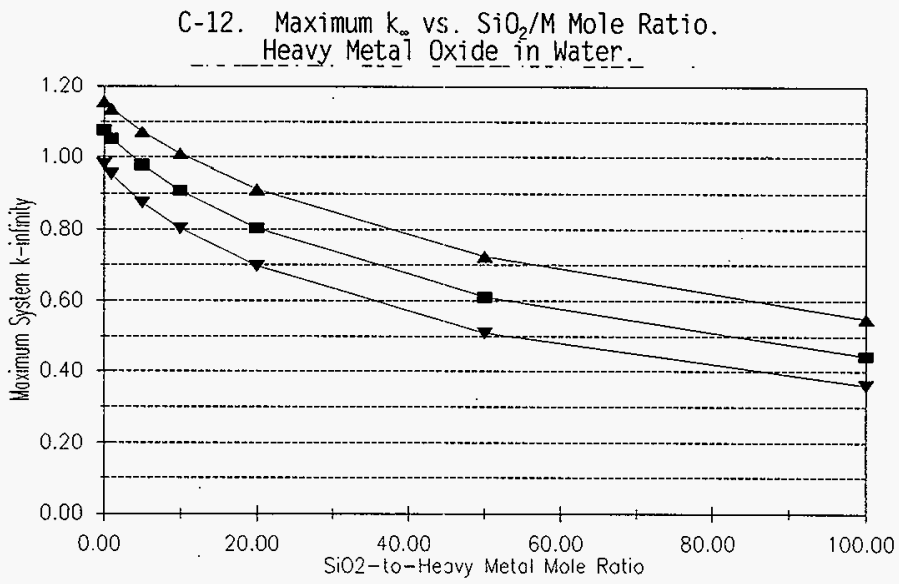

$E=1.2491 w t \% U-235 \rightarrow \varepsilon=0.5471 w t \% U-235 \rightarrow \sim$ Mixed (U.PU) Oxide 


\subsection{Heterogeneous Uranium Rods}

Heterogeneous systems were analyzed. Heavy metal rods with 0.25 -inch $0 D$ were immersed in an iron/water solution. The water content of the lattice. the spacing, and the iron concentration were varied, holding the heavy metal mass and the mass of iron equal. The rnixture density of the $\mathrm{Fe} / \mathrm{H}_{2} \mathrm{O}$ solution is determined from Equation (C.4), but with the heavy metal oxide fraction set to zero. With the mixture density known. the outer cylindricized lattice cell radius: $r_{\text {cenl }}$, is:

$$
r_{c e l l}=r_{f u e l} \sqrt{1+\frac{18.82}{\bar{\rho} f_{F e}}}
$$

Figure $\mathrm{C}-13$ shows the results. Figure $\mathrm{C}-13$ is plotted as a function of $\mathrm{H} / \mathrm{M}$ ratio. For the heterogeneous lattice, the $\mathrm{H} / \mathrm{M}$ ratio is defined as:

$$
\frac{H}{M}=\frac{2 \bar{\rho} \cdot\left(1-f_{F e}\right) M_{M}\left(r_{c e l l}^{2}-r_{\text {fuel }}^{2}\right)}{M_{H_{2} O}\left(18.82 r_{\text {fuel }}^{2}\right)}
$$

As long as the iron-to-heavy metal mass ratio exceeds one. subcriticality is assured for these systems. Careful comparison between the homogeneous and heterogeneous results do indicate a slight increase in reactivity for the heterogeneous lattices, but for this small rod diameter (and large amount of iron), the increase is not very large.

Figure C-13. $k_{\text {e }}$ vs. H/M Atom Ratio.

0.25-inch OD Uranium Rods in Fe, Water Solution: M Mass $=$ Fe Mass .

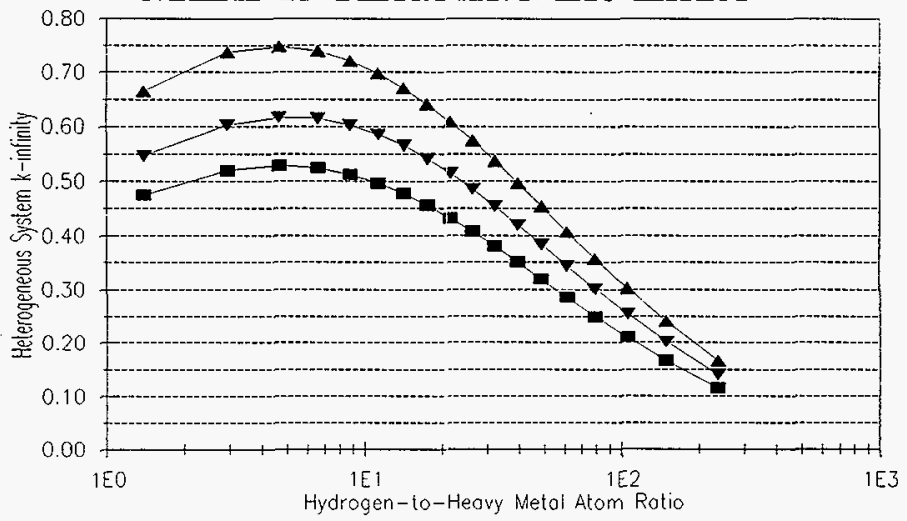

3.3

$\rightarrow E=0.9471$ wit $U-235 \rightarrow E=1.2493 \mathrm{w} 1 \% \mathrm{U}-235 \rightarrow$ Mixed (U.Pu) Metol

Ura

niu

m Solution Ideal Geometry Masses and Dimensions 
Finite slab and sphere calculations have been performed previously for uranium/water systems (Schwinkendorf 1995). Table C.1 contains a summary of these results for $0.95 \mathrm{wt} \%$ and $1.25 \mathrm{wt} \%$ enriched uranium solutions: $1.15 \mathrm{wt} \%$ is also included. This is the mass-averaged enrichment for $\mathrm{N}$ Reactor Mark IA fuel assemblies. As absorber is added to the system, the $k_{\infty}$ decreases; as $k_{\infty}$ decreases below some particular $k_{\text {eff }}$, the masses and dimensions for that particular $k_{\text {eff }}$ increase until they reach infinity.

Table C.1. Uranium/Water Solution Minimum Masses and Areal Densities.

\begin{tabular}{|c|c|c|c|c|c|c|}
\hline $\begin{array}{l}\text { Pure Uyater } \\
\text { Systems }\end{array}$ & Sphe & (cal? & 4.8 & & .69717 & der? \\
\hline (.) & Mass & $\begin{array}{l}\text { Radius } \\
\text { (cm) }\end{array}$ & $\begin{array}{l}\text { Areal } \\
\text { Bers 1 } 1 \text { y } \\
\text { kg/mo }\end{array}$ & $\begin{array}{l}\text { Theknes } \\
\text { (cm) }\end{array}$ & $\begin{array}{c}\text { Mass per: } \\
\text { unitu } \\
\text { length } \\
\text { kg\%m) }\end{array}$ & $\begin{array}{c}\text { Radigus } \\
(\mathrm{cm}) \\
0\end{array}$ \\
\hline$\underset{\text { wt\% }}{\text { Enrichment }}=0.95$ & $\begin{array}{c}\text { infini } \\
\text { te }\end{array}$ & $\begin{array}{c}\text { infini } \\
\text { te }\end{array}$ & $\mathrm{e}^{\text {infinit }}$ & infinite & infinite & $\underset{e}{\text { infinit }}$ \\
\hline$\underset{w t \%}{\text { Enrichment }}=1.15$ & 4272 & 125.5 & 2158 & 60.5 & 2780 & 100.1 \\
\hline$\underset{\text { Et.\% }}{\text { Enrichment }}=1.25$ & 2070 & 103.4 & 1533 & 48.8 & 1610 & 75.7 \\
\hline$k_{\text {er }}=0.98$ & 1. & 4.4 & 1.0. & 4 & 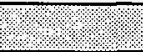 & 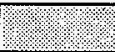 \\
\hline $\begin{array}{c}\text { Enrichment } \\
\text { wt\% } \%\end{array}=0.95$ & 66,461 & 295.9 & 6870 & 140.5 & 19.093 & 222.8 \\
\hline$\underset{\text { Wt\% }}{\text { Enrichment }}=1.15$ & 2477 & 104.6 & 1699 & 54.1 & 1860 & 81.3 \\
\hline $\begin{array}{c}\text { Enrichment } \\
\text { wt\% }\end{array}=1.25$ & 1364 & 89.9 & 1269 & 45.2 & 1204 & 65.5 \\
\hline $4 k_{e f t}=0.95$ & $4.4 \%$ & & & & & \\
\hline $\begin{array}{c}\text { Enrichment }=0.95 \\
\text { wt\% }\end{array}$ & 7839 & 145.0 & 2900 & 70.1 & 4305 & 115.1 \\
\hline$\underset{w t \%}{\text { Enrichment }}=1.15$ & 1311 & 88.6 & 1274 & 45.5 & 1171 & 64.5 \\
\hline $\begin{array}{c}\text { Enrichment } \\
\text { wt\% }\end{array}$ & 819 & 75.9 & 996 & 39.4 & 824 & 57.7 \\
\hline
\end{tabular}


HNF-SD-WM-ES-409, Rev. 0

\subsection{Heterogeneous Absorber Rods}

The final set of calculations addressed the question of how effective heterogeneous absorber rods would be in a $\mathrm{UO}_{2}$ /water solution. The enrichment was $1.25 \mathrm{wt} \%$, and the $\mathrm{H} / \mathrm{U}$ ratio was set to 5 to maximize $k_{\omega}$. Figures $\mathrm{C}-14$ through $\mathrm{C}-17$ show the results. Figures $\mathrm{C}-14$ and $\mathrm{C}-15$ depict six absorber rod diameters ranging from 0.1 to 3.0 inches $0 D$. The absorber rods were stainless stee 1 with 1 wt\% natural boron. The smaller rods have effective spacings of less than 2.5 inches, as shown in Figure $C-15$, but are more effective than the larger-diameter rods on a per unit volume basis, as shown in Figure $\mathrm{C}-14$. In Figure $\mathrm{C}-14$, the smaller-diameter rods suppress reactivity more than do the larger-diameter rods, when compared on a volume ratio basis. As the absorber rods become larger in diameter, their effectiveness decreases because of selfshielding. Absorber rods ten times as large in diameter have effective absorber spacings of less than 7.5 inches. Figures $\mathrm{C}-16$ and $\mathrm{C}-17$ compare absorber rods with annular absorber "pipes" of the same outer diameters. The legend notation "OD/A" is used to both label the outer diameter and to note that this particular absorber is annular with a 3/8-inch wall thickness. In Figure $\mathrm{C}-17$, very iittle difference is shown between rods and pipes at large spacings. For closer spacings, the largest 00 pipe becomes less effective as an absorber because of internal moderation. Per unit volume of absorber, the annular pipes retain effectiveness comparabie to the smaller-00 rods: again this is because of self-shielding.

\subsection{CONCLUSIONS}

Parametric calculations have been performed to characterize both homogeneous and heterogeneous lattice reactivity for various amounts of absorber added to uranium solutions, under conditions of optimal moderation. For uranium solutions, the enrichments were $0.95 \mathrm{wt} \%$ and $1.25 \mathrm{wt} \%{ }^{235} \mathrm{~J}$. A mixed uranium/plutonium oxide solution was also analyzed. The absorbers added to the homogeneous solutions were iron, natural boron, and silicon dioxide. which was used to simulate ground soil. Some heterogeneous calculations were performed for 0.25 -inch $0 D$ uranium rods in an iron/water solution, where the uranium mass was held equal to the mass of iron in solution. The heterogeneous absorber added to the uranium solution consisted of variouslysized borated stainless steel rods, with 1 wt\% natural boron. In the uranium solution, the $H / U$ was optimized to maximize the $k_{\infty}$.

If a sufficient quantity of absorber is added, the system can be made safely subcritical, assuming that the absorber does not separate from the fissionable material. Uranium heterogeneity does not significantly increase reactivity as long as the piece size is limited to no larger than 0.25 inches 00 . Absorber rods may not be practical because in the thermal spectrum of an optimally light-water-moderated system, neutron mean-free-paths are sufficiently short so that absorber rod spacings must be quite short. The center-to-center spacings required for effective reactivity reduction increases with larger-diameter rods, but because of self-shielding, the larger rods become less effective than the smaller rods on a per unit mass (or volume) basis.

The attachment contains a source listing of one of the Fortran computer codes used to generate the WIMS-E input files for the homogeneous parametric calculations, and two sample WIMS-E input files for the heterogeneous lattice 
calculations.

Figure C-14. $k_{\infty}$ 'vs. Solution-to-Absorber Rod Volume Ratio. 1 wt\% Boron in SS Rods. in 1.25 wt\% ${ }^{235} \mathrm{U}$ Solution.

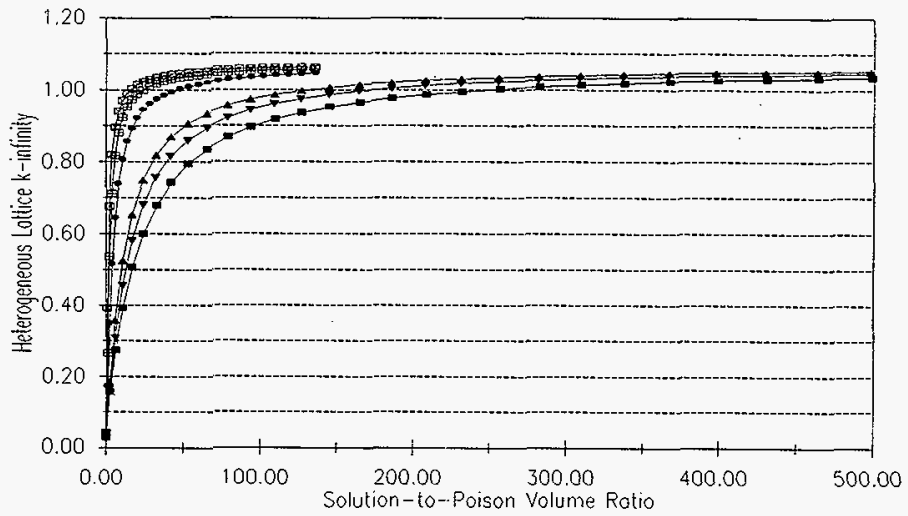

Fig $00=0.1$ in $\rightarrow 00=0.2$ in $\longrightarrow 00=0.3$ in $\rightarrow 00=1.0$ in $\rightarrow-00=2.0$ in $\rightarrow-00=3.0$ in

ure

$C-15 . k_{\infty} v s$. Lattice Spacing.

1 wt\% Boron in SS Rods. in 1.25 wt: 2350 Solution.

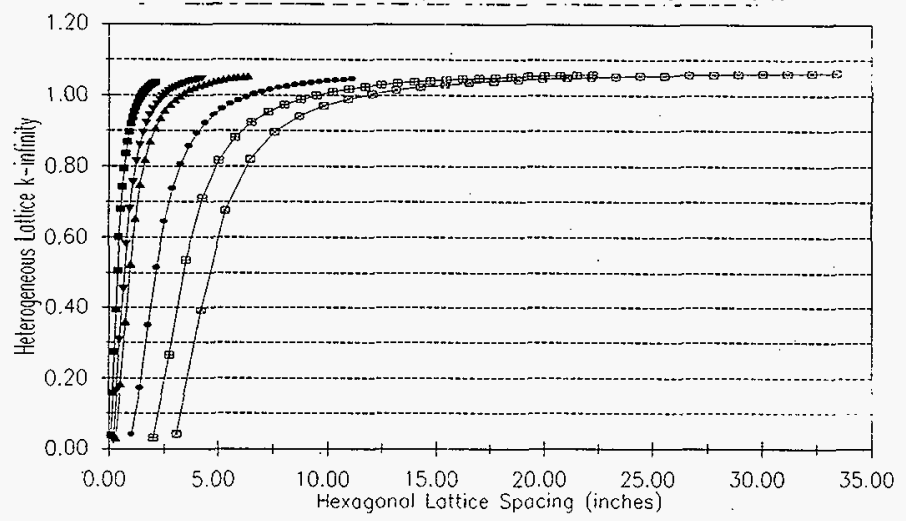

$$
\rightarrow 00=0.1 \text { in } \rightarrow 00=0.2 \text { in } \rightarrow 00=0.3 \text { in }-00=1.0 \text { in } \rightarrow-00=2.0 \text { in } \rightarrow 00=3.0 \text { in }
$$

Fig

ure

C-

16. $k_{m}$ vs. Solution-to-Absorber Rod Volume Ratio.

1 wt\% Boron in SS Rods and Tubes. in 1.25 wt\% ${ }^{235} \mathrm{U}$ Solution. 
HNF-SD-WM-ES-409, Rev. 0

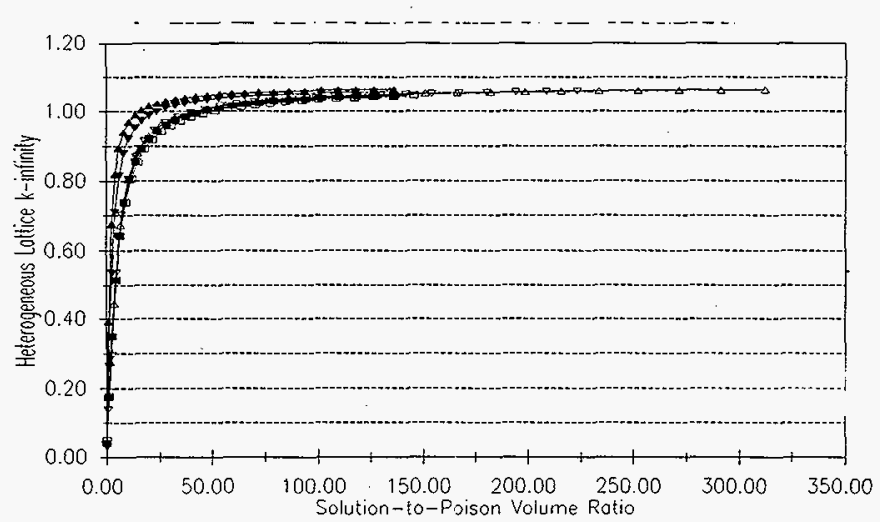

$O D=1.0$ in $\rightarrow 00=2.0$ in $\longrightarrow 0 D=3.0$ in $\longrightarrow 00 / A=1.0$ in $\rightarrow 0 D / A=2.0$ in $\rightarrow 00 / A=3.0$ in

Fig

ure $\mathrm{C}-17 . \mathrm{k}_{\infty}$ vs. Lattice Spacing.

1 wt\% Boron in SS Rods and Tubes. in 1.25 wt\% $235 \mathrm{U}$ Solution.

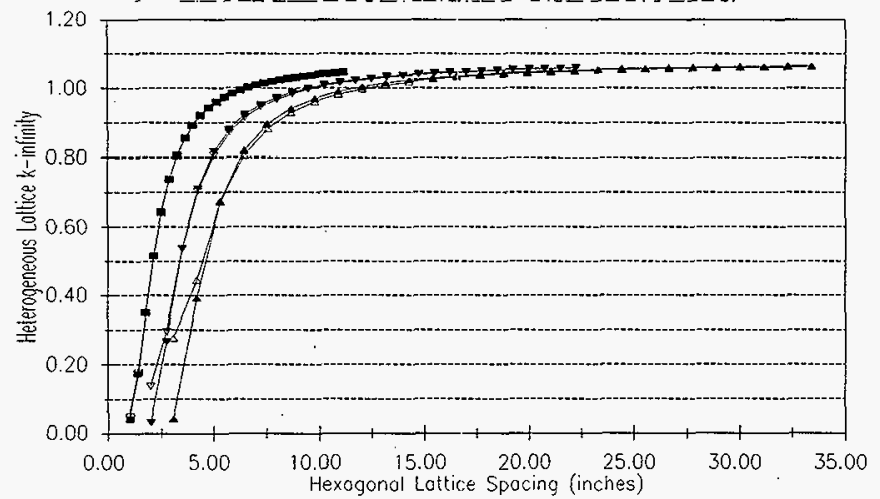

$\rightarrow-O D=1.0$ in $\rightarrow O D=2.0$ in $\rightarrow 00=3.0$ in $\rightarrow-0 D / A=1.0$ in $\rightarrow-O D / A=2.0$ in $\rightarrow 0 D / A=3.0$ in

\subsection{REFERENCES}

Gubbins, M. E., M. J. Roth, and C. J. Taubman, 1982, A General Introduction to the Use of the WMS-E Modular Program, AEEW-R 1329, Reactor Physics Division, AEE Winfrith, England. 
Schwinkendorf, K. N., 1995, Criticality Safety Evaluation Report for 300 Area N Reactor Fuel Fabrication and Storage Facility, WHC-SD-NR-CSER-010, Revision 1, Westinghouse Hanford Company, Richland, Washington.

Schwinkendorf. K. N., 1997, Criticality Safety Evaluation Report for Spent Nuclear Fuel Processing and Storage Facilities. HNF-SD-SNF-CSER-005. Revision 3. Fluor Daniel Northwest. Richland, Washington. 
The following is a source listing of one of the Fortran computer codes used to generate WIMS-E input files for the homogeneous parametric calculations:

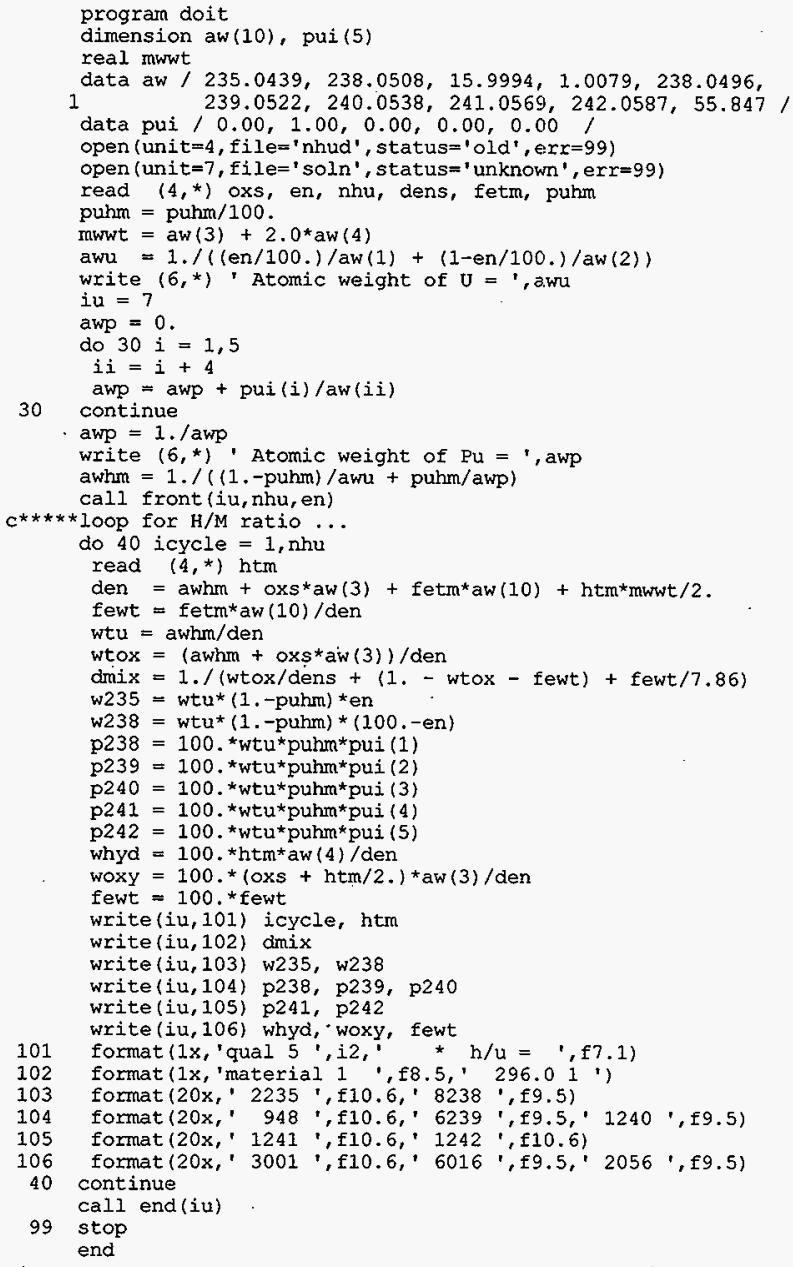




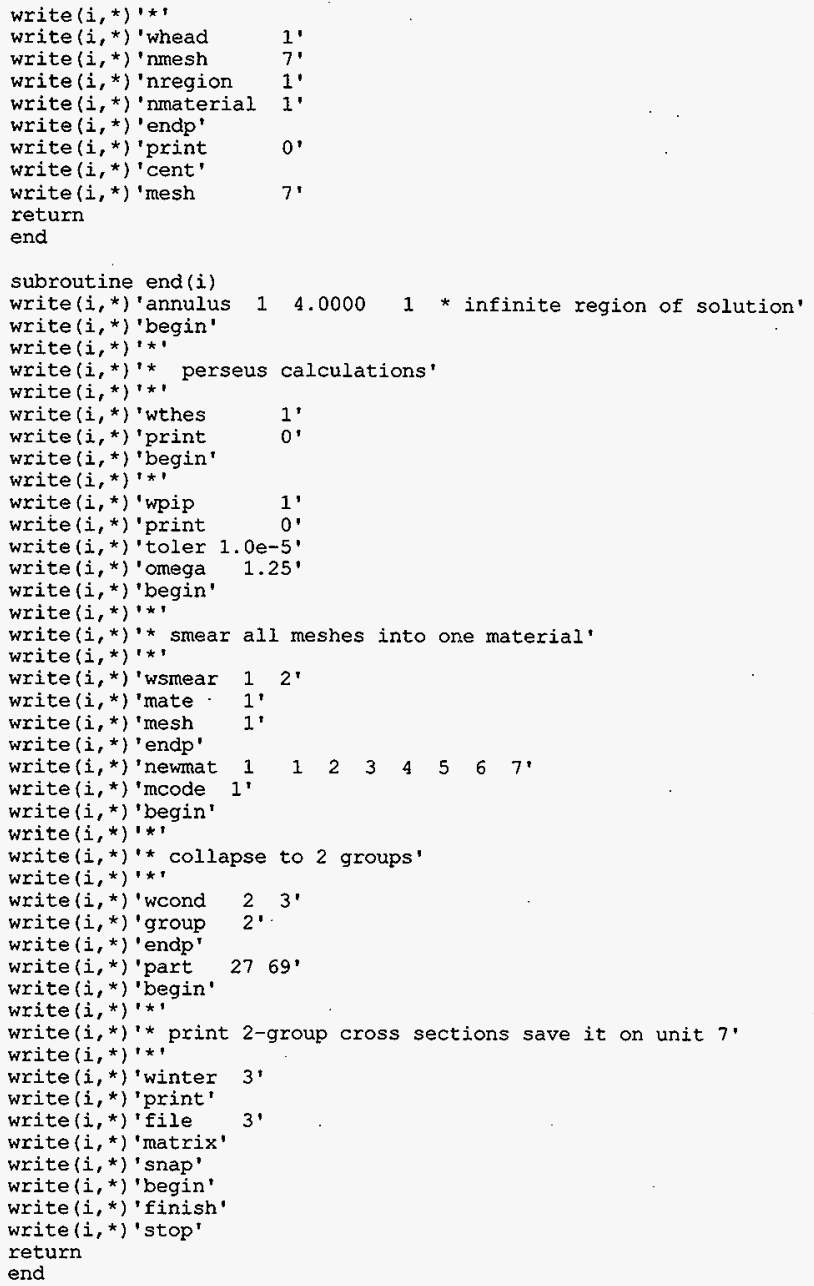


The following is a listing of one of the WMS-E input files that produced heterogeneous absorber rod results. This case was a parametric variation on spacing of 2.0-inch absorber rods in $1.25 \mathrm{wt} \%$ enriched uranium solution, where $\mathrm{H} / \mathrm{U}=5$ for maximum solution $\mathrm{k}_{\mathrm{w}}$.

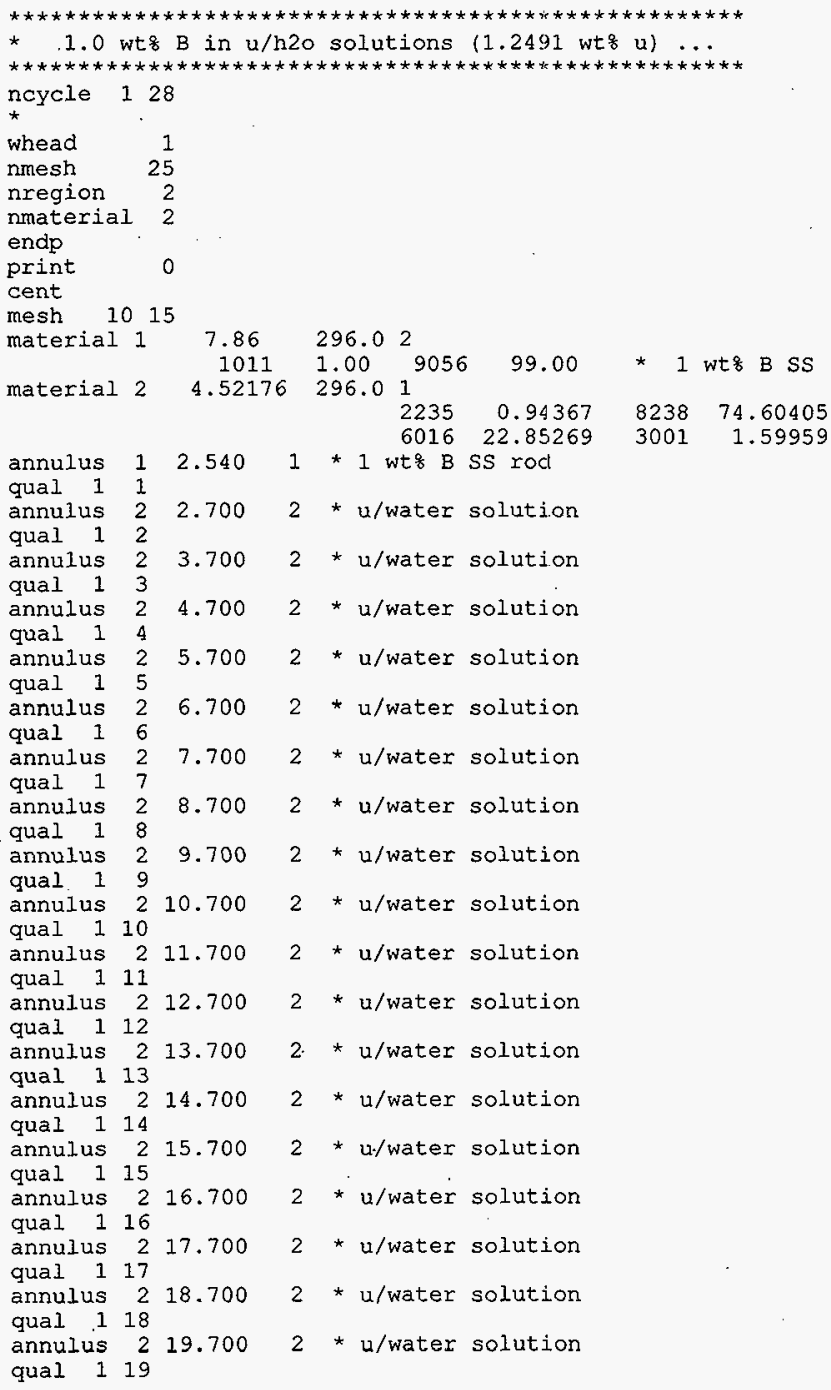


HNF-SD-WM-ES-409, Rev. 0

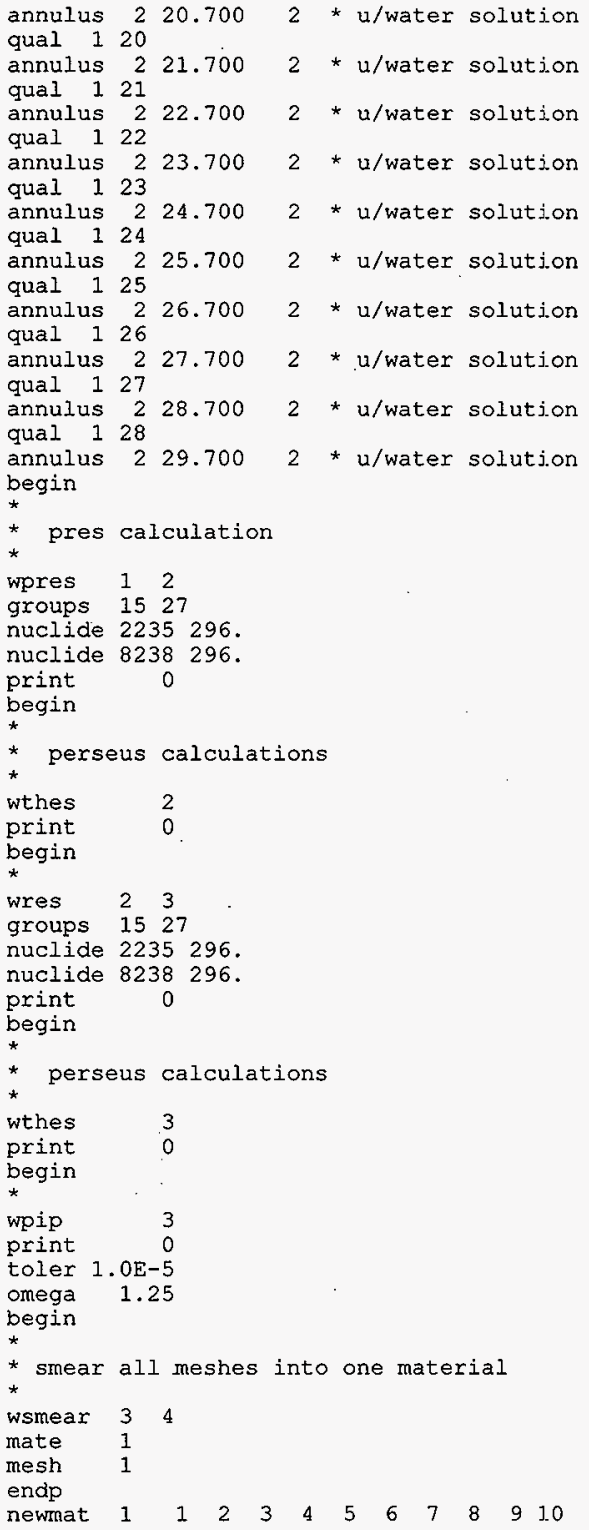


HNF-SD-WM-ES-409, Rev. 0

$\begin{array}{llllllllll}11 & 12 & 13 & 14 & 15 & 16 & 17 & 18 & 19 & 20\end{array}$

mcode 1

$\begin{array}{lllll}21 & 22 & 23 & 24 & 25\end{array}$

begin

*

* collapse to 2 groups

weond 45

group 2

endp

part 2769

begin

* print 2-group cross sections save it on unit 7

winter 5

print

file

matrix

snap

begin

finish

stop 
The following is a listing of one of the WIMS-E input files that helped produce Figure C-13. This input file calculates a set of lattice $\mathrm{k}_{\infty}$ values for $1.25 \mathrm{wt} \%{ }^{235} \mathrm{U}, 0.25$-inch $\mathrm{OD}$ uranium metal rods immersed in an iron/water solution, holding the mass of uranium equal to the mass of iron in the solution.

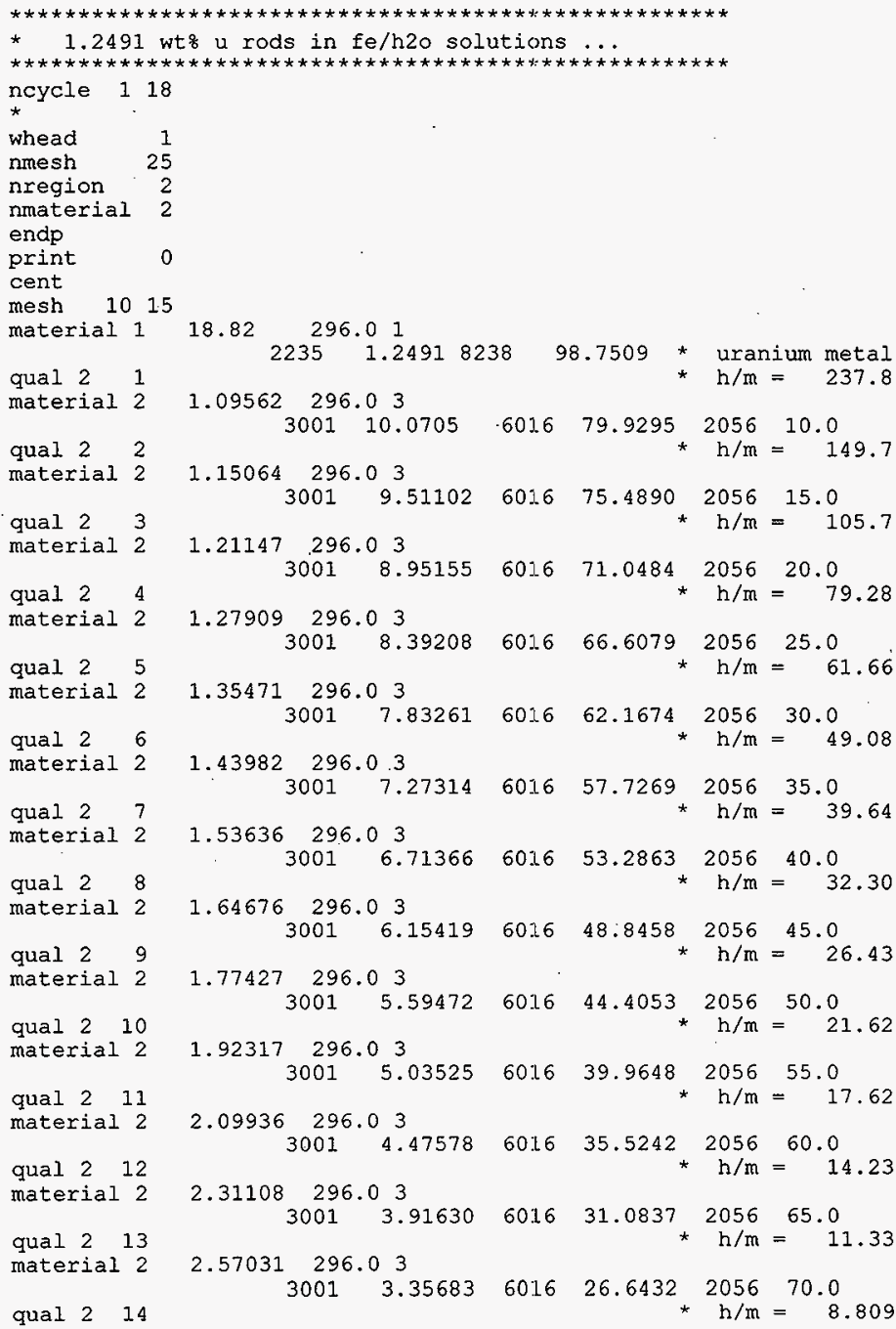


HNF-SD-WM-ES-409, Rev. 0

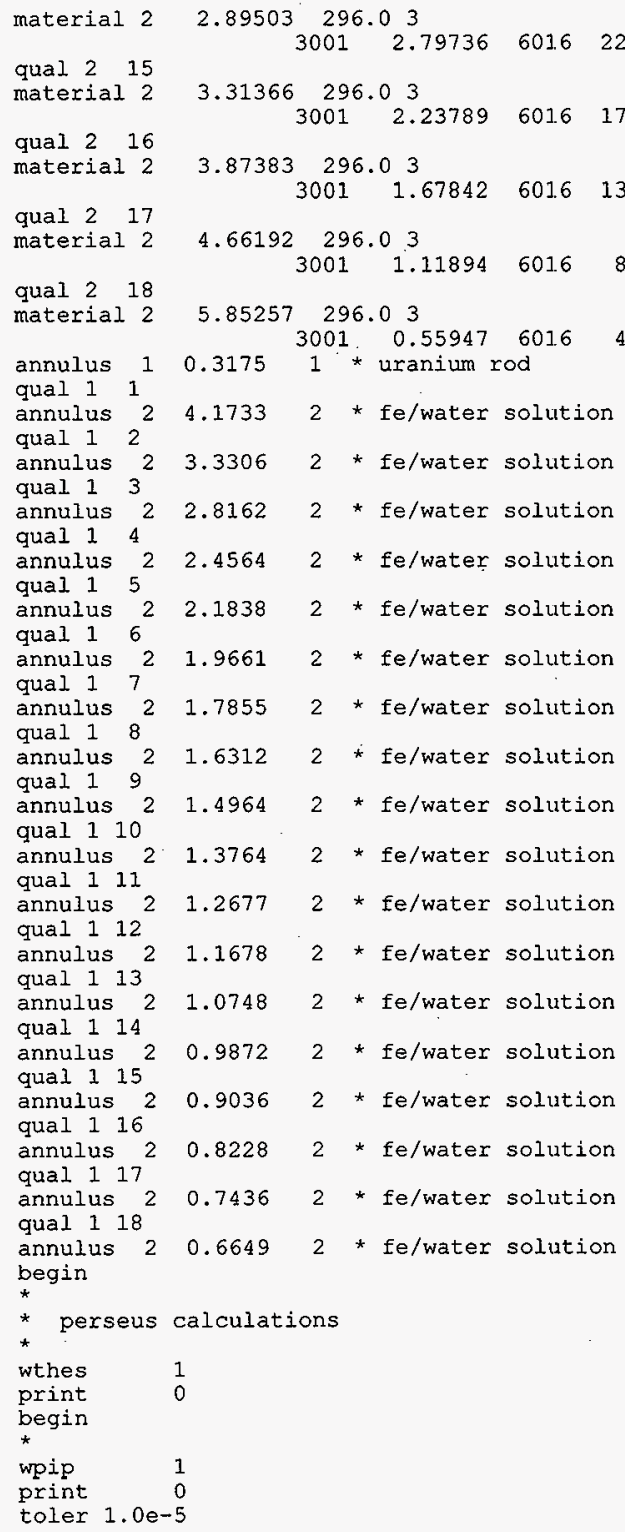


HNF-SD-WM-ES-409, Rev. 0

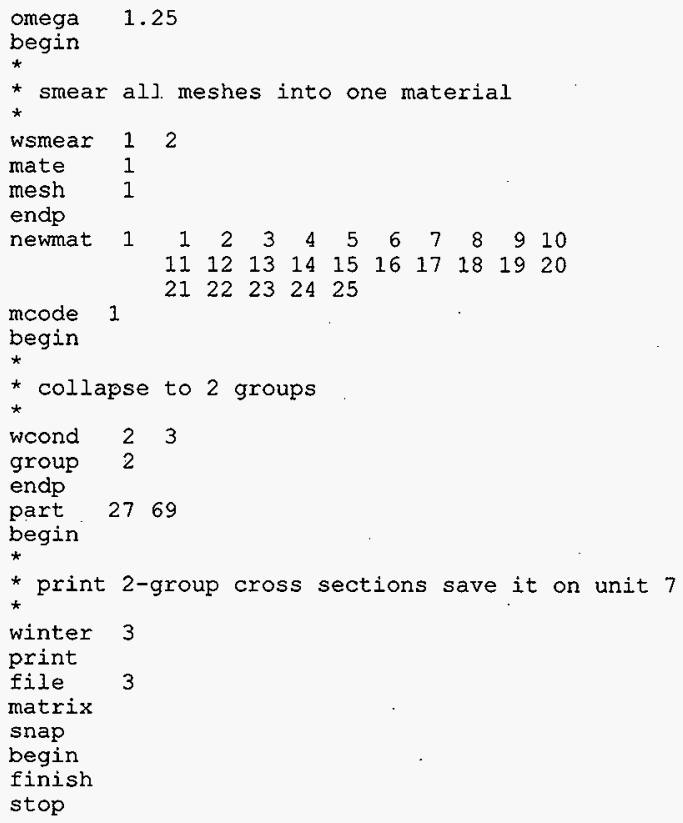




\section{DISTRIBUTION SHEET}

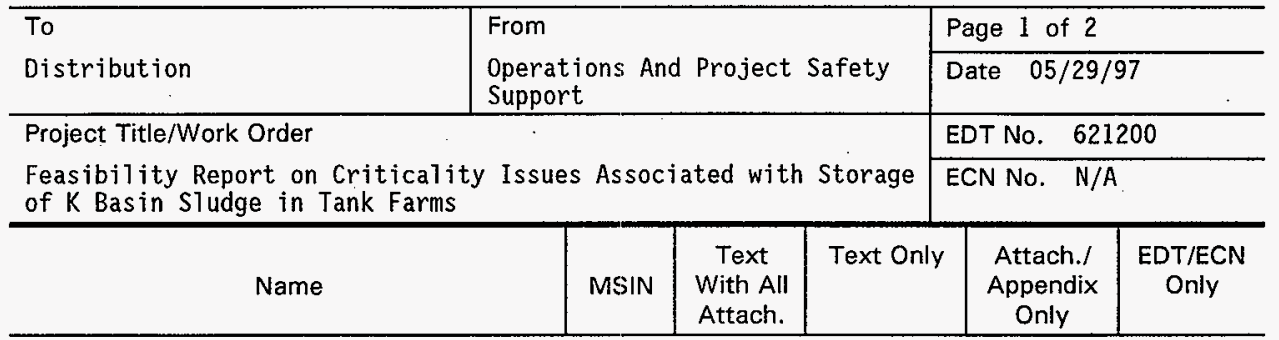

DE\&S Hanford, Inc.

C. J. ATderman

R. B. Baker

K, H. Bergsman

D. R. Bratzel

R. J. Cash

G. W. Gau $7 t$

T. C. Geer

N. W. Kirch

C. E. Leach

E. J. Lipke

R. H. Meichle

F. J. Muller

K. L. Pearce

D. R. Precechtel

J. G. Propson

O. M. Serrano

T. S. Vail

Lockheed Martin Hanford Corp.
D. G. Baide
K. G. Carothers
R. A. Dodd
J. 0. Honeyman
M. N. Islam
C. A. Rogers
R. L. Schlosser
P. L. Smith

Fluor Daniel Hanford

E. W. Gerber

Fluor Daniel Northwest

J. Greenborg

D. G. Erjckson

K. N. Schwinkendorf

$\begin{array}{ll}\text { X3-85 } & X \\ \text { H0-40 } & X \\ X 3-85 & X \\ \text { S7-14 } & X \\ \text { S7-14 } & X \\ \text { R1-44 } & X \\ \text { R1-43 } & X \\ \text { R2-11 } & X \\ \text { R1-49 } & X \\ \text { R1-43 } & 3 \text { copies } \\ \text { X3-79 } & X \\ X 3-85 & X \\ \text { R3-11 } & 2 \text { copies } \\ \text { X3-85 } & X \\ \text { R1-43 } & X \\ \text { R1-43 } & X \\ \text { R1-43 } & 3 \text { copies }\end{array}$

S5-05

R2-11

S5-07

G3-21

R3-.08

R1-56

R1-56

R3 -01

$X$
$X$
$X$
$X$
$X$
$X$
$X$
$X$

R3-11

$X$

HO- -35

HO- -35

HO- -35 $x$
$x$
$x$ $x$
$x$
$x$
$x$
$x$
$x$
$x$
$x$ 


\section{DISTRIBUTION SHEET}

\begin{tabular}{|c|c|c|c|c|c|}
\hline \multirow{2}{*}{$\begin{array}{l}\text { To } \\
\text { Distribution }\end{array}$} & \multirow{2}{*}{\multicolumn{3}{|c|}{$\begin{array}{l}\text { From } \\
\text { Operations And Project Safety } \\
\text { Support }\end{array}$}} & \multicolumn{2}{|l|}{ Page 2 of 2} \\
\hline & & & & \multicolumn{2}{|c|}{ Date $05 / 28 / 97$} \\
\hline \multicolumn{4}{|l|}{ Project Title/Work Order } & \multicolumn{2}{|c|}{ EDT No. 621200} \\
\hline \multicolumn{4}{|c|}{$\begin{array}{l}\text { Feasibility Report on Criticality Issues Associated with Storage } \\
\text { of } \mathrm{K} \text { Basin Sludge in Tank Farms }\end{array}$} & \multicolumn{2}{|l|}{ ECN No. $\quad N / A$} \\
\hline Name & MSIN & $\begin{array}{l}\text { Text } \\
\text { With All } \\
\text { Attach. }\end{array}$ & Text Only & $\begin{array}{l}\text { Attach./ } \\
\text { Appendix } \\
\text { Only }\end{array}$ & $\begin{array}{l}\text { EDT/ECN } \\
\text { Only }\end{array}$ \\
\hline
\end{tabular}

Numatec Hanford Corp.

J. P. Sloughter

H4-49X

Pacific Northwest National Laboratories
P. M. Daling
D. I. Kaplan
K. M. Krupka
S. V. Mattigod
J. R. Serne
G. A. Whyatt

Central Files

Project Files
K8- $-07 x$

$K 6-81 X$

K6-81X

K6-81X

K6-81 X

P7- $19 X$

A3-88 original +1

R1-29 $X$ 